\title{
Hanford Double-Shell Tank Thermal and Seismic Project - Dytran Benchmark Analysis of Seismically Induced Fluid-Structure Interaction in Flat-Top Tanks
}

\author{
TC Mackey
}

Richland, WA 99352

U.S. Department of Energy Contract DE-AC27-99RL14047

$\begin{array}{lll}\text { EDT/ECN: } & \text { EDT } 822360 & \text { UC: } \\ \text { Cost Center: } & & \text { Charge Code: } \\ \text { B\&R Code: } & & \text { Total Pages: } 1.38\end{array}$

Key Words: Double-Shell Tank, Tank, Integrity Project, Thermal, Seismic, TPA, M-48-14

Abstract: The overall scope of the project is to complete an up-to-date comprehensive analysis of record of the DST System at Hanford. The "Double-Shell Tank (DST) Integrity Project - DST Thermal and Seismic Project" is in support of Tri-Party Agreement Milestone M-48-14.

TRADEMARK DISCLAIMER. Reference herein to any specific commercial product, process, or service by trade name, trademark, manufacturer, or otherwise, does not necessarily constitute or imply its endorsement, recommendation, or favoring by the United States Government or any agency thereof or its contractors or subcontractors.

Printed in the United States of America. To obtain copies of this document, contact: Document Control Services, P.O. Box 950, Mailstop H6-08, Richland WA 99352, Phone (509) 372-2420; Fax (509) 376-4989.
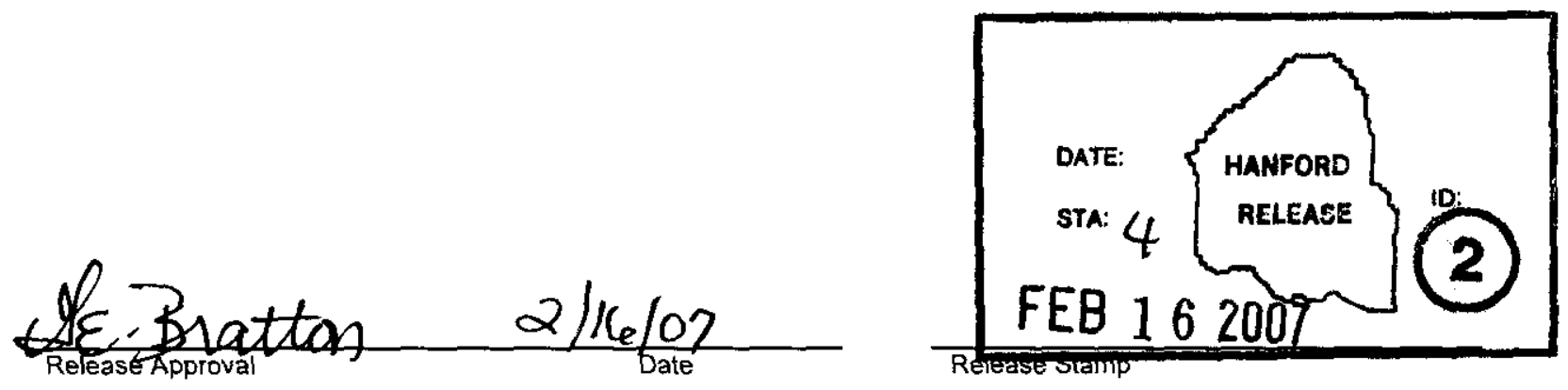

\section{Approved For Public Release}




\section{SUBCONTRACTOR CALCULATION REVIEW CHECKLIST}

Page 1 of 1

Subject: Hanford Double-Shell Tank Thermal and Seismic Project - Dytran Benchmark Analysis of Seismically Induced Fluid-Structure Interaction in Flat-Top Tanks

The subject document has been reviewed by the undersigned.

The reviewer reviewed and verified the following items as applicable.

Documents Reviewed: $\quad$ RPP-RPT-30807 Rev. 0

Analysis Performed By: M. Rinker et.al.

- Design Input

- Basic Assumptions

- Approach/Design Methodology

- Consistency with item or document supported by the calculation

- Conclusion/Results Interpretation

- Impact on existing requirements

$\bullet$

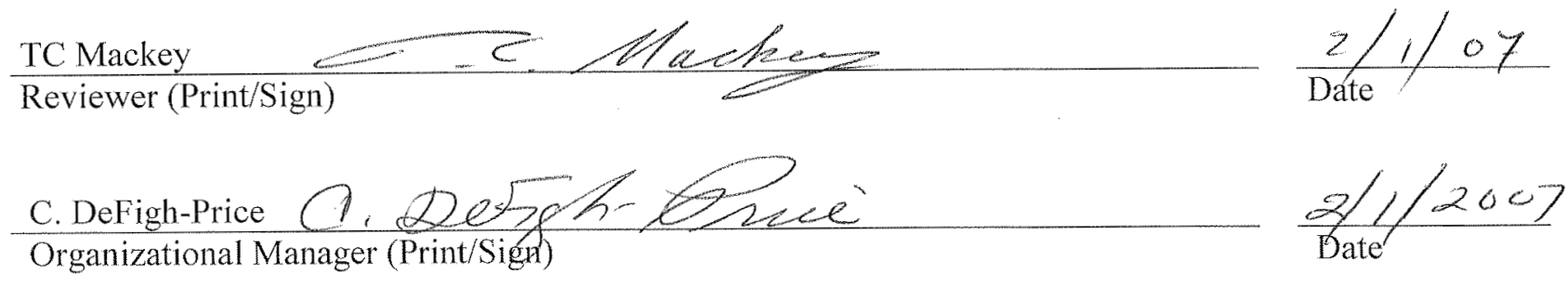




\section{Pacific Northwest}

National Laboratory

Operated by Battelle for the

U.S. Department of Energy

\section{Hanford Double-Shell Tank Thermal and Seismic Project - Dytran Benchmark Analysis of Seismically Induced Fluid- Structure Interaction in Flat-Top Tanks}

F.G. Abbott
M.W. Rinker

January 2007

Prepared for

CH2M HILL Hanford Group, Inc.

in Support of the

Double-Shell Tank Integrity Program

Sponsored by the U.S. Department of Energy under Contract DE-ACO5-76RL01830 
RPP-RPT-30807, Rev. 0

\title{
DISCLAIMER
}

This report was prepared as an account of work sponsored by an agency of the United States Government. Neither the United States Government nor any agency thereof, nor Battelle Memorial Institute, nor any of their employees, makes any warranty, express or implied, or assumes any legal liability or responsibility for the accuracy, completeness, or usefulness of any information, apparatus, product, or process disclosed, or represents that its use would not infringe privately owned rights. Reference herein to any specific commercial product, process, or service by trade name, trademark, manufacturer, or otherwise does not necessarily constitute or imply its endorsement, recommendation, or favoring by the United States Government or any agency thereof, or Battelle Memorial Institute. The views and opinions of authors expressed herein do not necessarily state or reflect those of the United States Government or any agency thereof.

\author{
PACIFIC NORTHWEST NATIONAL LABORATORY \\ operated by \\ BATTELLE \\ for the \\ UNITED STATES DEPARTMENT OF ENERGY \\ under Contract DE-AC05-76RL01830
}


RPP-RPT-30807, Rev. 0

M\&D-2008-005-RPT-02, Rev. 0

\section{Acknowledgments}

The Double-Shell Tank Thermal and Seismic Project has been funded at PNNL for the past three and a half years by DOE and CH2M HILL. There has been a tremendous amount of work and progress made by many people from many organizations in order to get to this point.

In particular, one of the greatest challenges of this project has been the seismic analysis of the double-shell tanks. The project team would like to acknowledge the dedicated effort by M\&D Professional Services technical staff in completing this work.

It is also important to acknowledge, that while this report has a PNNL cover on it, all of this work was completed by George Abatt, one of the senior technical staff at M\&D. 


\title{
Dytran Benchmark Analysis of Seismically Induced Fluid-Structure Interaction in Flat-Top Tanks
}

\author{
F.G. Abatt
}

November 2006

\author{
Prepared by \\ M\&D Professional Services, Inc. \\ for
}

Pacific Northwest National Laboratory
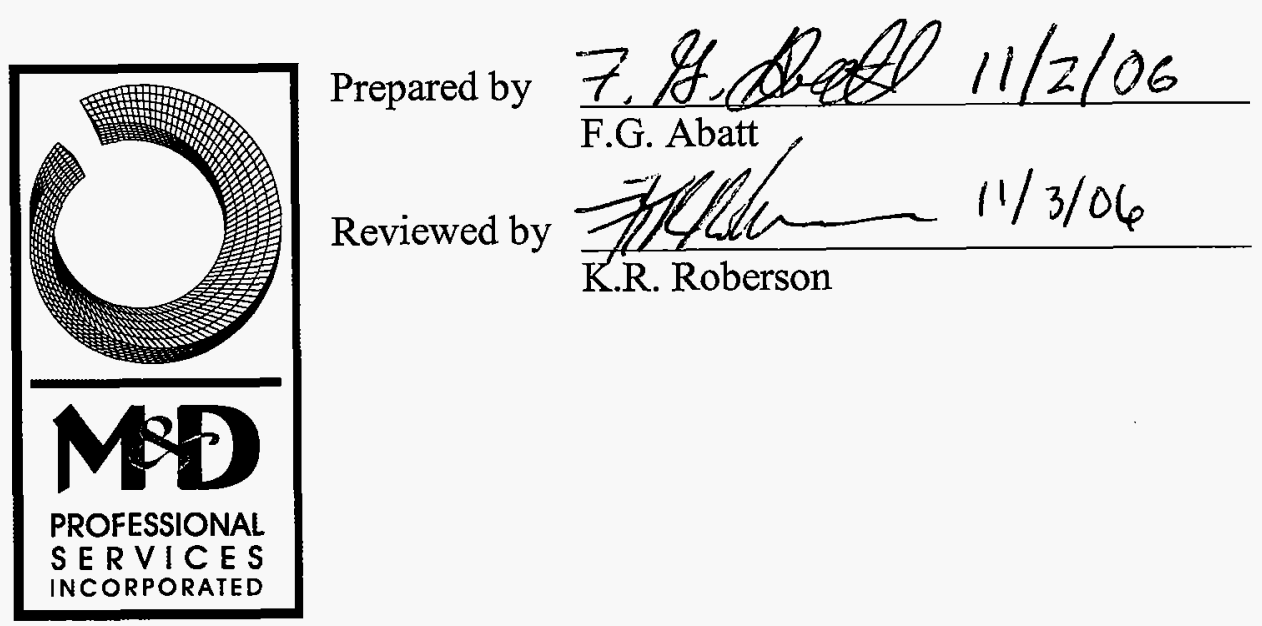


\section{Executive Summary}

The work reported in this document was performed in support of a project entitled Double-Shell Tank (DST) Integrity Project - DST Thermal and Seismic Analyses. The overall scope of the project is to complete an up-to-date comprehensive analysis of record of the DST System at Hanford. The work described herein was performed in support of the seismic analysis of the DSTs. The thermal and operating loads analysis of the DSTs is documented in Rinker et al. (2004).

The work herein was motivated by review comments from a Project Review Meeting held on March 20-21, 2006. One of the recommendations from that meeting was that the effects of the interaction between the tank liquid and the roof be further studied (Rinker, Deibler, Johnson, Karri, Pilli, Abatt, Carpenter, and Hendrix - Appendix E of RPP-RPT-28968, Rev. 1). The reviewers recommended that solutions be obtained for seismic excitation of flat roof tanks containing liquid with varying headspace between the top of the liquid and the tank roof. It was recommended that the solutions be compared with simple, approximate procedures described in BNL (1995) and Malhotra (2005).

This report documents the results of the requested studies and compares the predictions of Dytran ${ }^{1}$ simulations to the approximate procedures in BNL (1995) and Malhotra (2005) for flat roof tanks. The four cases analyzed all employed a rigid circular cylindrical flat top tank with a radius of $450 \mathrm{in}$. and a height of $500 \mathrm{in}$. The initial liquid levels in the tank were 460,480, 490, and 500 in. For the given tank geometry and the selected seismic input, the maximum unconstrained slosh height of the liquid is slightly greater than 25 in. Thus, the initial liquid level of 460 in. represents an effectively roofless tank, the two intermediate liquid levels lead to intermittent interaction between the liquid and tank roof, and the 500 in. liquid level represents a completely full tank with no sloshing. Although this work was performed in support of the seismic analysis of the Hanford DSTs, the tank models in this study are for an idealized flat top configuration. Moreover, the liquid levels used in the present models are for study purposes only and are independent of the actual operating levels of the DSTs.

The response parameters that are evaluated in this study are the total hydrodynamic reaction forces, the peak convective hydrodynamic forces, the fundamental convective frequencies, the liquid pressures, and peak slosh heights. The results show that the Dytran solutions agree well with the known solutions for the roofless tank and completely full tank. At the two intermediate liquid levels, there are some significant differences between the Dytran results and the approximate estimates.

The results show that the estimates of peak hydrodynamic reaction forces appearing in BNL (1995) and Malhotra (2005) are reasonable and generally conservative relative to the Dytran solutions. At the 460 and 480 in. liquid levels, Dytran underestimates the convective component of the reaction force compared to the estimated in BNL (1995) and Malhotra (2005), but the convective component of the reaction force is small relative

\footnotetext{
${ }^{1}$ Dytran is a registered trademark of MSC Software Corporation.
} 
to the total reaction force. At the 490 in. liquid levels, the peak convective reaction force is more than twice as large as predicted by the approximate methods in BNL (1995) and Malhotra (2005). All three methods give similar answers for the fundamental convective frequency at the 460 and 480 in. liquid levels, but the Dytran solution indicates a significant increase in the apparent convective frequency at the $490 \mathrm{in}$. liquid level that is caused by the interaction with the roof.

The peak wall pressures in the tank at the two intermediate liquid levels are essentially the same as for a roofless tank in the lower two-thirds of the tank wall, but diverge from that solution in the upper third of the tank wall. The estimates of peak wall pressures appearing in BNL (1995) are quite conservative lower in the tank, but may underestimate the peak wall pressures closer to the tank roof. Finally, the peak roof pressures predicted by Dytran at the 480 and 490 in. liquid levels are approximately twice as large as those predicted using the methodology of Appendix D of BNL (1995) and are ten to twenty times higher than predicted using the simple hydrostatic approach in Malhotra (2005). 
RPP-RPT-30807, Rev. 0

M\&D-2008-005-RPT-02, Rev. 0

\section{CONTENTS}

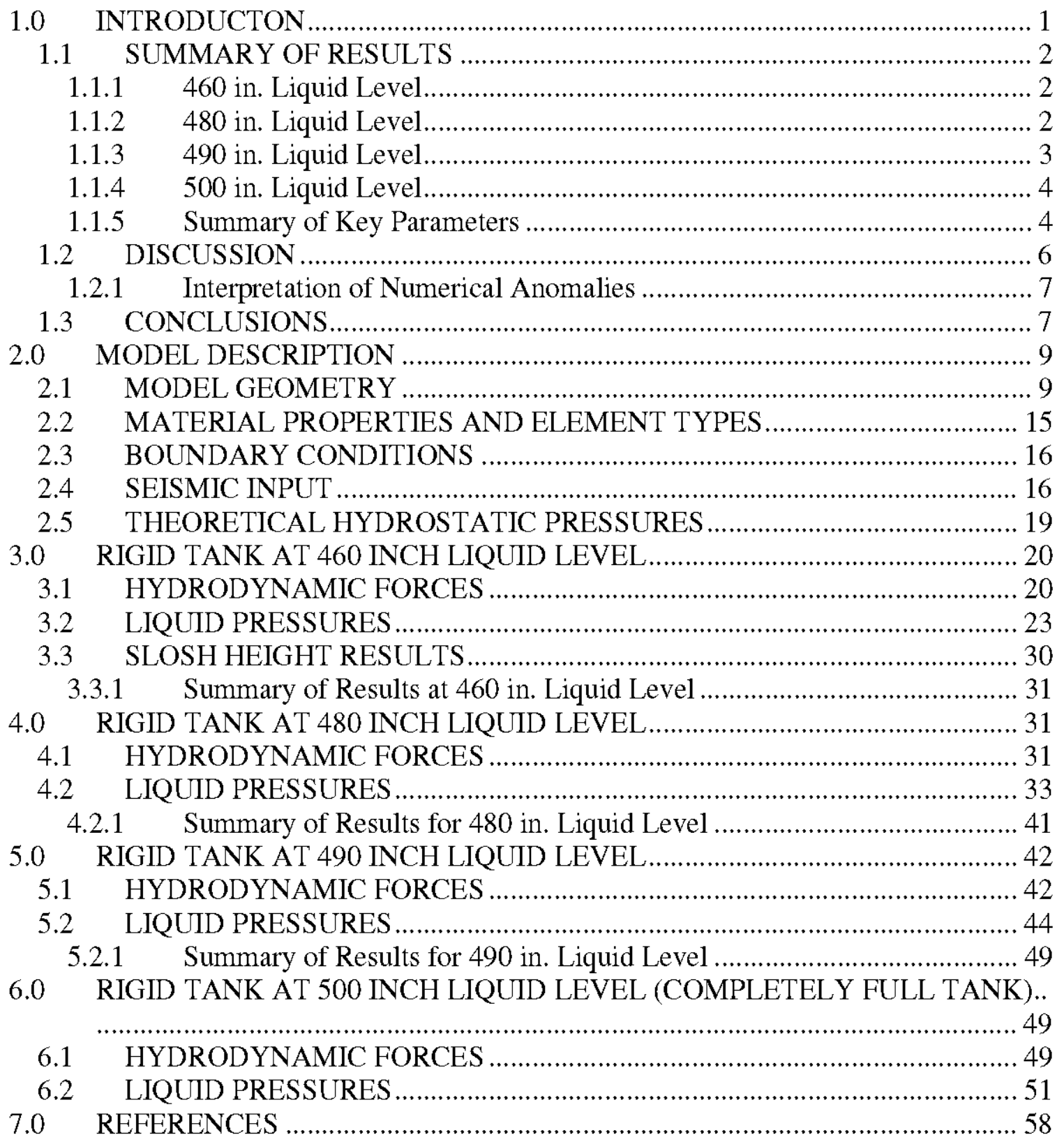

APPENDIX A Description of Input and Results Files

APPENDIX B Theoretical and Approximate Solutions 
RPP-RPT-30807, Rev. 0

M\&D-2008-005-RPT-02, Rev. 0

\section{LIST OF FIGURES}

Figure 1-1. Normalized Peak Reaction Force vs. Normalized Headspace .......................... 5

Figure 2-1. Plot of Tank Structural Elements. .............................................................. 10

Figure 2-2. Elevation View of Tank and Eulerian Mesh at 460 in. Liquid Level........... 11

Figure 2-3. Elevation View of Tank and Eulerian Mesh at 480 in. Liquid Level........... 11

Figure 2-4. Elevation View of Tank and Eulerian Mesh at 490 in. Liquid Level........... 12

Figure 2-5. Elevation View of Tank and Eulerian Mesh at 500 in. Liquid Level.......... 12 Figure 2-6. Plan View of Model Showing the Angular Locations of Fluid Elements at Which Pressures Were Monitored. ................................................................................ 13 Figure 2-7. Elevation View of Model Showing the Locations of "plusx_els", "press_45", and "plusz_els" Fluid Elements Sets at Which Pressures Were Monitored. ..................... 14 Figure 2-8. Element Numbering for Element Sets "plusx_els", "press_45", and "plusz_els", ...................................................................................................... 14

Figure 2-9. Element Numbering for Element Sets "minusx_els", and cent_press". ....... 15

Figure 2-10. Horizontal Acceleration Time History Output from ANSYS Model. ........ 17

Figure 2-11. Horizontal Velocity Time History Output from ANSYS Model................ 17

Figure 2-12. Horizontal Displacement Time History Output from ANSYS Model........ 18 Figure 2-13. Comparison of Horizontal Dome Apex Response Spectra at Different Damping Values for Low Frequencies. .......................................................................... 18

Figure 3-1. Horizontal Reaction Force for the Rigid Tank at 460 in. Liquid Level Under Horizontal Seismic Input.

Figure 3-2. Horizontal Reaction Force for Rigid Tank at 460 in. Liquid Level Under Horizontal Seismic Excitation - Convective Response............................................... 22 Figure 3-3. Liquid Pressure Time Histories for the Rigid Tank With 460 in. of Liquid Under Horizontal Excitation at $\theta=0$......................................................................... 26 Figure 3-4. Selected Liquid Pressure Time Histories for the Rigid Tank With 460 in. of

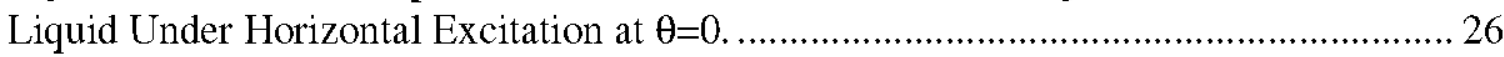

Figure 3-5. Liquid Pressure Time Histories for the Rigid Tank With 460 in. of Liquid Under Horizontal Excitation at $\theta=45^{\circ}$.

Figure 3-6. Liquid Pressure Time Histories for the Rigid Tank With 460 in. of Liquid Under Horizontal Excitation at $\theta=90^{\circ}$.

Figure 3-7. Maximum and Minimum Liquid Pressures vs. Normalized Height from Tank Bottom for Horizontal Excitation at $\theta=0$ and Initial Liquid Height of 460 in................. 28 Figure 3-8. Maximum and Minimum Liquid Pressures vs. Normalized Height from Tank Bottom for Horizontal Excitation at $\theta=45^{\circ}$ and Initial Liquid Height of 460 in. ............ 29 Figure 3-9. Maximum and Minimum Liquid Pressures vs. Normalized Height from Tank Bottom for Horizontal Excitation at $\theta=90^{\circ}$ and Initial Liquid Height of 460 in. ............ 29 Figure 3-10. Maximum Slosh Height Time History Over All Free-Surface Liquid Elements for Horizontal Excitation for Initial Liquid Height of 460 in. .......................... 30 Figure 4-1. Horizontal Reaction Force for Rigid Tank With Initial Liquid Level of 480 in. (20 in. Headspace).

Figure 4-2. Horizontal Reaction Force for Rigid Tank at 480 in. Liquid Level Under Horizontal Seismic Excitation - Convective Response.................................................... 33 Figure 4-3. Liquid Pressure Time Histories for the Rigid Tank With 480 in. of Liquid Under Horizontal Excitation at $\theta=0^{\circ}$. 34 
RPP-RPT-30807, Rev. 0

M\&D-2008-005-RPT-02, Rev. 0

Figure 4-4. Selected Liquid Pressure Time Histories for the Rigid Tank With 480 in. of

Liquid Under Horizontal Excitation at $\theta=0^{\circ}$.

Figure 4-5. Liquid Pressure Time Histories for the Rigid Tank With 480 in. of Liquid

Under Horizontal Excitation at $\theta=45^{\circ}$.

Figure 4-6. Liquid Pressure Time Histories for the Rigid Tank With 480 in. of Liquid

Under Horizontal Excitation at $\theta=90^{\circ}$.

Figure 4-7. Liquid Pressure Comparisons for the Bottom of the Tank at the $480 \mathrm{in.}$

Liquid Level at $\theta=0$ and $180^{\circ}$ and at the Tank Center................................................... 36

Figure 4-8. Liquid Pressure Comparisons for the Top of the Tank at the 480 in. Liquid

Level at $\theta=0$ and $180^{\circ}$ and at the Tank Center.

Figure 4-9. Maximum and Minimum Waste Pressure Comparison for Roofless Tank,

BNL Flat Top Estimate, and Dytran Solution at the 480 in. Liquid Level at $\theta=0$............ 38

Figure 4-10. Maximum and Minimum Waste Pressure Comparison for Roofless Tank,

BNL Flat Top Estimate, and Dytran Solution at the 480 in. Liquid Level at $\theta=180^{\circ}$...... 39

Figure 4-11. Pressure Time History for Fluid Element 24113 at 480 in. Liquid Level

Showing Character of Isolated Pressure Spike at 13.16s.....

Figure 4-12. Pressure Time History for Fluid Element 24113 at 480 in. Liquid Level

Showing Character of Isolated Pressure Spike During Time from 13.15 to 13.18s......... 41

Figure 5-1. Horizontal Reaction Force for Rigid Tank With Initial Liquid Level of 490

in. (10 in. Headspace).

Figure 5-2. Horizontal Reaction Force for Rigid Tank at 490 in. Liquid Level Under Horizontal Seismic Excitation - Convective Response.

Figure 5-3. Liquid Pressure Time Histories for the Rigid Tank With 490 in. of Liquid

Under Horizontal Excitation at $\theta=0^{\circ}$.

Figure 5-4. Selected Liquid Pressure Time Histories for the Rigid Tank With 490 in. of

Liquid Under Horizontal Excitation at $\theta=0$.

Figure 5-5. Comparison of Waste Pressures for the Uppermost Fluid Elements at the 480

and 490 in. Liquid Levels at $\theta=0$.

Figure 5-6. Liquid Pressure Time Histories for the Rigid Tank With 490 in. of Liquid

Under Horizontal Excitation at $\theta=45^{\circ}$.

Figure 5-7. Liquid Pressure Time Histories for the Rigid Tank With 490 in. of Liquid

Under Horizontal Excitation at $\theta=90^{\circ}$.

Figure 5-8. Maximum and Minimum Waste Pressure Comparison for Roofless Tank,

BNL Flat Top Estimate, and Dytran Solution at the 490 in. Liquid Level...................... 48

Figure 6-1. Horizontal Coupling Surface Reaction Force for the Rigid Tank at 500 in.

Liquid Level Under Horizontal Seismic Input................................................................... 50

Figure 6-2. Comparison of Coupling Surface Reaction Force and Input Acceleration for

the Completely Full Tank (500 in. Liquid Level)............................................................ 51

Figure 6-3. Liquid Pressure Time Histories for the Rigid Tank With 500 in. of Liquid

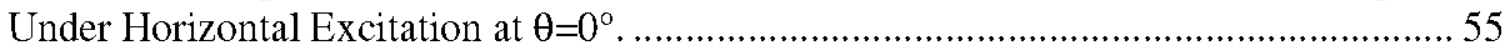

Figure 6-4. Selected Liquid Pressure Time Histories for the Rigid Tank With 500 in. of

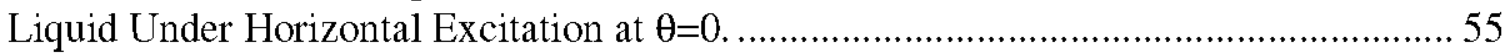

Figure 6-5. Liquid Pressure Time Histories for the Rigid Tank With 500 in. of Liquid

Under Horizontal Excitation at $\theta=45^{\circ}$.

Figure 6-6. Liquid Pressure Time Histories for the Rigid Tank With 500 in. of Liquid

Under Horizontal Excitation at $\theta=90^{\circ}$. 56 
RPP-RPT-30807, Rev. 0

M\&D-2008-005-RPT-02, Rev. 0

Figure 6-7. Comparison of Liquid Pressure Time Histories at Three Locations for the

500 in. Liquid Level (Completely Full Tank).............................................................. 57 Figure 6-8. Maximum and Minimum Liquid Pressures vs. Normalized Height from Tank Bottom for Horizontal Excitation at $\theta=0$ and Liquid Height of 500 in........................... 57 
RPP-RPT-30807, Rev. 0

M\&D-2008-005-RPT-02, Rev. 0

\section{LIST OF TABLES}

Table 1-1. Summary of Convective Frequencies (Hz). 4

Table 1-2. Summary of Peak Horizontal Reaction Forces (lbf)......................................... 4

Table 1-3. Summary of Peak Horizontal Convective Reaction Forces (lbf), .................... 5

Table 1-4. Summary of Maximum Wall Pressures ( $\left(\mathrm{bf} / \mathrm{in}^{2}\right.$ gage), .................................... 5

Table 1-5. Summary of Maximum Roof Pressures (lbf// $\mathrm{in}^{2}$ gage), ................................. 6

Table 2-1. Theoretical Hydrostatic Pressure of Liquid Elements for Various Initial

Liquid Heights. 19

Table 3-1. Theoretical Maximum Liquid Pressures for Horizontal Excitation in the Rigid

Tank at 460 in. Liquid Level for Elements at $\theta=0$. 24

Table 3-2. Theoretical Maximum Liquid Pressures for Horizontal Excitation in the Rigid

Tank at $460 \mathrm{in}$. Liquid Level for Elements at $\theta=45^{\circ}$. 25

Table 3-3. Summary of Results for 460 in. Liquid Level................................................ 31

Table 4-1. Summary of Results for 480 in. Liquid Level................................................ 41

Table 5-1. Summary of Results for 490 in. Liquid Level.............................................. 49

Table 6-1. Theoretical Maximum Liquid Pressures for Horizontal Excitation in the Rigid

Tank at $500 \mathrm{in.}$ Liquid Level for Elements at $\theta=0^{\circ}$. 53

Table 6-2. Theoretical Maximum Liquid Pressures for Horizontal Excitation in the Rigid Tank at $460 \mathrm{in.}$ Liquid Level for Elements at $\theta=45^{\circ}$. 54 
RPP-RPT-30807, Rev. 0

M\&D-2008-005-RPT-02, Rev. 0

\subsection{INTRODUCTON}

This work was performed in support of a project entitled Double-Shell Tank(DST) Integrity Project-DST Thermal and Seismic Analysis. The analysis is directly related to work reported in Rinker and Abatt RPP RPT-28963, Rev. 0 and Rinker, Carpenter, and Abatt RPP-RPT-28965, Rev. 0 and was motivated by recommendations from a Project Review held on March 20-21, 2006 (Rinker et al. Appendix E of RPP-RPT-28968, Rev. 1).

Due to uncertainties in the solutions for domed tanks with an initial liquid level of 460 in. that were presented in Rinker and Abatt RPP-RPT-28963, Rev. 0, the reviewers recommended that the effects of liquid-roof interaction be further studied. Two of the specific recommendations made in Rinker et al. Appendix E of RPP-RPT-28968, Rev. 1 are shown below.

1. Solutions should be obtained for a flexible tank with a rigid, horizontal roof located at different distances above the liquid surface.

2. These solutions, along with those for the tank with the spherical dome, should be compared with the predictions of the simple, approximate procedures described in Appendix D of BNL (1995) and in Malhotra (2005).

The purpose of this study is to address the first recommendation by quantifying the effects of liquid interaction with the roof of a rigid flat-top tank for varying ratios of freeboard height $\left(h_{0}\right)$ to unconstrained maximum slosh height $\left(h_{\mathrm{s}}\right)$ when subjected to seismic excitation. A central question to be addressed is how the interaction with the tank roof affects the impulsive and convective responses of the liquid, and if the local roof interaction significantly affects peak pressures lower in the tank.

The second recommendation was addressed in a new appendix to Rinker and Abatt RPP-RPT-28963, Rev. 1, in which the response under seismic loading of both rigid and flexible wall domed tanks with an initial liquid level of $460 \mathrm{in}$. is presented. The initial issue of Rinker and Abatt RPP-RPT-28963, Rev. 0 documented the response of both of these configurations, but the new revision improves on that analysis with more refined models and removes the uncertainties present in the original analysis. The re-analysis of the flexible wall domed tank is intended to address the request for additional analysis of a flexible wall tank as contained in the first recommendation.

In this analysis, the finite element code Dytran was used to simulate the response of the contained liquid in flat-topped tanks to seismic excitation. Simulations were performed for a configuration in which no interaction with the roof occurred (an essentially roofless tank with an initial liquid level of 460 in.), for two configurations in which transient interaction with the roof occurred (480 and 490 in. initial liquid levels), and for a completely full tank (500 in. initial liquid level). Although this work was performed in support of the seismic analysis of the Hanford DSTs, the tank models in this study are for an idealized flat top configuration. Moreover, the liquid levels used in the present models 
RPP-RPT-30807, Rev. 0

M\&D-2008-005-RPT-02, Rev. 0

are for study purposes only and are independent of the actual operating levels of the DSTs.

The results of the Dytran simulations are compared with exact theoretical solutions or approximate solutions appearing in BNL (1995) and Malhotra (2005). The response parameters that are evaluated in this study are the total hydrodynamic reaction forces, the peak convective hydrodynamic forces, the fundamental convective frequencies, the liquid pressures, and peak slosh heights.

\subsection{SUMMARY OF RESULTS}

\subsubsection{0 in. Liquid Level}

For the effectively roofless tank at the 460 in. initial liquid level, the peak horizontal hydrodynamic reaction force predicted with Dytran was $6 \%$ greater than the theoretical prediction. The peak horizontal hydrodynamic reaction force due to convective effects only was $25 \%$ less than predicted by theory, although the reaction force due to convective effects only is typically an order of magnitude less than the total reaction force. That is, roughly $90 \%$ of the total reaction force is due to the impulsive component. The convective frequency predicted by Dytran exactly matched the theoretical value. The peak fluid pressures and pressure distributions also agreed well with theoretical predictions, and the maximum slosh height predicted by Dytran was $7 \%$ greater than predicted using the procedure in BNL (1995) and 9\% less than predicted using the procedure of Malhotra (2005).

\subsubsection{0 in. Liquid Level}

At the 480 in. initial liquid level, with a freeboard to unconstrained maximum slosh height ratio of 0.8 (per BNL 1995), the peak horizontal hydrodynamic reaction force predicted by Dytran was $76 \%$ of the peak force predicted using the approximate procedure in Appendix D of BNL (1995) and $80 \%$ of the value predicted using the simpler procedure in Malhotra (2005). The peak hydrodynamic reaction force predicted by Dytran due to convective effects only was $30 \%$ less than predicted using the methodology in Appendix D of BNL (1995) and nearly $40 \%$ less than predicted by the simpler methodology in Malhotra (2005). The convective response during the unforced motion following the seismic excitation was very similar to what would be expected in a roofless tank. That is, the effective damping was very low, and there was no discernable convective frequency shift due to the interaction with the roof.

The maximum liquid pressures in the lower $70 \%$ of the tank are essentially the same as for a roofless tank. Relative to the open tank solution, the maximum pressures increase in the upper $30 \%$ of the tank indicating interaction with the tank roof. The results show that the BNL estimate is quite conservative for predicting peak wall pressures in the 
RPP-RPT-30807, Rev. 0

M\&D-2008-005-RPT-02, Rev. 0

majority of the tank height, but may underestimate peak wall forces near the top of the tank.

The maximum roof pressure predicted by the Dytran model was approximately twice that predicted using the equivalent flat top tank methodology from Appendix D of

BNL (1995) and more than twenty times greater than the value predicted using the simple hydrostatic methodology in Malhotra (2005).

The estimate of the peak dynamic roof pressures that is given in Malhotra (2005) is an expression of the hydrostatic pressure associated with a rigid tank that is accelerating at the spectral acceleration associated with the convective response of the contained liquid. The estimate does not account for the impulsive response of the fluid, or for the dynamics of the fluid impacting the roof. Apparently that expression dramatically underestimates the peak dynamic roof pressures and associated roof forces during a seismic event.

\subsubsection{0 in. Liquid Level}

At the 490 in. initial liquid level, with a freeboard to unconstrained maximum slosh height ratio of 0.4 (per BNL 1995), the peak horizontal hydrodynamic reaction force predicted by Dytran was $78 \%$ of the peak force predicted using the approximate procedure in Appendix D of BNL (1995) and 75\% of the peak predicted by Malhotra (2005). The peak hydrodynamic reaction force predicted by Dytran due to convective effects only was more than twice that predicted using the methodology in Appendix D of BNL (1995) or Malhotra (2005), but was quickly damped out due to interaction with the roof. The effective damping caused by interaction with the roof during the unforced motion following the seismic excitation is approximately $6 \%$ of critical damping. In addition to effectively damping the response, the interaction with the roof increases the apparent convective frequency from approximately $0.2 \mathrm{~Hz}$ for a roofless tank to an average frequency of approximately $1.67 \mathrm{~Hz}$.

In contrast to the roofless tank solution, wall pressures at $\theta=45$ and $90^{\circ}$ show noticeable nonzero dynamic pressures particularly near the liquid surface. The pressure traces display the apparent convective frequency of $1.67 \mathrm{~Hz}$ and indicate interaction with the roof at these locations. Maximum liquid pressures are the same as for the roofless tank in the lower $60 \%$ of the tank, while the maximum pressures gradually increase above those predicted for the roofless tank in the upper $40 \%$ of the tank. As in the 480 in. liquid level case, the results show that the BNL estimate is quite conservative for predicting peak wall pressures in the majority of the tank height, but may underestimate peak wall forces near the top of the tank.

The predictions for maximum roof pressures at the $490 \mathrm{in}$. liquid level are similar to those for the 480 in. level. The prediction using the BNL (1995) methodology is unchanged, the Dytran result is more than 50\% higher than the BNL prediction, and the estimate using the procedure of Malhotra (2005) underestimates the peak roof pressures by nearly an order of magnitude. 


\subsubsection{0 in. Liquid Level}

For the completely full tank at the 500 in. liquid level, the peak horizontal hydrodynamic reaction force predicted by Dytran is within $1 \%$ of the theoretical value. The horizontal reaction force time history is equal to the product of the waste mass and input time history. The liquid pressures predicted by Dytran are independent of the depth in the tank and exactly match those predicted by the theoretical solution.

\subsubsection{Summary of Key Parameters}

The following tables and plot provide a summary of the important parameters from this study. Included are convective frequencies, horizontal reaction forces, peak wall pressures, and peak roof pressures. Figure 1-1 is intended to show that the peak reaction forces from the Dytran simulations are close to the predictions for an open tank for normalized headspace ratios as low as 0.4 . The Dytran solution then transitions to match the full tank solution. Further simulations would be required to provide additional data for normalized headspace ratios between 0 and 0.4 .

Table 1-1. Summary of Convective Frequencies $(\mathrm{Hz})$.

\begin{tabular}{|c|c|c|c|}
\hline $\begin{array}{c}\text { Liquid Height } \\
\text { (in) }\end{array}$ & $\begin{array}{c}\text { Open Top } \\
\text { Theory } \\
\text { (BNL 1995) }\end{array}$ & $\begin{array}{c}\text { Open Top } \\
\text { Estimate per } \\
\text { Malhotra } \\
\text { (2005) }\end{array}$ & Dytran Result \\
\hline 460 & 0.196 & 0.195 & 0.196 \\
\hline 480 & 0.196 & 0.195 & 0.194 \\
\hline 490 & 0.197 & 0.196 & 1.67 \\
\hline 500 & Not applicable & Not applicable & Not applicable \\
\hline
\end{tabular}

Table 1-2. Summary of Peak Horizontal Reaction Forces (lbf).

\begin{tabular}{|c|c|c|c|c|c|}
\hline $\begin{array}{l}\text { Initial } \\
\text { Liquid } \\
\text { Level (in.) }\end{array}$ & $\begin{array}{l}\mathbf{h}_{\mathbf{0}} / \mathbf{h}_{\mathbf{s}} \text { for } \\
\text { Open } \\
\text { Tank }\end{array}$ & $\begin{array}{c}\text { Roofless Tank } \\
\text { Solution } \\
\text { (SRSS) }\end{array}$ & BNL (1995) & $\begin{array}{c}\text { Malhotra } \\
\mathbf{( 2 0 0 5 )}\end{array}$ & Dytran Result \\
\hline 460 & $>1$ & $2.98 \times 10^{6}$ & $2.98 \times 10^{6}$ & $3.47 \times 10^{6}$ & $3.15 \times 10^{6}$ \\
\hline 480 & 0.8 & $3.19 \times 10^{6}$ & $4.47 \times 10^{6} 1$ & $4.26 \times 10^{6}$ & $3.41 \times 10^{6}$ \\
\hline 490 & 0.4 & $3.3 \times 10^{6}$ & $4.76 \times 10^{6} 1$ & $4.98 \times 10^{6}$ & $3.74 \times 10^{6}$ \\
\hline 500 & 0 & $3.4 \times 10^{6}$ & $5.71 \times 10^{6}$ & $5.71 \times 10^{6}$ & $5.76 \times 10^{6}$ \\
\hline
\end{tabular}

${ }^{1}$ Estimated from Appendix D of BNL (1995) for flat top tanks. 
Table 1-3. Summary of Peak Horizontal Convective Reaction Forces (lbf).

\begin{tabular}{|c|c|c|c|c|}
\hline $\begin{array}{c}\text { Liquid Height } \\
\text { (in) }\end{array}$ & $\begin{array}{c}\text { Open Top } \\
\text { Theory } \\
\text { (BNL 1995) }\end{array}$ & $\begin{array}{c}\text { Equivalent } \\
\text { Flat Top } \\
\text { Estimate } \\
\text { (BNL 1995) }\end{array}$ & Malhotra (2005) & Dytran Result \\
\hline 460 & $5.34 \times 10^{5}$ & Not applicable & $5.59 \times 10^{5}$ & $4.0 \times 10^{5}$ \\
\hline 480 & $5.37 \times 10^{5}$ & $3.42 \times 10^{5}$ & $3.82 \times 10^{5}$ & $2.2 \times 10^{5}$ \\
\hline 490 & $5.39 \times 10^{5}$ & $2.77 \times 10^{5}$ & $1.92 \times 10^{5}$ & $6.75 \times 10^{5}$ \\
\hline 500 & Not applicable & Not applicable & Not applicable & Not applicable \\
\hline
\end{tabular}

Figure 1-1. Normalized Peak Reaction Force vs. Normalized Headspace

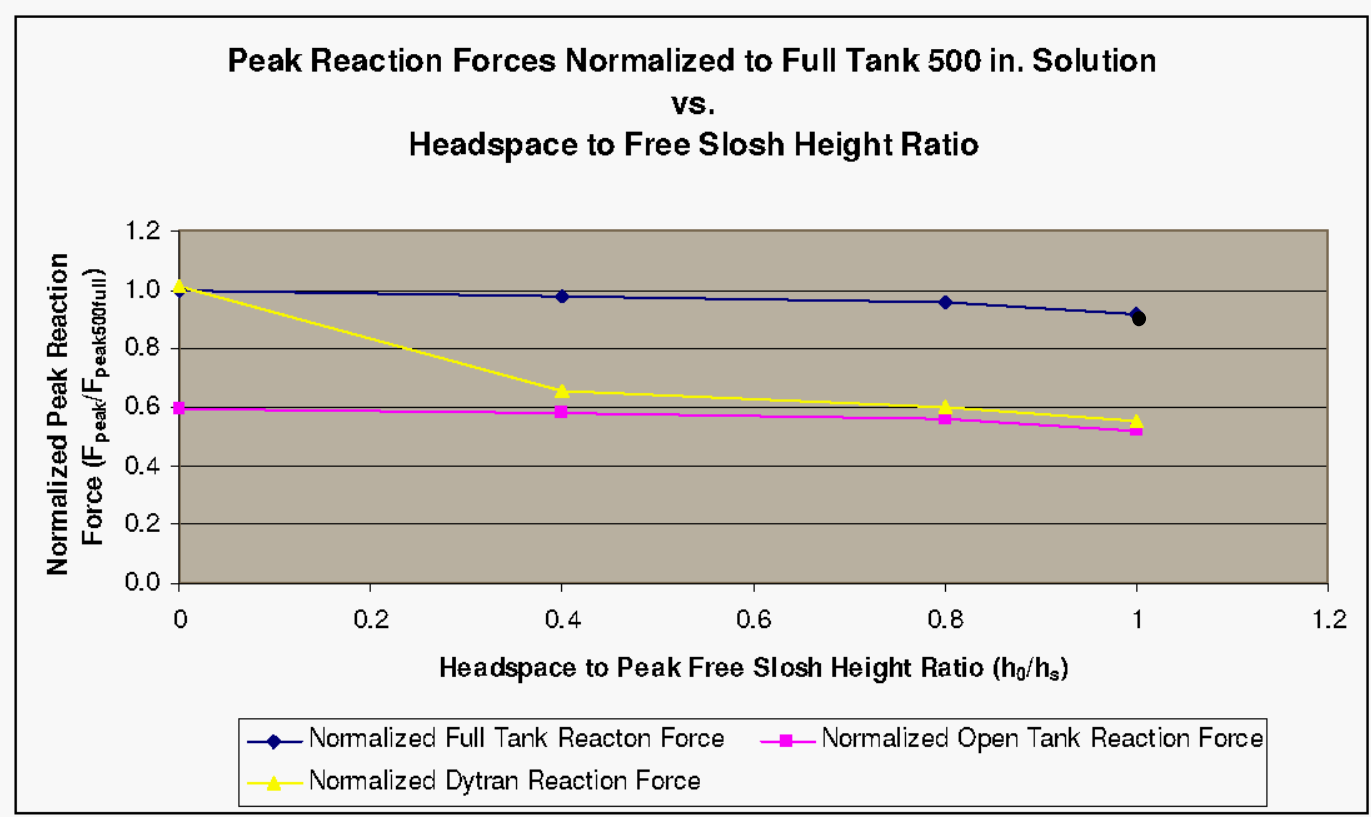

Table 1-4. Summary of Maximum Wall Pressures (lbf/in ${ }^{2}$ gage).

\begin{tabular}{|c|c|c|c|c|c|}
\hline $\begin{array}{c}\text { Liquid Height } \\
\text { (in) }\end{array}$ & $\begin{array}{c}\text { Open Top } \\
\text { Theory } \\
\text { (BNL 1995) }\end{array}$ & $\begin{array}{c}\text { Equivalent } \\
\text { Flat Top } \\
\text { Estimate } \\
\text { (BNL 1995) }\end{array}$ & $\begin{array}{c}\text { Malhotra } \\
\mathbf{( 2 0 0 5 )}\end{array}$ & Dytran Result & Location \\
\hline 460 & 36.3 & $\begin{array}{c}\text { Not } \\
\text { applicable }\end{array}$ & Not applicable & 36.4 & Tank bottom at $\theta=0$ \\
\hline 480 & 37.7 & 46.4 & Not applicable & 37.8 & Tank bottom at $\theta=0$ \\
\hline 490 & 38.5 & 47.1 & Not applicable & 38.7 & Tank bottom at $\theta=0$ \\
\hline 500 & Not applicable & 40.9 & Not applicable & 40.9 & Tank bottom at $\theta=0$ \\
\hline
\end{tabular}


RPP-RPT-30807, Rev. 0

M\&D-2008-005-RPT-02, Rev. 0

Table 1-5. Summary of Maximum Roof Pressures (lbf/in² gage).

\begin{tabular}{|c|c|c|c|}
\hline $\begin{array}{c}\text { Liquid Height } \\
\text { (in) }\end{array}$ & $\begin{array}{c}\text { Equivalent } \\
\text { Flat Top } \\
\text { Estimate } \\
\text { (BNL 1995) }\end{array}$ & $\begin{array}{c}\text { Malhotra } \\
\mathbf{( 2 0 0 5 )}\end{array}$ & Dytran Result \\
\hline 460 & Not applicable & Not applicable & Not applicable \\
\hline 480 & 8.2 & 0.7 & 16.2 \\
\hline 490 & 8.2 & 1.5 & 12.5 \\
\hline 500 & 8.2 & Not applicable & 8.5 \\
\hline
\end{tabular}

\subsection{DISCUSSION}

In the two cases where exact analytical solutions exist, namely the effectively roofless tank at the $460 \mathrm{in.} \mathrm{liquid} \mathrm{level} \mathrm{and} \mathrm{the} \mathrm{completely} \mathrm{full} \mathrm{tank} \mathrm{at} \mathrm{the} 500 \mathrm{in}$. liquid level, the Dytran results generally agreed very well with theoretical values, although for the roofless tank, the peak horizontal hydrodynamic reaction force due to convective effects only was approximately $25 \%$ less than the theoretical value. However, when sloshing occurs, the total hydrodynamic reaction force is dominated by the impulsive component with the convective component being roughly an order of magnitude less.

At the two intermediate liquid levels where intermittent interaction between the liquid and the roof occurs, several interesting results were observed. In both cases, the predictions of peak hydrodynamic force predictions using the methodology of Appendix D in BNL (1995) were conservative, as expected as were the predictions using the methodology of Malhotra (2005). At both initial liquid levels, estimates of peak wall pressures using the methodology of Appendix D in BNL (1995) were quite conservative lower in the tank, but may not be conservative in predicting peak pressures near the top of the tank wall. The peak roof pressures predicted by Dytran were 50 to $100 \%$ higher than predicted using the BNL methodology and much higher than predicted by the methodology of Malhotra (2005). It is clear that the simple hydrostatic methodology in Malhotra (2005) grossly underestimates the roof pressures.

Increased peak pressures above those expected for the corresponding roofless tank solution that were caused by interaction with the tank roof were limited to approximately the upper third of the tank. Finally, interaction with the roof had little effect on the unforced convective response at the $480 \mathrm{in}$. liquid level, but at the $490 \mathrm{in}$. level, it effectively damped the response and increased the apparent convective frequency dramatically.

It is interesting to note that the maximum roof pressures predicted by BNL (1995) for the 480 and 490 in. liquid levels are precisely the internal pressures predicted for a completely full tank. Moreover, the maximum roof pressures predicted by Dytran at the 480 and 490 in. initial liquid levels are higher than the roof pressures for the completely full tank. That is, although the completely full tank represents an upper bound configuration for hydrodynamic reaction forces, the peak pressures associated with roof impact at the lower liquid levels are higher than those experienced in a completely full tank. 
RPP-RPT-30807, Rev. 0

M\&D-2008-005-RPT-02, Rev. 0

Finally, it is worth noting that slosh height plots were not presented for the simulations at the 480 and 490 in. liquid levels for the simple reason that the lack of element resolution within the headspace tends to make the plots somewhat misleading.

\subsubsection{Interpretation of Numerical Anomalies}

Many of the pressure time histories presented in the report display an initial response approximately $2.25 \mathrm{~s}$ into the simulation. The input acceleration time history is not read until $2 \mathrm{~s}$ of simulation time has passed, and the initial $1 \mathrm{~s}$ of the input time history consists of essentially null input as shown in Figure 2-13. Thus, no significant response is expected until at least $3 \mathrm{~s}$ into the simulation, and the initial non-zero pressure response is "non-causal". Such behavior does not occur in any of the reaction force time histories, where the initial non-zero responses begin at approximately $3 \mathrm{~s}$. Such response is also much less apparent during the simulation at the $500 \mathrm{in}$. liquid level.

Apparently a numerical artifice, the behavior has no significant effect on the pressure results since it has dissipated before the beginning of the strong motion seismic input.

Another phenomenon that occurred in some of the pressure time histories was the appearance of isolated peaks. These isolated peaks are also judged to be numerically spurious and are of no physical consequence to the structural analysis. This phenomenon is addressed in more detail in Section 4.2.

\subsection{CONCLUSIONS}

1. Dytran agrees well with the theoretical solutions for the roofless tank and completely full tank.

2. The estimates of peak hydrodynamic forces appearing in BNL (1995) and Malhotra (2005) are reasonable and generally conservative, relative to the Dytran solutions.

3. Relative to the Dytran solutions, the estimates of wall pressures appearing in Appendix D of BNL (1995) for flat top tanks are quite conservative over the majority of the wall height, but may underestimate peak pressures near the top of the wall.

4. For the conditions in this study (excitation levels, horizontal shaking, liquid levels, head space) the effects of roof impact are limited to the upper portion of the tanks and do not have any significant effect on the pressures in the lower twothirds of the tanks.

5. The completely full tank represents an upper bound for peak hydrodynamic reaction forces, but not for peak dynamic pressures.

6. At the 460 and $480 \mathrm{in}$. liquid level, the convective component of the hydrodynamic reaction force predicted by Dytran was less than predicted by the 
BNL or Malhotra estimates, but the total hydrodynamic reaction force is dominated by the impulsive component.

7. At the $490 \mathrm{in}$. liquid level, the peak convective reaction forces predicted using the methodologies in BNL (1995) and Malhotra (2005) were less than half of the peak predicted by Dytran.

8. The hydrostatic methodology in Malhotra (2005) grossly underestimates the peak roof pressures.

9. Initial pressure pulses apparent in the Dytran solutions prior to the seismic excitation are numerically spurious results and do not affect the results of the simulation.

10. Isolated peak minimum pressures in the Dytran simulations that lead to deviations in the maximum and minimum pressure plots are numerically spurious and do not affect the results of the simulations. 
RPP-RPT-30807, Rev. 0

M\&D-2008-005-RPT-02, Rev. 0

\subsection{MODEL DESCRIPTION}

Models of rigid flat top tanks were created using the 2005 version of MSC.Patran ${ }^{2}$, and were analyzed using the Dytran 2006 Development Version. Models were created at four different initial liquid levels representing no interaction with the roof (an effectively roofless tank), a completely full tank, and two intermediate liquid levels where the sloshing of the liquid impacts the tank roof. All Dytran models are full three-dimensional (3D) representations of the tanks. Applied loads include gravity loading and seismic loading, with seismic loading applied in a single horizontal direction.

The rigid tank configuration was run without damping other than the artificial viscosities inherent in the Dytran program. The artificial viscosities implemented in Dytran are referred to as the linear (BULKL) and quadratic (BULKQ) bulk viscosities. The bulk viscosities act to control the formation of shock waves by introducing viscosity to the bulk straining of the fluid. Experience with similar models (Rinker and Abatt 2006) has shown that it is necessary to increase the bulk viscosity coefficients relative to the default values in order to properly calibrate the models. Consequently, all simulations were run with the linear and quadratic bulk viscosity parameters set to 0.2 and 1.1 , respectively. The default values for the bulk viscosity coefficients are 0 for the linear coefficient and 1.0 for the quadratic coefficient.

Based on the decay of the convective response following the seismic excitation, the resulting effective damping in the model is in the range of $0.1 \%$ to $0.5 \%$. It is shown in Section 2.4 that the convective response is insensitive to damping. Accordingly, all theoretical estimates were made using a convective acceleration from a $0.1 \%$ damped spectrum.

\subsection{MODEL GEOMETRY}

The tank model incorporated for this analysis has a radius of $450 \mathrm{in}$. and a height of 500 in. A plot of the tank structural elements is shown in Figure 2-1. The models were run using liquid depths of 460, 480, 490, and 500 in. With the seismic excitation used in this analysis, the maximum theoretical slosh height for an open (roofless) tank is 25.2 in. according to the methodology in BNL (1995) Thus, the liquid depth of 460 in. represents an open top tank, the liquid depths of 480 and 490 in. represent freeboard to maximum (open top) slosh height ratios of 0.8 and 0.4 , respectively, and the $500 \mathrm{in}$. liquid level represents a completely full tank.

At the 460 in. initial liquid level, the Dytran results can be compared to solutions obtained for an open top tank using the methodology described in Chapter 4 of BNL (1995). At the two intermediate liquid levels, the Dytran results can be compared with estimates provided in Appendix D of BNL (1995) and in Malhotra (2005). The expected

\footnotetext{
${ }^{2}$ MSC.Patran is a registered trademark of MSC.Software Corporation.
} 
solution for a completely full tank can be obtained by physical reasoning and modification of the solution for an open tank that is presented in BNL (1995). This provides a benchmark to which the Dytran resul ts for the completely full tank can be compared.

Figure 2-1. Plot of Tank Structural Elements.

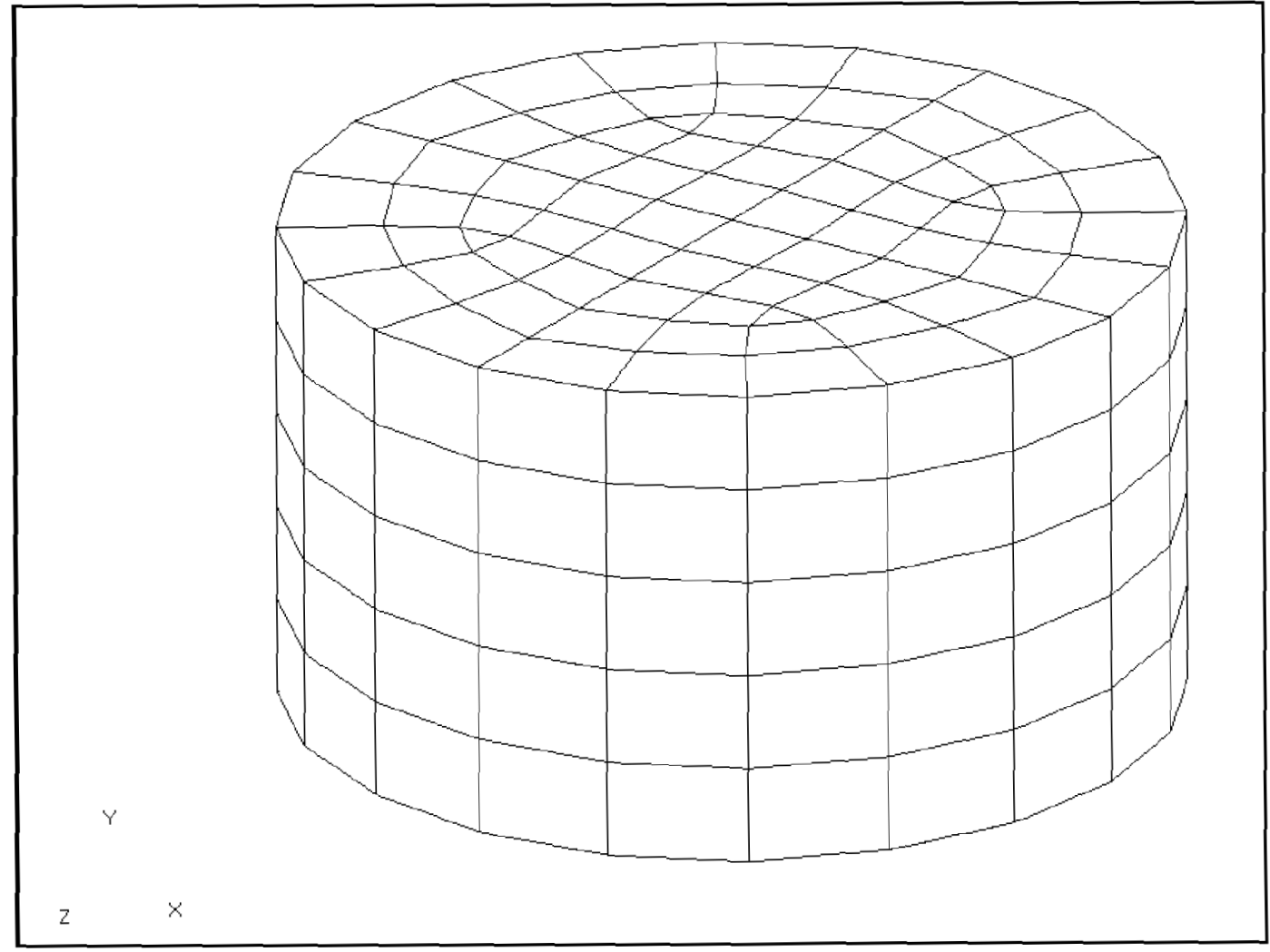

The relative height of the liquid to the tank for the four configurations is shown in Figure 2-2 through Figure 2-5, respectively. In the figures, the liquid is shown in light blue and the air is shown in the copper tone. The tank floor, walls, and roof form what is known as a Dytran coupling surface with the enclosed fluids. The coupling surface allows the Eulerian liquid mesh to interact with the Lagrangian structural mesh, and although the Eulerian mesh extends beyond the tank boundary, all the fluid dynamics occurs inside the tank. 
Figure 2-2. Elevation View of Tank and Eulerian Mesh at $460 \mathrm{in.} \mathrm{Liquid} \mathrm{Level.}$

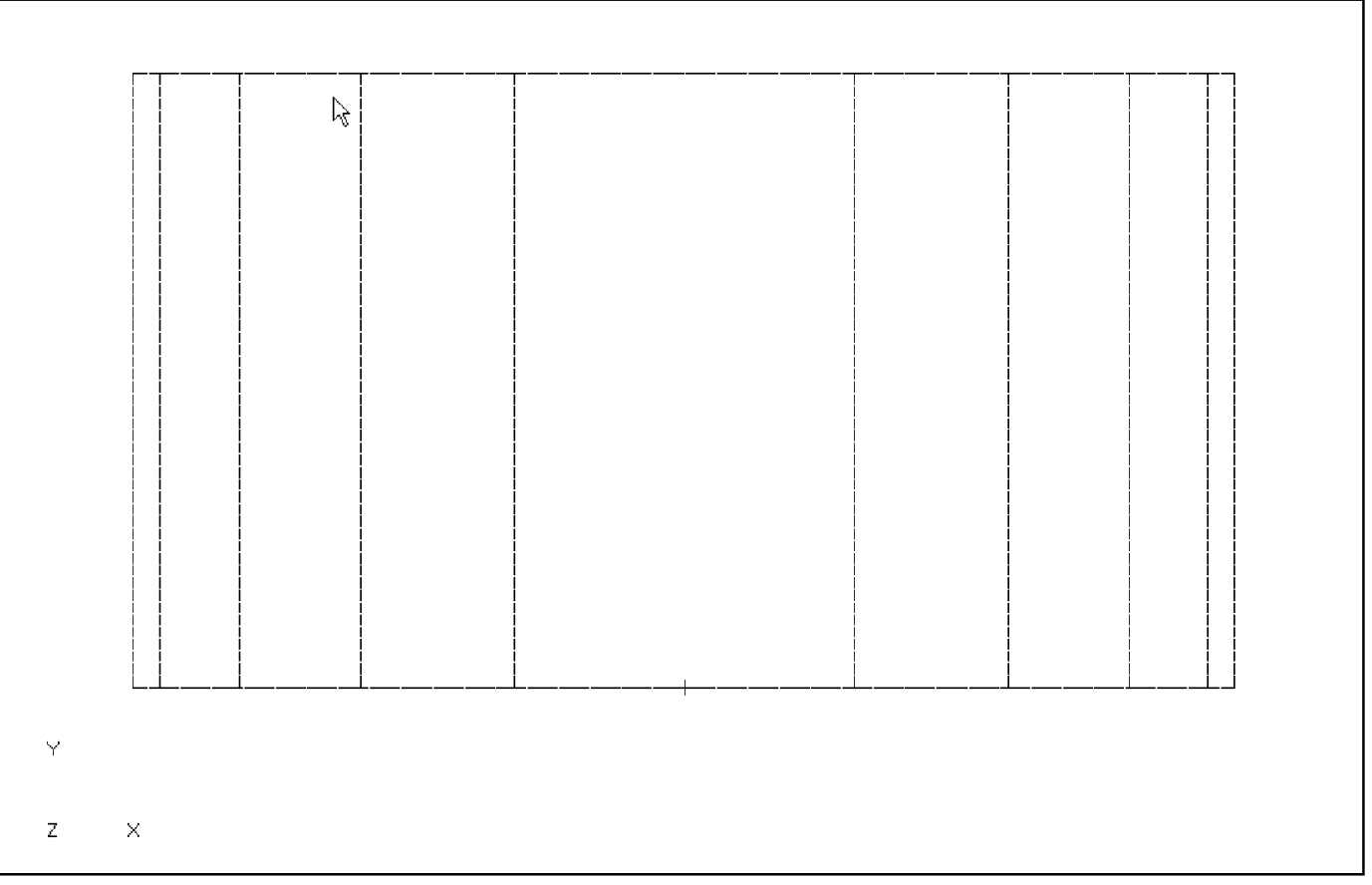

Figure 2-3. Elevation View of Tank and Eulerian Mesh at $480 \mathrm{in.}$ Liquid Level.

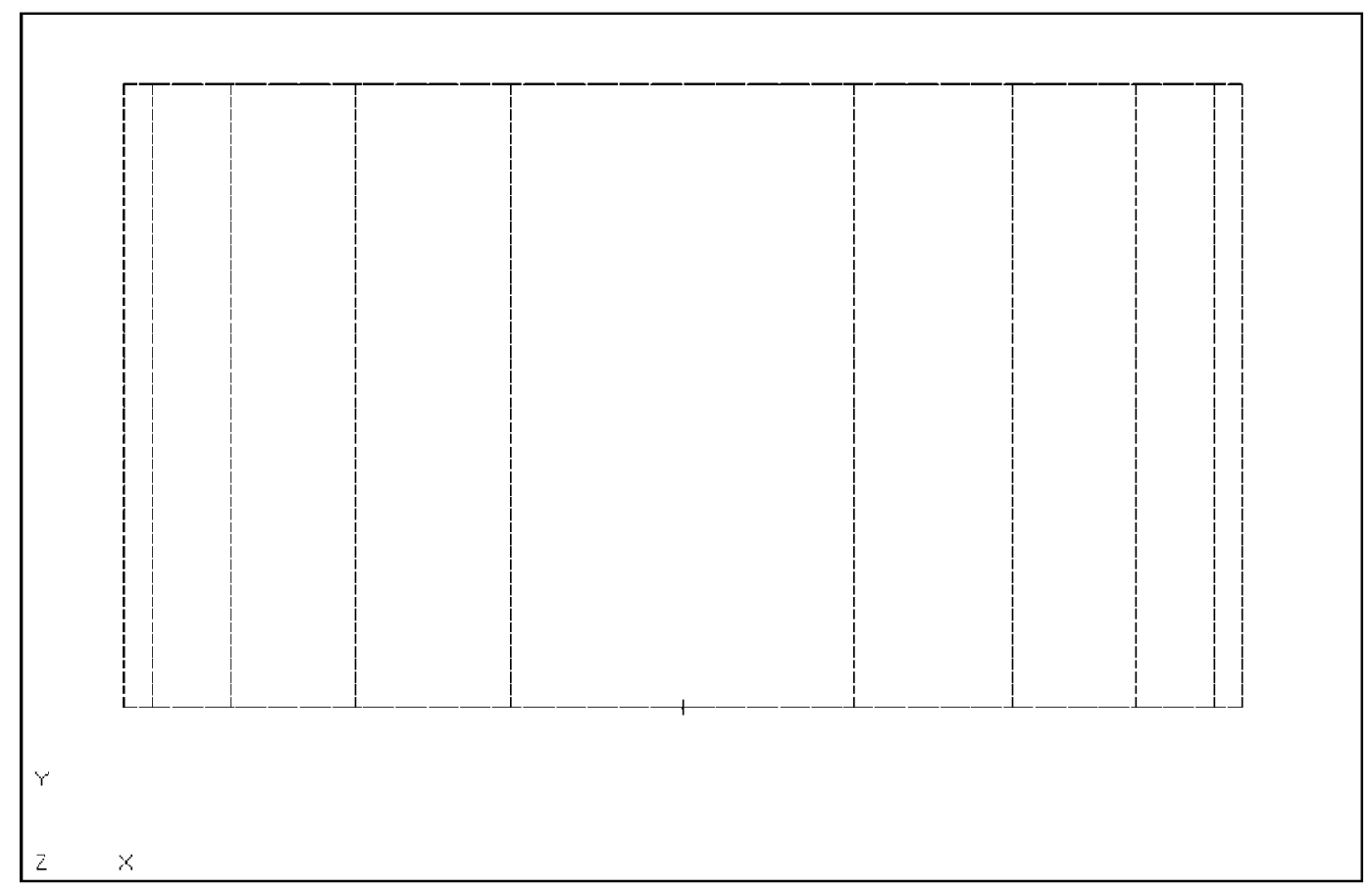


Figure 2-4. Elevation View of Tank and Eulerian Mesh at 490 in. Liquid Level.

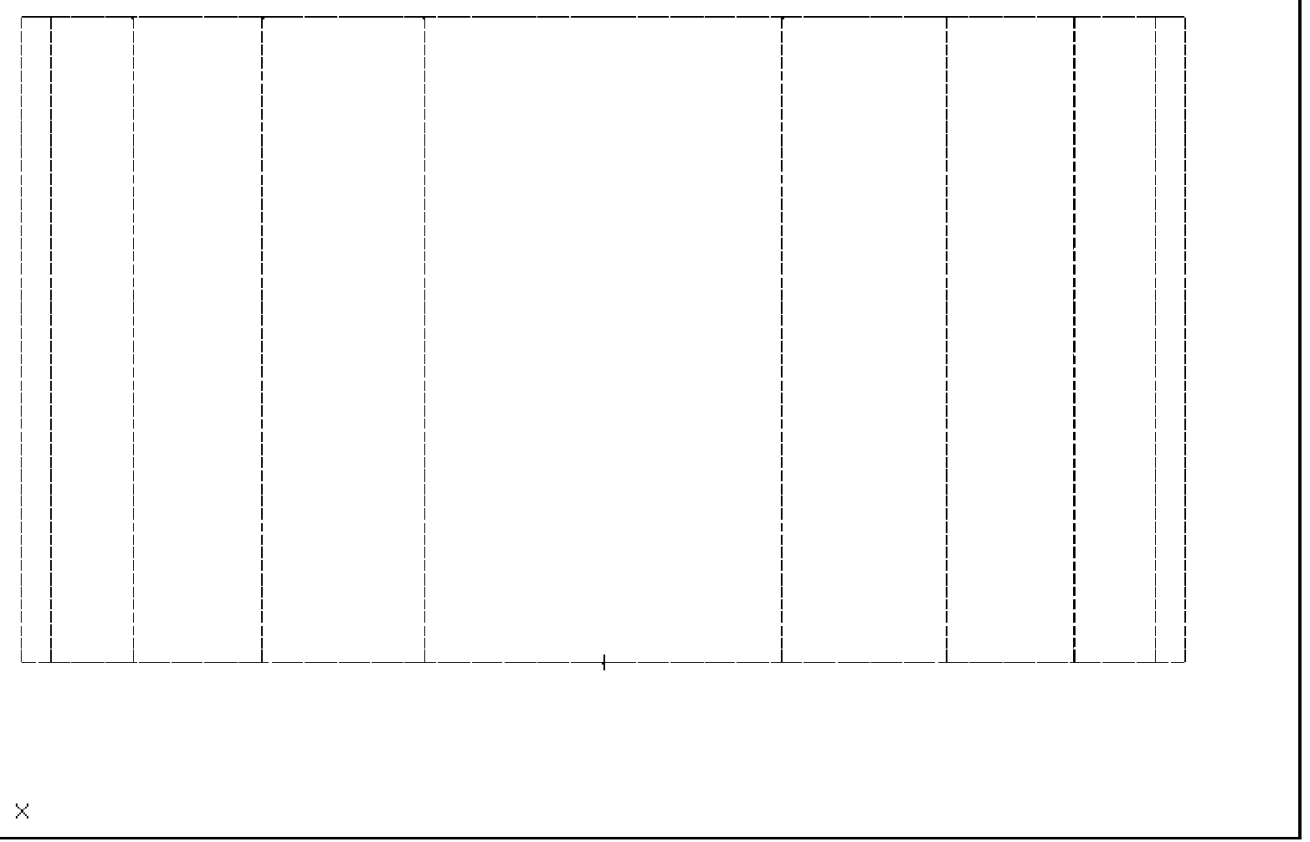

Figure 2-5. Elevation View of Tank and Eulerian Mesh at 500 in. Liquid Level.

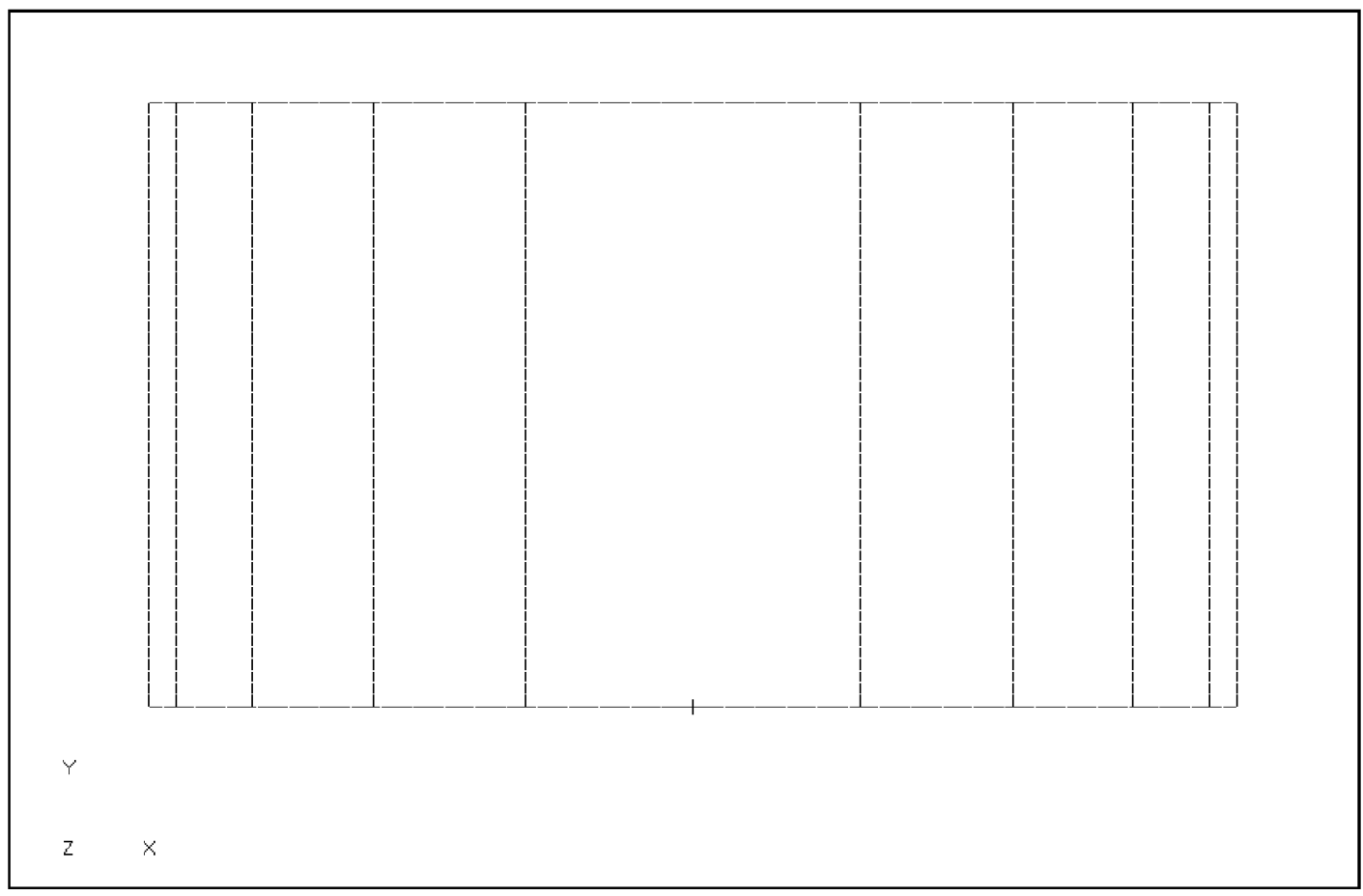

Dynamic liquid pressures are a function of depth, angular location and radial location of the fluid element. Liquid pressures were extracted from five sets of fluid elements throughout the tank as shown in Figure 2-6 through Figure 2-9. The element set 
"plusx_els" is located near the tank wall in the positive $\mathrm{x}$-direction $(\theta=0)$ in the plane of the seismic excitation. The angle $\theta$ is measured from the positive $\mathrm{x}$-axis to the positive $\mathrm{z}$ axis to describe the angular position of elements in the model. Element sets "press_45" and "plusz_els" are located near the tank wall at $45^{\circ}$ and $90^{\circ}$ from the excitation direction. Element sets "minusx_els" and "cent_press" are located at $\theta=180^{\circ}$ and at the center of the tank, respectively. Figure 2-8 shows the numbering for element sets "plusx_els", "press_45", and "plusz_els". Figure 2-9 shows the numbering for element sets "cent_press", and "minusx_els".

Figure 2-6. Plan View of Model Showing the Angular Locations of Fluid Elements at Which Pressures Were Monitored.

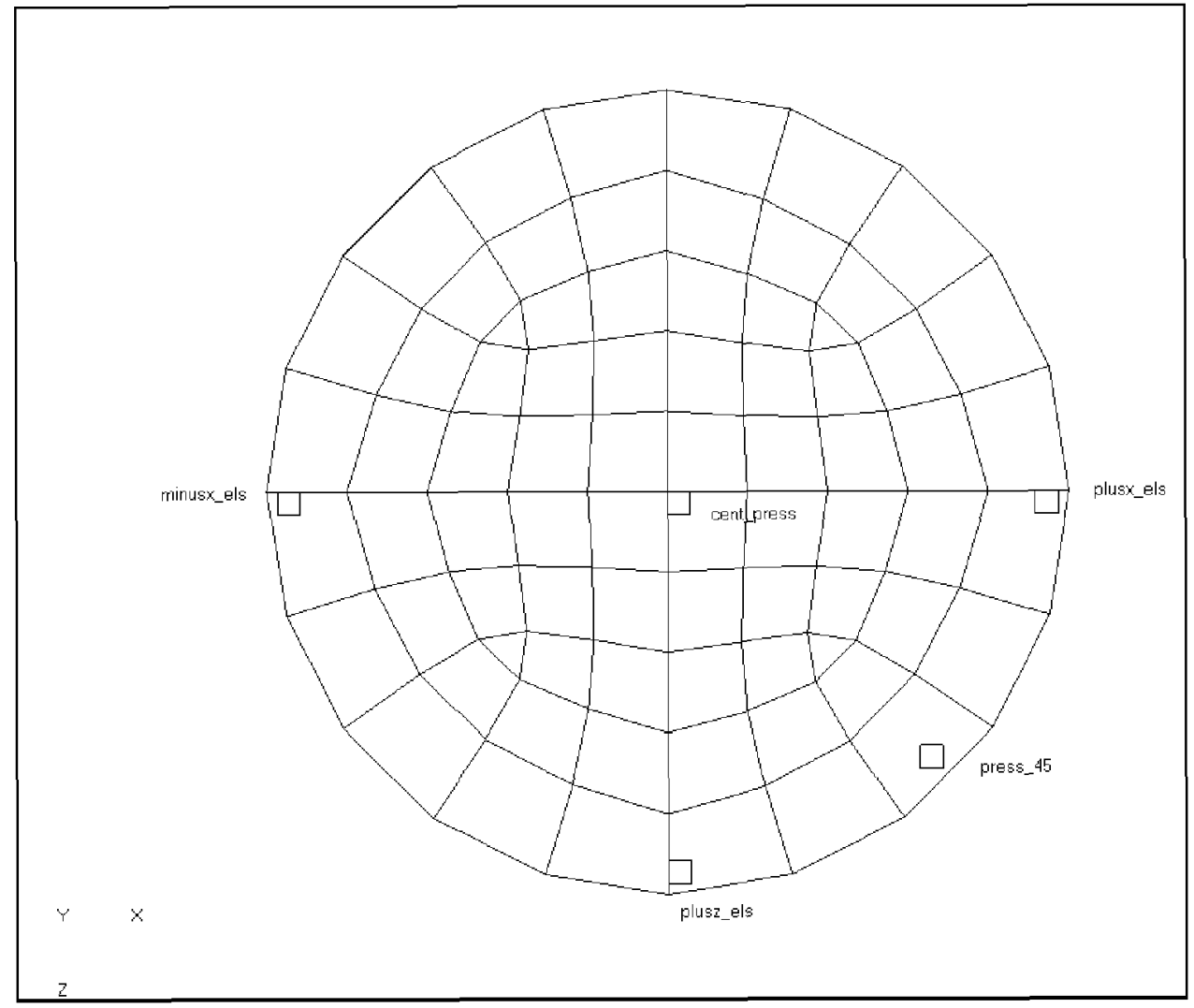


Figure 2-7. Elevation View of Model Showing the Locations of "plusx_els", "press_45", and "plusz_els" Fluid Elements Sets at Which Pressures Were Monitored.

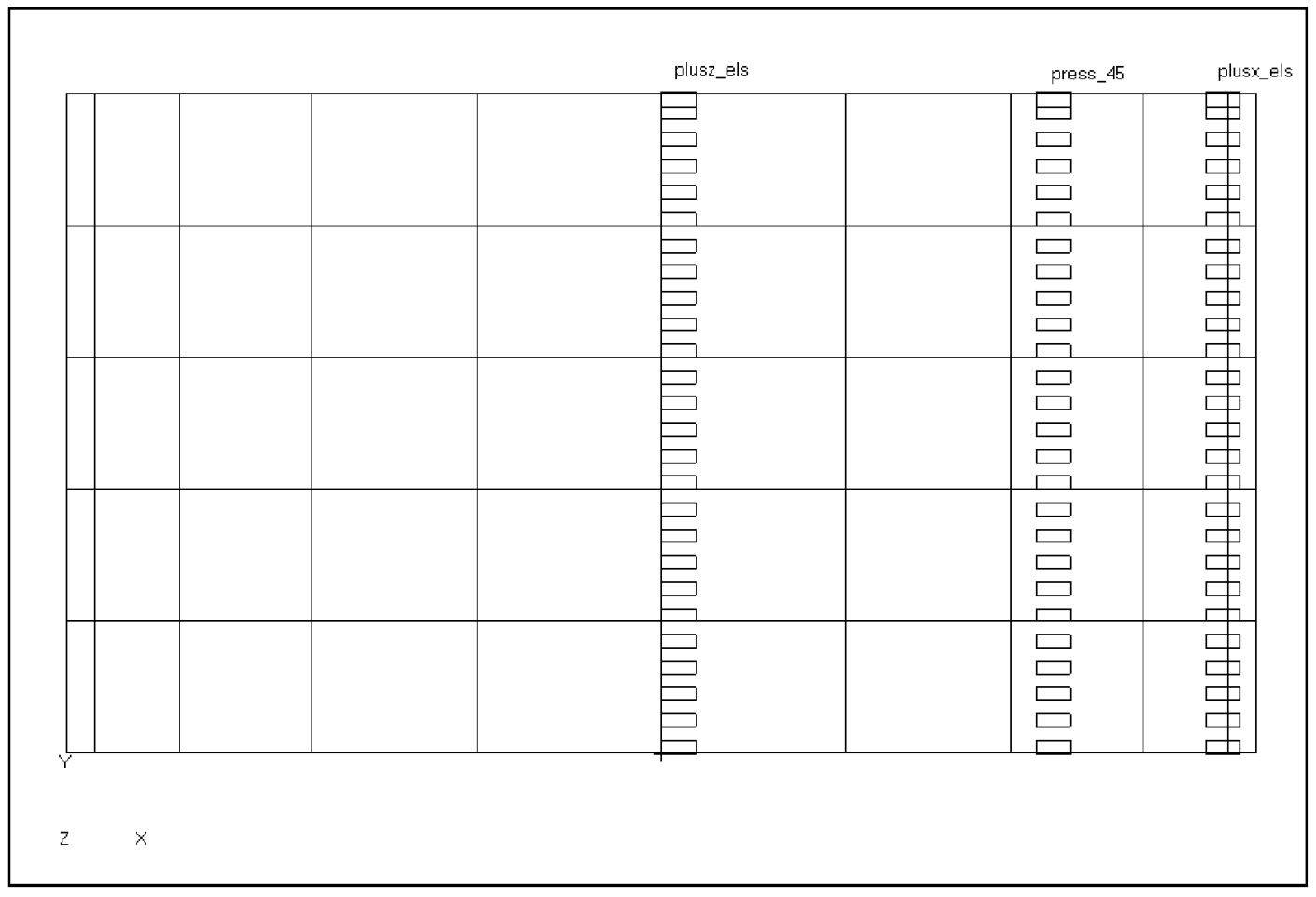

Figure 2-8. Element Numbering for Element Sets "plusx_els", "press_45”, and "plusz_els".

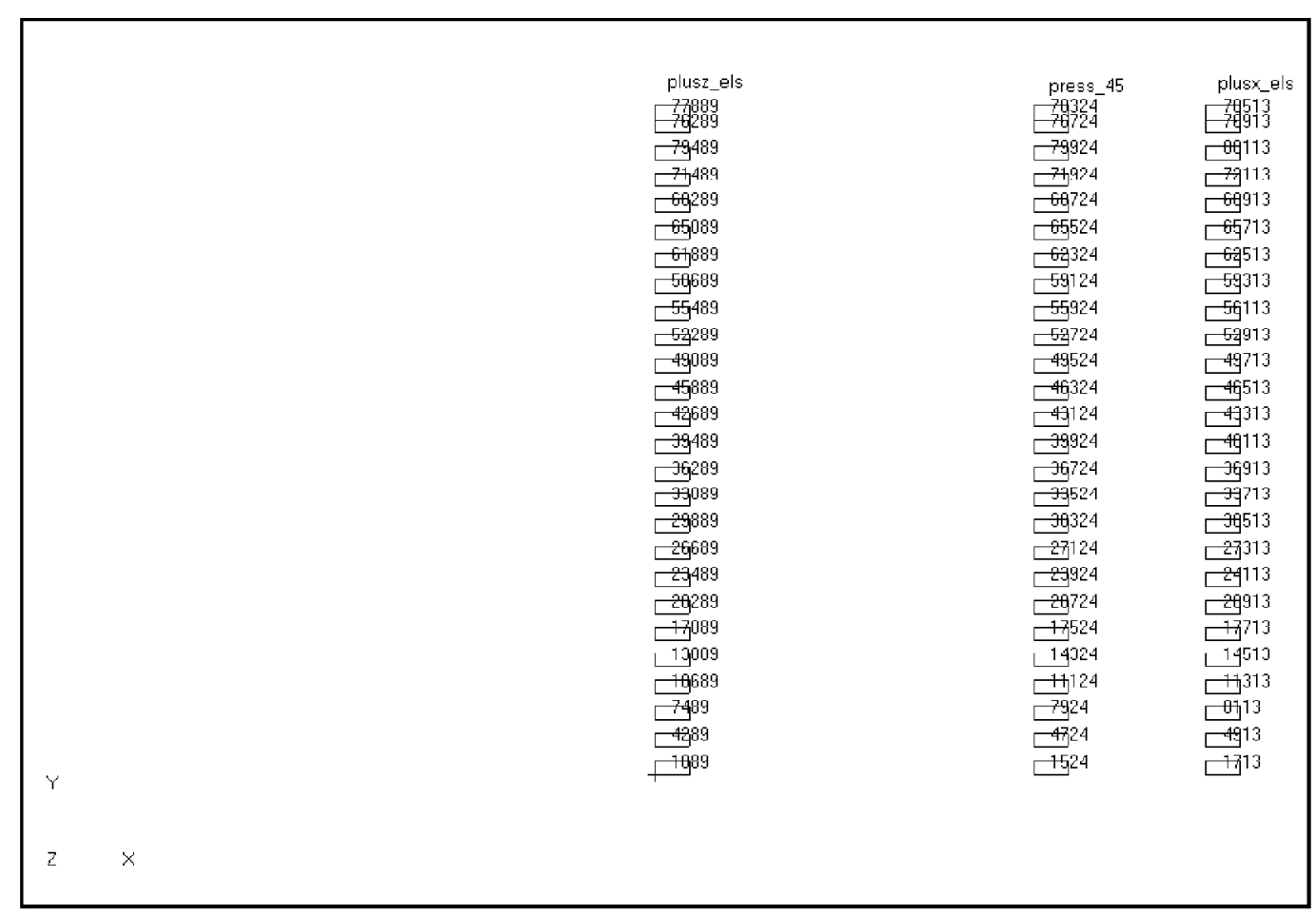


RPP-RPT-30807, Rev. 0

M\&D-2008-005-RPT-02, Rev. 0

Figure 2-9. Element Numbering for Element Sets "minusx_els", and cent_press".

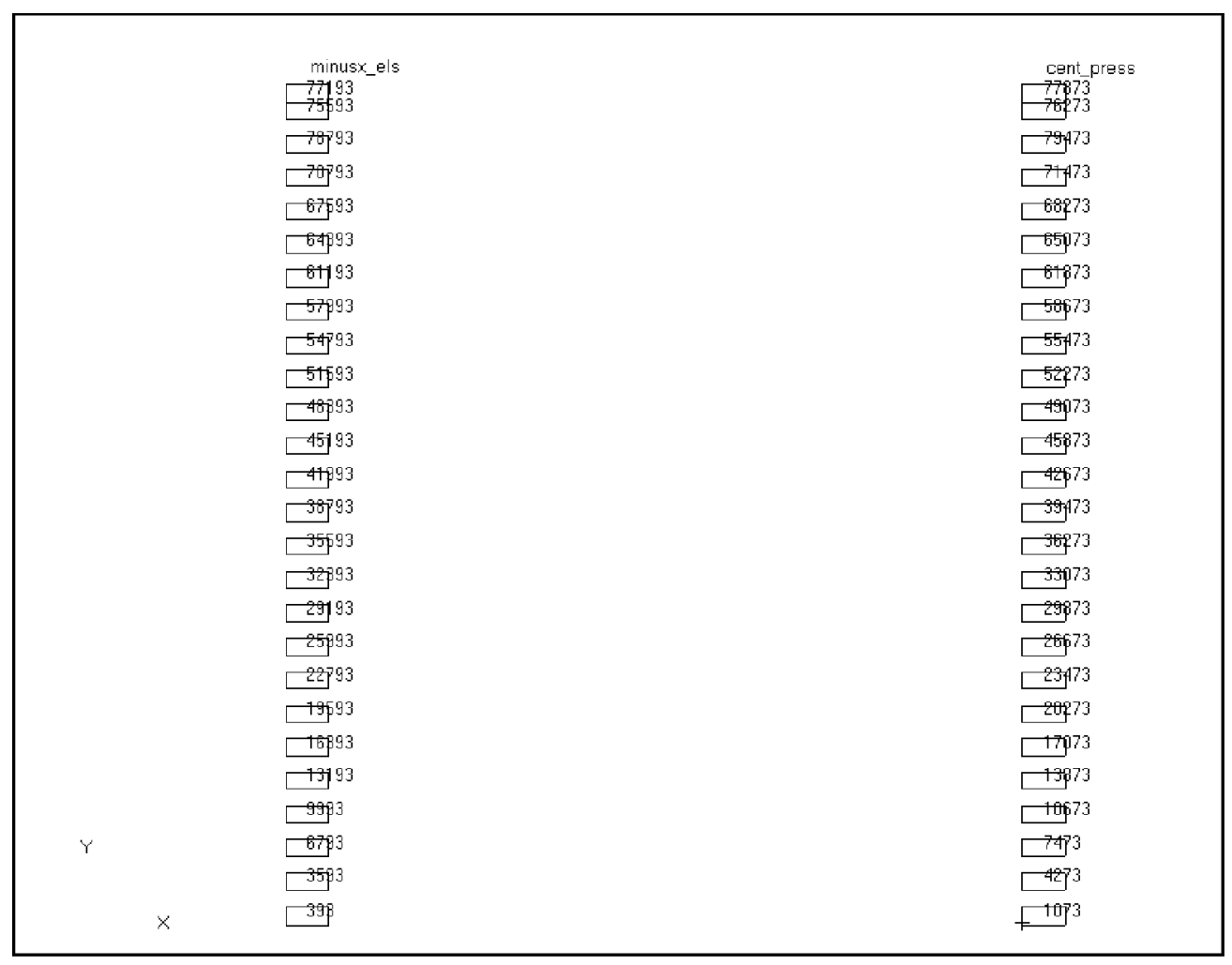

\subsection{MATERIAL PROPERTIES AND ELEMENT TYPES}

The tank was modeled in Dytran using 4-node CQUAD4 shell elements and the complete tank was modeled as a rigid body using the "MATRIG" command. The mass of the tank was much larger than the mass of the liquid to faithfully reflect the applied seismic motion.

The liquid and air were modeled using 8-node CHEXA Eulerian solid elements. The Eulerian elements inside the coupling surface defined by the tank boundary are $25.75 \mathrm{in}$. in each lateral direction and 10 in. tall. Because two fluids are present, the Eulerian elements were assigned multi-material hydrodynamic material properties (MMHYDRO). Both the air and the liquid were modeled as homogeneous, inviscid, fluids.

The liquid was modeled using a polynomial equation of state (EOSPOL) that requires the initial mass density and the bulk modulus of the fluid as input. The initial density of the liquid was set to $1.71 \times 10^{-4} \mathrm{lbf}-\mathrm{s}^{2} / \mathrm{in}^{4}$ (specific gravity $=1.83$ ). The bulk modulus of the liquid was set to $305,000 \mathrm{lbf} / \mathrm{in}^{2}$, which is a typical bulk modulus for water. However, the results are expected to be insensitive to the value of the bulk modulus since fluid compressibility is not critical to the response in this problem.

The air was modeled using the gamma law equation of state (EOSGAM), where the pressure is a function of the density $\rho$, the specific internal energy per unit mass $e$, and the ideal gas ratio of specific heats $\gamma$ via $p=(\gamma-1) p e$. The mass density of air is 
RPP-RPT-30807, Rev. 0

M\&D-2008-005-RPT-02, Rev. 0

$1.167 \times 10^{-7} \mathrm{lbf}-\mathrm{s}^{2} / \mathrm{in}^{4}$, and the ratio of constant-pressure specific heat to constant-volume specific heat is 1.4. All simulations were performed using absolute pressure, and the specific internal energy per unit mass of the air was set to $3.15 \times 10^{8} \mathrm{in}^{2} / \mathrm{s}^{2}$. The internal energy corresponds to an air pressure of $14.7 \mathrm{lbf} / \mathrm{in}^{2}$.

\subsection{BOUNDARY CONDITIONS}

The simulations represent horizontal excitation in a single direction (x-direction). Accordingly, the rigid tank was free in the x-direction, and fixed in the other five degrees-of-freedom.

The Dytran general coupling algorithm was used to allow the Eulerian liquid mesh to interact with the Lagrangian structural mesh. The problem was set up to take advantage of the "fast coupling" option in Dytran.

\subsection{SEISMIC INPUT}

The study reported here is a comparative study, and the time history used for the study is not critical to the results except as it affects the unconstrained slosh height of the liquid. However, the time history used was the most representative available for the motion of a Hanford DST primary tank. The seismic time history used to excite the tank model was output from a linear ANSYS model of a Hanford DST and surrounding soil and is the same time horizontal time history used in the studies documented in RPP-RPT-28963, Rev. 0, and RPP-RPT-28965, Rev. 0. The input acceleration time history consisted of 2,048 points defined at $0.01 \mathrm{~s}$ intervals giving a seismic record having a duration of $20.48 \mathrm{~s}$.

The horizontal (x-direction) seismic time history was applied to the rigid tank Dytran models as a body force acceleration per unit mass on the tank nodes.

The horizontal acceleration, velocity, and displacement time histories are shown in Figure 2-10, Figure 2-11, and Figure 2-12, respectively. A comparison of horizontal response spectra at damping values of $0.1 \%$, and $0.5 \%$, is shown in Figure 2-13. The plots in Figure 2-13 show that the spectral accelerations in the range of 0.1 to $0.5 \mathrm{~Hz}$ (typical convective frequencies) are nearly the same for 0.1 and $0.5 \%$ damping. That is, in this range of frequencies and damping values, the convective response is not sensitive to damping. 
RPP-RPT-30807, Rev. 0

M\&D-2008-005-RPT-02, Rev. 0

Figure 2-10. Horizontal Acceleration Time History Output from ANSYS Model.

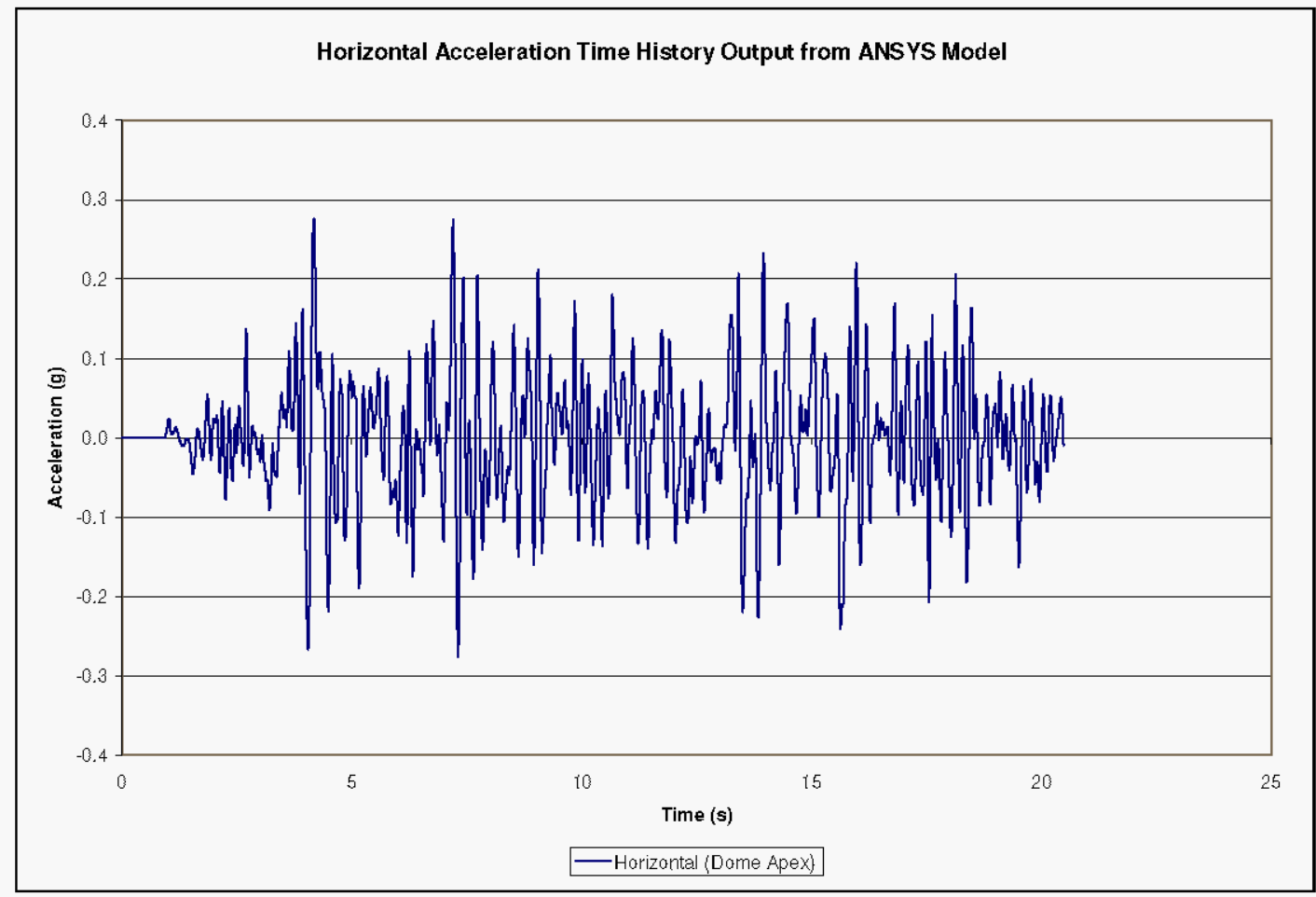

Figure 2-11. Horizontal Velocity Time History Output from ANSYS Model.

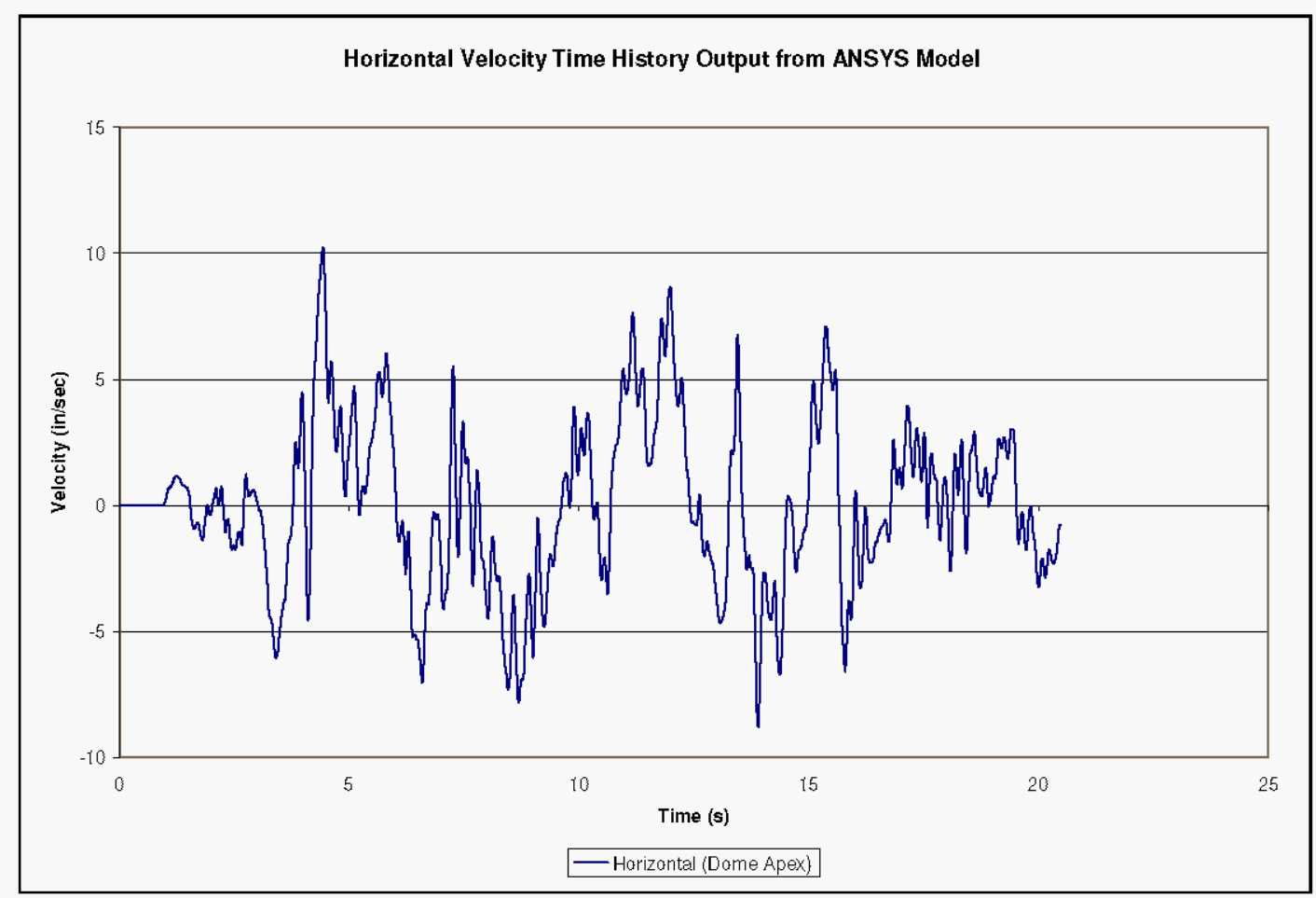


Figure 2-12. Horizontal Displacement Time History Output from ANSYS Model.

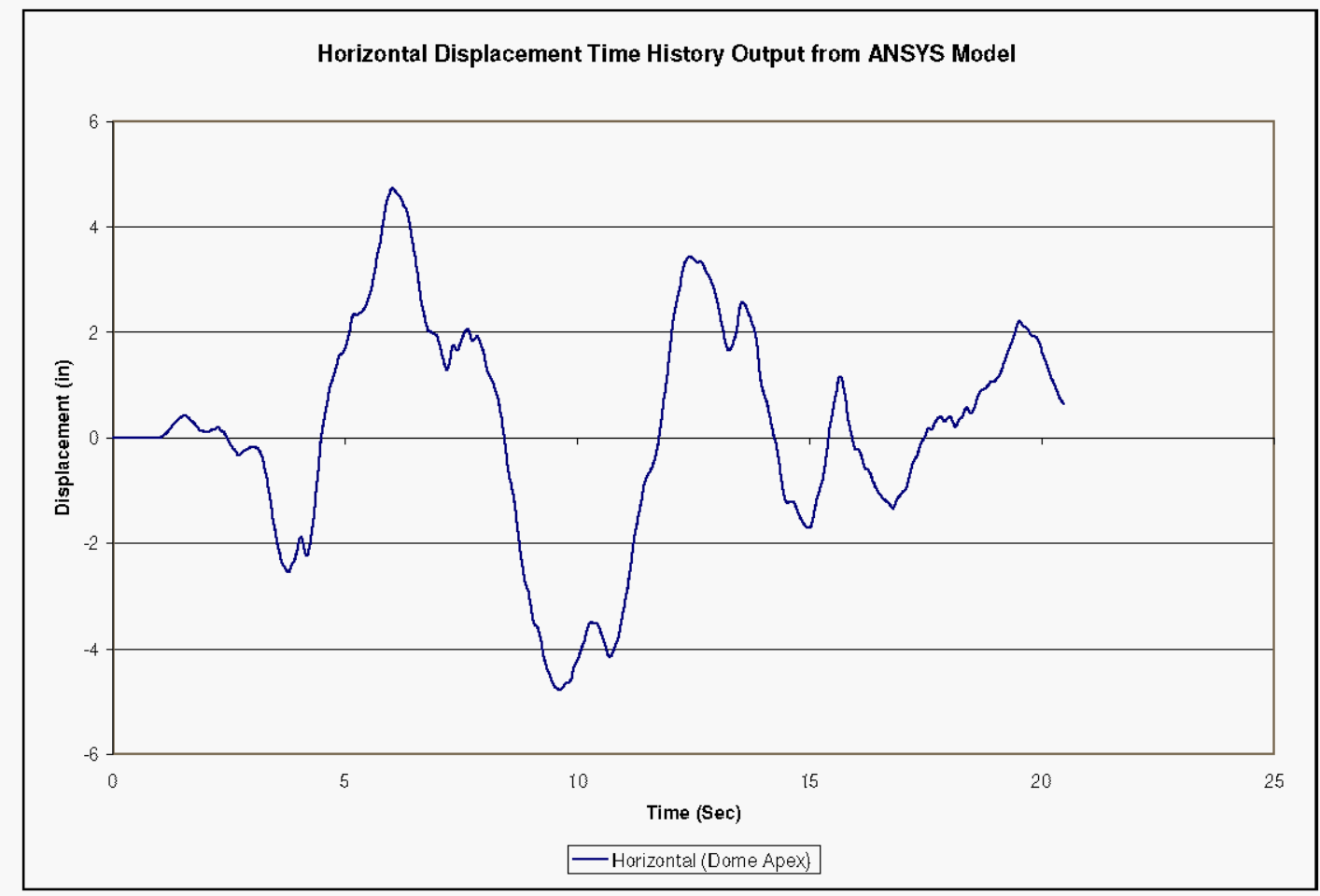

Figure 2-13. Comparison of Horizontal Dome Apex Response Spectra at Different Damping Values for Low Frequencies.

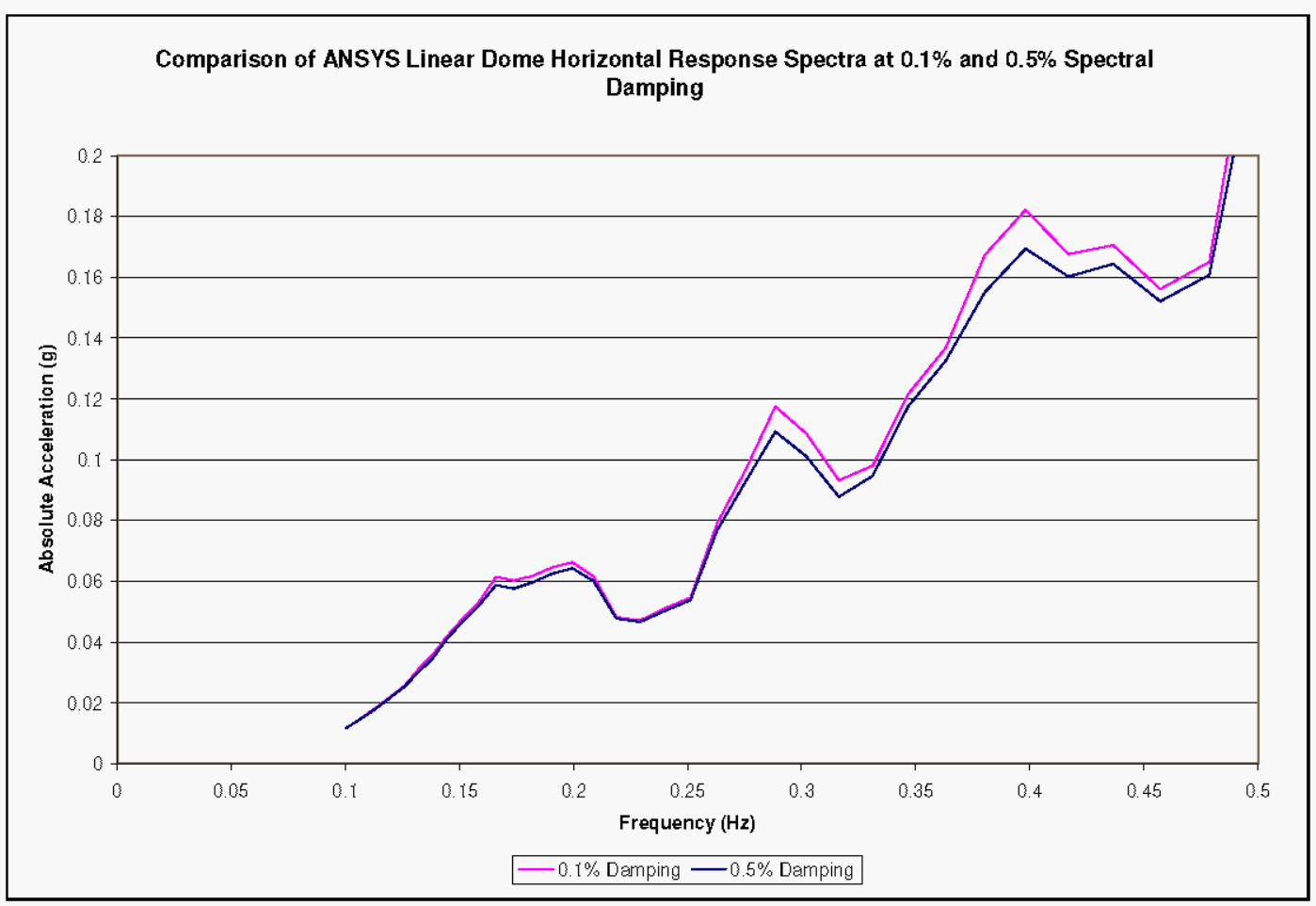


RPP-RPT-30807, Rev. 0

M\&D-2008-005-RPT-02, Rev. 0

\subsection{THEORETICAL HYDROSTATIC PRESSURES}

The expected hydrostatic pressure at the centroid of the liquid elements is easily calculated knowing the vertical location of the liquid elements and the initial pressure using the equation $p=p_{0}+\rho g \Delta h$, where $p_{0}$ is the ambient pressure at the free surface, $\rho$ is the liquid mass density, $g$ is the gravitational acceleration, and $\Delta h$ is the depth of the fluid element centroid below the initial free surface. The expected hydrostatic pressures for the element sets "plusx_els", "press_45", "plusz_els","cent_press", and "minusx_els" are shown in Table 2-1.

Table 2-1. Theoretical Hydrostatic Pressure of Liquid Elements for Various Initial Liquid Heights.

\begin{tabular}{|c|c|c|c|c|c|c|c|c|}
\hline "Plusx_els" & "Press_45" & "Plusz_els" & "Cent_press" & "Minusx_els" & \multicolumn{3}{|c|}{$\begin{array}{l}\text { Hydrostatic Pressure } \\
\text { (psi absolute) }\end{array}$} \\
& & & & & & \multicolumn{3}{|c|}{} \\
\cline { 5 - 9 } & & & & & & \multicolumn{3}{|c|}{ Initial Liquid Height } \\
& & & & & & & \multicolumn{3}{|c|}{ (in) } \\
\hline Element & Element & Element & Element & Element & 460 & 480 & 490 & $\mathbf{5 0 0}$ \\
\hline 78513 & 78324 & 77889 & 77873 & 77193 & 14.7 & 14.7 & 14.7 & 15.0 \\
\hline 76913 & 76724 & 76289 & 76273 & 75593 & 14.7 & 14.7 & 15.0 & 15.7 \\
\hline 80113 & 79924 & 79489 & 79473 & 78793 & 14.7 & 15.7 & 16.4 & 17.0 \\
\hline 72113 & 71924 & 71489 & 71473 & 70793 & 15.7 & 17.0 & 17.7 & 18.3 \\
\hline 68913 & 68724 & 68289 & 68273 & 67593 & 17.0 & 18.3 & 19.0 & 19.7 \\
\hline 65713 & 65524 & 65089 & 65073 & 64393 & 18.3 & 19.7 & 20.3 & 21.0 \\
\hline 62513 & 62324 & 61889 & 61873 & 61193 & 19.7 & 21.0 & 21.6 & 22.3 \\
\hline 59313 & 59124 & 58689 & 58673 & 57993 & 21.0 & 22.3 & 23.0 & 23.6 \\
\hline 56113 & 55924 & 55489 & 55473 & 54793 & 22.3 & 23.6 & 24.3 & 24.9 \\
\hline 52913 & 52724 & 52289 & 52273 & 51593 & 23.6 & 24.9 & 25.6 & 26.3 \\
\hline 49713 & 49524 & 49089 & 49073 & 48893 & 24.9 & 26.3 & 26.9 & 27.6 \\
\hline 46513 & 46324 & 45889 & 45873 & 45193 & 26.3 & 27.6 & 28.2 & 28.9 \\
\hline 43313 & 43124 & 42689 & 42673 & 41993 & 27.6 & 28.9 & 29.6 & 30.2 \\
\hline 40113 & 39924 & 39489 & 39473 & 38793 & 28.9 & 30.2 & 30.9 & 31.5 \\
\hline 36913 & 36724 & 36289 & 36273 & 35593 & 30.2 & 31.5 & 32.2 & 32.9 \\
\hline 33713 & 33524 & 33089 & 33073 & 32393 & 31.5 & 32.9 & 33.5 & 34.2 \\
\hline 30513 & 30324 & 29889 & 29873 & 29193 & 32.9 & 34.2 & 34.9 & 35.5 \\
\hline 27313 & 27124 & 26689 & 26673 & 25993 & 34.2 & 35.5 & 36.2 & 36.8 \\
\hline 24113 & 23924 & 23489 & 23473 & 22793 & 35.5 & 36.8 & 37.5 & 38.2 \\
\hline 20913 & 20724 & 20289 & 20273 & 19593 & 36.8 & 38.2 & 38.8 & 39.5 \\
\hline 17713 & 17524 & 17089 & 17073 & 16393 & 38.2 & 39.5 & 40.1 & 40.8 \\
\hline 14513 & 14324 & 13889 & 13873 & 13193 & 39.5 & 40.8 & 41.5 & 42.1 \\
\hline 11313 & 11124 & 10689 & 10673 & 9993 & 40.8 & 42.1 & 42.8 & 43.4 \\
\hline 8113 & 7924 & 7489 & 7473 & 6793 & 42.1 & 43.4 & 44.1 & 44.8 \\
\hline 4913 & 4724 & 4289 & 4273 & 3593 & 43.4 & 44.8 & 45.4 & 46.1 \\
\hline 1713 & 1524 & 1089 & 1073 & 393 & 44.8 & 46.1 & 46.8 & 47.4 \\
\hline & & & & & & &
\end{tabular}


RPP-RPT-30807, Rev. 0

M\&D-2008-005-RPT-02, Rev. 0

\subsection{RIGID TANK AT 460 INCH LIQUID LEVEL}

In all cases, the gravity load was run for $2 \mathrm{~s}$ before beginning the seismic input. In the 460,480 , and 490 in. initial liquid heights, the $20.48 \mathrm{~s}$ seismic record was followed by $20 \mathrm{~s}$ of unforced motion with gravity loading (giving a total simulation time of $42.5 \mathrm{~s}$ ) in order to observe the convective response. In the case of the completely full tank (500 in. liquid level), there is no convective response, so the total simulation time was limited to $30 \mathrm{~s}$.

\subsection{HYDRODYNAMIC FORCES}

Dytran provides output of the overall reaction forces between the Euler elements (fluid elements) and the coupling surface that is the interface between the fluid elements and the structural elements. The coupling surface reaction forces are compared to the total hydrodynamic forces calculated using the methodologies described in BNL (1995) and shown in Appendix B.

At the 460 in. initial liquid level, there is no interaction between the liquid and the tank roof, so the peak hydrodynamic force induced against the tank wall due to horizontal excitation can be calculated via Equation 4.31 of BNL (1995) with the instantaneous accelerations replaced by the appropriate spectral accelerations. If the contributions of the impulsive mode and first three convective modes are combined in a square-root-sumof-squares (SRSS) fashion, the theoretical maximum horizontal hydrodynamic force is $2.98 \times 10^{6} \mathrm{lbf}$, based on a zero-period acceleration for the impulsive response, and convective accelerations from the $0.1 \%$ damped spectrum as described below. The supporting calculations using the methodology of BNL (1995) are included in Appendix B.

The horizontal coupling surface reaction force time history reported by Dytran is shown in Figure 3-1. The peak reaction force is $3.15 \times 10^{6} \mathrm{lbf}$, which is approximately $6 \%$ greater than the predicted value. However, a more conservative estimate of the theoretical peak reaction force calculated by directly summing the impulsive and convective contributions leads to a predicted peak reaction force of $3.5 \times 10^{6} \mathrm{lbf}$, which is $11 \%$ greater than the peak reaction force predicted by Dytran.

Application of the logarithmic decrement $\delta$ to the decay of a selected response implies that for a constant critical damping ratio $\xi$, the ratio of successive peak responses is constant. For small critical damping ratios, the logarithmic decrement can be approximated as

$$
\delta \equiv \ln \left(\frac{x_{1}}{x_{2}}\right) \approx 2 \pi \xi
$$


More generally, the number of cycles $n$ required to achieve a $R \%$ reduction in amplitude for a given critical damping ratio $\xi$ is

$$
n \approx \frac{1}{2 \pi \xi} \ln \left(\frac{100}{100-R}\right) .
$$

When the logarithmic decrement is used to quantify the damping present in the convective response during the free-oscillation period shown in Figure 3-2, the resulting critical damping ratio is on the order of a few tenths of a percent. The use of the $0.1 \%$ damped spectrum for the calculation of the reaction forces is consistent with this response and as noted previously, the spectral accelerations are insensitive to damping values in this range damping ratios and frequencies (see Figure 2-13).

Although the total horizontal hydrodynamic force is slightly greater than predicted by the SRSS combination, the convective contribution is less than predicted by theory. The theoretical peak reaction force due to the first three convective modes only is $5.34 \times 10^{5} \mathrm{lbf}$ based on the accelerations from the $0.1 \%$ damped spectrum.

The Dytran calculated convective component of the horizontal reaction force during the free vibration phase following the seismic excitation appears as Figure 3-2. The peak reaction force due to the convective response is approximately $4 \times 10^{5} \mathrm{lbf}$ or $75 \%$ of the theoretical value. Also apparent in the free vibration response is the period of the first convective mode. The period shown in Figure 3-2 during the free vibration phase is approximately $5.1 \mathrm{~s}$, which matches the theoretical fundamental convective frequency of $0.196 \mathrm{~Hz}$. 
Figure 3-1. Horizontal Reaction Force for the Rigid Tank at 460 in. Liquid Level Under Horizontal Seismic Input.

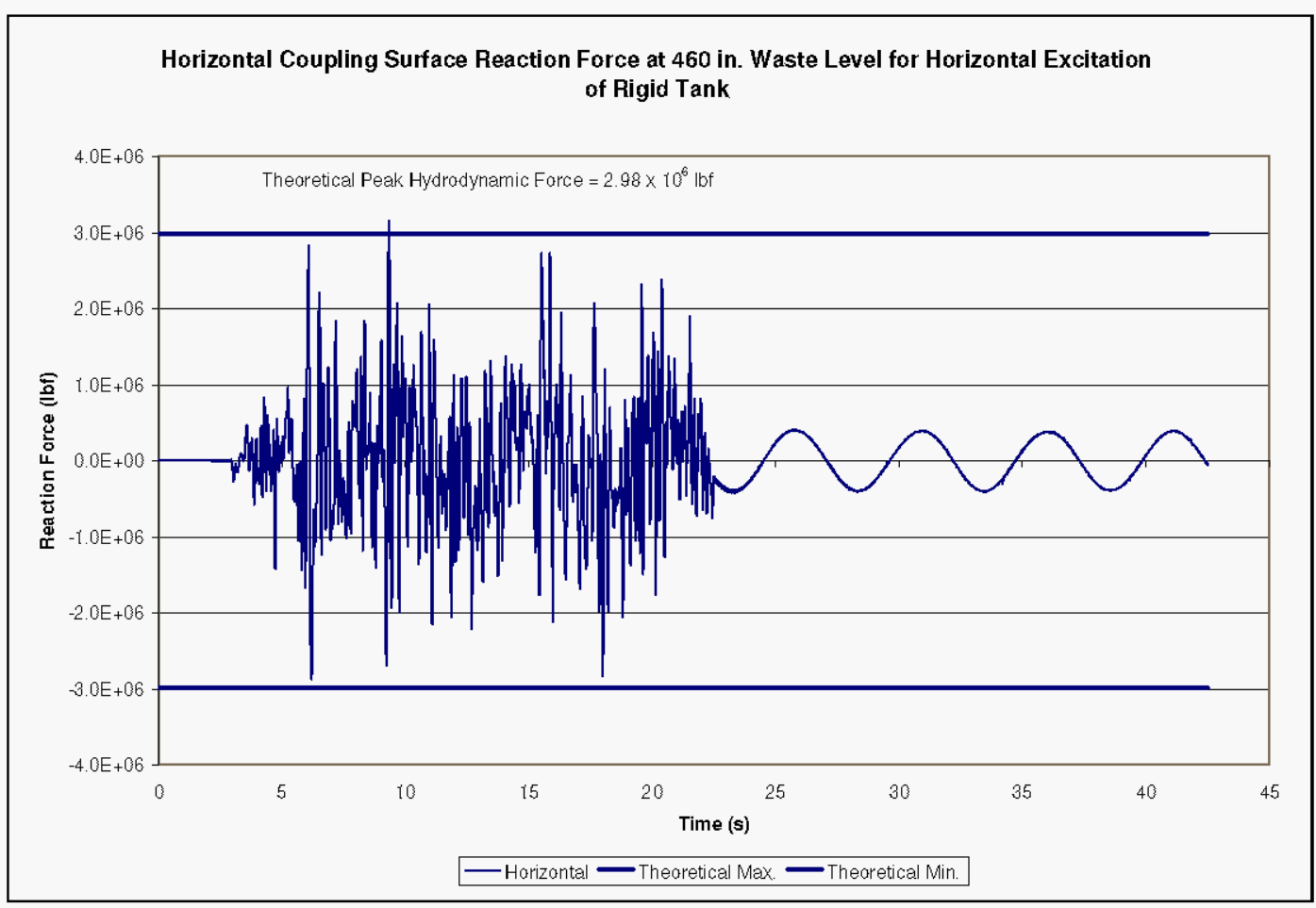

Figure 3-2. Horizontal Reaction Force for Rigid Tank at 460 in. Liquid Level Under Horizontal Seismic Excitation - Convective Response.

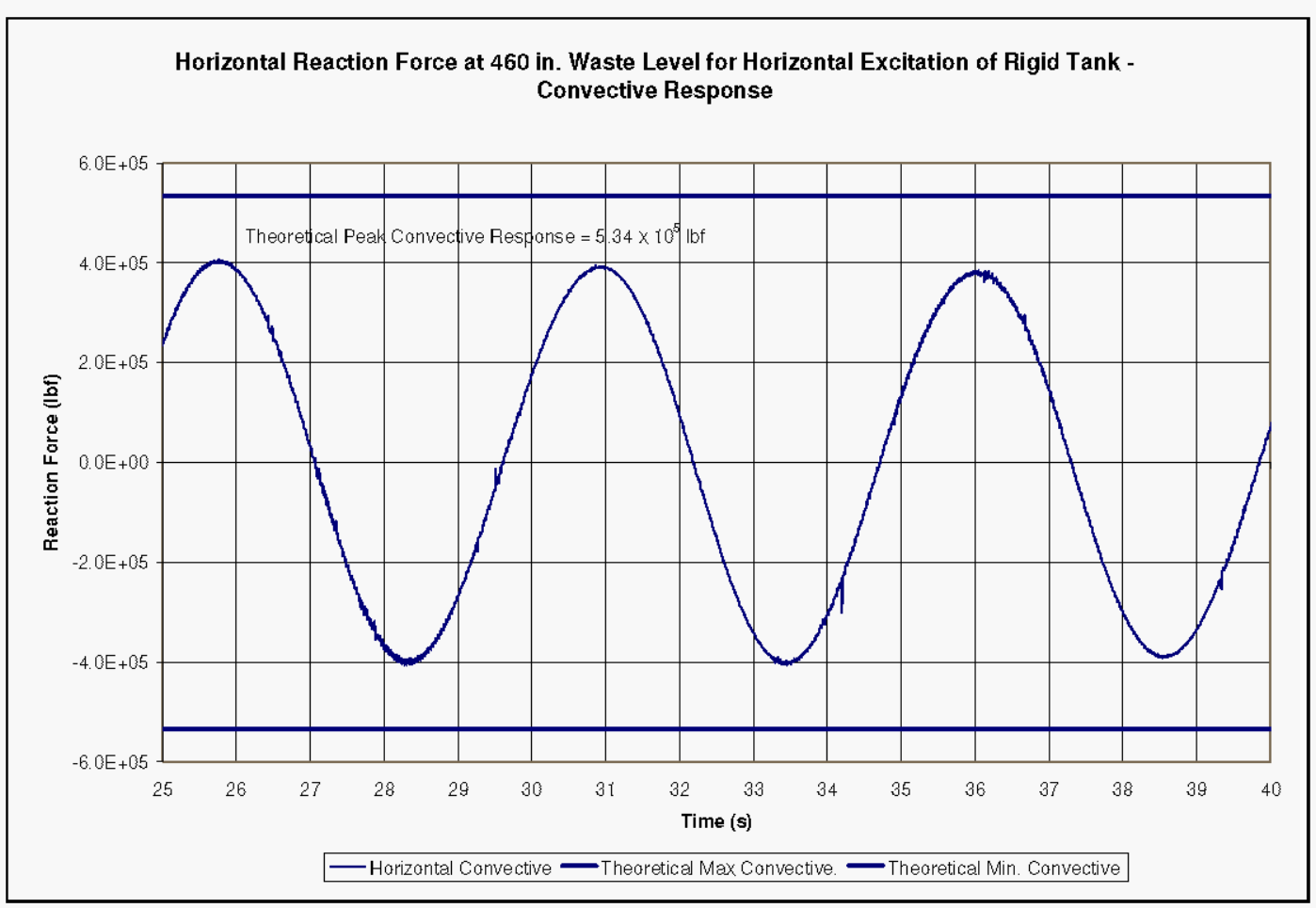


RPP-RPT-30807, Rev. 0

M\&D-2008-005-RPT-02, Rev. 0

\subsection{LIQUID PRESSURES}

The hydrodynamic pressures in the tank are caused by impulsive and convective components and depend on the location of the fluid element within the tank. In the case of horizontal excitation, both the impulsive and convective components vary in the circumferential direction as $\cos \theta$, with the maximum theoretical values occurring along the plane of excitation, and decreasing to zero hydrodynamic pressure at $\theta=90^{\circ}$ to the plane of excitation. The impulsive hydrodynamic pressure increases with depth, while the convective dynamic pressure is a maximum at the top of the liquid. The theoretical peak hydrodynamic pressures are given by Equation 4.24 of BNL (1995), and the total pressures are the sum of the hydrostatic pressures and the hydrodynamic pressures. The hydrostatic, peak hydrodynamic and peak total pressures for the elements in the sets "plusx_els", "press_45", are shown in Table 3-1 and Table 3-2. The maximum theoretical pressures for the elements sets "plusz_els" and "cent_press" is simply the hydrostatic pressures shown in Table 2-1 because the theoretical hydrodynamic pressures are zero at $\theta=90^{\circ}$ and at the tank center. The pressure time histories for the liquid element sets at $\theta=0,45$, and $90^{\circ}$, are shown in Figure 3-3, Figure 3-4, Figure 3-5, and Figure 3-6. Both the trends and the numerical values of the pressures shown in those figures are as expected. For example, the peak pressure for element 1713 located near the bottom of the tank at $\theta=0^{\circ}$ is $51 \mathrm{lbf} / \mathrm{in}^{2}$ as shown in Table 3-1. It is also evident from the plots that the response of elements lower in the tank is dominated by the higher frequency impulsive effects, while the response of elements near the free surface is dominated by lower frequency convective effects. The dynamic pressures of elements located at $\theta=45^{\circ}$ is lower than the corresponding elements at $\theta=0^{\circ}$, with the peak pressure of element 1524 being approximately $49 \mathrm{lbf} / \mathrm{in}^{2}$ as predicted in Table $3-2$. The dynamic pressure of elements located at $\theta=90^{\circ}$ is low as expected. 
RPP-RPT-30807, Rev. 0

M\&D-2008-005-RPT-02, Rev. 0

Table 3-1. Theoretical Maximum Liquid Pressures for Horizontal Excitation in the Rigid Tank at $460 \mathrm{in}$. Liquid Level for Elements at $\theta=0$.

\begin{tabular}{|c|c|c|c|}
\hline "Plusx_els" & Hydrostatic & & Peak Total \\
\hline Element No. & $\begin{array}{l}\text { Pressure } \\
\text { (psi absolute) }\end{array}$ & $\begin{array}{l}\text { Hydrodynamic } \\
\text { Pressure } \\
\text { (psi absolute) }\end{array}$ & $\begin{array}{l}\text { Pressure } \\
\text { (psi absolute) }\end{array}$ \\
\hline 78513 & 14.7 & 1.9 & 16.6 \\
\hline 76913 & 14.7 & 1.9 & 16.6 \\
\hline 80113 & 14.7 & 1.9 & 16.6 \\
\hline 72113 & 15.7 & 1.9 & 17.6 \\
\hline 68913 & 17.0 & 2.2 & 19.2 \\
\hline 65713 & 18.3 & 2.6 & 21.0 \\
\hline 62513 & 19.7 & 3.0 & 22.7 \\
\hline 59313 & 21.0 & 3.4 & 24.4 \\
\hline 56113 & 22.3 & 3.7 & 26.0 \\
\hline 52913 & 23.6 & 4.1 & 27.7 \\
\hline 49713 & 24.9 & 4.3 & 29.3 \\
\hline 46513 & 26.3 & 4.6 & 30.9 \\
\hline 43313 & 27.6 & 4.8 & 32.4 \\
\hline 40113 & 28.9 & 5.1 & 34.0 \\
\hline 36913 & 30.2 & 5.2 & 35.5 \\
\hline 33713 & 31.5 & 5.4 & 37.0 \\
\hline 30513 & 32.9 & 5.6 & 38.4 \\
\hline 27313 & 34.2 & 5.7 & 39.9 \\
\hline 24113 & 35.5 & 5.8 & 41.3 \\
\hline 20913 & 36.8 & 5.9 & 42.7 \\
\hline 17713 & 38.2 & 6.0 & 44.1 \\
\hline 14513 & 39.5 & 6.1 & 45.5 \\
\hline 11313 & 40.8 & 6.1 & 46.9 \\
\hline 8113 & 42.1 & 6.1 & 48.3 \\
\hline 4913 & 43.4 & 6.2 & 49.6 \\
\hline 1713 & 44.8 & 6.2 & 51.0 \\
\hline
\end{tabular}


RPP-RPT-30807, Rev. 0

M\&D-2008-005-RPT-02, Rev. 0

Table 3-2. Theoretical Maximum Liquid Pressures for Horizontal Excitation in the Rigid Tank at $460 \mathrm{in.} \mathrm{Liquid} \mathrm{Level} \mathrm{for} \mathrm{Elements} \mathrm{at} \theta=45^{\circ}$.

\begin{tabular}{|c|c|c|c|}
\hline "Press_45" & Hydrostatic & & Peak Total \\
\hline Element No. & $\begin{array}{l}\text { Pressure } \\
\text { (psi absolute) }\end{array}$ & $\begin{array}{l}\text { Hydrodynamic } \\
\text { Pressure } \\
\text { (psi absolute) }\end{array}$ & $\begin{array}{l}\text { Pressure } \\
\text { (psi absolute) }\end{array}$ \\
\hline 78324 & 14.7 & 1.3 & 16.0 \\
\hline 76724 & 14.7 & 1.3 & 16.0 \\
\hline 79924 & 14.7 & 1.3 & 16.0 \\
\hline 71924 & 15.7 & 1.3 & 17.0 \\
\hline 68724 & 17.0 & 1.6 & 18.6 \\
\hline 65524 & 18.3 & 1.9 & 20.2 \\
\hline 62324 & 19.7 & 2.1 & 21.8 \\
\hline 59124 & 21.0 & 2.4 & 23.4 \\
\hline 55924 & 22.3 & 2.6 & 24.9 \\
\hline 52724 & 23.6 & 2.9 & 26.5 \\
\hline 49524 & 24.9 & 3.1 & 28.0 \\
\hline 46324 & 26.3 & 3.3 & 29.5 \\
\hline 43124 & 27.6 & 3.4 & 31.0 \\
\hline 39924 & 28.9 & 3.6 & 32.5 \\
\hline 36724 & 30.2 & 3.7 & 33.9 \\
\hline 33524 & 31.5 & 3.8 & 35.4 \\
\hline 30324 & 32.9 & 3.9 & 36.8 \\
\hline 27124 & 34.2 & 4.0 & 38.2 \\
\hline 23924 & 35.5 & 4.1 & 39.6 \\
\hline 20724 & 36.8 & 4.2 & 41.0 \\
\hline 17524 & 38.2 & 4.2 & 42.4 \\
\hline 14324 & 39.5 & 4.3 & 43.8 \\
\hline 11124 & 40.8 & 4.3 & 45.1 \\
\hline 7924 & 42.1 & 4.3 & 46.5 \\
\hline 4724 & 43.4 & 4.4 & 47.8 \\
\hline 1524 & 44.8 & 4.4 & 49.2 \\
\hline
\end{tabular}


Figure 3-3. Liquid Pressure Time Histories for the Rigid Tank With 460 in. of Liquid Under Horizontal Excitation at $\boldsymbol{\theta}=\mathbf{0}$.

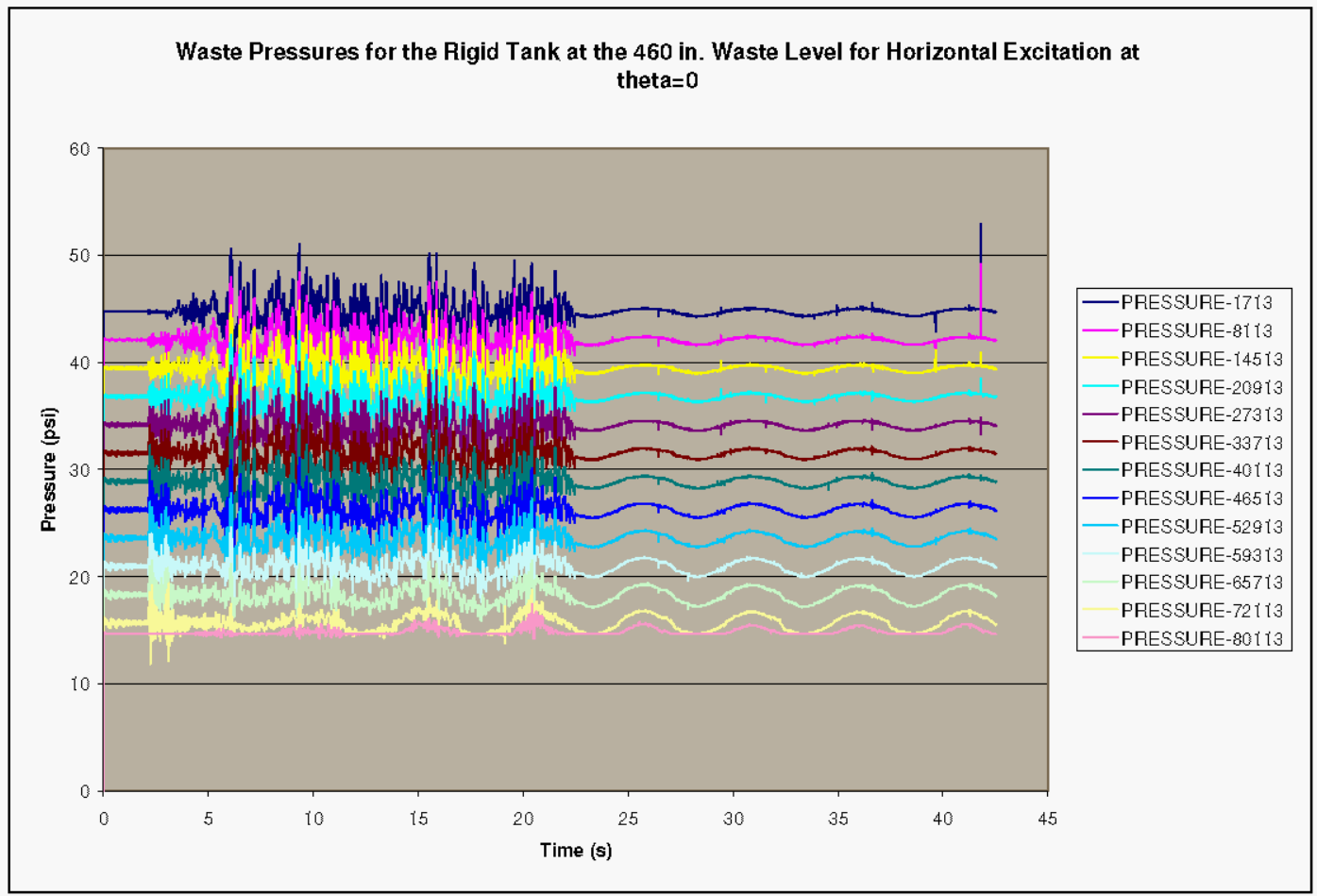

Figure 3-4. Selected Liquid Pressure Time Histories for the Rigid Tank With 460 in. of Liquid Under Horizontal Excitation at $\theta=0$.

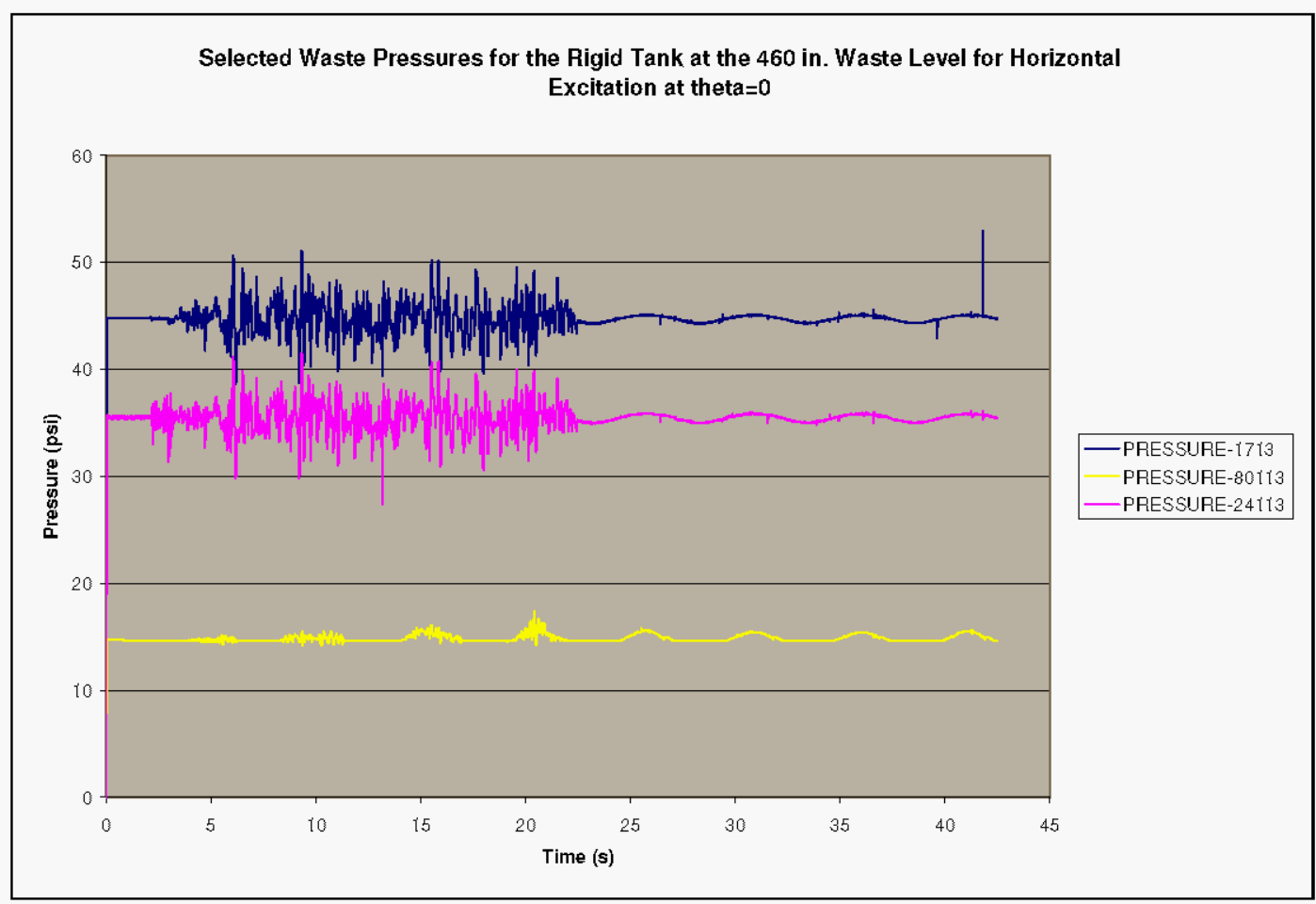


Figure 3-5. Liquid Pressure Time Histories for the Rigid Tank With 460 in. of Liquid Under Horizontal Excitation at $\boldsymbol{\theta}=\mathbf{4 5 ^ { \circ }}$.

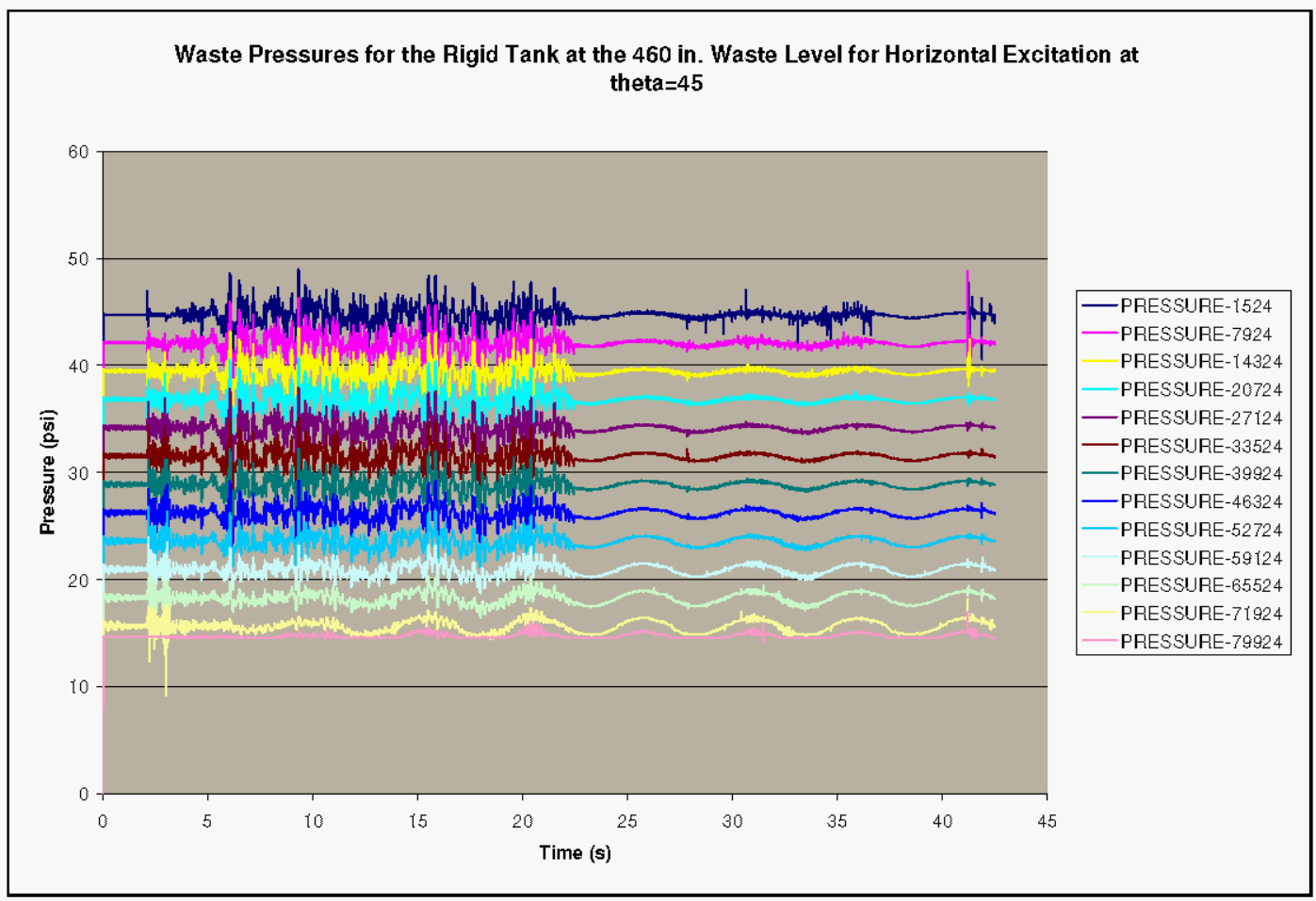

Figure 3-6. Liquid Pressure Time Histories for the Rigid Tank With $460 \mathrm{in}$. of Liquid Under Horizontal Excitation at $\theta=90^{\circ}$.

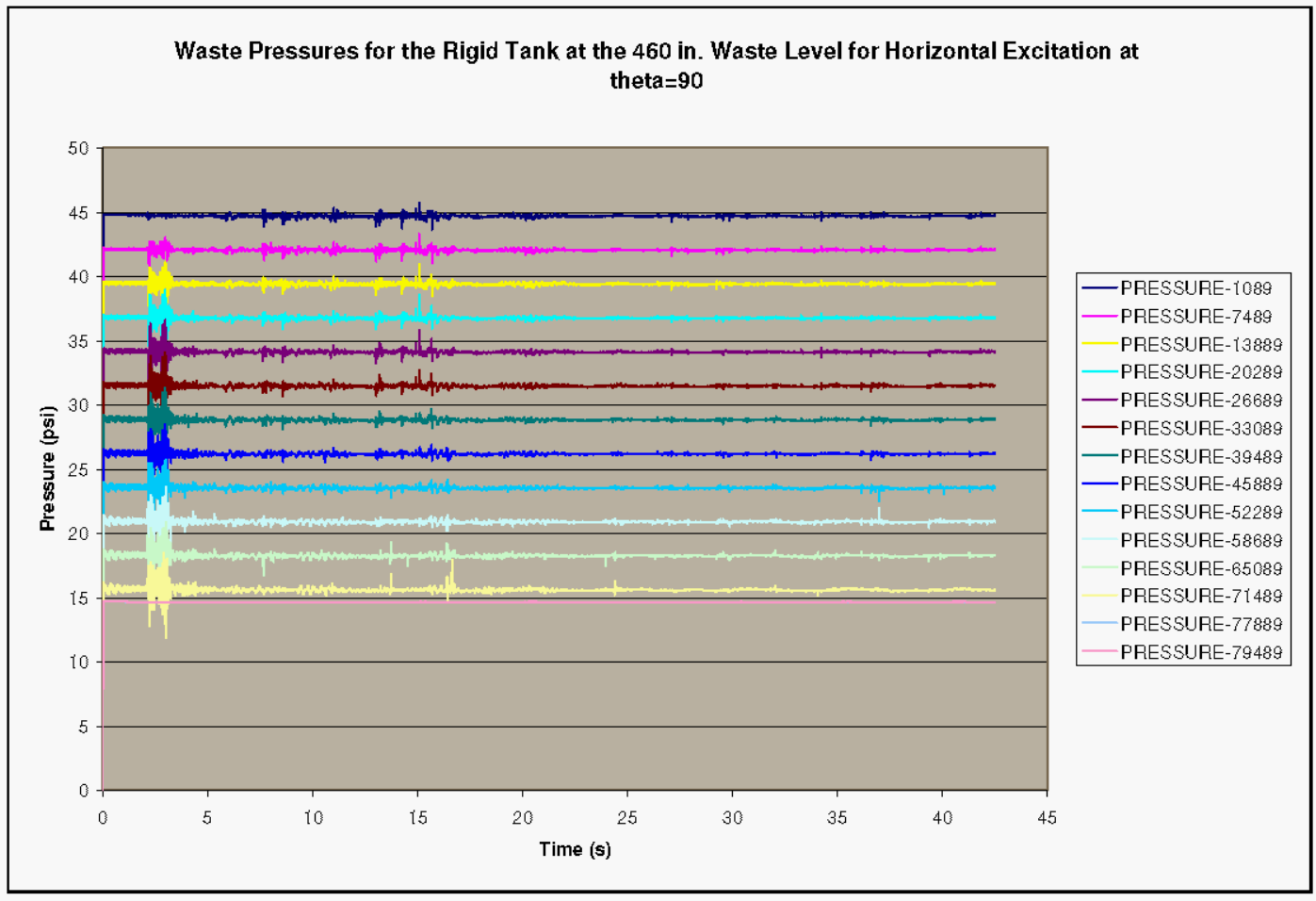


Another way of presenting some of the information in the previous plots is to look at maximum and minimum pressures as a function of angular position and liquid depth. Plots of the Dytran calculated and theoretically calculated maximum and minimum liquid pressures at $\theta=0,45$, and $90^{\circ}$ are shown in Figure 3-7, Figure 3-8, and Figure 3-9. The three plots show that Dytran is producing the expected solution for the roofless tank. It is noted from Figure 3-7 that the minimum pressures are slightly lower than expected in the middle portion of the tank along the plane of excitation. This result was mentioned in Section 1.2.1 and will be discussed further in Section 4.2.

Figure 3-7. Maximum and Minimum Liquid Pressures vs. Normalized Height from Tank Bottom for Horizontal Excitation at $\theta=0$ and Initial Liquid Height of 460 in.

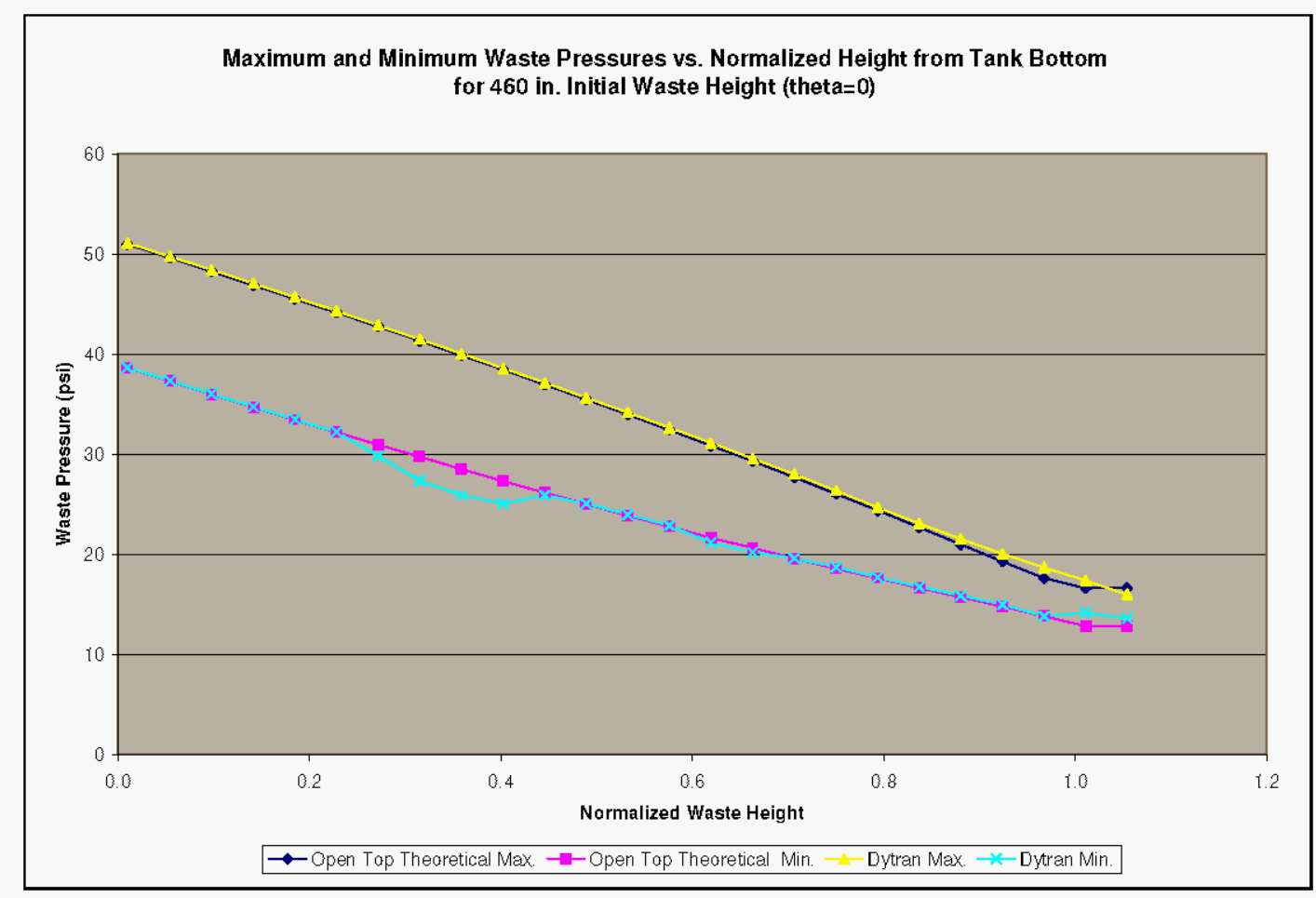


Figure 3-8. Maximum and Minimum Liquid Pressures vs. Normalized Height from Tank Bottom for Horizontal Excitation at $\theta=45^{\circ}$ and Initial Liquid Height of $460 \mathrm{in}$.

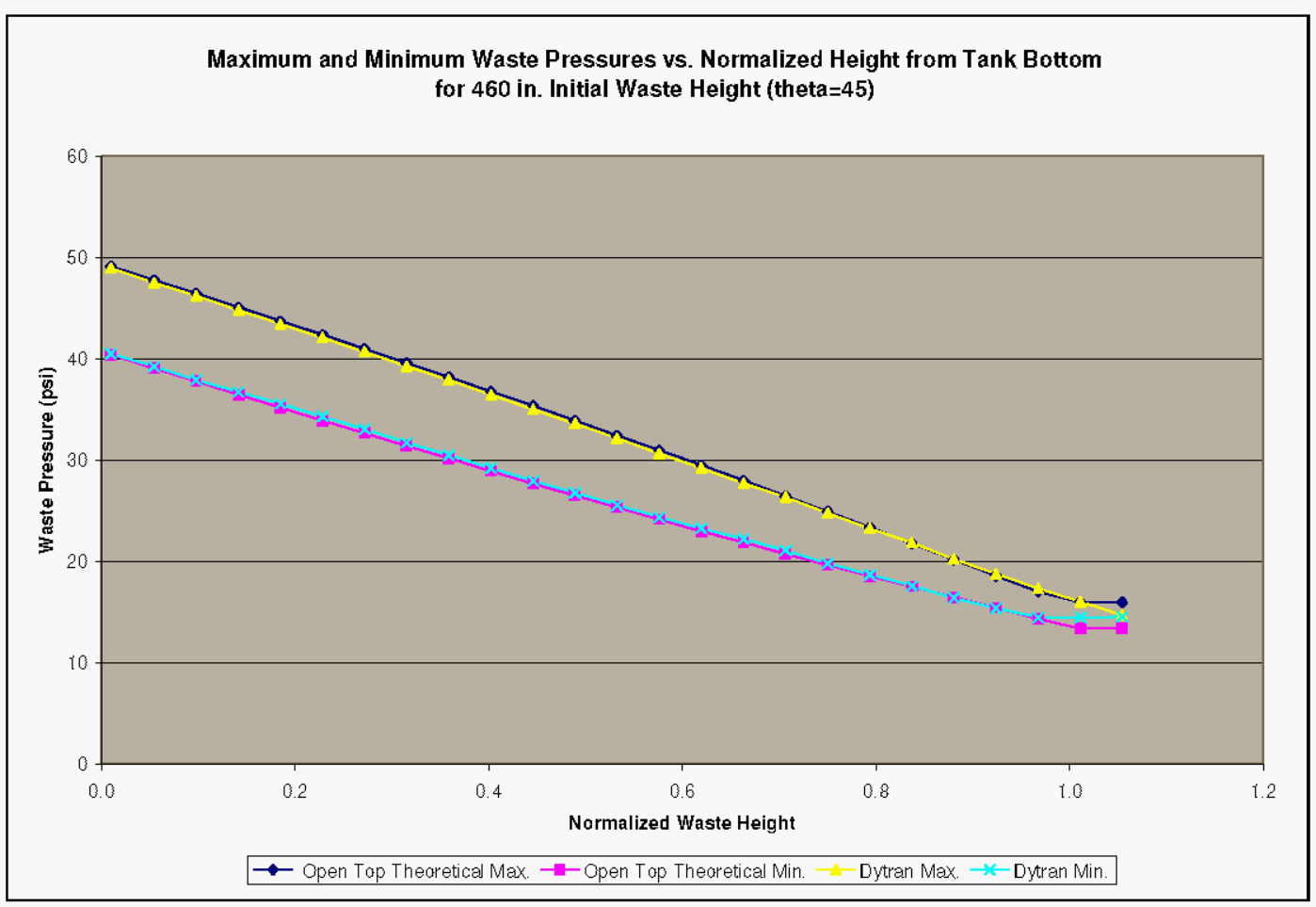

Figure 3-9. Maximum and Minimum Liquid Pressures vs. Normalized Height from Tank Bottom for Horizontal Excitation at $\theta=90^{\circ}$ and Initial Liquid Height of $460 \mathrm{in}$.

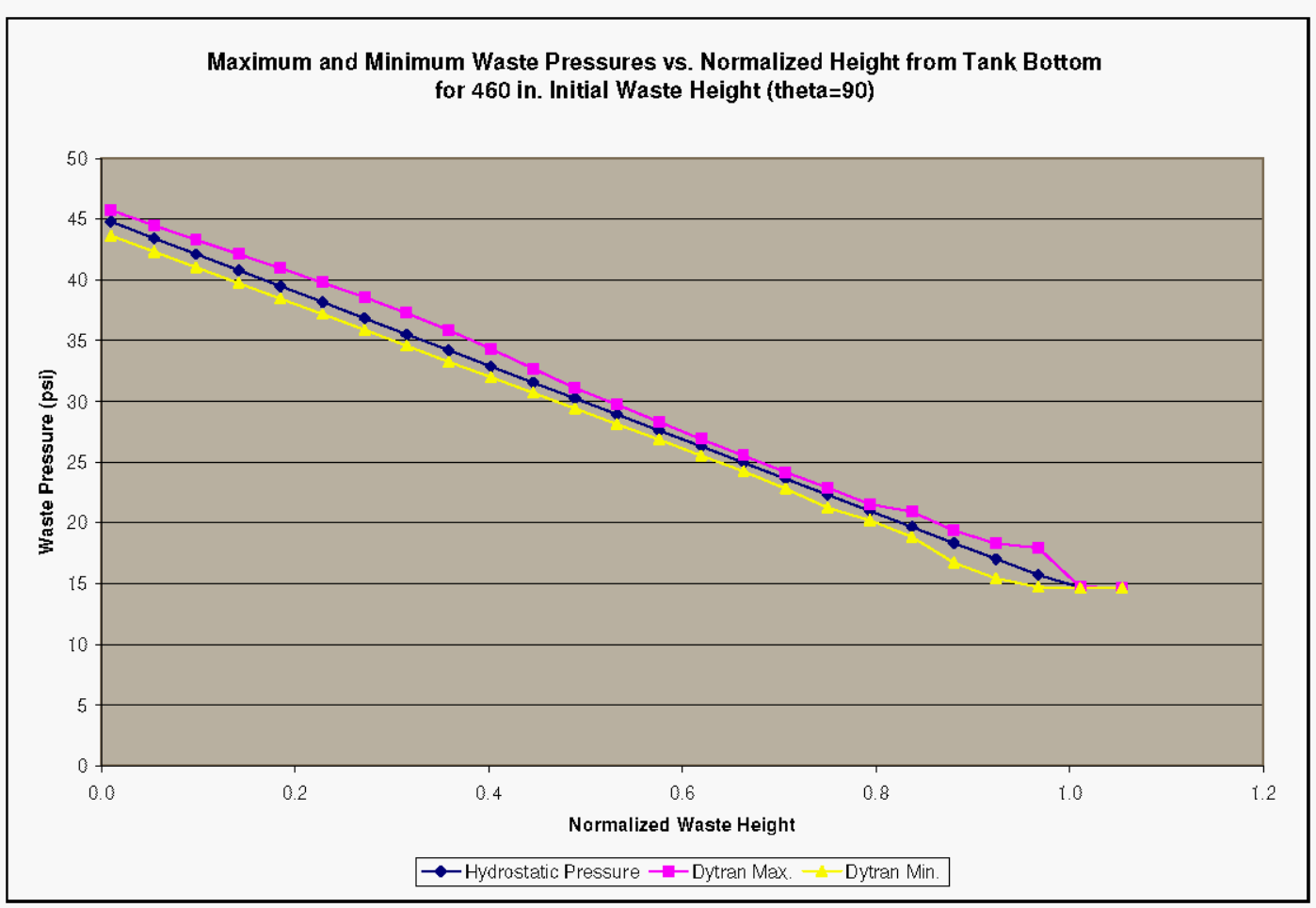




\subsection{SLOSH HEIGHT RESULTS}

According to Equation 4.60 of BNL (1995), the maximum predicted slosh height due to horizontal excitation is $25.2 \mathrm{in}$. The time history of the maximum slosh height across all free-surface elements is shown in Figure 3-10, where the maximum height of the free surface is shown as $26.9 \mathrm{in}$. above the initial level.

Figure 3-10. Maximum Slosh Height Time History Over All Free-Surface Liquid Elements for Horizontal Excitation for Initial Liquid Height of $460 \mathrm{in.}$

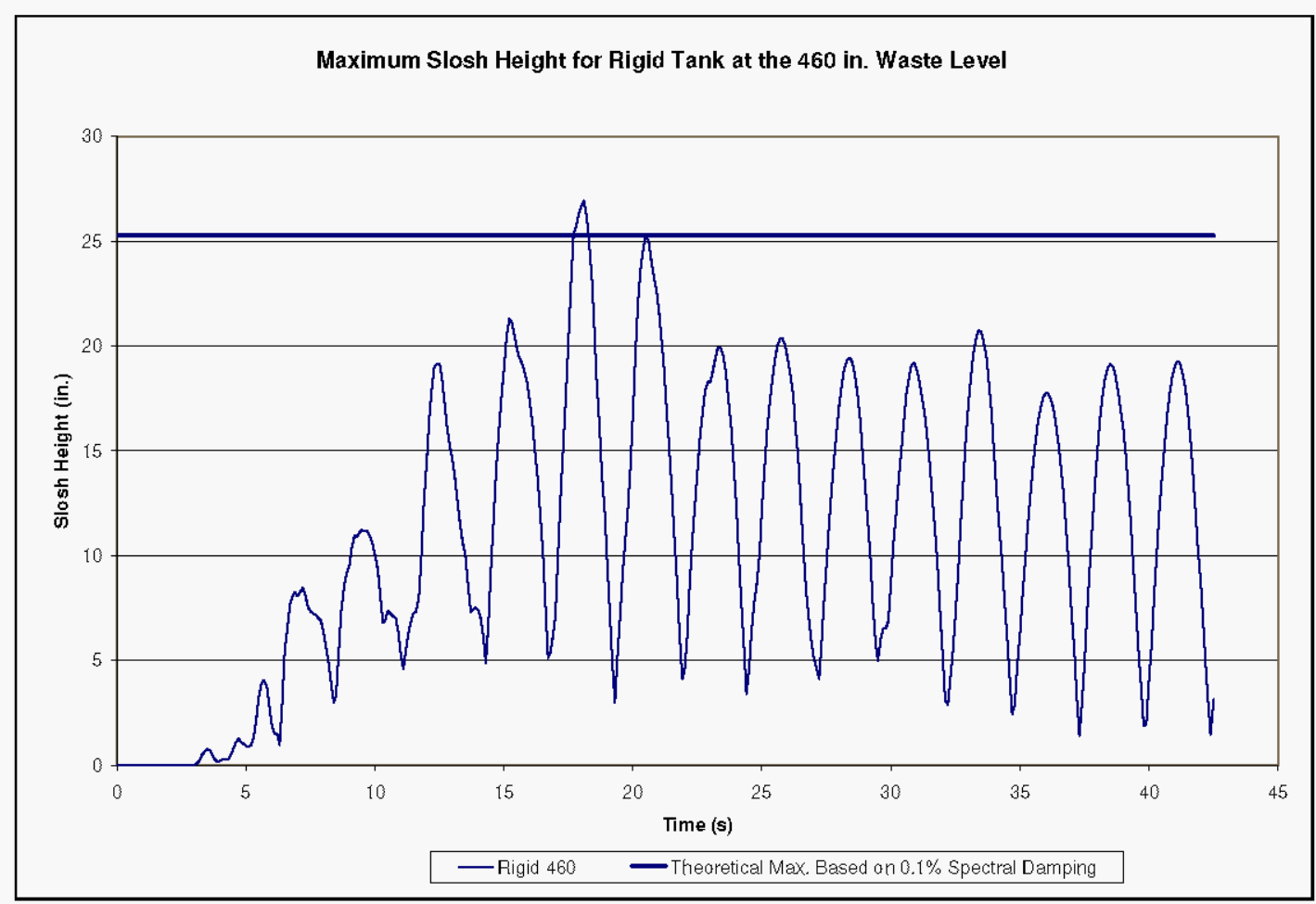




\subsubsection{Summary of Results at 460 in. Liquid Level}

Table 3-3. Summary of Results for $460 \mathrm{in}$. Liquid Level.

\begin{tabular}{|l|c|c|c|}
\hline \multicolumn{1}{|c|}{ Parameter } & $\begin{array}{c}\text { Open Top } \\
\text { Theory } \\
\text { (BNL 1995) }\end{array}$ & $\begin{array}{c}\text { Malhotra } \\
\text { Estimate }\end{array}$ & $\begin{array}{c}\text { Dytran } \\
\text { Result }\end{array}$ \\
\hline Convective Frequency (Hz) & 0.196 & 0.195 & 0.196 \\
\hline $\begin{array}{l}\text { Peak Horizontal Reaction } \\
\text { Force (lbf) }\end{array}$ & $2.98 \times 10^{6}$ & $3.47 \times 10^{6}$ & $3.15 \times 10^{6}$ \\
\hline $\begin{array}{l}\text { Peak Convective } \\
\text { Horizontal Reaction Force } \\
\text { (lbf) }\end{array}$ & $5.34 \times 10^{5}$ & $5.59 \times 10^{5}$ & $4.0 \times 10^{5}$ \\
\hline $\begin{array}{l}\text { Maximum Wall Pressure } \\
\text { (lbf/in }{ }^{2} \text { gage) }\end{array}$ & 36.3 & $\begin{array}{c}\text { Not } \\
\text { applicable }\end{array}$ & 36.4 \\
\hline $\begin{array}{l}\text { Maximum Slosh Height } \\
\text { (in) }\end{array}$ & 25.2 & 29.7 & 26.9 \\
\hline
\end{tabular}

\subsection{RIGID TANK AT 480 INCH LIQUID LEVEL}

The 480 in. liquid level represents 20 in. of freeboard. The configuration can also be expressed in terms of the characteristic ratio of the freeboard distance $\left(h_{0}\right)$ to the maximum slosh height for a roofless tank $\left(h_{s}\right)$. Using the unconstrained slosh height from the BNL methodology, the characteristic ratio is

$$
\left(\mathrm{h}_{0} / \mathrm{h}_{\mathrm{s}}\right)_{480 \mathrm{BNL}}=(20 / 25.2)=0.8
$$

If the unconstrained slosh height is estimated using the methodology in Malhotra (2005), the ratio freeboard to slosh height ratio is

$$
\left(\mathrm{h}_{0} / \mathrm{h}_{\mathrm{s}}\right)_{480 \text { Malhorta }}=(20 / 29.7)=0.67 \text {. }
$$

\subsection{HYDRODYNAMIC FORCES}

The peak hydrodynamic force induced against the tank wall due to horizontal excitation can be estimated using the procedure in Appendix D of BNL (1995). It is stated in Section D.1 of BNL (1995) that the procedure is believed to be conservative.

The hydrodynamic wall force consists of three components - the impulsive component induced by the constrained portion of the liquid, the impulsive component induced by the unconstrained portion of the liquid, and the convective component due to the unconstrained portion of the liquid. As shown in Appendix B, the peak values of the three components are $2.06 \times 10^{6}, 2.06 \times 10^{6}$, and $3.4 \times 10^{5} \mathrm{lbf}$, respectively, giving a total estimated peak force of $4.47 \times 10^{6} \mathrm{lbf}$. The theoretical convective response is based on the acceleration from the $0.1 \%$ damped spectrum. 
The procedure described in Malhotra (2005) decomposes the peak wall force into impulsive and convective components. According to that methodology, the peak impulsive and convective components are $3.87 \times 10^{6}$, and $3.82 \times 10^{5} \mathrm{lbf}$, respectively, giving a total peak force of $4.26 \times 10^{6} \mathrm{lbf}$.

The time history plot of the horizontal coupling surface reaction force for this case is shown as Figure 4-1. The maximum reaction force predicted by Dytran is $3.41 \times 10^{6} \mathrm{lbf}$, which is $76 \%$ of the value estimated using the methodology in Appendix D of BNL (1995) and $80 \%$ of the value using Malhotra's methodology. The BNL methodology for predicting wall forces is indeed conservative relative to the results of the Dytran simulation, as expected.

Figure 4-1. Horizontal Reaction Force for Rigid Tank With Initial Liquid Level of 480 in. (20 in. Headspace).

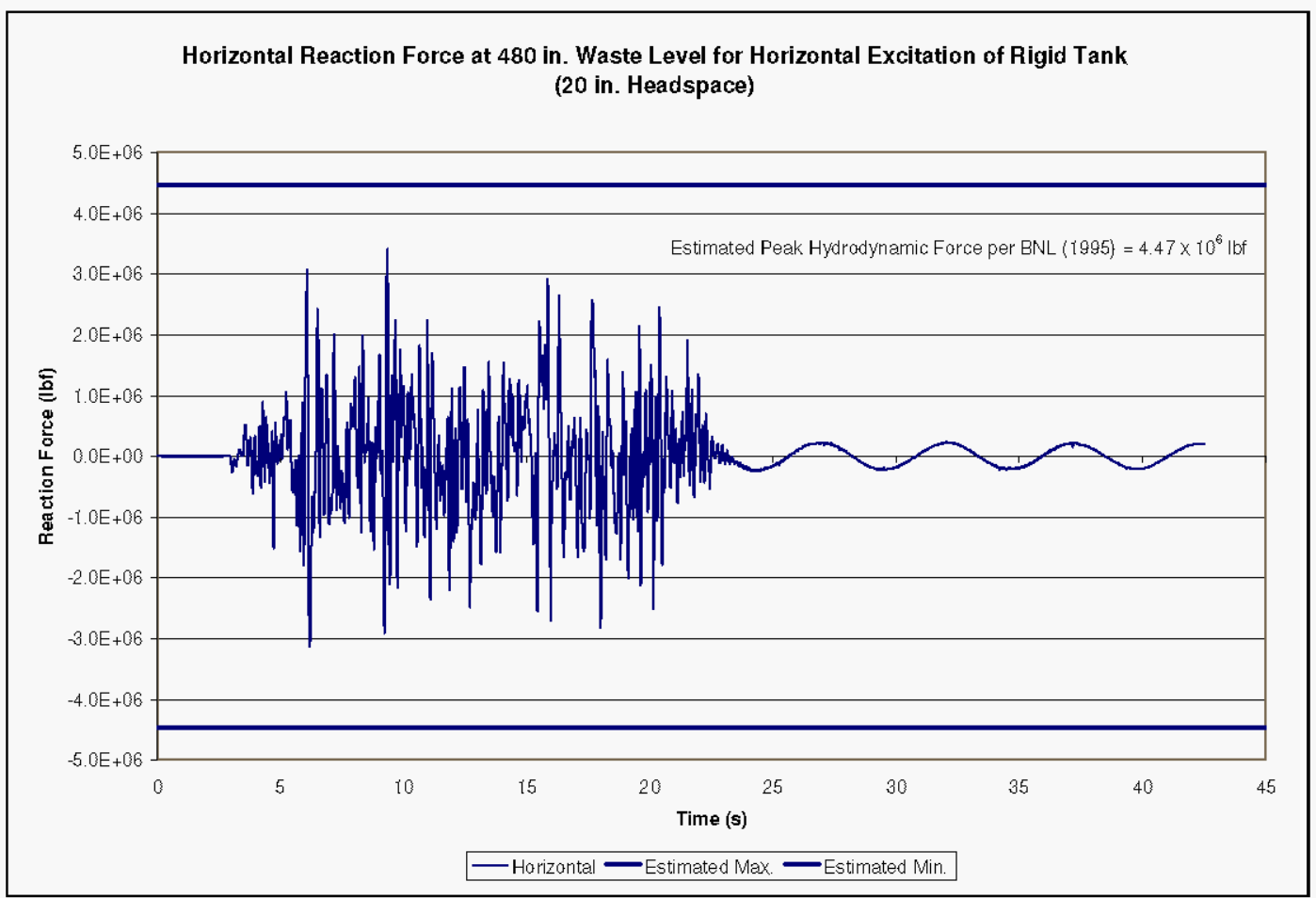


Figure 4-2. Horizontal Reaction Force for Rigid Tank at 480 in. Liquid Level Under Horizontal Seismic Excitation - Convective Response.

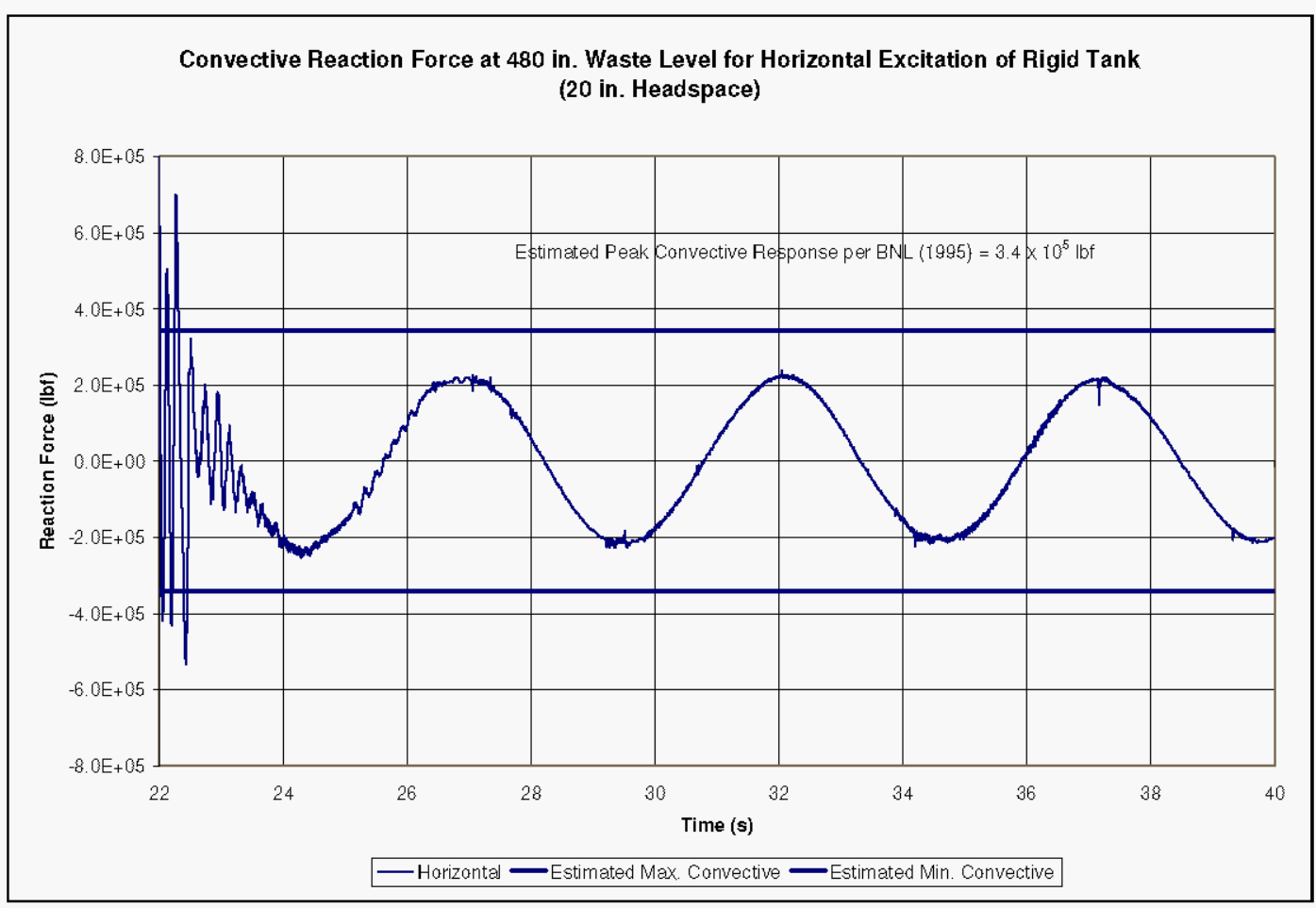

\subsection{LIQUID PRESSURES}

Pressure time histories adjacent to the tank wall at $\theta=0^{\circ}$ are shown in Figure 4-3 and Figure 4-4. The response of the fluid elements in the lower portion of the tank is very similar to that in seen in Figure 3-3 for the effectively roofless tank. Elements near the liquid free surface show evidence of interaction with the tank roof. As an example, element 78513 is adjacent to the tank roof as shown in Figure 2-8. The pressure time history in Figure 4-4 for element 78513 shows that the pressure is initially atmospheric, but the pressure periodically increases during the seismic event indicating that fluid sloshes in and out of this element and interacts with the tank roof during the earthquake. The pressure pulses between approximately 15 and $27 \mathrm{~s}$ are consistent with the $5 \mathrm{~s}$ convective period of the response for a roofless tank showing that the interaction with the roof has not altered the convective period significantly in this case.

Pressure time histories for fluid elements adjacent to the wall at $\theta=45$ and $90^{\circ}$ are shown in Figure 4-5 and Figure 4-6. Figure 4-7 shows a comparison of pressure traces for elements at the bottom of the tank for $\theta=0$ and $180^{\circ}$ and at the bottom center of the tank. The traces indicate that the dynamic pressures at $\theta=0$ and $180^{\circ}$ are of opposite sign and that the dynamic pressure at the bottom center of the tank is nearly zero as expected.

Figure 4-8 is similar to Figure 4-7 except that the three fluid elements are at the top of the tank. Elements 78513 and 77193 on opposite sides of the tank show responses indicative 
of an approximately $5 \mathrm{~s}$ period and are out of phase with each other. This is the expected behavior as the liquid sloshes from one side of the tank to the other.

Figure 4-3. Liquid Pressure Time Histories for the Rigid Tank With 480 in. of Liquid Under Horizontal Excitation at $\theta=0^{\circ}$.

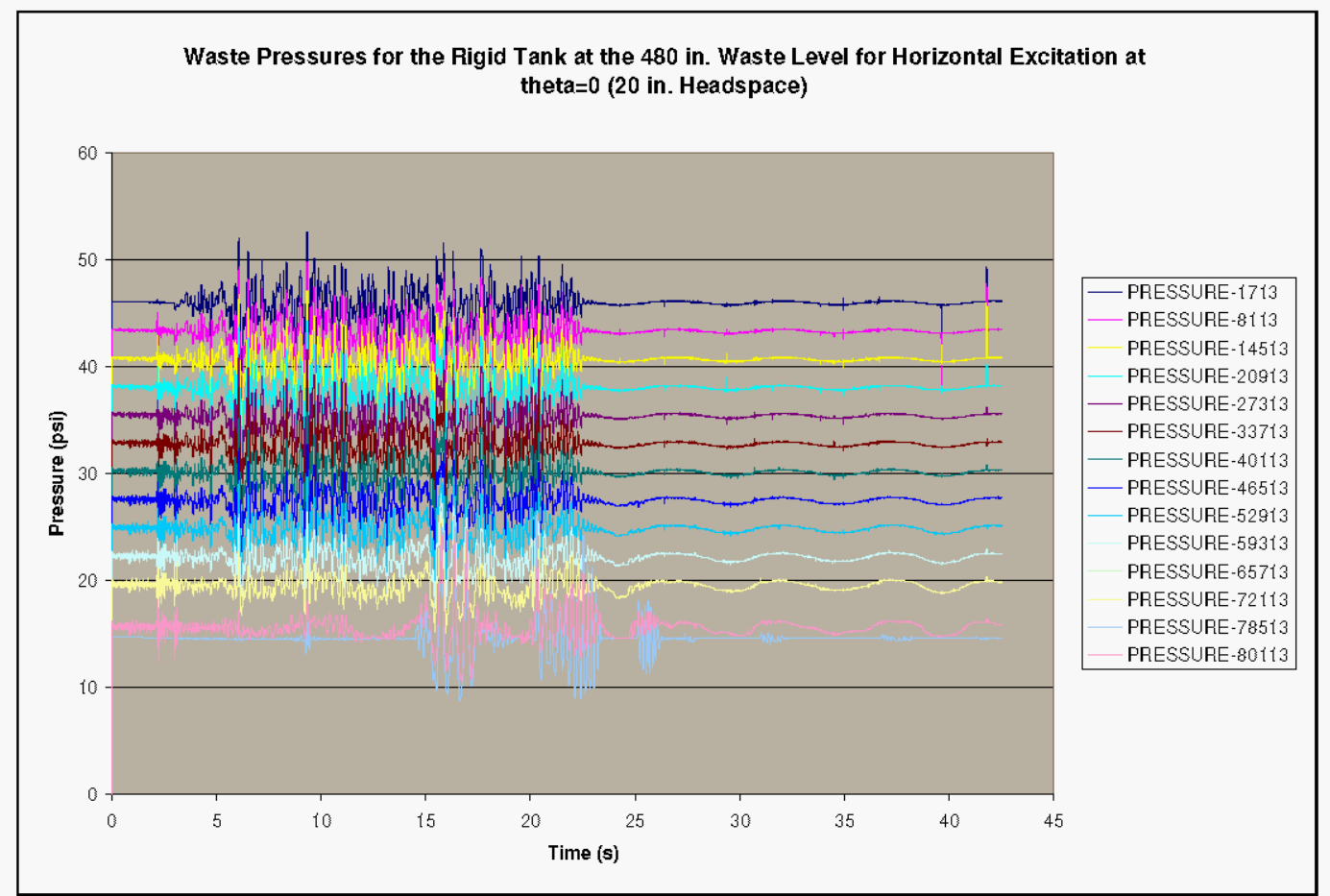


Figure 4-4. Selected Liquid Pressure Time Histories for the Rigid Tank With 480 in. of Liquid Under Horizontal Excitation at $\theta=0^{\circ}$.

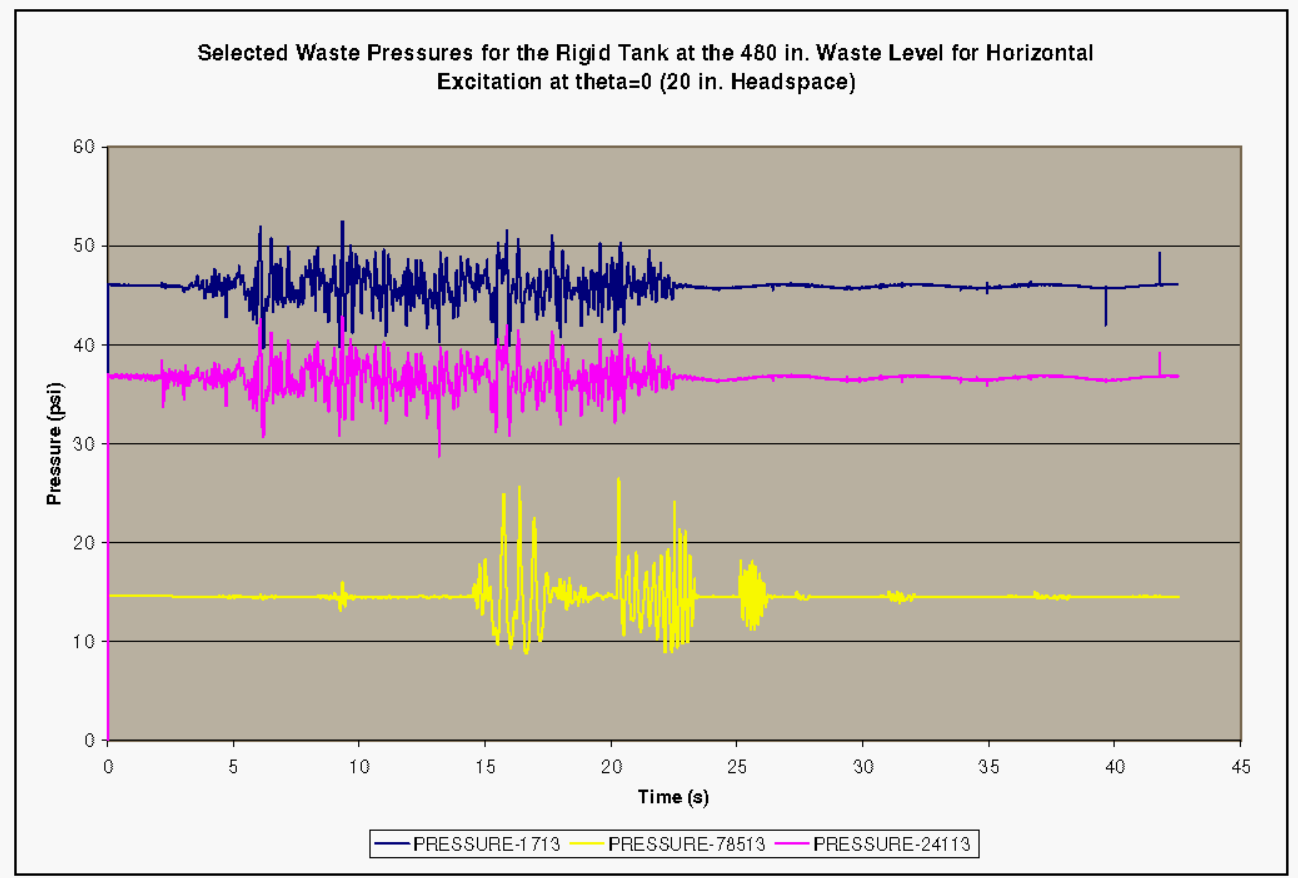

Figure 4-5. Liquid Pressure Time Histories for the Rigid Tank With 480 in. of Liquid Under Horizontal Excitation at $\boldsymbol{\theta}=\mathbf{4 5}^{\circ}$.

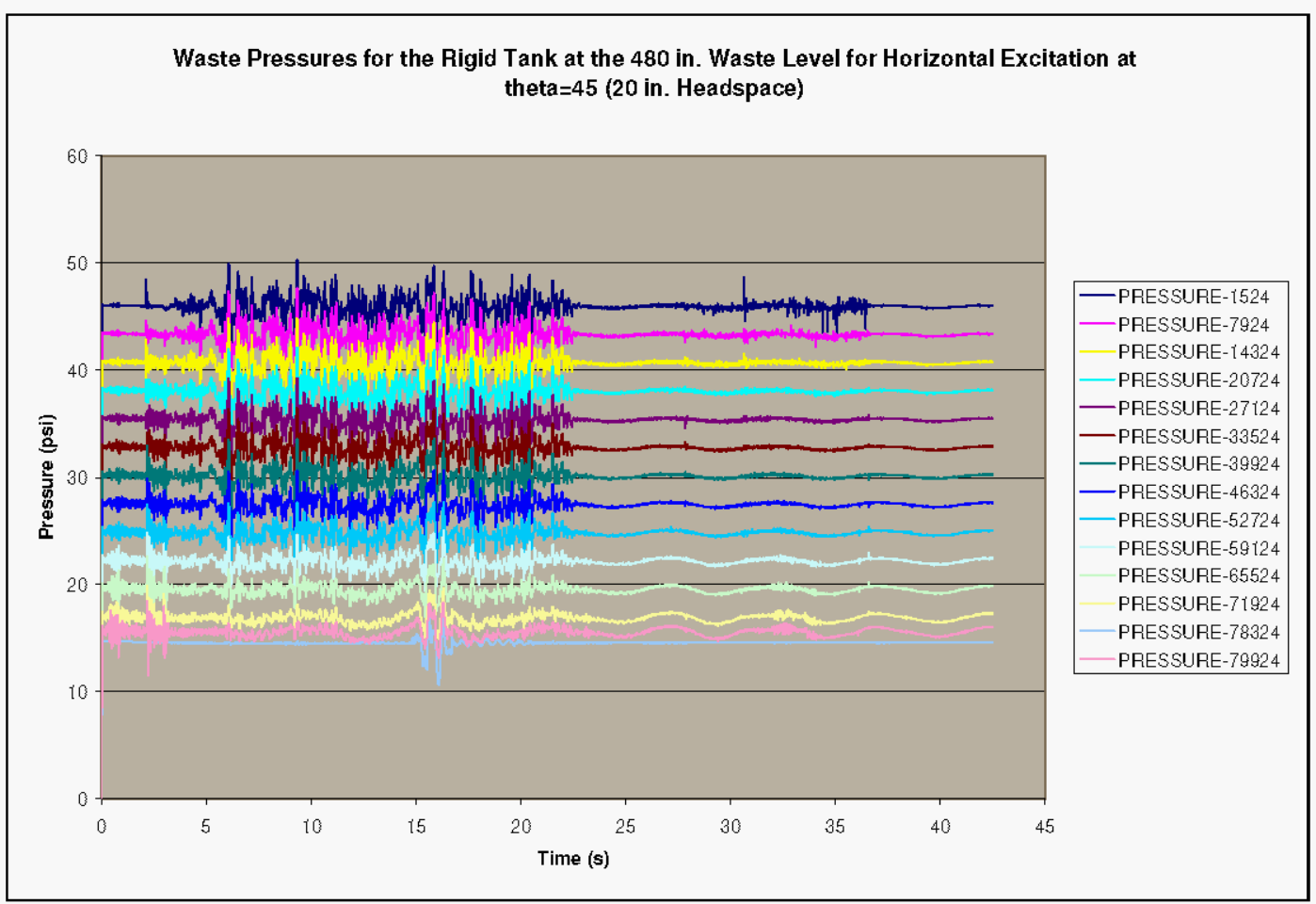


Figure 4-6. Liquid Pressure Time Histories for the Rigid Tank With 480 in. of Liquid Under Horizontal Excitation at $\theta=90^{\circ}$.

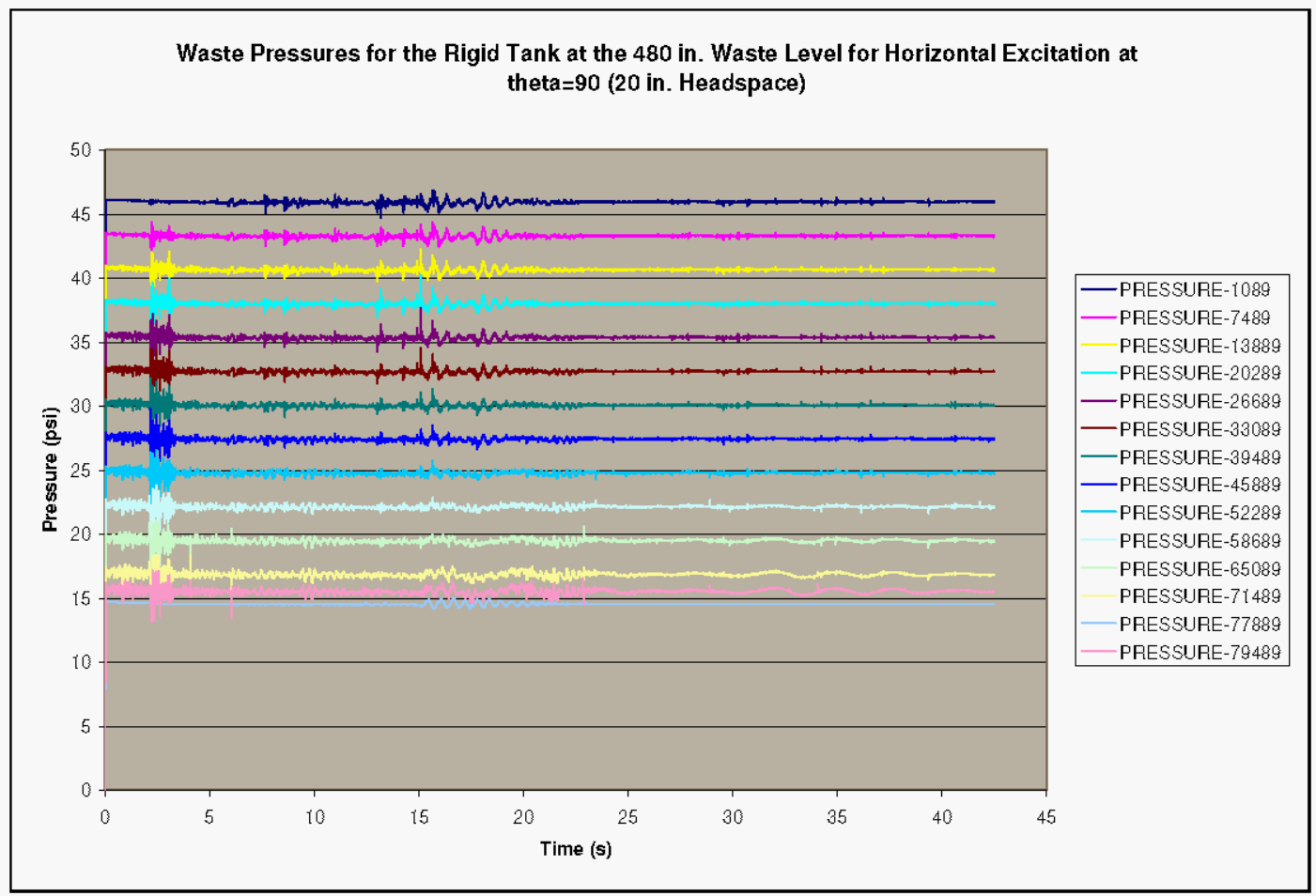

Figure 4-7. Liquid Pressure Comparisons for the Bottom of the Tank at the $480 \mathrm{in}$. Liquid Level at $\theta=0$ and $180^{\circ}$ and at the Tank Center.

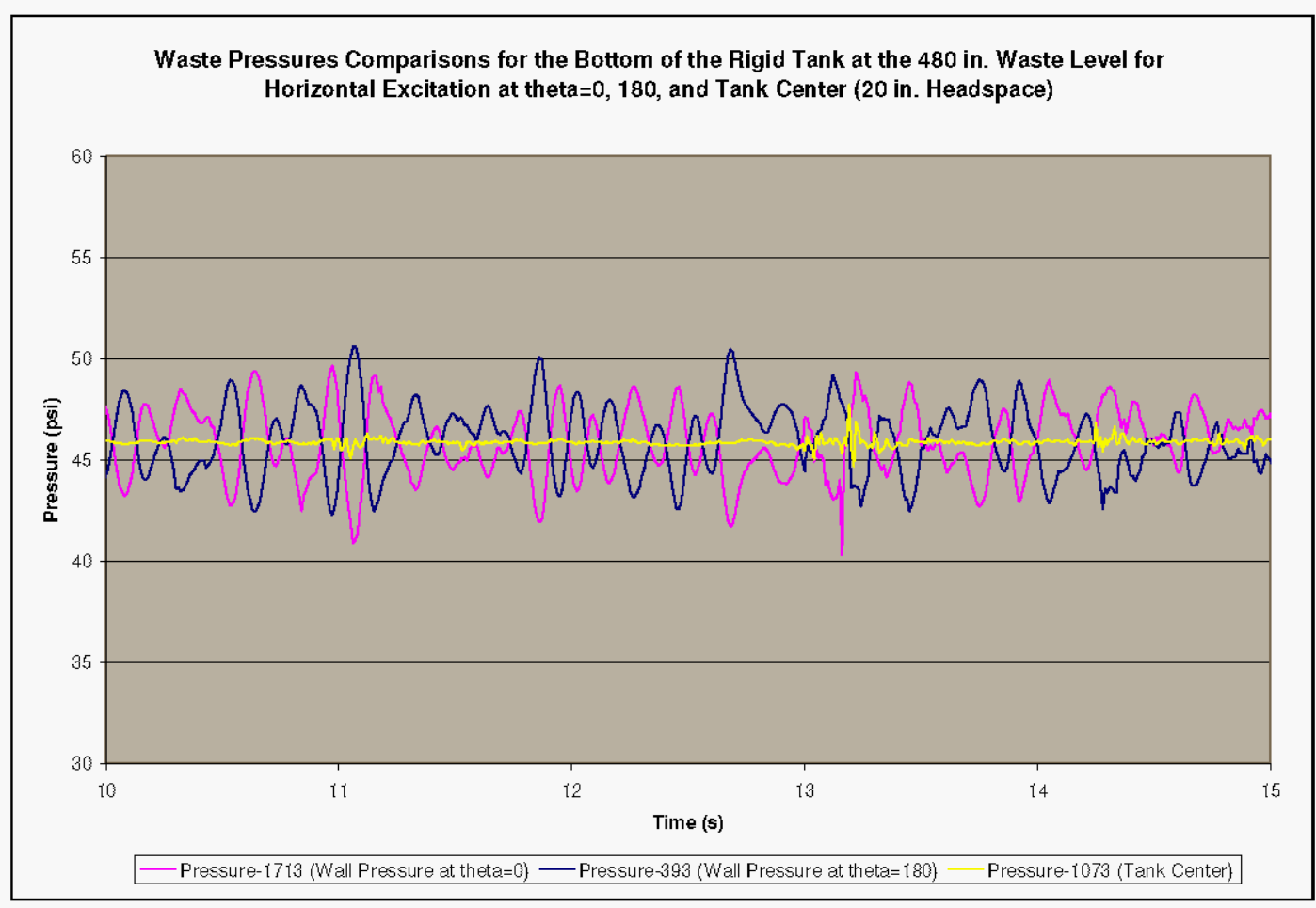


Figure 4-8. Liquid Pressure Comparisons for the Top of the Tank at the $480 \mathrm{in}$. Liquid Level at $\theta=0$ and $180^{\circ}$ and at the Tank Center.

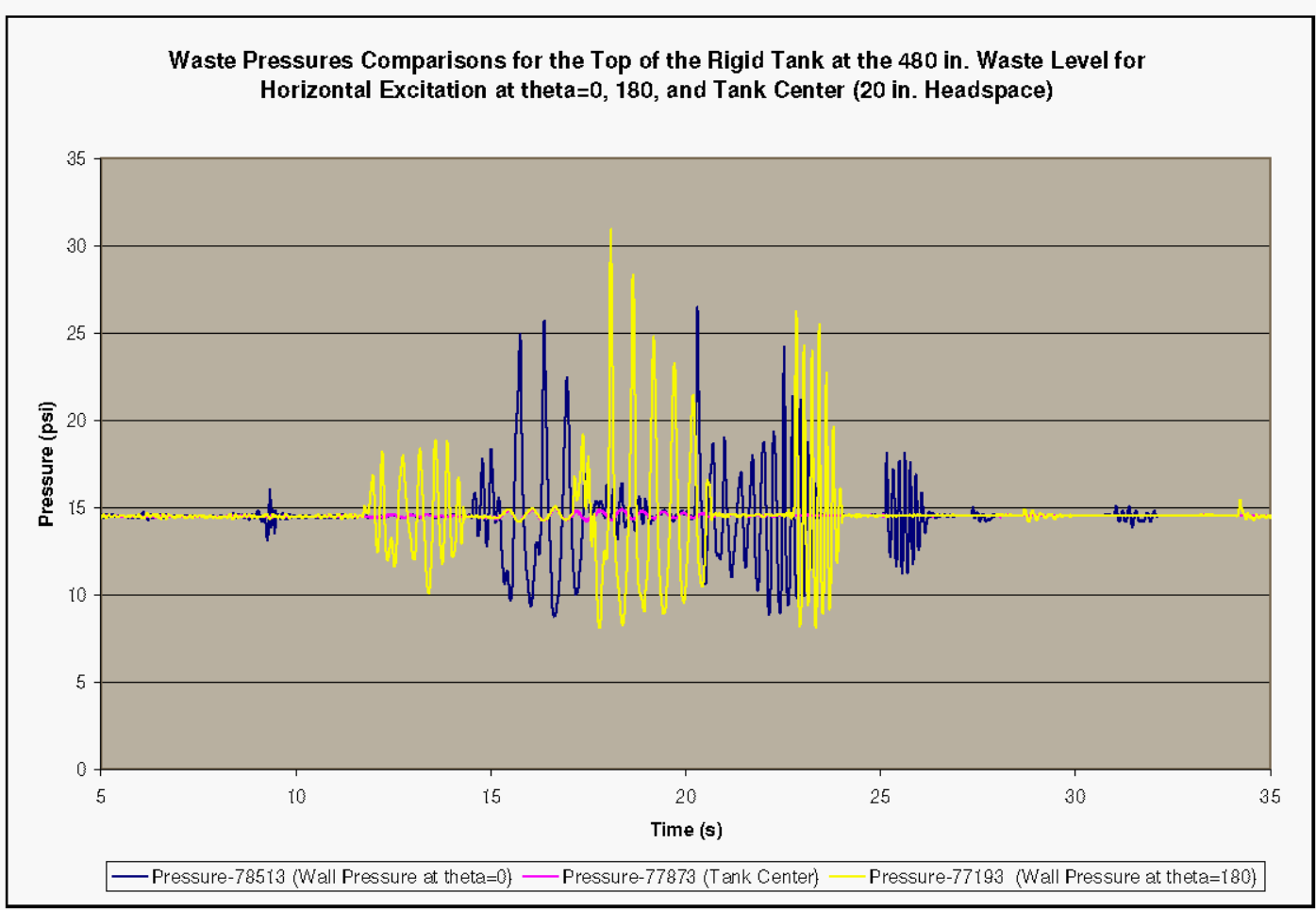

The maximum and minimum wall pressures vs. normalized height from the tank bottom are shown in Figure 4-9 for elements adjacent to the tank wall at $\theta=0^{\circ}$ and in Figure 4-10 for elements adjacent to the wall at $\theta=180^{\circ}$. An important observation from both plots is that the maximum pressures in the lower portion (approximately 70\%) of the tank are essentially the same as for the roofless tank. The solutions only diverge in the upper $30 \%$ of the tank where the effects of roof interaction become apparent.

Also included in Figure 4-9 are the maximum and minimum pressures estimated using the methodology in Appendix D of BNL (1995) for flat top tanks. Just as with the hydrodynamic forces, the estimate of pressures consists of the impulsive component induced by the constrained portion of the liquid, the impulsive component induced by the unconstrained portion of the liquid, and the convective component due to the unconstrained portion of the liquid. The impulsive and convective components due to the unconstrained portion of the liquid constitute the solution for the roofless tank. The additional impulsive term due to the constrained portion of the liquid is exactly the same as the dynamic pressure in a completely full tank. That is, the estimate of total dynamic wall pressure given in Appendix D of BNL (1995) for a flat roof tank with liquid impacting the roof is sum of the pressures for a roofless tank and a completely full tank.

The BNL flat top tank pressures in Figure 4-9 show the contribution of the term representing the impulsive effect of the constrained liquid (the full tank solution). If this term is removed from the BNL flat top solutions in Figure 4-9, one simply ends up with the open tank solution. Figure 4-9 and Figure 4-10 show that the BNL estimate is quite 
conservative for predicting peak wall pressures in the majority of the tank height, but may underestimate peak wall forces near the top of the tank.

The maximum dynamic roof pressure calculated using the methodology of BNL (1995) is $8.2 \mathrm{lbf} / \mathrm{in}^{2}$, giving a total absolute peak roof pressure of $22.9 \mathrm{lbf} / \mathrm{in}^{2}$. This pressure is predicted to occur along the plane of excitation at the junction of the roof and the tank wall. The maximum dynamic roof pressure using the methodology in Malhotra (2005) is $0.7 \mathrm{lbf} / \mathrm{in}^{2}$ giving a total absolute peak roof pressure of $15.4 \mathrm{lbf} / \mathrm{in}^{2}$. The peak pressure in Dytran element 78513 adjacent to the roof at $\theta=0^{\circ}$ is $26.5 \mathrm{lbf} / \mathrm{in}^{2}$. The peak pressure in Dytran element 77193 at $\theta=180^{\circ}$ is $30.9 \mathrm{lbf} / \mathrm{in}^{2}$.

Figure 4-9. Maximum and Minimum Waste Pressure Comparison for Roofless Tank, BNL Flat Top Estimate, and Dytran Solution at the $480 \mathrm{in}$. Liquid Level at $\boldsymbol{\theta}=\mathbf{0}$.

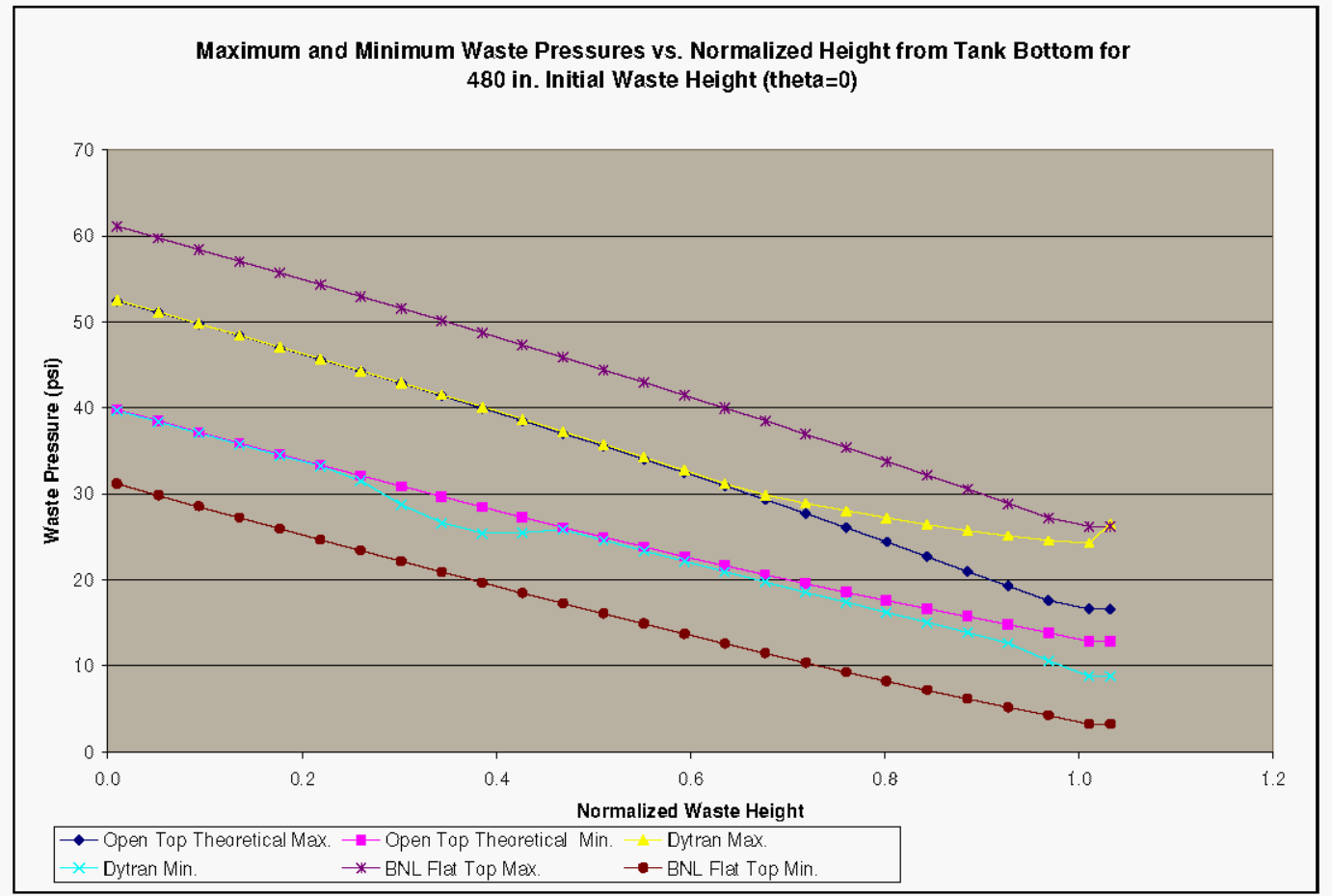


Figure 4-10. Maximum and Minimum Waste Pressure Comparison for Roofless Tank, BNL Flat Top Estimate, and Dytran Solution at the $480 \mathrm{in}$. Liquid Level at $\theta=180^{\circ}$.

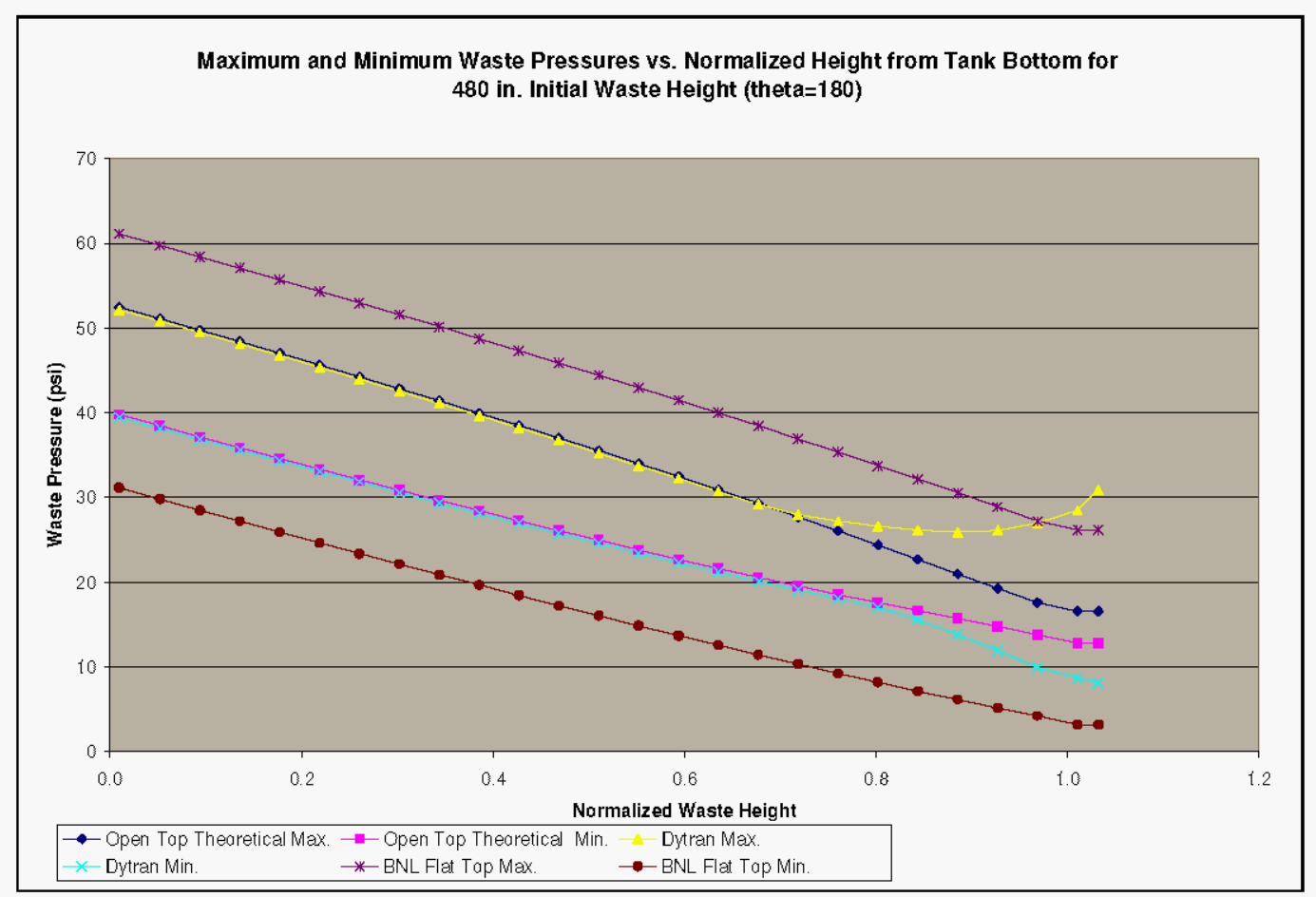

The minimum pressures predicted by Dytran that are shown in Figure 4-9 are less than predicted for a roofless tank for fluid elements in the range of approximately $25-40 \%$ of the normalized wall height. Similar behavior was noted in the simulation at the $460 \mathrm{in}$. liquid level as shown in Figure 3-7. In both cases, the pressures that deviated from the open tank solution occurred at fluid elements 20913, 24113, 27313, and 30513. In both cases, the deviations from the open tank solution occurred at $13.16 \mathrm{~s}$. To investigate the cause of the deviations, the simulation at the 480 in. liquid level was rerun up to $16 \mathrm{~s}$ of simulation time with the pressure output frequency increased from $10 \mathrm{~ms}$ to $1 \mathrm{~ms}$. When resolved at this frequency, it becomes clear that the isolated peaks leading to the deviations in the maximum and minimum plots are of a much higher frequency character than neighboring relative maxima and minima.

Figure 4-4 shows the time history trace for the pressure in fluid element 24113 when extracted at $10 \mathrm{~ms}$ intervals with the isolated spike at $13.16 \mathrm{~s}$ showing a minimum pressure of $28.7 \mathrm{lbf} / \mathrm{in}^{2}$. The same trace with the pressure extracted at $1 \mathrm{~ms}$ intervals is shown in Figure 4-11 for the time from 10 to $16 \mathrm{~s}$. The isolated peak at $13.16 \mathrm{~s}$ is clearly of a different character than neighboring maxima and minima. The same time history is shown again in Figure 4-12. It is apparent from that plot that the frequency associated with the "isolated" pressure spike is approximately $300 \mathrm{~Hz}$ and of no physical consequence to a structural analysis of the tank. Not only is the pressure spike of no physical consequence, but it is almost certainly numerically spurious because it does not appear in any of the time history plots at $\theta=45,90$, or $180^{\circ}$. If the peak were physical in 
nature, it would be expected to appear at other locations. Further evidence that the peaks are numerically spurious is shown in for example in Figure 3-3 and Figure 4-4. In both of these plots and others, isolated pressure peaks occur near the end of the simulation long after the seismic excitation has ended and after any causal physical mechanism gone.

The peaks that occur at13.16 s in fluid elements 20913, 27313, and 30513 have similar high frequency content. If spurious peaks at these element are disregarded, the minimum pressures predicted by Dytran that are shown in Figure 3-7, Figure 4-9, and Figure 5-8 fall more into line with the open tank solutions.

Figure 4-11. Pressure Time History for Fluid Element 24113 at 480 in. Liquid Level Showing Character of Isolated Pressure Spike at 13.16s.

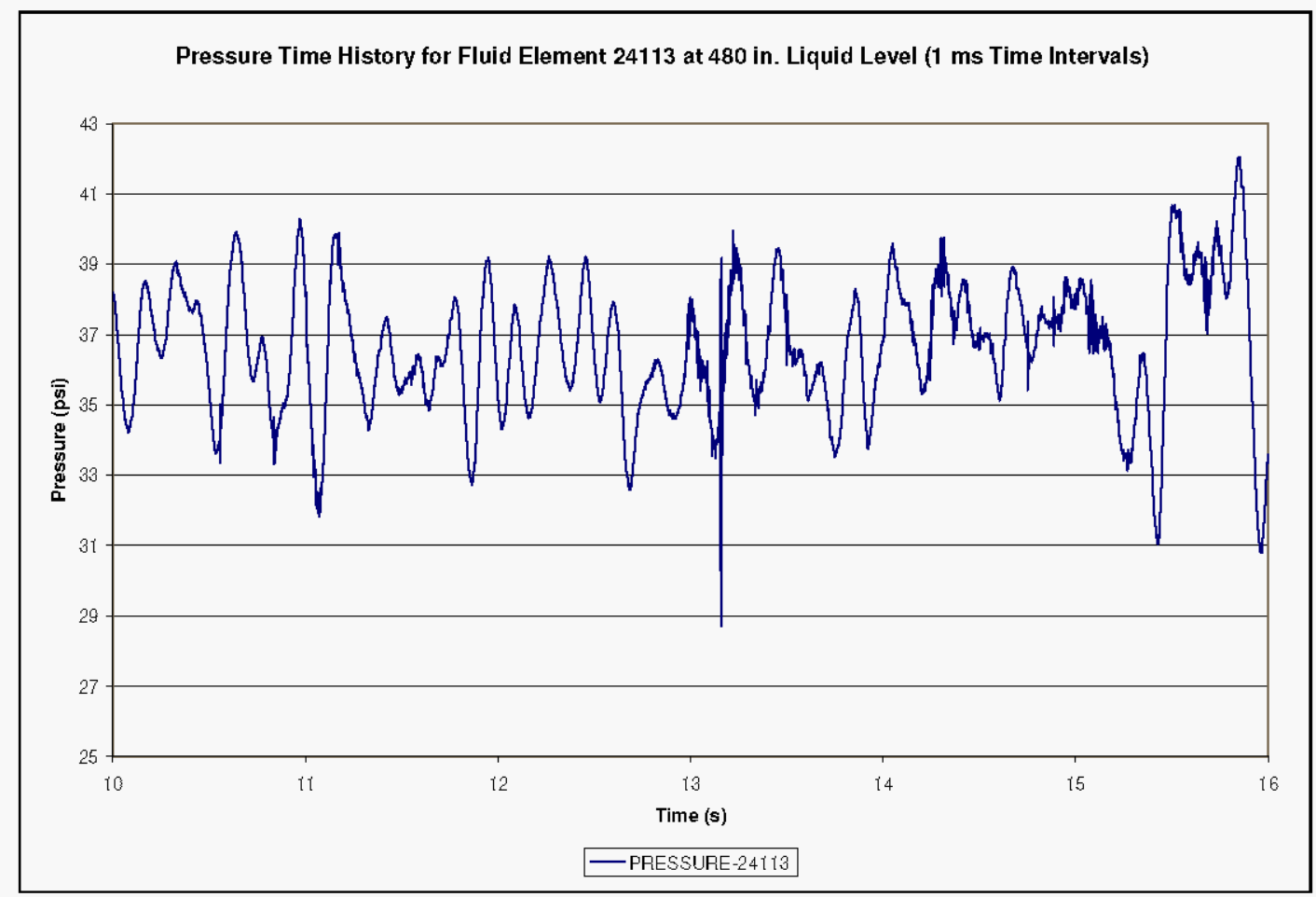


Figure 4-12. Pressure Time History for Fluid Element 24113 at 480 in. Liquid Level Showing Character of Isolated Pressure Spike During Time from 13.15 to 13.18s.

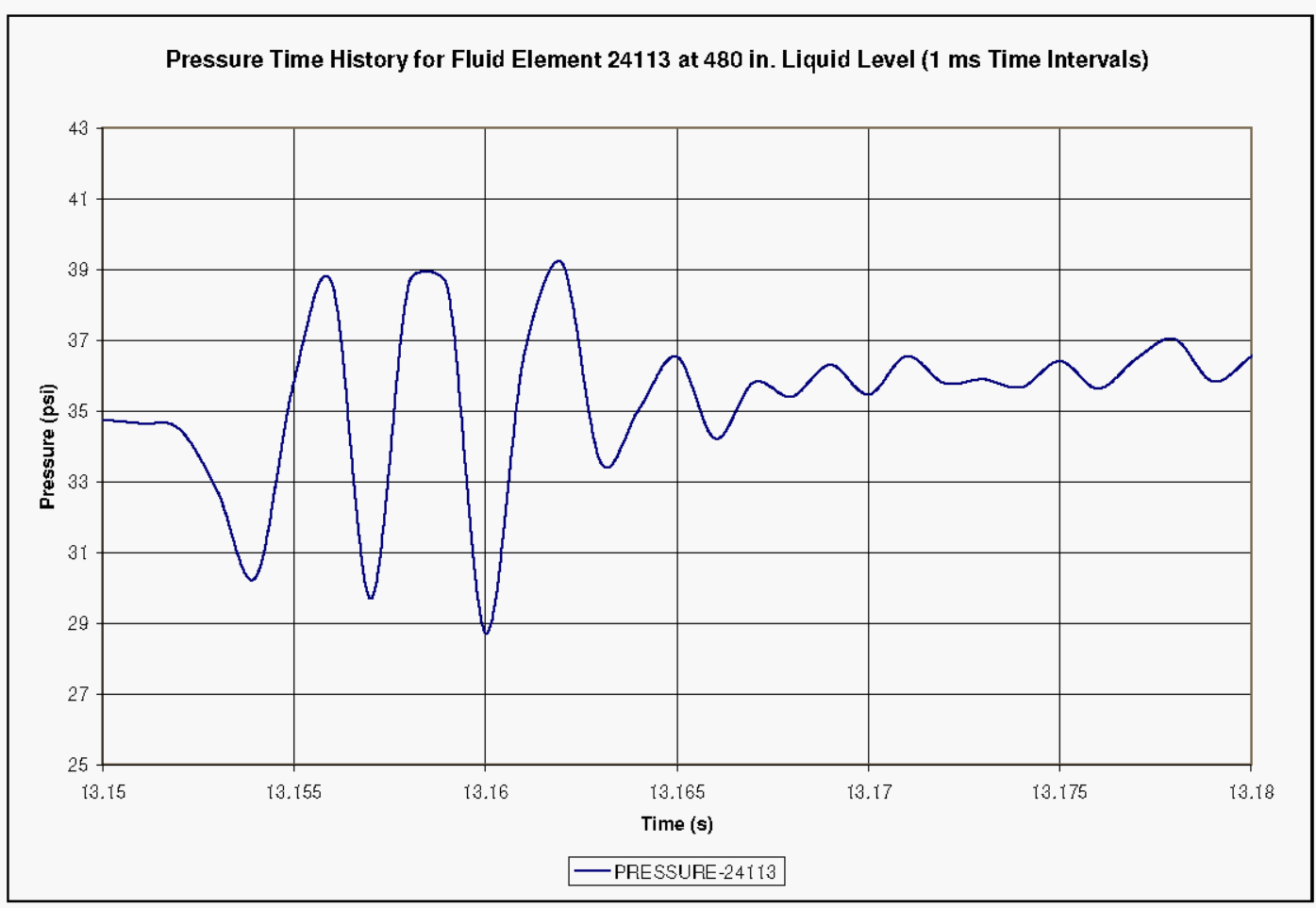

\subsubsection{Summary of Results for $\mathbf{4 8 0}$ in. Liquid Level}

Table 4-1. Summary of Results for 480 in. Liquid Level.

\begin{tabular}{|c|c|c|c|c|}
\hline Parameter & $\begin{array}{c}\text { Open Top } \\
\text { Theory } \\
\text { (BNL 1995) }\end{array}$ & $\begin{array}{c}\text { Equivalent } \\
\text { Flat Top } \\
\text { Estimate } \\
\text { (BNL 1995) }\end{array}$ & $\begin{array}{c}\text { Malhotra } \\
\text { Flat Top } \\
\text { Estimate }\end{array}$ & $\begin{array}{l}\text { Dytran } \\
\text { Result }\end{array}$ \\
\hline Convective Frequency $(\mathrm{Hz})$ & 0.196 & $\begin{array}{c}\text { Not } \\
\text { applicable }\end{array}$ & 0.195 & 0.194 \\
\hline $\begin{array}{l}\text { Peak Horizontal Reaction } \\
\text { Force (lbf) }\end{array}$ & $3.19 \times 10^{6}$ & $4.47 \times 10^{6}$ & $4.26 \times 10^{6}$ & $3.41 \times 10^{6}$ \\
\hline $\begin{array}{l}\text { Peak Horizontal Convective } \\
\text { Reaction Force (lbf) }\end{array}$ & $5.37 \times 10^{5}$ & $3.42 \times 10^{5}$ & $3.82 \times 10^{5}$ & $2.2 \times 10^{5}$ \\
\hline $\begin{array}{l}\text { Maximum Wall Pressure } \\
\text { (lbf/in }{ }^{2} \text { gage) }\end{array}$ & 37.7 & 46.4 & $\begin{array}{c}\text { Not } \\
\text { applicable }\end{array}$ & 37.8 \\
\hline $\begin{array}{l}\text { Maximum Roof Pressure } \\
\left(\mathrm{lbf} / \mathrm{in}^{2} \text { gage }\right)\end{array}$ & Not applicable & 8.2 & 0.7 & 16.2 \\
\hline $\begin{array}{l}\text { Maximum Slosh Height for } \\
\text { Roofless Tank (in) }\end{array}$ & 25.2 & $\begin{array}{c}\text { Not } \\
\text { applicable }\end{array}$ & 29.7 & 26.9 \\
\hline
\end{tabular}


RPP-RPT-30807, Rev. 0

M\&D-2008-005-RPT-02, Rev. 0

\subsection{RIGID TANK AT 490 INCH LIQUID LEVEL}

The $490 \mathrm{in.} \mathrm{liquid} \mathrm{level} \mathrm{represents} 10 \mathrm{in.} \mathrm{of} \mathrm{freeboard.} \mathrm{The} \mathrm{configuration} \mathrm{can} \mathrm{also} \mathrm{be}$ expressed in terms of the characteristic ratio of the freeboard distance $\left(\mathrm{h}_{0}\right)$ to the maximum slosh height for a roofless tank $\left(h_{s}\right)$.

$$
\left(\mathrm{h}_{0} / \mathrm{h}_{\mathrm{s}}\right)_{490}=(10 / 25.2)=0.4
$$

\subsection{HYDRODYNAMIC FORCES}

The peak hydrodynamic force induced against the tank wall due to horizontal excitation can be estimated using the procedure in Appendix D of BNL (1995).

As shown in Appendix B, the peak values of the impulsive component induced by the constrained portion of the liquid, the impulsive component induced by the unconstrained portion of the liquid, and the convective component due to the unconstrained portion of the liquid are $2.8 \times 10^{6}, 1.7 \times 10^{6}$, and $2.8 \times 10^{5} \mathrm{lbf}$, respectively, giving a total estimated peak force of $4.76 \times 10^{6} \mathrm{lbf}$. The convective response is based on the acceleration from the $0.1 \%$ damped spectrum.

The procedure described in Malhotra (2005) decomposes the peak wall force into impulsive and convective components. According to that methodology, the peak impulsive and convective components are $4.78 \times 10^{6}$, and $1.92 \times 10^{5} \mathrm{lbf}$, respectively, giving a total peak force of $4.98 \times 10^{6} \mathrm{lbf}$.

The time history plot of the horizontal coupling surface reaction force for this case is shown as Figure 5-1. The maximum reaction force predicted by Dytran is $3.74 \times 10^{6} \mathrm{lbf}$, which is $78 \%$ of the value estimated using the methodology in Appendix D of BNL (1995) and 75\% of the value estimated using Malhotra's procedure. Again, the BNL methodology for predicting wall forces is conservative relative to the results of the Dytran simulation, as expected.

The convective response following the termination of the seismic excitation is shown in Figure 5-2. The response shows several interesting characteristics. First, the peak convective reaction force of $6.75 \times 105$ is greater than predicted by either the BNL or Malhotra methodologies. Second, the interaction with the roof has the effect of adding damping to the system. Based on the reaction force history shown in Figure 5-2, it takes approximately 12 cycles for the reaction force to reach the steady state value of zero. Using the logarithmic decrement to quantify the damping leads to an effective critical damping ratio of approximately $6 \%$ due to the roof interaction. Finally, the interaction with the roof has the effect of significantly increasing the apparent convective frequency relative to the roofless tank response. Rather than the $0.2 \mathrm{~Hz}$ convective frequency for the roofless tank, the frequency is increased to an average frequency of approximately 1.67 Hz due to the interaction with the roof. The initial convective frequency following the termination of the seismic excitation is approximately $1.4 \mathrm{~Hz}$, but increases to 
approximately $2.5 \mathrm{~Hz}$ as the response damps out. The increased convective frequency is reasonable since the presence of the roof inhibits the longer period free convective oscillation of the liquid.

The acceleration from the $0.1 \%$ damped spectrum at $1.4 \mathrm{~Hz}$ is $0.85 \mathrm{~g}$, which is 13 times greater than the spectral acceleration of $0.066 \mathrm{~g}$ associated with the fundamental convective frequency of approximately $0.2 \mathrm{~Hz}$ for an open top tank. However, according to the data in Figure 5-2, the peak convective reaction force is only 2.4 times greater than predicted by the BNL estimate and 3.5 times greater than predicted by the Malhotra estimate. Evidently the peak convective response is not directly proportional to the increased convective spectral acceleration.

Figure 5-1. Horizontal Reaction Force for Rigid Tank With Initial Liquid Level of $490 \mathrm{in.} \mathrm{(10} \mathrm{in.} \mathrm{Headspace).}$

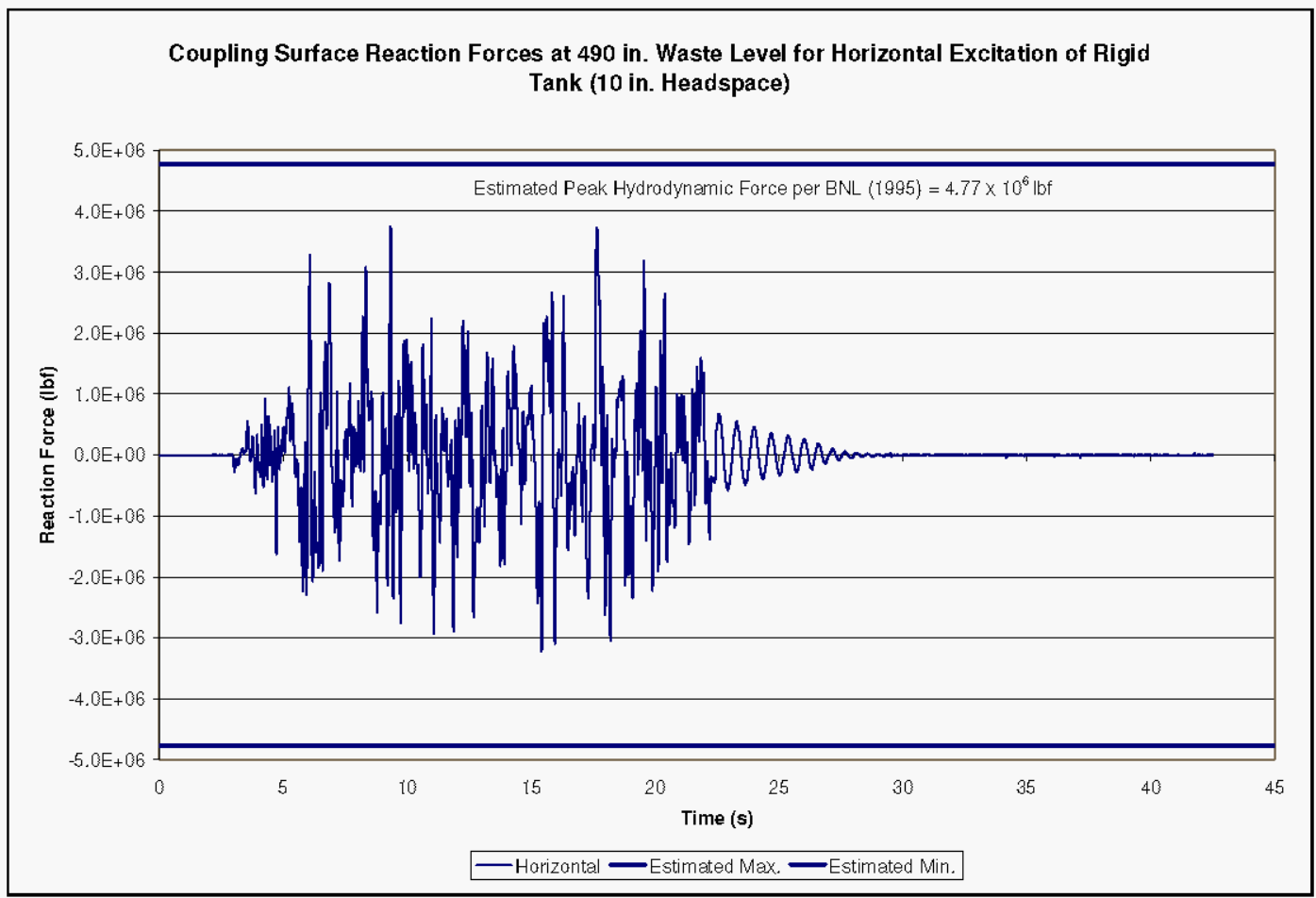


Figure 5-2. Horizontal Reaction Force for Rigid Tank at 490 in. Liquid Level Under Horizontal Seismic Excitation - Convective Response.

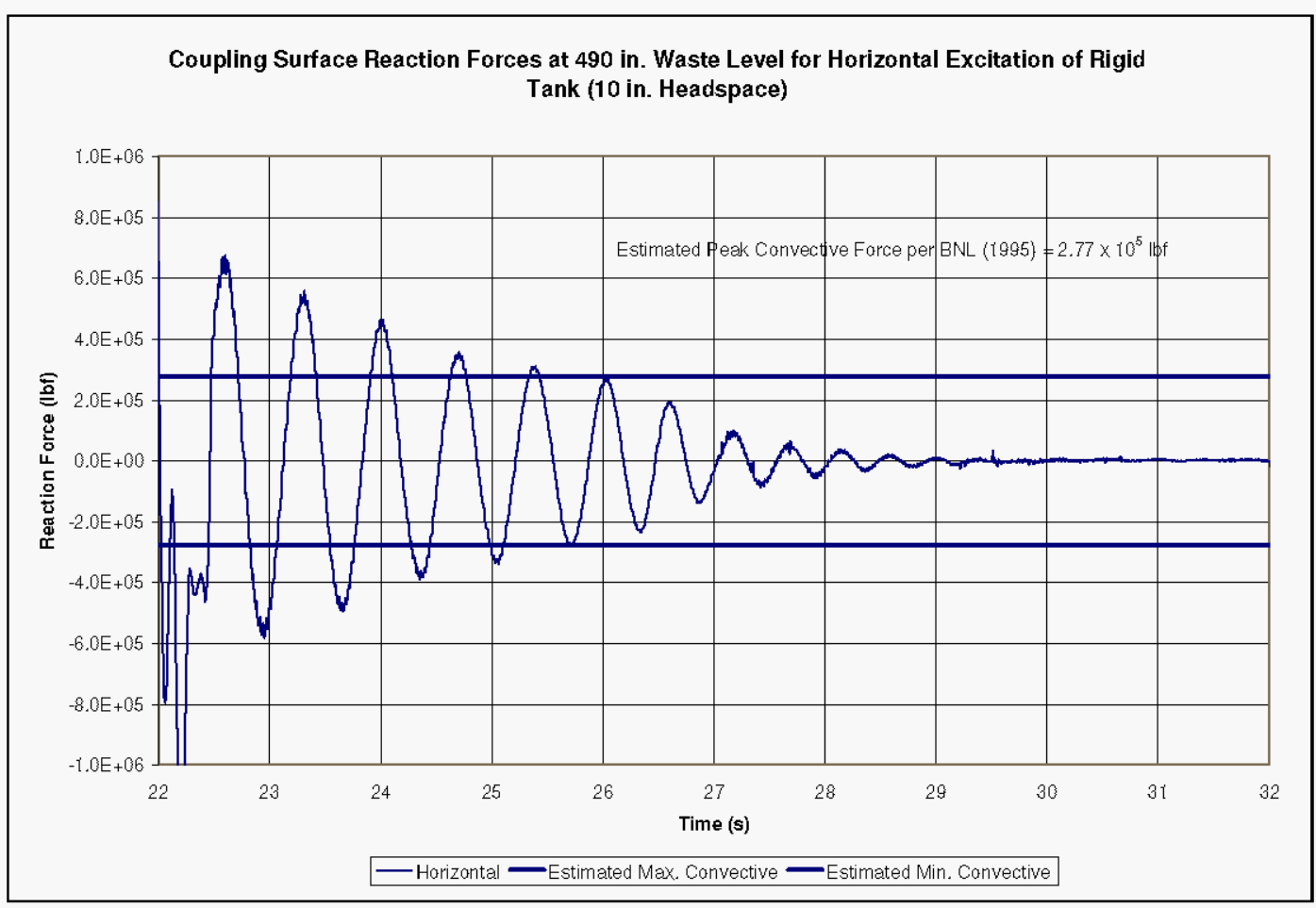

\subsection{LIQUID PRESSURES}

Pressure time histories for fluid elements adjacent to the tank wall at $\theta=0^{\circ}$ are shown in Figure 5-3 and Figure 5-4. Again, the plots show that the elements lower in the tank are dominated by impulsive effects while elements closer to the free surface are dominated by convective effects. Figure 5-5 shows a comparison of pressures for the uppermost fluid element (element 78513) in the set "plusx_els" for the 480 and 490 in. liquid levels. The comparison in Figure 5-5 illustrates differences in the convective responses at the two liquid levels. As expected, interaction with the roof occurs much sooner at the higher liquid level. The response at the higher liquid level shows the approximately $1.5 \mathrm{~Hz}$ frequency content displayed in Figure 5-2. At the lower liquid level, the response shows the $0.2 \mathrm{~Hz}$ frequency content more indicative of the roofless tank response. The lower frequency content appears as packets spaced at approximately $5 \mathrm{~s}$ intervals with increasingly higher frequency content within each subsequent packet. The response also indicates that there is very little difference in the maximum roof pressures generated at the 480 and 490 in. liquid levels. This is consistent with the predictions in BNL (1995), but is not consistent with the predictions in Malhotra (2005), where the peak roof pressure is predicted to be directly proportional to the wetted width of the tank. According the Figure 3 and Eqn. (12) in Malhotra (2005), the peak pressure at the 490 in. liquid level is predicted to be more than twice that at the $480 \mathrm{in}$. level.

Plots of the wall pressures at $\theta=45$ and $90^{\circ}$ are shown in Figure 5-6 and Figure 5-7, respectively. The pressure traces in Figure 5-7 show noticeable nonzero dynamic 
pressures, particularly near the top of the liquid. For example, element 77889 (the top fluid element at $\theta=90^{\circ}$ ) shows dynamic pressures consistent with a convective response, indicating that fluid sloshing extends to that location.

Figure 5-3. Liquid Pressure Time Histories for the Rigid Tank With 490 in. of Liquid Under Horizontal Excitation at $\theta=0^{\circ}$.

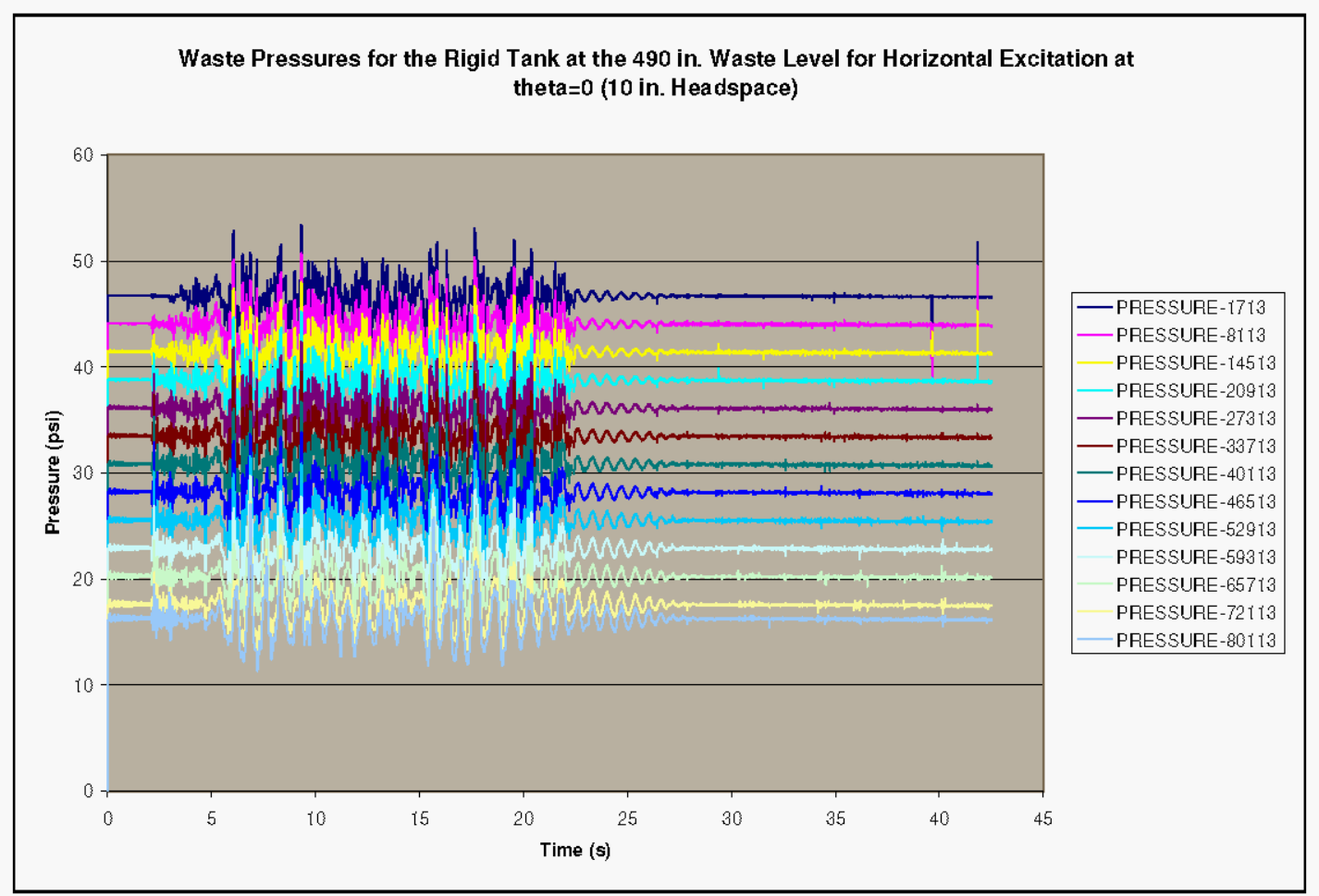


Figure 5-4. Selected Liquid Pressure Time Histories for the Rigid Tank With 490 in. of Liquid Under Horizontal Excitation at $\theta=0$.

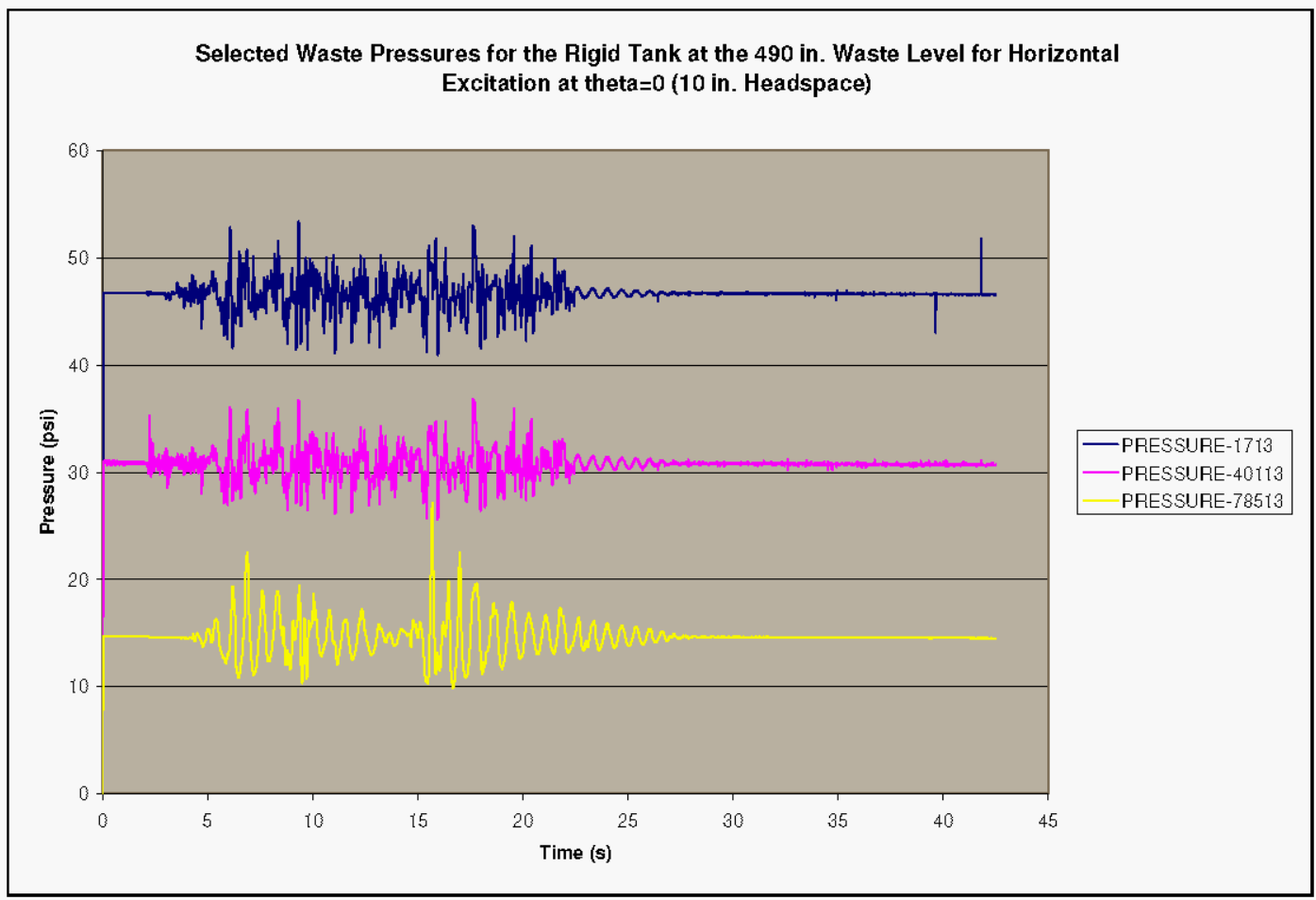

Figure 5-5. Comparison of Waste Pressures for the Uppermost Fluid Elements at the 480 and $490 \mathrm{in}$. Liquid Levels at $\theta=0$.

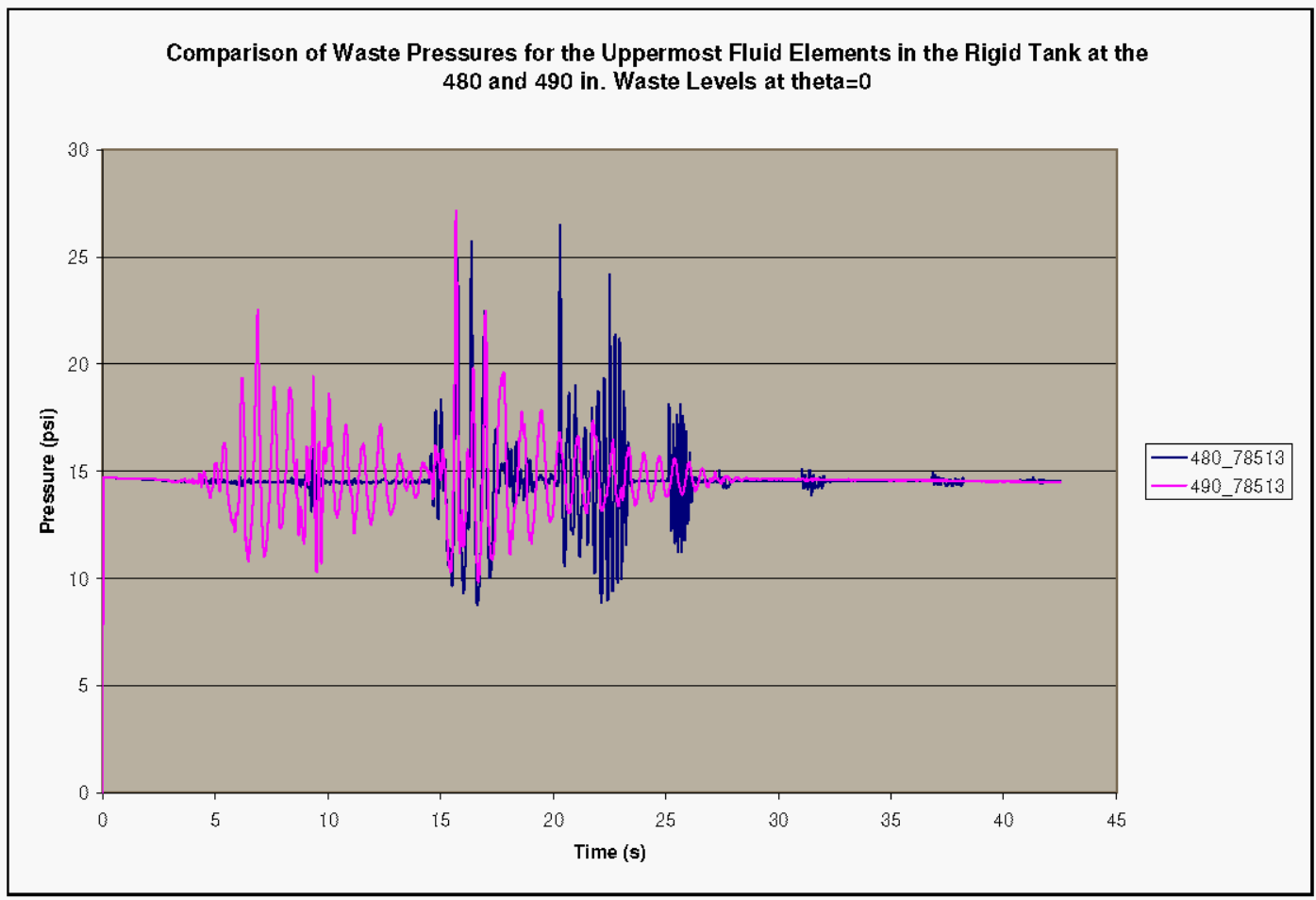


Figure 5-6. Liquid Pressure Time Histories for the Rigid Tank With 490 in. of Liquid Under Horizontal Excitation at $\boldsymbol{\theta}=\mathbf{4 5 ^ { \circ }}$.

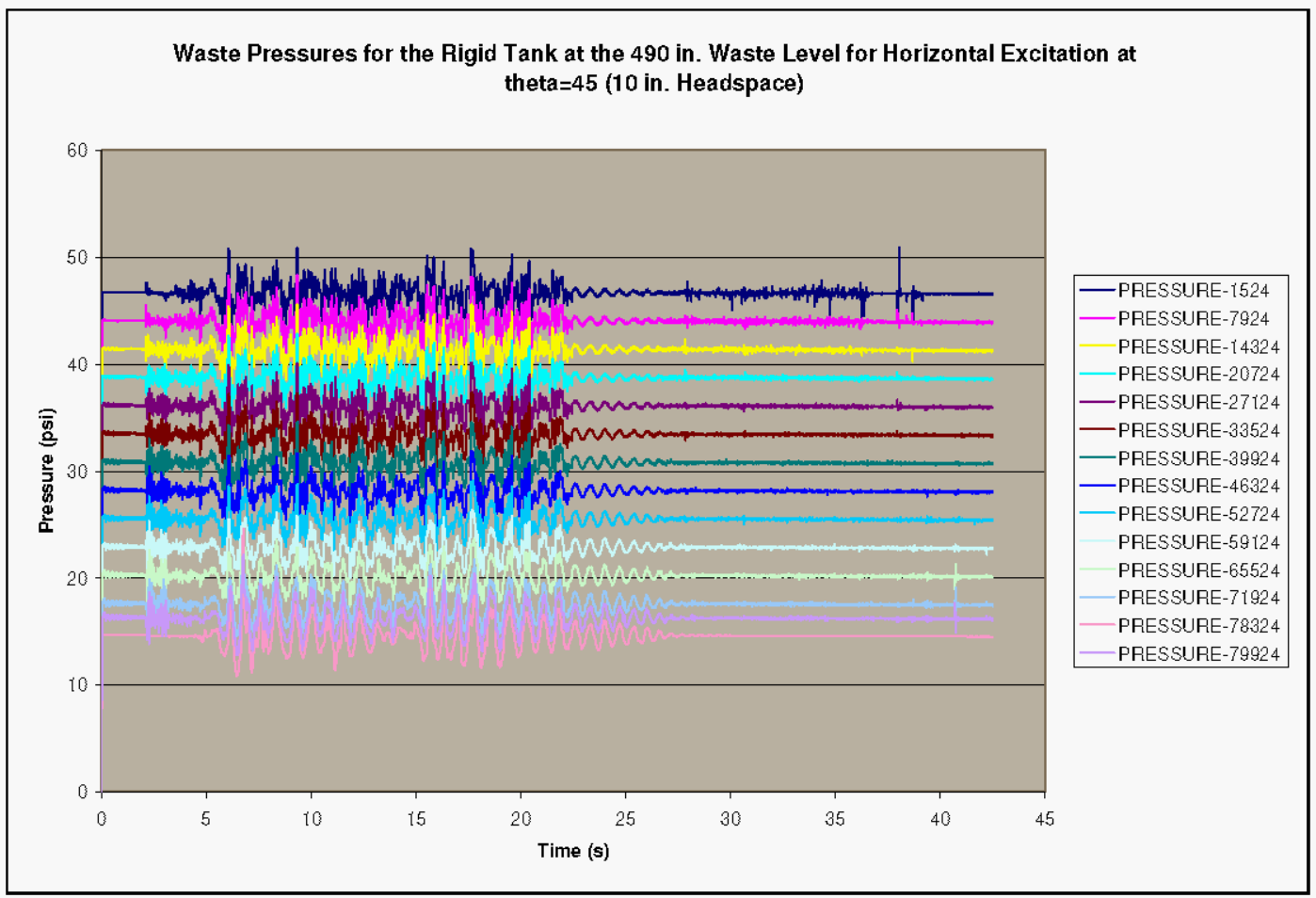

Figure 5-7. Liquid Pressure Time Histories for the Rigid Tank With 490 in. of Liquid Under Horizontal Excitation at $\theta=90^{\circ}$.

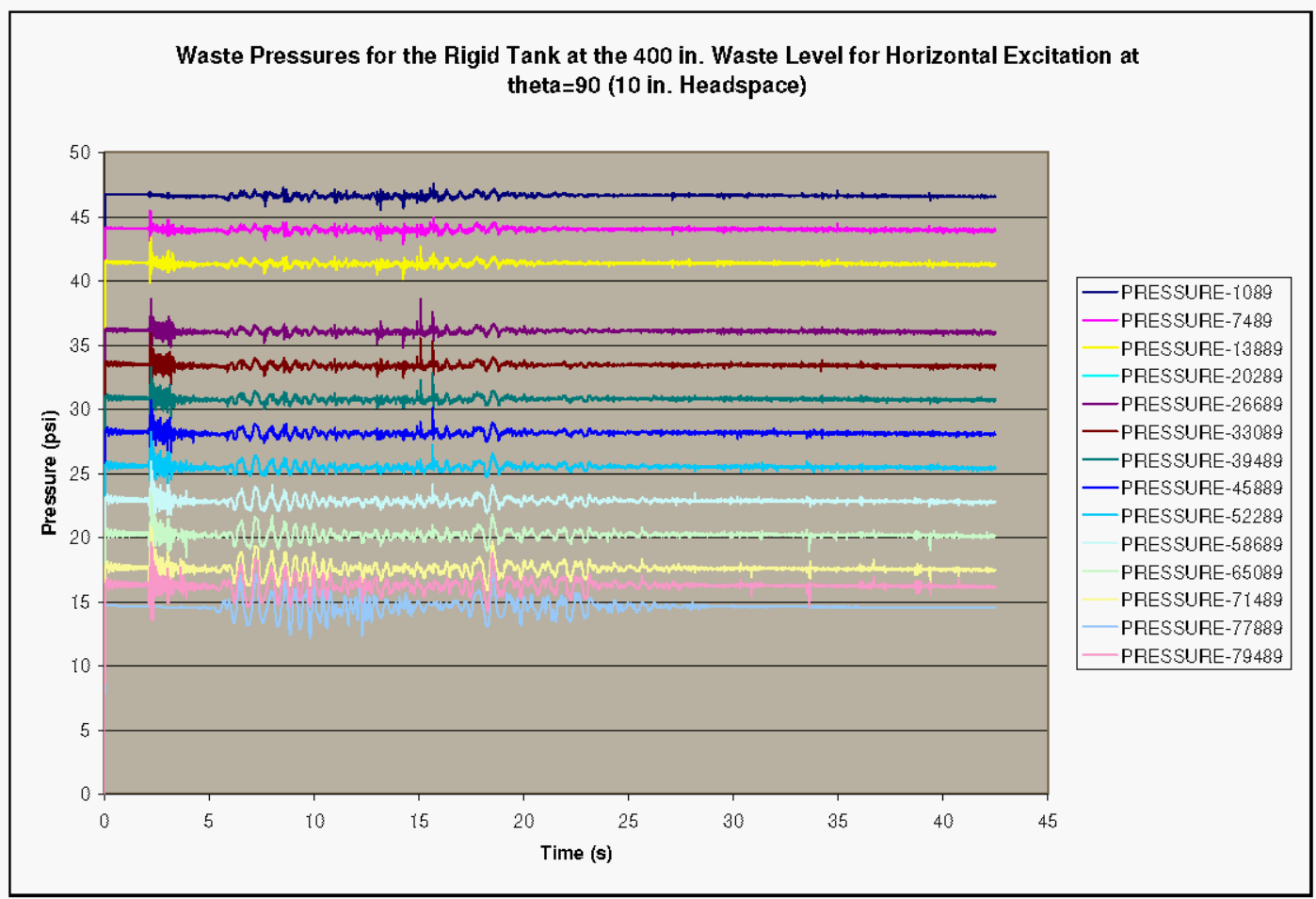


The maximum and minimum pressures vs. normalized height from the tank bottom are shown in Figure 5-8 for elements adjacent to the tank wall at $\theta=0$. As for the $480 \mathrm{in}$. liquid level, an important observation is that the maximum pressures in the lower portion (approximately 60\%) of the tank are essentially the same as for the roofless tank. The solutions only diverge in the upper $40 \%$ of the tank where the effects of roof interaction become apparent.

As in Figure 4-9, the BNL flat top solution is conservative for predicting maximum wall pressures in the majority of the tank height, but may underestimate peak wall pressures near the tank roof.

The maximum dynamic roof pressure calculated using the methodology of BNL (1995) is $8.2 \mathrm{lbf} / \mathrm{in}^{2}$, giving a total absolute peak roof pressure of $22.9 \mathrm{lbf} / \mathrm{in}^{2}$. This pressure is predicted to occur along the plane of excitation at the junction of the roof and the tank wall. The maximum dynamic roof pressure using the methodology in Malhotra (2005) is $1.5 \mathrm{lbf} / \mathrm{in}^{2}$ giving a total absolute peak roof pressure of $16.2 \mathrm{lbf} / \mathrm{in}^{2}$. The peak pressure in Dytran element 78513 adjacent to the roof at $\theta=0$ is $27.2 \mathrm{lbf} / \mathrm{in}^{2}$.

Figure 5-8. Maximum and Minimum Waste Pressure Comparison for Roofless Tank, BNL Flat Top Estimate, and Dytran Solution at the $490 \mathrm{in}$. Liquid Level.

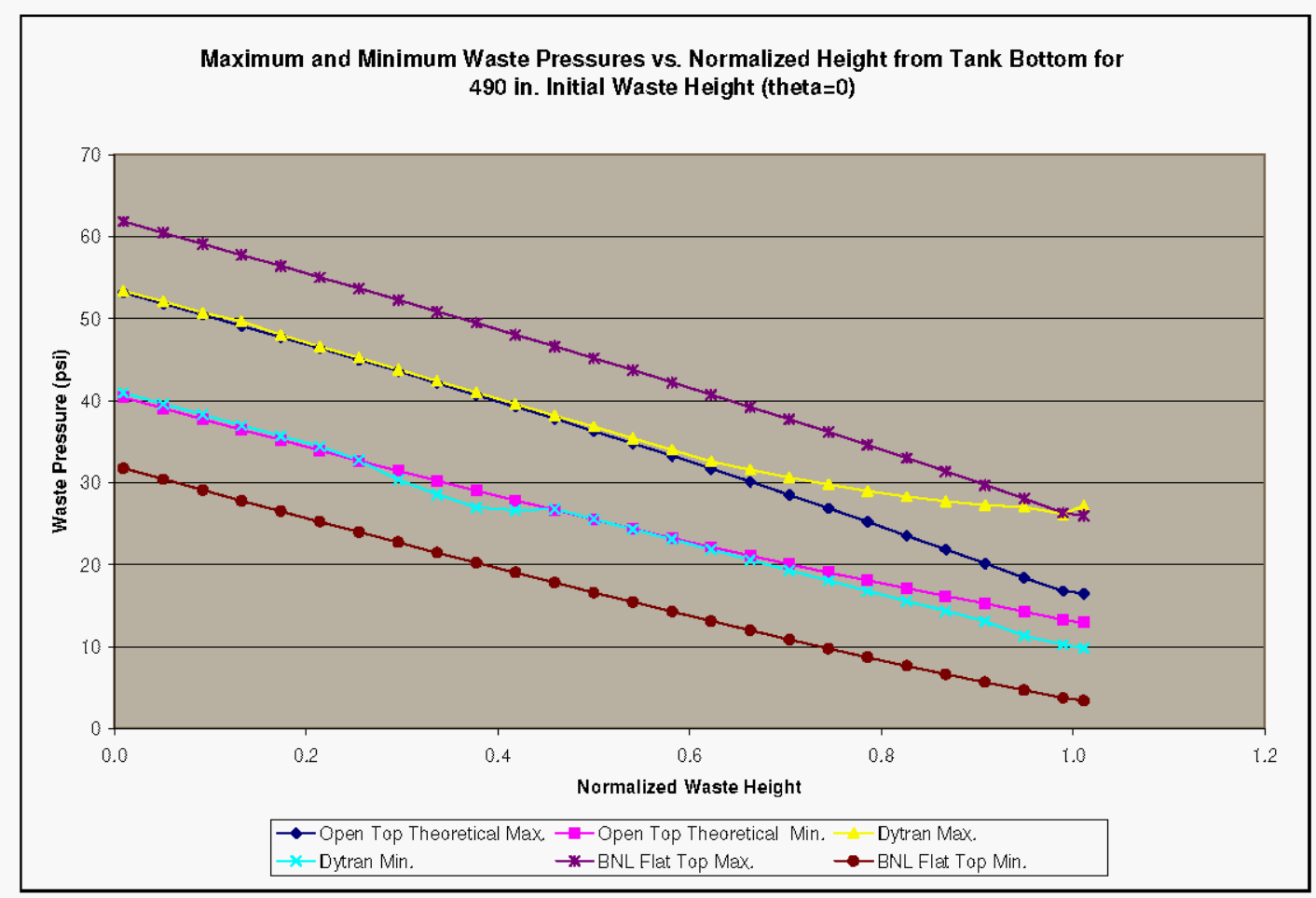




\subsubsection{Summary of Results for 490 in. Liquid Level}

Table 5-1. Summary of Results for 490 in. Liquid Level.

\begin{tabular}{|l|c|c|c|c|}
\hline \multicolumn{1}{|c|}{ Parameter } & $\begin{array}{c}\text { Open Top } \\
\text { Theory } \\
\text { (BNL 1995) }\end{array}$ & $\begin{array}{c}\text { Equivalent } \\
\text { Flat Top } \\
\text { Estimate } \\
\text { (BNL 1995) }\end{array}$ & $\begin{array}{c}\text { Malhotra } \\
\mathbf{( 2 0 0 5 )}\end{array}$ & $\begin{array}{c}\text { Dytran } \\
\text { Result }\end{array}$ \\
\hline Convective Frequency (Hz) & 0.197 & Not applicable & 0.196 & 1.67 \\
\hline $\begin{array}{l}\text { Peak Horizontal Reaction } \\
\text { Force (lbf) }\end{array}$ & $3.3 \times 10^{6}$ & $4.47 \times 10^{6}$ & $4.98 \times 10^{6}$ & $3.74 \times 10^{6}$ \\
\hline $\begin{array}{l}\text { Peak Horizontal Convective } \\
\text { Reaction Force (lbf) }\end{array}$ & $5.39 \times 10^{5}$ & $2.77 \times 10^{5}$ & $1.92 \times 105$ & $6.75 \times 10^{5}$ \\
\hline $\begin{array}{l}\text { Maximum Wall Pressure } \\
\text { (lbf/in }{ }^{2} \text { gage) }\end{array}$ & 38.5 & 46.4 & Not applicable & 37.8 \\
\hline $\begin{array}{l}\text { Maximum Roof Pressure } \\
\text { (lbf/in }{ }^{2} \text { gage) }\end{array}$ & Not applicable & 8.2 & 1.5 & 12.5 \\
\hline $\begin{array}{l}\text { Maximum Slosh Height for } \\
\text { Roofless Tank (in) }\end{array}$ & 25.2 & Not applicable & 29.7 & 26.9 \\
\hline
\end{tabular}

\subsection{RIGID TANK AT 500 INCH LIQUID LEVEL (COMPLETELY FULL TANK)}

The 500 in. liquid level corresponds to a completely full tank as shown in Figure 2-5.

The response for a completely full tank will be $100 \%$ impulsive and $0 \%$ convective as all of the fluid mass moves in concert with the tank.

\subsection{HYDRODYNAMIC FORCES}

The peak hydrodynamic force induced against the tank wall due to horizontal excitation should be equal to the product of mass of the contained fluid and the lateral acceleration of the tank. The mass of the contained fluid as calculated by Dytran is $5.35 \times 10^{4} \mathrm{lbf}-\mathrm{s}^{2} / \mathrm{in}$. The maximum lateral acceleration is $106.65 \mathrm{in} / \mathrm{s}^{2}$, giving a maximum expected reaction force of $5.71 \times 10^{6} \mathrm{lbf}$. The coupling surface reaction force time history reported by Dytran for horizontal excitation is shown in Figure 6-1. The peak reaction force is $5.76 \times 10^{6} \mathrm{lbf}$, which is within $1 \%$ of the expected value. 
Figure 6-1. Horizontal Coupling Surface Reaction Force for the Rigid Tank at 500 in. Liquid Level Under Horizontal Seismic Input.

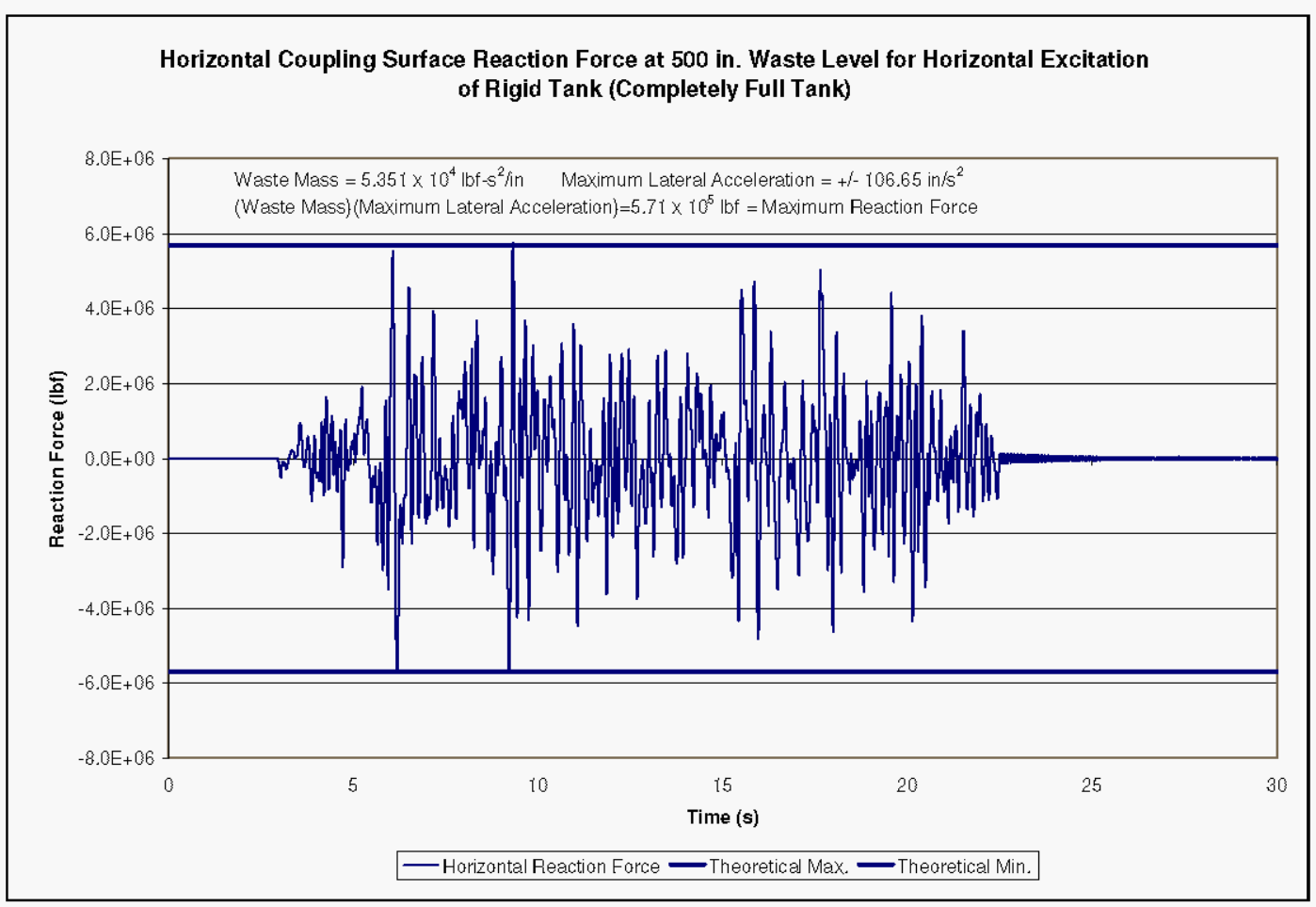

The relationship between the horizontal reaction force and the input acceleration is shown in Figure 6-2. The plot shows the normalized horizontal reaction force plotted along with the normalized input acceleration for the time segment from 2 to $10 \mathrm{~s}$. The acceleration time history plotted along the secondary vertical axis has had the sign reversed to match the sign of the reaction force. The reaction data in this plot were extracted at $1 \mathrm{~ms}$ intervals and the slight lag of the reaction force relative to the input acceleration is in the range of $20 \mathrm{~ms}$ and corresponds to the characteristic time for an acoustic wave to travel the $900 \mathrm{in}$. tank diameter at the acoustic speed of $42,230 \mathrm{in} / \mathrm{s}$. 
Figure 6-2. Comparison of Coupling Surface Reaction Force and Input Acceleration for the Completely Full Tank (500 in. Liquid Level).

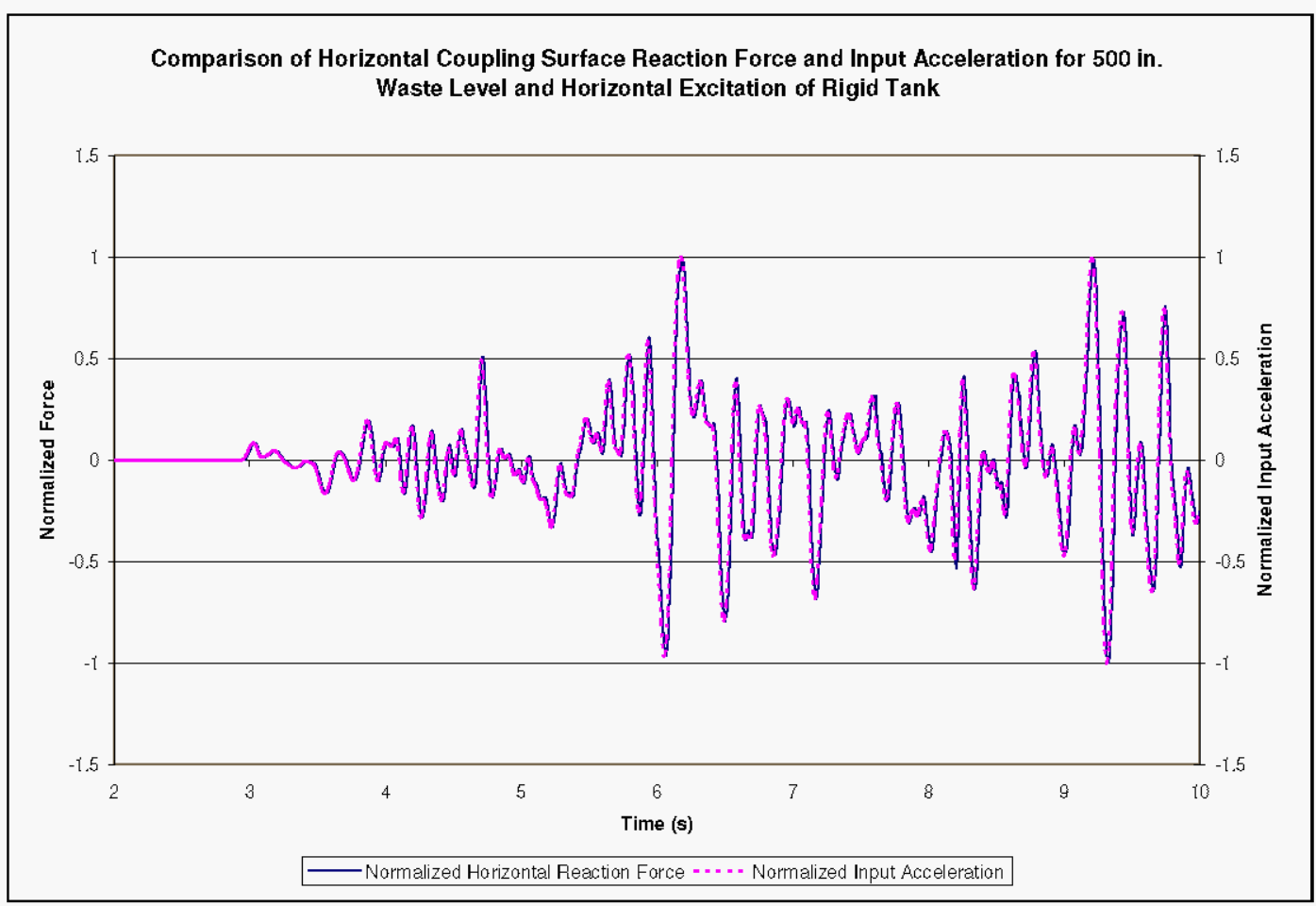

\subsection{LIQUID PRESSURES}

By definition, the response of the liquid is completely impulsive in that all fluid moves in synchronism with the tank. That is, the acceleration of any fluid element in the tank is a reflection of the input acceleration time history.

Physical arguments coupled with insight from the solution to the open top tank problem suggest certain behavior for the liquid pressures.

Dynamic liquid pressures should be independent of vertical position. This is expected physically since the fluid response is completely impulsive and the contained fluid moves with the tank independent of vertical position. The impulsive wall pressure for an open tank appears as Equation 4.2 of BNL (1995). If the impulsive coefficient is set to 1.0 (independent of height) and the impulsive pressure is interpreted to be the total dynamic pressure (convective pressures are zero), then the dynamic wall pressures are expected to be

$$
p_{\text {wall }}\left(\eta_{l}, \theta\right)=p_{\text {wall }}(\theta)=(1.0) \rho_{l} \cdot R \cdot A_{i}(t) \cdot \cos (\theta) \quad(\text { Eqn. 6-1) }
$$

In the above equation, $\rho_{1}$ is the liquid mass density, $R$ is the tank radius, $\theta$ is the angle from the plane of excitation measured from the positive $\mathrm{x}$-axis, and $\mathrm{A}_{\mathrm{i}}(\mathrm{t})$ is the pseudoacceleration of a single-degree-of-freedom oscillator for the impulsive response. In the 
case of the rigid tank, the oscillator is rigid and moves in concert with the tank at the exciting acceleration. That is, $\mathrm{A}_{\mathrm{i}}(\mathrm{t})$ reduces to the input acceleration.

With these considerations in mind, it is expected that for a given angular position, the liquid pressures will be directly proportional to the input acceleration. Given the dependence of the pressures on the angular position, it is expected that the dynamic pressures will be zero at $\theta=90^{\circ}$. The angular dependence of the wall pressure as well as physical and symmetry arguments leads one to expect that diametrically opposed points should have dynamic pressures that are in phase but of opposite signs. Symmetry and continuity arguments lead one to expect that the pressure will be directly proportional to the radial distance from the tank center, and that the dynamic pressure at the tank center will be zero. More generally, for the ground acceleration $\ddot{x}_{g}(t)$, the pressure at any point in the liquid may be written as

$$
p(r, \theta)=-\rho_{l} \cdot r \cdot \ddot{x}_{g}(t) \cdot \cos (\theta) \quad(\text { Eqn. 6-2) }
$$

The expected peak hydrodynamic pressures are obtained at the wall along the plane of excitation $\left(\theta=0\right.$ and $\left.180^{\circ}\right)$ and are equal to the product of the liquid mass density, the tank radius, and the peak input acceleration. Given the peak input acceleration of $106.65 \mathrm{in} / \mathrm{s}^{2}$, the peak dynamic pressure is $8.2 \mathrm{lbf} / \mathrm{in}^{2}$.

The hydrostatic, peak hydrodynamic, and peak total pressures for the elements in the sets "plusx_els", "press_45", are shown in Table 6-1 and Table 6-2. The maximum theoretical pressures for the elements set "plusz_els" is simply the hydrostatic pressures shown in Table 2-1 because the theoretical hydrodynamic pressures are zero at $\theta=90^{\circ}$. Pressure time histories for the fluid element sets at $\theta=0,45$, and $90^{\circ}$, are shown in Figure 6-3 through Figure 6-6. The time histories show that the peak pressures are as expected, the dynamic pressures are indeed independent of vertical position, and the pressures do vary as a cosine function of the angular position. The time histories in Figure 6-7 show that the wall pressures at $\theta=0$ and $180^{\circ}$ are in phase and of opposite sign as expected and that the dynamic liquid pressures near the tank center are essentially zero.

Plots of the Dytran calculated and theoretically calculated (i.e. expected) maximum and minimum wall pressures at $\theta=0^{\circ}$ are shown in Figure 6-8. The maximum and minimum pressures predicted by Dytran match those given by Eqn. 6-2. In summary, the wall pressures are correctly predicted by Eqn. 6-2 and the dynamic pressure is zero at the tank center as expected. 
RPP-RPT-30807, Rev. 0

M\&D-2008-005-RPT-02, Rev. 0

Table 6-1. Theoretical Maximum Liquid Pressures for Horizontal Excitation in the Rigid Tank at 500 in. Liquid Level for Elements at $\theta=0^{\circ}$.

\begin{tabular}{|c|c|c|c|}
\hline "Plusx_els" & Hydrostatic & Peak & Peak Total \\
\hline Element No. & $\begin{array}{l}\text { Pressure } \\
\text { (psi absolute) }\end{array}$ & $\begin{array}{l}\text { Hydrodynamic } \\
\text { Pressure } \\
\text { (psi absolute) }\end{array}$ & $\begin{array}{l}\text { Pressure } \\
\text { (psi absolute) }\end{array}$ \\
\hline 78513 & 15.0 & 8.2 & 23.2 \\
\hline 76913 & 15.7 & 8.2 & 23.9 \\
\hline 80113 & 17.0 & 8.2 & 25.2 \\
\hline 72113 & 18.3 & 8.2 & 26.5 \\
\hline 68913 & 19.7 & 8.2 & 27.9 \\
\hline 65713 & 21.0 & 8.2 & 29.2 \\
\hline 62513 & 22.3 & 8.2 & 30.5 \\
\hline 59313 & 23.6 & 8.2 & 31.8 \\
\hline 56113 & 24.9 & 8.2 & 33.1 \\
\hline 52913 & 26.3 & 8.2 & 34.5 \\
\hline 49713 & 27.6 & 8.2 & 35.8 \\
\hline 46513 & 28.9 & 8.2 & 37.1 \\
\hline 43313 & 30.2 & 8.2 & 38.4 \\
\hline 40113 & 31.5 & 8.2 & 39.7 \\
\hline 36913 & 32.9 & 8.2 & 41.1 \\
\hline 33713 & 34.2 & 8.2 & 42.4 \\
\hline 30513 & 35.5 & 8.2 & 43.7 \\
\hline 27313 & 36.8 & 8.2 & 45.0 \\
\hline 24113 & 38.2 & 8.2 & 46.4 \\
\hline 20913 & 39.5 & 8.2 & 47.7 \\
\hline 17713 & 40.8 & 8.2 & 49.0 \\
\hline 14513 & 42.1 & 8.2 & 50.3 \\
\hline 11313 & 43.4 & 8.2 & 51.6 \\
\hline 8113 & 44.8 & 8.2 & 53.0 \\
\hline 4913 & 46.1 & 8.2 & 54.3 \\
\hline 1713 & 47.4 & 8.2 & 55.6 \\
\hline
\end{tabular}


RPP-RPT-30807, Rev. 0

M\&D-2008-005-RPT-02, Rev. 0

Table 6-2. Theoretical Maximum Liquid Pressures for Horizontal Excitation in the Rigid Tank at $460 \mathrm{in.} \mathrm{Liquid} \mathrm{Level} \mathrm{for} \mathrm{Elements} \mathrm{at} \theta=45^{\circ}$.

\begin{tabular}{|c|c|c|c|}
\hline "Press_45" & Hydrostatic & & Peak Total \\
\hline Element No. & $\begin{array}{l}\text { Pressure } \\
\text { (psi absolute) }\end{array}$ & $\begin{array}{l}\text { Hydrodynamic } \\
\text { Pressure } \\
\text { (psi absolute) }\end{array}$ & $\begin{array}{l}\text { Pressure } \\
\text { (psi absolute) }\end{array}$ \\
\hline 78324 & 15.0 & 5.8 & 20.8 \\
\hline 76724 & 15.7 & 5.8 & 21.5 \\
\hline 79924 & 17.0 & 5.8 & 22.8 \\
\hline 71924 & 18.3 & 5.8 & 24.1 \\
\hline 68724 & 19.7 & 5.8 & 25.5 \\
\hline 65524 & 21.0 & 5.8 & 26.8 \\
\hline 62324 & 22.3 & 5.8 & 28.1 \\
\hline 59124 & 23.6 & 5.8 & 29.4 \\
\hline 55924 & 24.9 & 5.8 & 30.7 \\
\hline 52724 & 26.3 & 5.8 & 32.1 \\
\hline 49524 & 27.6 & 5.8 & 33.4 \\
\hline 46324 & 28.9 & 5.8 & 34.7 \\
\hline 43124 & 30.2 & 5.8 & 36.0 \\
\hline 39924 & 31.5 & 5.8 & 37.3 \\
\hline 36724 & 32.9 & 5.8 & 38.7 \\
\hline 33524 & 34.2 & 5.8 & 40.0 \\
\hline 30324 & 35.5 & 5.8 & 41.3 \\
\hline 27124 & 36.8 & 5.8 & 42.6 \\
\hline 23924 & 38.2 & 5.8 & 44.0 \\
\hline 20724 & 39.5 & 5.8 & 45.3 \\
\hline 17524 & 40.8 & 5.8 & 46.6 \\
\hline 14324 & 42.1 & 5.8 & 47.9 \\
\hline 11124 & 43.4 & 5.8 & 49.2 \\
\hline 7924 & 44.8 & 5.8 & 50.6 \\
\hline 4724 & 46.1 & 5.8 & 51.9 \\
\hline 1524 & 47.4 & 5.8 & 53.2 \\
\hline
\end{tabular}


Figure 6-3. Liquid Pressure Time Histories for the Rigid Tank With 500 in. of Liquid Under Horizontal Excitation at $\theta=0^{\circ}$.

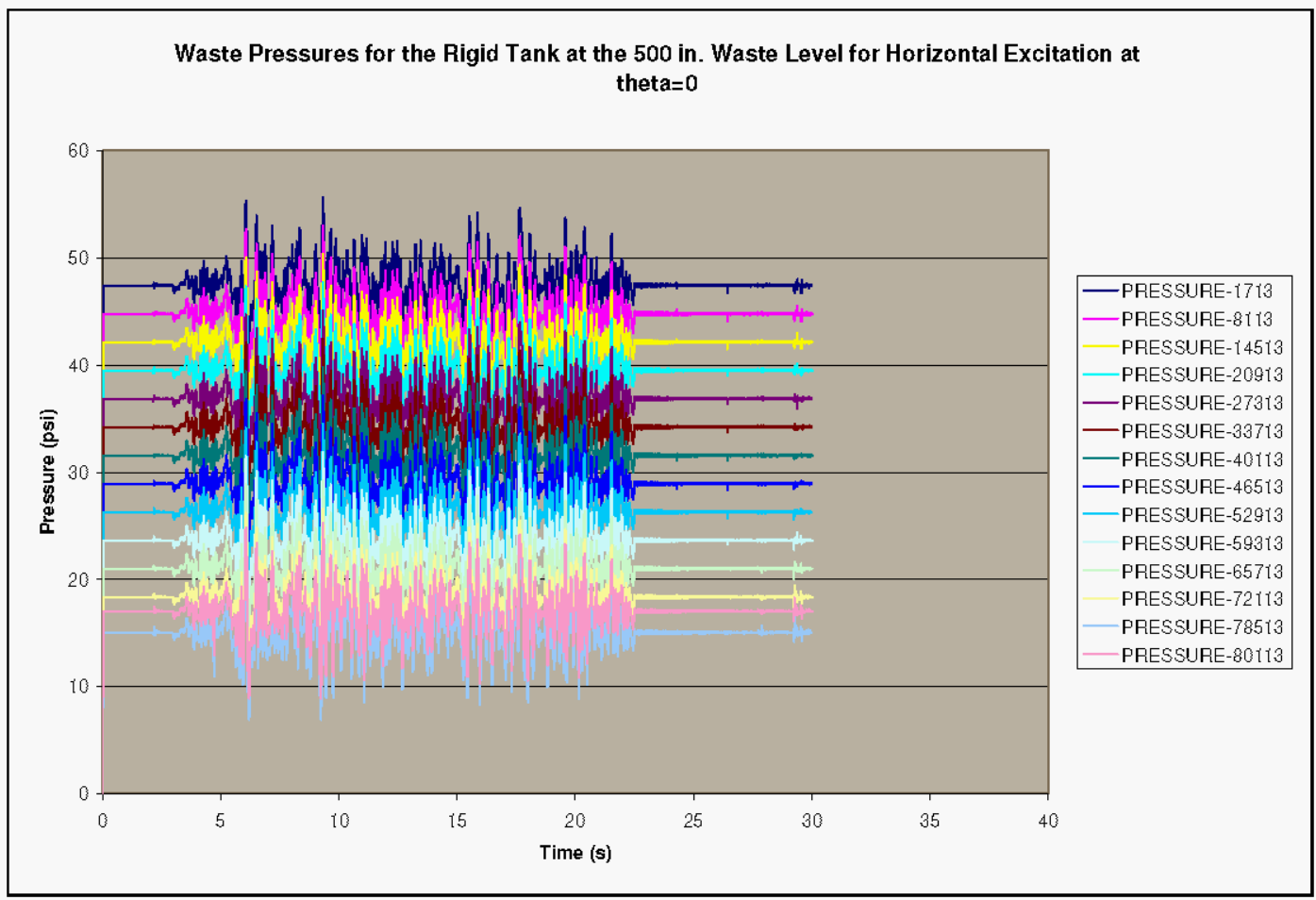

Figure 6-4. Selected Liquid Pressure Time Histories for the Rigid Tank With 500 in. of Liquid Under Horizontal Excitation at $\theta=0$.

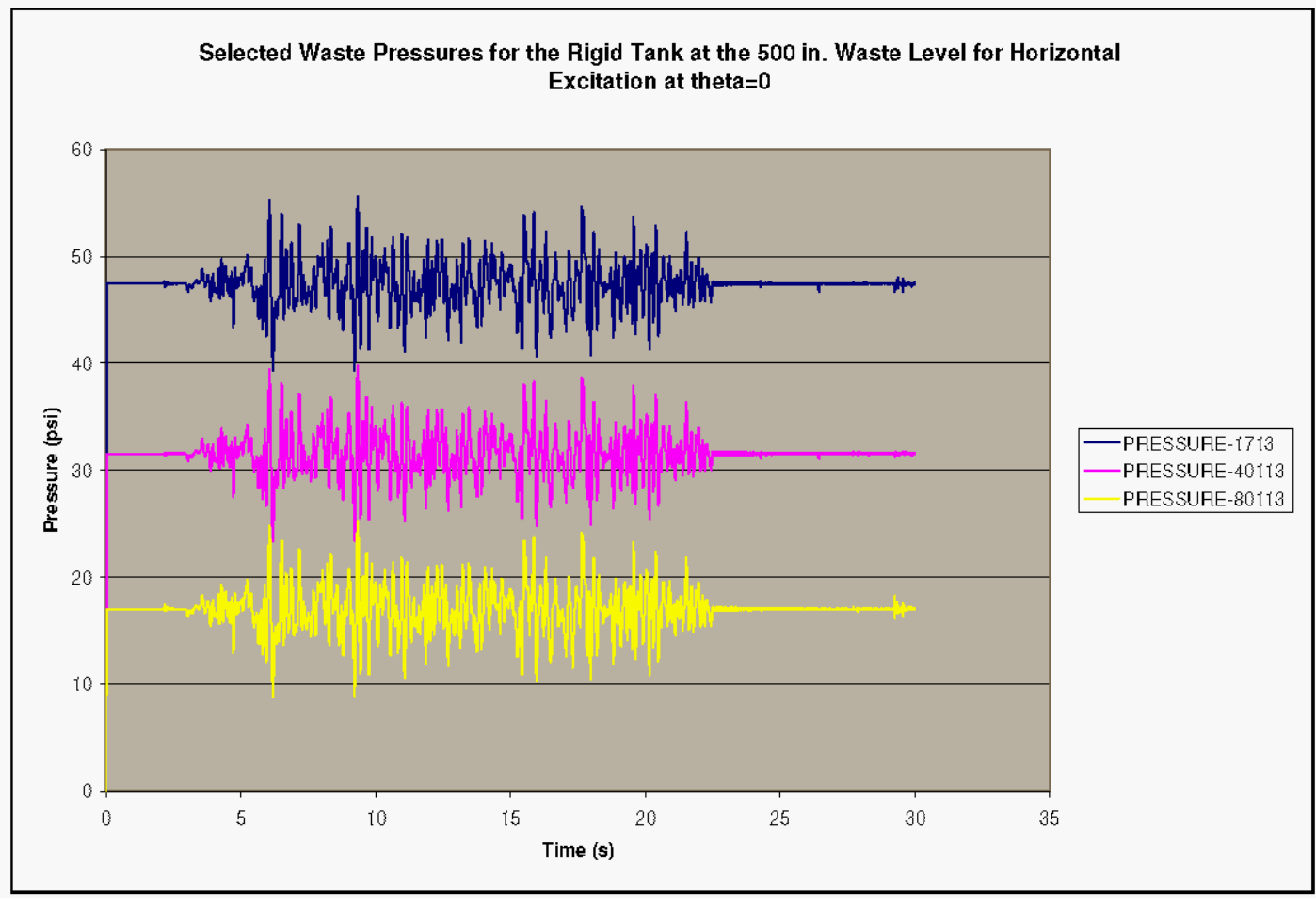


Figure 6-5. Liquid Pressure Time Histories for the Rigid Tank With 500 in. of Liquid Under Horizontal Excitation at $\boldsymbol{\theta}=\mathbf{4 5 ^ { \circ }}$.

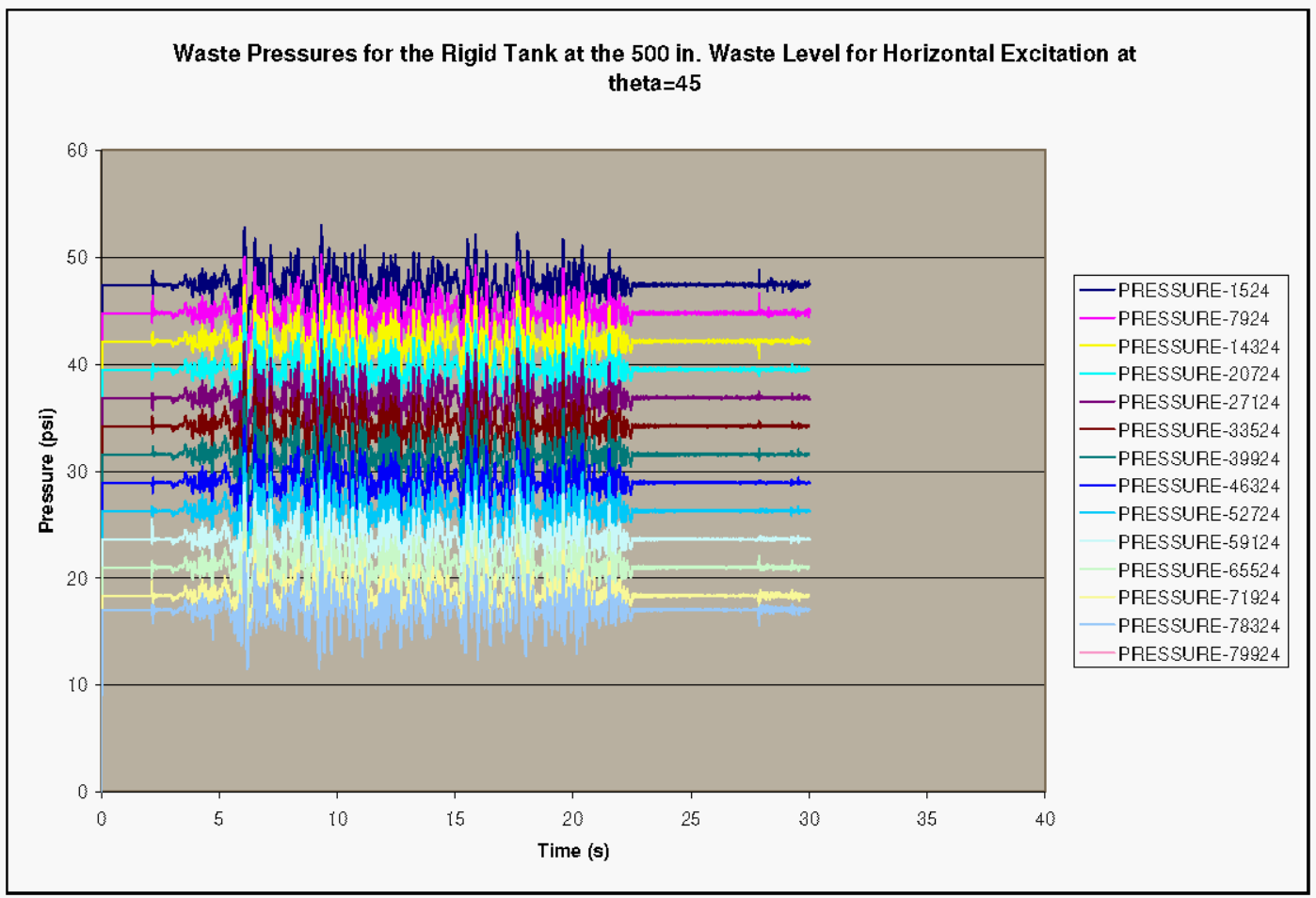

Figure 6-6. Liquid Pressure Time Histories for the Rigid Tank With 500 in. of Liquid Under Horizontal Excitation at $\boldsymbol{\theta}=90^{\circ}$.

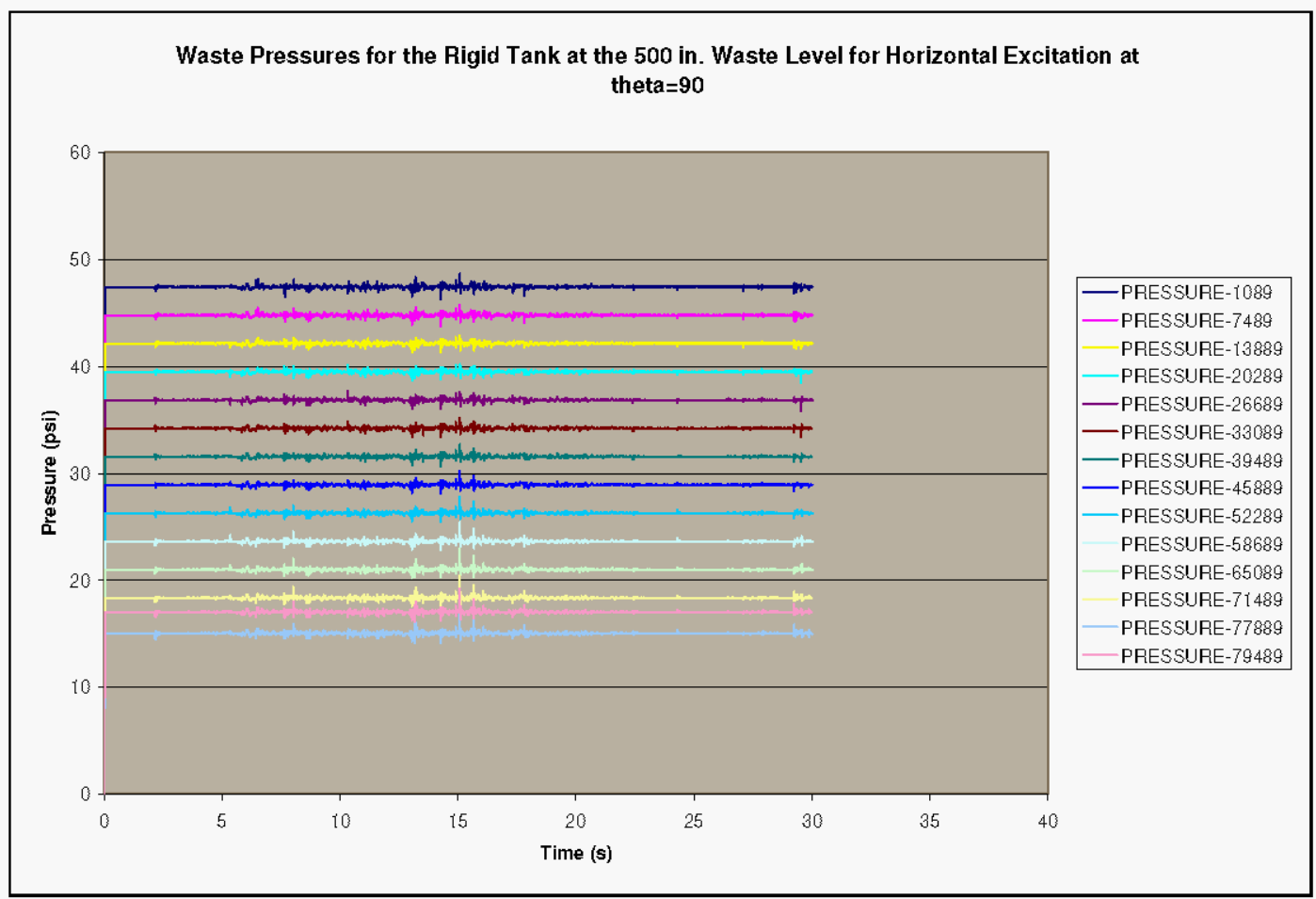


Figure 6-7. Comparison of Liquid Pressure Time Histories at Three Locations for the 500 in. Liquid Level (Completely Full Tank).

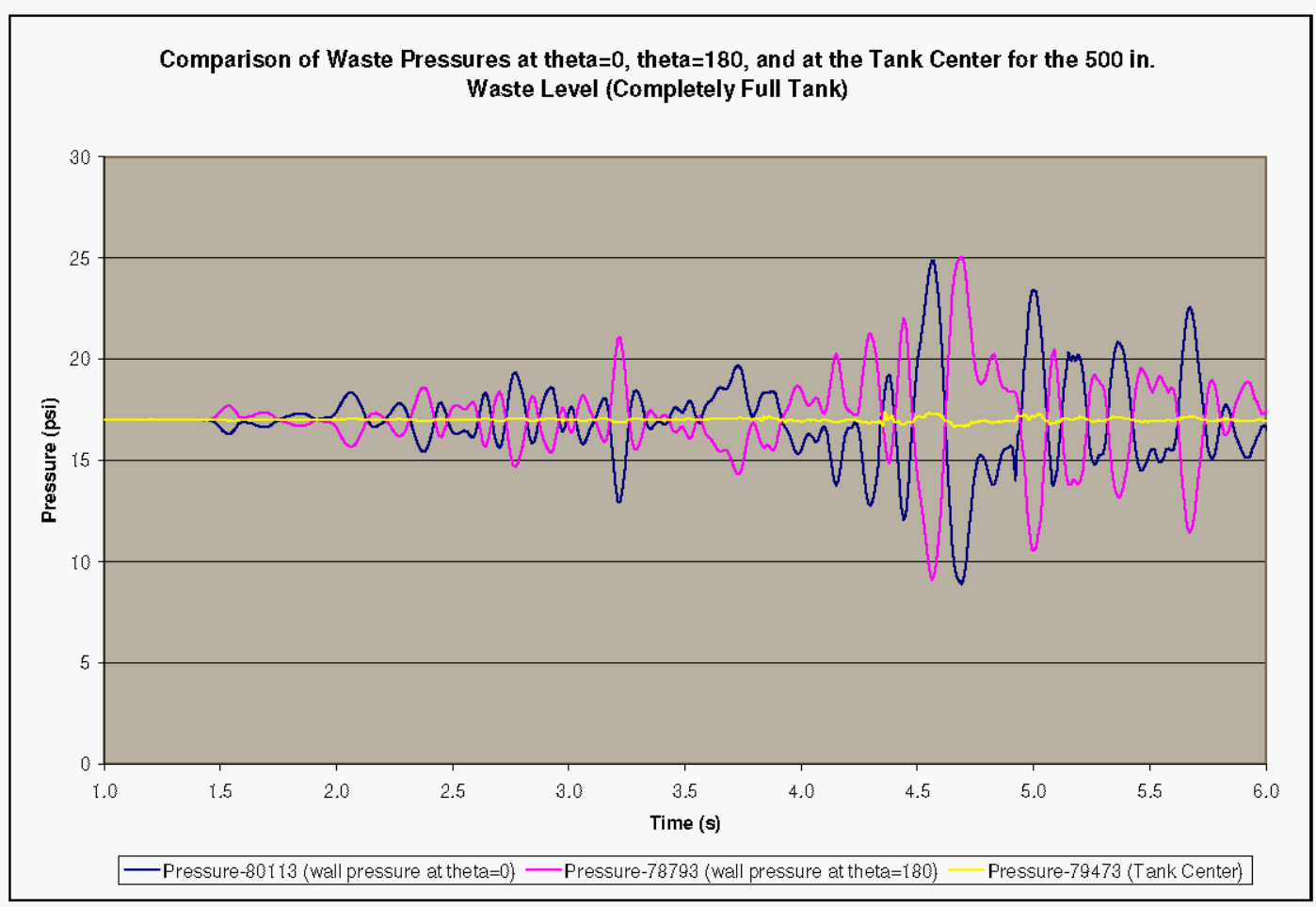

Figure 6-8. Maximum and Minimum Liquid Pressures vs. Normalized Height from Tank Bottom for Horizontal Excitation at $\theta=0$ and Liquid Height of $500 \mathrm{in}$.

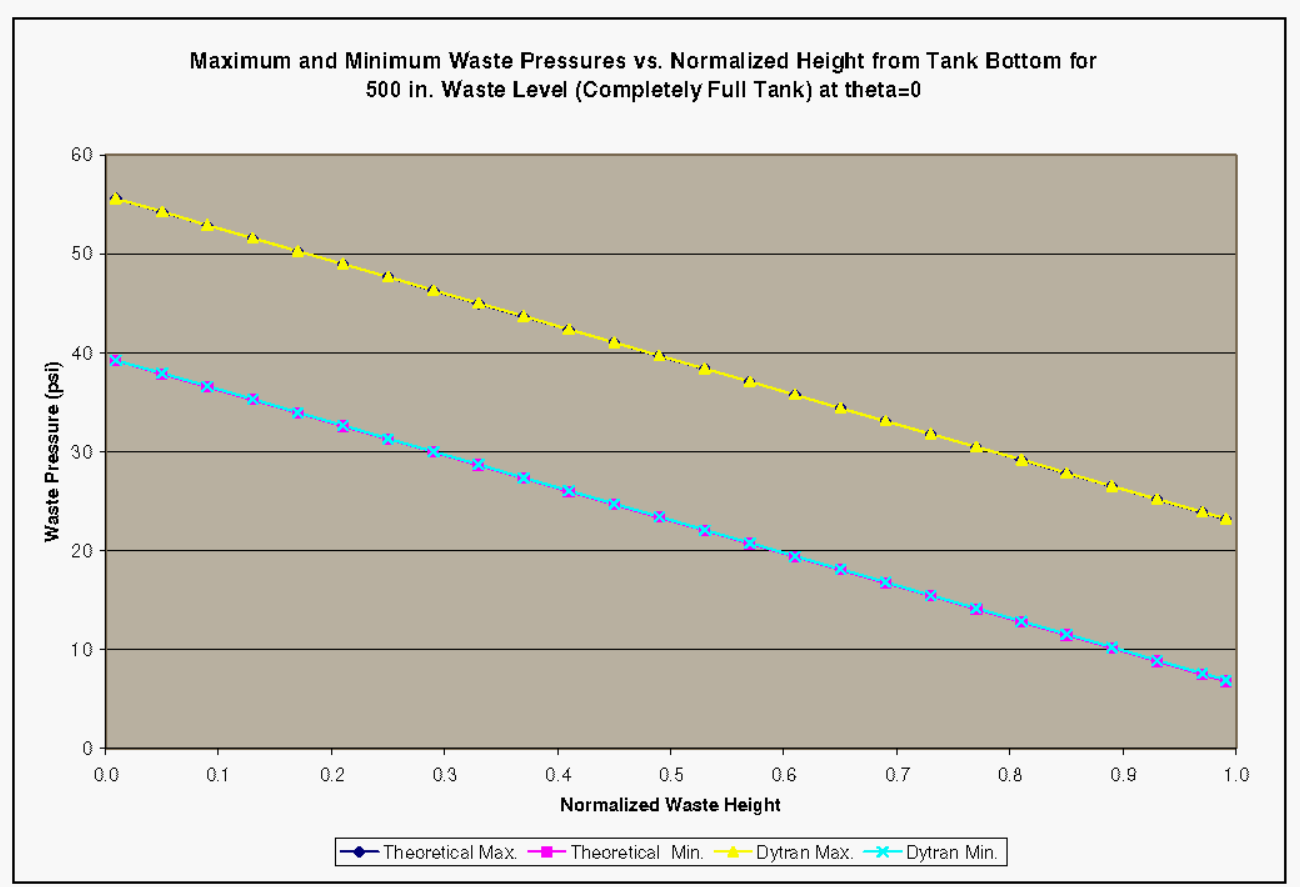


RPP-RPT-30807, Rev. 0

M\&D-2008-005-RPT-02, Rev. 0

\subsection{REFERENCES}

BNL 1995, Seismic Design and Evaluation Guidelines for the Department of Energy High-Level Liquid Storage Tanks and Appurtenances, Report No. 52361, October 1995, Engineering Research and Applications Division, Department of Advanced Technology, Brookhaven National Laboratory, Associated Universities, Inc., Upton, New York.

Malhotra, Praveen K., 2005, Sloshing Loads in Liquid-Storage Tanks with Insufficient Freeboard, Earthquake Spectra, Volume 21, No. 4, pp. 1185-1192, November 2005.

Rinker, M.W., and F.G. Abatt,, 2006, Dytran Benchmark Analysis of Seismically Induced Fluid-Structure Interaction in a Hanford Double Shell Primary Tank, RPP-RPT-28963, Rev. 0, and Rev. 1, prepared by M\&D Professional Services, Inc. for Pacific Northwest National Laboratory, Richland, Washington.

Rinker, M.W., et al. 2006, Hanford Double-Shell Tank Thermal and Seismic Project Summary of Combined Thermal and Operating Loads, RPP-RPT-28968, Rev. 1, Prepared by Pacific Northwest National Laboratory, Richland, Washington.

Rinker, M.W, B.G. Carpenter, and F.G. Abatt, 2006, ANSYS Benchmark Analysis of Seismically Induced Fluid-Structure Interaction in a Hanford Double Shell Primary Tank, RPP-RPT-28965, Rev. 0, Prepared by M\&D Professional Services, Inc. for Pacific Northwest National Laboratory, Richland, Washington. 


\section{APPENDIX A}

\section{Description of Input and Results Files}

2 pages including cover sheet 
RPP-RPT-30807, Rev. 0

M\&D-2008-005-RPT-02, Rev. 0

Table A-1. Description of Input and Results Files for Flat Top Tank Studies.

\begin{tabular}{|c|c|c|}
\hline $\begin{array}{c}\text { File } \\
\text { Extension }\end{array}$ & Typical File Name & Description \\
\hline. $\mathrm{db}$ & $\begin{array}{l}\text { Rigid_460.db } \\
\text { Rigid_480.db } \\
\text { Rigid_490.db } \\
\text { Rigid_500.db } \\
\text { Rigid_500_short.db } \\
\end{array}$ & $\begin{array}{l}\text { Patran database file used for model } \\
\text { creation. The Dytran input files are } \\
\text { created by translating this file to } \\
\text { Dytran input file format within Patran. }\end{array}$ \\
\hline .dat & $\begin{array}{l}\text { Rigid_460.dat } \\
\text { Rigid_480.dat } \\
\text { Rigid_490.dat } \\
\text { Rigid_500.dat } \\
\text { Rigid_500_short.dat }\end{array}$ & $\begin{array}{l}\text { Main Dytran input file. Required bulk } \\
\text { data files are called from this file The } \\
\text { rigid_500_short file is for the } 500 \text { in. } \\
\text { liquid level with the additional output } \\
\text { request for liquid pressures at } \theta=180^{\circ} \\
\text { run for } 10 \mathrm{~s} \text { simulation time. }\end{array}$ \\
\hline. $\mathrm{bdf}$ & $\begin{array}{c}\text { Rigid_460.bdf } \\
\text { Rigid_480.bdf } \\
\text { Rigid_490.bdf } \\
\text { Rigid_500.bdf } \\
\text { Rigid_500_short.bdf } \\
\end{array}$ & $\begin{array}{l}\text { Dytran bulk data file containing node } \\
\text { and element information. This file is } \\
\text { called by the main input file. }\end{array}$ \\
\hline .bdf & DomeTH.bdf & $\begin{array}{l}\text { Dytran bulk data file containing the } \\
\text { seismic time history. }\end{array}$ \\
\hline xls & $\begin{array}{l}\text { Results_460_rigid.xls } \\
\text { Results_480_rigid.xls } \\
1 \mathrm{~ms} \text { output_results } \\
\text { Results_490_rigid.xls } \\
\text { Results_500_rigid.xls }\end{array}$ & $\begin{array}{l}\text { Excel spreadsheet containing results } \\
\text { from a given run. The } \\
1 \mathrm{~ms} \text { output_results file is the results } \\
\text { from the } 480 \text { in. liquid level when } \\
\text { results were extracted at } 1 \mathrm{~ms} \text { intervals } \\
\text { instead of } 10 \mathrm{~ms} \text { intervals }\end{array}$ \\
\hline
\end{tabular}




\section{APPENDIX B}

\section{Theoretical and Approximate Benchmark Solutions \\ 65 pages including cover sheet}


Prepared by: F. G. Abatt

M\&D Professional Services

$8 / 3 / 06$

Rev. 0

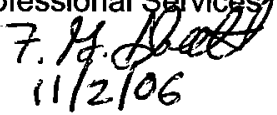

RPP-RPT-30807, Rev. 0

Theoretical Fluid Response

Calculations for Rigid Roofless Tank at 460 in. Waste Level
Checked by: K.R. Roberson

$14 / 3 / 06$

This worksheet contains calculations for a rigid open top tank with an initial liquid level of 460 in. The calculations are performed using the methodology in Chapter 4 of BNL (1995) and in Malthotra (2005). The location of the fluid elements corresponds to the Dytran model of the flat top tank.

$H_{1}:=460.0 \cdot$ in $\quad$ Baseline liquid level

$H_{t}:=500.0$.in Height to tank roof

$\frac{\mathrm{H}_{1}}{\mathrm{H}_{\mathrm{t}}}=9.2 \times 10^{-1} \quad$ Ratio of waste height to tank height

$\mathrm{g}:=386.4 \cdot \frac{\mathrm{in}}{\mathrm{sec}^{2}}$

R $:=450 \cdot$ in $\quad$ Tank radius

$\frac{\mathrm{H}_{1}}{\mathrm{R}}=1.02 \times 10^{0} \quad$ Ratio of waste height to tank radius

$\mathrm{i}:=0 . .2$

$\lambda:=\left(\begin{array}{l}1.841 \\ 5.331 \\ 8.536)\end{array} \quad\right.$ Bessel function roots

$\theta:=\left(\begin{array}{c}0 \cdot \operatorname{deg} \\ 45 \cdot \operatorname{deg} \\ 90 \cdot \operatorname{deg}\end{array}\right) \quad$ Circumferential location of waste elements for which pressures are reported

Convective Frequencies

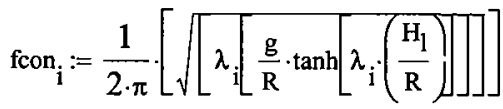

Eqn. 4.14 BNL (1995)

$\mathrm{fcon}=\left(\begin{array}{l}0.196) \\ 0.341 \mathrm{~Hz}\end{array} \quad\right.$ First three convective frequencies

B-2 of B-65 
Prepared by: F. G. Abatt M\&D Professional Services $8 / 3 / 06$

Rev. 0

IfA
RPP-RPT-30807, Rev. 0

Theoretical Fluid Response Calculations for Rigid Roofless Tank at 460 in. Waste Level
Checked by: K.R. Roberson

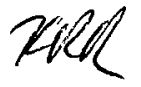

$\rho_{1}:=1.71 \cdot 10^{-4} \cdot \frac{\mathrm{lbf} \cdot \sec ^{2}}{\text { in }^{4}} \quad$ waste density - specific gravity $=1.83$

Determine Convective Pressures on the Tank Wall:

$z:=\left(\begin{array}{l}4.5 \cdot \text { in } \\ 25 \cdot \text { in } \\ 45 \cdot \text { in } \\ 65 \cdot \text { in } \\ 85 \cdot \text { in } \\ 105 \cdot \text { in } \\ 125 \cdot \text { in } \\ 145 \cdot \text { in } \\ 165 \cdot \text { in } \\ 185 \cdot \text { in } \\ 205 \cdot \text { in } \\ 225 \cdot \text { in } \\ 245 \cdot \text { in } \\ 265 \cdot \text { in } \\ 285 \cdot \text { in } \\ 305 \cdot \text { in } \\ 325 \cdot \text { in } \\ 345 \cdot \text { in } \\ 365 \cdot \text { in } \\ 385 \cdot \text { in } \\ 405 \cdot \text { in } \\ 425 \cdot \text { in }\end{array}\right)$

Vertical location of Euler element centroids at which pressures are reported in the Dytran model. 
Prepared by: F. G. Abatt M\&D Professional Services 8/3/06

Rev. 0

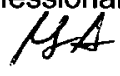

$\eta_{1}:=\frac{z}{H_{1}}$

\begin{tabular}{|r|r|}
\hline & \multicolumn{1}{|c|}{0} \\
\hline 0 & 0.01 \\
\hline 1 & 0.054 \\
\hline 2 & 0.098 \\
\hline 3 & 0.141 \\
\hline 4 & 0.185 \\
\hline 5 & 0.228 \\
\hline 6 & 0.272 \\
\hline 7 & 0.315 \\
\hline 8 & 0.359 \\
\hline 9 & 0.402 \\
\hline 10 & 0.446 \\
\hline 11 & 0.489 \\
\hline 12 & 0.533 \\
\hline 13 & 0.576 \\
\hline 14 & 0.62 \\
\hline 15 & 0.663 \\
\hline 16 & 0.707 \\
\hline 17 & 0.75 \\
\hline 18 & 0.793 \\
\hline 19 & 0.837 \\
\hline 20 & 0.88 \\
\hline 21 & 0.924 \\
\hline 22 & 0.967 \\
\hline & \\
\hline 17 &
\end{tabular}

RPP-RPT-30807, Rev. 0

Theoretical Fluid Response Calculations for Rigid Roofless Tank at 460 in. Waste Level

\section{Checked by: K.R. Roberson}

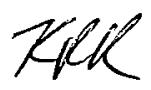

Ratio of tank wall vertical location to waste height for waste element centroids.

Determine convective coefficients as a function of dimensionless height per Eqn. 4.4 BNL (1995)

$$
\begin{aligned}
& \operatorname{con}_{0}\left(\eta_{1}\right):=\left[\frac{2}{\left(\lambda_{0}\right)^{2}-1} \cdot \frac{\cosh \left[\lambda_{0} \cdot\left(\frac{H_{1}}{R}\right) \cdot \eta_{1}\right]}{\cosh \left[\lambda_{0} \cdot\left(\frac{H_{1}}{R}\right)\right]}\right] \\
& \operatorname{con}_{1}\left(\eta_{1}\right):=\left[\frac{2}{\left(\lambda_{1}\right)^{2}-1} \cdot \frac{\cosh \left[\lambda_{1} \cdot\left(\frac{H_{1}}{R}\right)^{-\eta_{1}}\right]}{\cosh \left[\lambda_{1} \cdot\left(\frac{H_{1}}{R}\right)\right]}\right] \\
& \operatorname{con}_{2}\left(\eta_{1}\right):=\left[\frac{2}{\left(\lambda_{2}\right)^{2}-1} \cdot \frac{\cosh \left[\lambda_{2} \cdot\left(\frac{H_{1}}{R}\right)^{\eta_{1}}\right]}{\cosh \left[\lambda_{2}\left(\frac{H_{1}}{R}\right)\right]}\right]
\end{aligned}
$$


Prepared by: F. G. Abatt M\&D Professional Services $8 / 3 / 06$

Rev. 0
RPP-RPT-30807, Rev. 0

Theoretical Fluid Response

Calculations for Rigid Roofless Tank at $460 \mathrm{in}$. Waste Level
Checked by: K.R. Roberson

KRk

\begin{tabular}{|c|r|}
\hline & 0 \\
\hline 0 & 0.001 \\
\hline 1 & 0.001 \\
\hline 2 & 0.001 \\
\hline 3 & 0.001 \\
\hline 4 & 0.001 \\
\hline 5 & 0.001 \\
\hline 6 & 0.001 \\
\hline 7 & 0.002 \\
\hline 8 & 0.002 \\
\hline 9 & 0.003 \\
\hline 10 & 0.004 \\
\hline 11 & 0.005 \\
\hline 12 & 0.006 \\
\hline 13 & 0.007 \\
\hline 14 & 0.009 \\
\hline 15 & 0.012 \\
\hline 16 & 0.015 \\
\hline 17 & 0.019 \\
\hline 18 & 0.024 \\
\hline 19 & 0.03 \\
\hline 20 & 0.038 \\
\hline 21 & 0.048 \\
\hline 22 & 0.061 \\
\hline
\end{tabular}


Prepared by: F. G. Abatt M\&D Professional Services 8/3/06

Rev. 0
RPP-RPT-30807, Rev. 0

Theoretical Fluid Response Calculations for Rigid Roofless Tank at 460 in. Waste Level
Checked by: K.R. Roberson

krk

Impulsive pressure coefficient as a function of dimensionless wall height

$c_{i}\left(\eta_{1}\right):=1-\operatorname{con}_{0}\left(\eta_{1}\right)-\operatorname{con}_{1}\left(\eta_{1}\right)-\operatorname{con}_{2}\left(\eta_{1}\right)$

Eqn. 4.7 BNL (1995)

$c_{i}\left(n_{1}\right)=$\begin{tabular}{|c|c|}
\hline & 0 \\
\hline 0 & $7.5 \cdot 10^{-1}$ \\
\hline 1 & $7.49 \cdot 10^{-1}$ \\
\hline 2 & $7.46 \cdot 10^{-1}$ \\
\hline 3 & $7.41 \cdot 10^{-1}$ \\
\hline 4 & $7.35 \cdot 10^{-1}$ \\
\hline 5 & $7.26 \cdot 10^{-1}$ \\
\hline 6 & $7.16 \cdot 10^{-1}$ \\
\hline 7 & $7.04 \cdot 10^{-1}$ \\
\hline 11 & $6.89 \cdot 10^{-1}$ \\
\hline 8 & $6.73 \cdot 10^{-1}$ \\
\hline 12 & $6.33 \cdot 10^{-1}$ \\
\hline 13 & $6.09 \cdot 10^{-1}$ \\
\hline 14 & $5.82 \cdot 10^{-1}$ \\
\hline 15 & $5.51 \cdot 10^{-1}$ \\
\hline 16 & $5.17 \cdot 10^{-1}$ \\
\hline 17 & $4.79 \cdot 10^{-1}$ \\
\hline 18 & $4.37 \cdot 10^{-1}$ \\
\hline 19 & $3.89 \cdot 10^{-1}$ \\
\hline 20 & $3.36 \cdot 10^{-1}$ \\
\hline 21 & $2.75 \cdot 10^{-1}$ \\
\hline 22 & $2.07 \cdot 10^{-1}$ \\
\hline & $1.28 \cdot 10^{-1}$ \\
\hline
\end{tabular}

Calculate maximum values of dynamic wall pressures from spectral acceleration of dome input $\mathrm{TH}$.

Consider the first three convective mode spectral accelerations for the $0.1 \%$ damped spectrum

$$
\begin{array}{ll}
\mathrm{SA}_{\mathrm{c} 0}:=0.066 . \mathrm{g} & \mathrm{SA}_{\mathrm{c} 0}=2.55 \times 10^{1} \frac{\mathrm{in}}{\mathrm{sec}^{2}} \\
\mathrm{SA}_{\mathrm{c} 1}:=0.11 \cdot \mathrm{g} & \mathrm{SA}_{\mathrm{c} 1}=4.25 \times 10^{1} \frac{\mathrm{in}}{\mathrm{sec}^{2}} \text { ANSYS dome RS from Spectr } \\
\mathrm{SA}_{\mathrm{c} 2}:=0.17 \cdot \mathrm{g} & \mathrm{SA}_{\mathrm{c} 2}=6.57 \times 10^{1 \frac{\mathrm{in}}{\mathrm{sec}^{2}}}
\end{array}
$$


Prepared by: F. G. Abatt M\&D Professignal Services $8 / 3 / 06$

Rev. 0
RPP-RPT-30807, Rev. 0

Theoretical Fluid Response

Calculations for Rigid Roofless Tank at 460 in. Waste Level
Checked by: K.R. Roberson

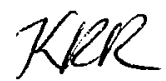

Associate the impulsive mode with the peak ground acceleration (PGA), since the tank is rigid.

$$
\begin{aligned}
& \text { PGA := 0.276.g } \quad \text { PGA }=1.07 \times 10^{2} \frac{\text { in }}{2} \quad \text { ANSYS dome RS from Spectr } \\
& \mathrm{p}_{\text {maxconv }}\left(\eta_{1}, \theta\right):=\left[\sqrt{\left(\operatorname{son}_{0}\left(\eta_{1}\right) \cdot \mathrm{SA}_{\mathrm{c} 0}\right)^{2}+\left(\operatorname{con}_{1}\left(\eta_{1}\right) \cdot \mathrm{SA}_{\mathrm{c} 1}\right)^{2}+\left(\operatorname{con}_{2}\left(\eta_{1}\right) \cdot \mathrm{SA}_{\mathrm{c} 2}\right)^{2}}\right] \cdot\left(\rho_{\mathrm{l}} \cdot \mathrm{R} \cdot \cos (\theta \cdot \mathrm{deg})\right) \\
& \mathrm{p}_{\text {maximpulsive }}\left(\eta_{1}, \theta\right):=\left[\sqrt{\left[\mathrm{c}_{\mathrm{i}}\left(\eta_{1}\right) \cdot(\mathrm{PGA})\right]^{2}}\right] \cdot\left(\rho_{1} \cdot \mathrm{R} \cdot \cos (\theta \cdot \mathrm{deg})\right) \\
& \mathrm{p}_{\max }\left(\eta_{1}, \theta\right):=\left[\sqrt{\left[\left(\mathrm{c}_{\mathrm{i}}\left(\eta_{1}\right)\right) \cdot(\mathrm{PGA})\right]^{2}+\left(\operatorname{con}_{0}\left(\eta_{1}\right) \cdot \mathrm{SA}_{\mathrm{c} 0}\right)^{2}+\left(\operatorname{con}_{1}\left(\eta_{1}\right) \cdot \mathrm{SA}_{\mathrm{cl}}\right)^{2}+\left(\operatorname{con}_{2}\left(\eta_{1}\right) \cdot \mathrm{SA}_{\mathrm{c} 2}\right)^{2}}\right] \cdot\left(\rho_{1} \cdot \mathrm{R} \cdot \cos (\theta \cdot \mathrm{deg})\right)
\end{aligned}
$$

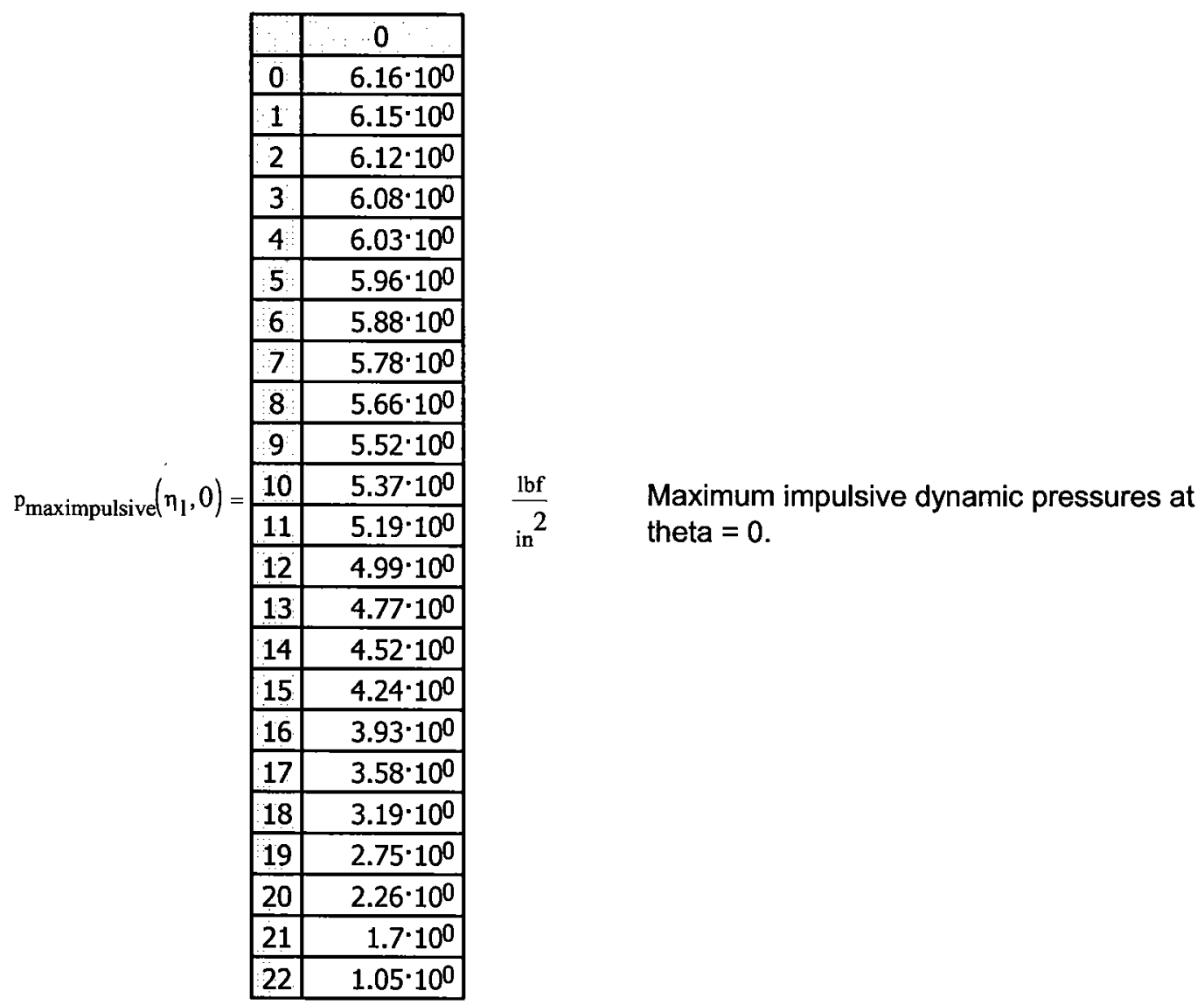


Prepared by: F. G. Abatt M\&D Professional Services $8 / 3 / 06$

Rev. 0

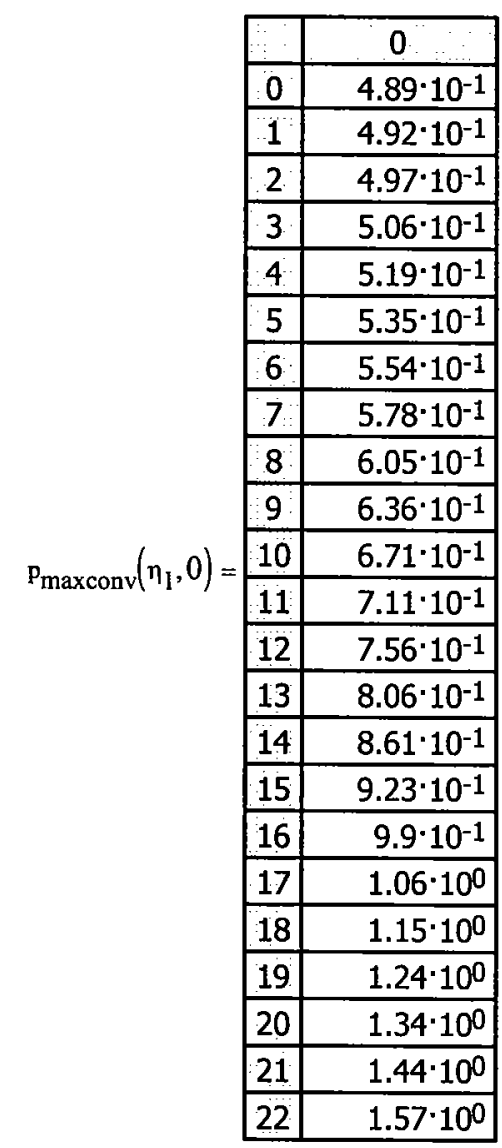

RPP-RPT-30807, Rev. 0 Theoretical Fluid Response Calculations for Rigid Roofless Tank at 460 in. Waste Level

Checked by: K.R. Roberson<smiles>Cc1ccccc1C(C)C1CCCCC1</smiles>

$$
\begin{aligned}
& \frac{\text { lbf }}{2} \quad \text { Maximum convective dynamic } \\
& \text { pressures at theta }=0 \text {. } \\
& \begin{array}{|c|c|}
\hline & 0 \\
\hline 0 & 6.18 \cdot 10^{\circ} \\
\hline 1 & 6.16 \cdot 10^{0} \\
\hline
\end{array} \\
& \begin{array}{|l|l|}
\hline 1 & 6.16 \cdot 10^{0} \\
\hline 2
\end{array} \\
& \begin{array}{|l|l|}
\hline 2 & 6.14 \cdot 10^{0} \\
\hline 3 & 6.1 \cdot 10^{\circ}
\end{array} \\
& 3 \text { 6.1.100 } \\
& \begin{array}{l|l}
\hline 4 & 6.05 \cdot 10^{0} \\
\hline 5
\end{array} \\
& \begin{array}{|r|r|}
\hline 5 & 5.98 \cdot 10^{0} \\
\hline 6 & 5.9 \cdot 10^{0}
\end{array} \\
& \begin{array}{|l|r|}
\hline 6 & 5.9 \cdot 10^{0} \\
\hline
\end{array} \\
& \begin{array}{l|l|}
\hline 7 & 5.8 \cdot 10^{0} \\
\hline
\end{array} \\
& \begin{array}{|r|r|}
\hline 8 & 5.69 \cdot 10^{0} \\
\hline
\end{array} \\
& \begin{array}{|l|l|}
\hline 9 & 5.56 \cdot 10^{\circ} \\
\hline
\end{array}
\end{aligned}
$$

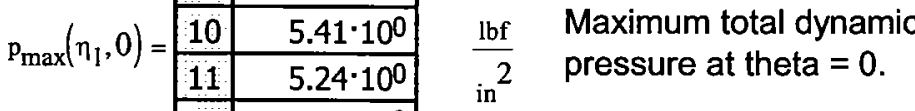

$$
\begin{aligned}
& \begin{array}{|l|l|}
\hline 12 & 5.05 \cdot 10^{0} \\
\hline 13 & 4.84 \cdot 10^{\circ} \\
\hline
\end{array} \\
& \text { 13. } 4.84 \cdot 10^{0} \\
& \begin{array}{|r|r|}
\hline 14 & 4.6 \cdot 10^{\circ} \\
\hline
\end{array} \\
& \begin{array}{|l|l|}
\hline 15 & 4.34 \cdot 10^{\circ} \\
\hline
\end{array} \\
& \begin{array}{|l|l|}
\hline 16 & 4.06 \cdot 10^{\circ} \\
\hline
\end{array} \\
& \begin{array}{|l|l|}
\hline 17 & 3.74 \cdot 10^{\circ} \\
\hline
\end{array} \\
& \begin{array}{l|l|}
\hline 18 & 3.39 \cdot 10^{\circ} \\
\hline
\end{array} \\
& 1903.02 \cdot 10^{\circ} \\
& 20 \quad 2.62 \cdot 10^{0} \\
& \begin{array}{l|l|}
\hline 21 & 2.23 \cdot 10^{0} \\
\hline
\end{array} \\
& \begin{array}{|r|r|}
\hline 22 & 1.89 \cdot 10^{0} \\
\hline
\end{array}
\end{aligned}
$$


Prepared by: F. G. Abatt M\&D Professignal Services 8/3/06

Rev. 0
RPP-RPT-30807, Rev. 0

Theoretical Fluid Response Calculations for Rigid Roofless Tank at 460 in. Waste Level
Checked by: K.R. Roberson

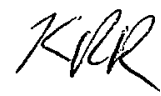

Maximum total dynamic pressure at theta $=45$ degrees.

\section{Calculate Maximum Slosh Height per BNL (1995):}

conmax $:=\left(\begin{array}{l}0.837 \\ 0.073 \\ 0.028\end{array}\right) \quad$ Maximum value of convective coefficients at $\eta_{1}=1$

$$
\begin{aligned}
& \mathrm{h}_{\text {maxslosh }}:=\mathrm{R} \cdot \sqrt{\left(\operatorname{conmax} \cdot \frac{\mathrm{SA}_{\mathrm{c} 0}}{\mathrm{~g}}\right)^{2}+\left(\operatorname{conmax} \frac{\mathrm{SA}_{\mathrm{cl}}}{\mathrm{g}}\right)^{2}+\left(\operatorname{conmax}_{2} \cdot \frac{\mathrm{SA}_{\mathrm{c} 2}}{\mathrm{~g}}\right)^{2}} \text { Eqn. 4.60 BNL (1995) } \\
& \mathrm{h}_{\text {maxslosh }}=2.52 \times 10^{1} \text { in } \quad \text { Maximum theoretical slosh height }
\end{aligned}
$$


Prepared by: F. G. Abatt M\&D Profesgignal Services 8/3/06

Rev. 0
RPP-RPT-30807, Rev. 0

Theoretical Fluid Response Calculations for Rigid Roofless Tank at 460 in. Waste Level
Checked by: K.R. Roberson

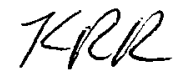

Recalculate Maximum Slosh Height per Malhotra (2005):

$$
j:=0 . .1
$$$$
\mathrm{H}_{\mathrm{r}}:=\left(\begin{array}{l}
1.0 \\
1.5
\end{array}\right)
$$$$
\mathrm{C}_{\text {cref }}:=\left(\begin{array}{l}
1.52) \\
1.48
\end{array}\right)
$$

Table 1 of Malhotra (2005)

$\mathrm{C}_{\mathrm{c}}:=\operatorname{linterp}\left(\mathrm{H}_{\mathrm{r}}, \mathrm{C}_{\mathrm{cref}}, \frac{\mathrm{H}_{\mathrm{l}}}{\mathrm{R}}\right) \frac{\mathrm{sec}}{\sqrt{\mathrm{m}}} \quad \mathrm{C}_{\mathrm{c}}=1.52 \times 10^{0} \frac{\mathrm{sec}}{\mathrm{m}^{0.5}}$

$\mathrm{T}_{\text {con }}:=\mathrm{C}_{\mathrm{c}} \cdot \sqrt{\mathrm{R}} \quad \mathrm{T}_{\text {con }}=5.13 \times 10^{0} \mathrm{sec}$

$\mathrm{f}_{\mathrm{cMalhotra}}:=\frac{1}{\mathrm{~T}_{\text {con }}} \quad \mathrm{f}_{\text {cMalhotra }}=0.195 \mathrm{~Hz} \quad \begin{aligned} & \text { Fundamental convective frequency per } \\ & \text { Malhotra }(2005)\end{aligned}$

Since this agrees with the frequency calculated via BNL (1995), the convective acceleration is the same in both cases.

$\mathrm{h}_{\mathrm{sMahhotra}}:=\mathrm{R} \cdot \frac{\mathrm{SA} \mathrm{c} 0}{\mathrm{~g}} \quad$ Eqn. (9) of Malhotra (2005)

$\mathrm{h}_{\mathrm{sMalhotra}}=2.97 \times 10^{1}$ in $\quad$ Maximum slosh height for roofless tank per Malhotra (2005)

\section{Calculate Maximum Total Hydrodynamic Force:}

The maximum hydrodynamic force induced on the tank wall is given by Eqn. 4.31 of BNL 1995 with the instantaneous accelerations replaced by the maximum spectral accelerations. First determine the effective impulsive and convective masses.

$\mathrm{m}_{\text {lapprox }}:=\pi \cdot \mathrm{R}^{2} \cdot \mathrm{H}_{\mathrm{l}} \cdot \rho_{1} \quad \mathrm{~m}_{\text {lapprox }}=5 \times 10^{4} \frac{\mathrm{lbf} \cdot \mathrm{sec}^{2}}{\mathrm{in}} \quad \begin{aligned} & \text { Total waste mass based on circular cylinder } \\ & \text { approximation. }\end{aligned}$

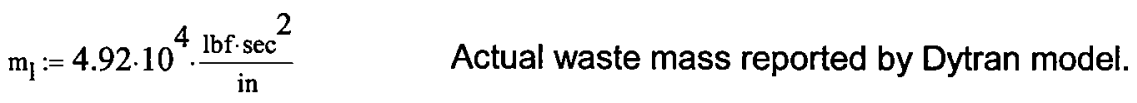

$\mathrm{m}_{\mathrm{c} 0}:=\left[\frac{2}{\lambda_{0} \cdot\left[\left(\lambda_{0}\right)^{2}-1\right] \cdot\left(\frac{\mathrm{H}_{1}}{\mathrm{R}}\right)}\right] \cdot \tanh \left[\lambda_{0} \cdot\left(\frac{\mathrm{H}_{1}}{\mathrm{R}}\right)\right] \cdot \mathrm{m}_{1} \quad$ Eqn. 4.32 BNL (1995)

$\mathrm{m}_{\mathrm{c} 0}=2.09 \times 10^{4} \frac{\mathrm{lbf} \cdot \mathrm{sec}^{2}}{\mathrm{in}} \quad$ First mode convective mass 
$\mathrm{m}_{\mathrm{cl}}:=\left[\frac{2}{\lambda_{1} \cdot\left[\left(\lambda_{1}\right)^{2}-1\right] \cdot\left(\frac{\mathrm{H}_{1}}{\mathrm{R}}\right)}\right] \cdot \tanh \left[\lambda_{1} \cdot\left(\frac{\mathrm{H}_{1}}{\mathrm{R}}\right)\right] \cdot \mathrm{m}_{\mathrm{l}} \quad$ Second mode convective mass

$\mathrm{m}_{\mathrm{c} 1}=6.59 \times 10^{2} \frac{\mathrm{lbf} \cdot \mathrm{sec}^{2}}{\text { in }}$

$\mathrm{m}_{\mathrm{c} 2}:=\left[\frac{2}{\lambda_{2} \cdot\left[\left(\lambda_{2}\right)^{2}-1\right] \cdot\left(\frac{\mathrm{H}_{1}}{\mathrm{R}}\right)}\right] \cdot \tanh \left[\lambda_{2} \cdot\left(\frac{\mathrm{H}_{1}}{\mathrm{R}}\right)\right] \cdot \mathrm{m}_{1} \quad$ Third mode convective mass

$\mathrm{m}_{\mathrm{c} 2}=1.57 \times 10^{2} \frac{\mathrm{lbf} \cdot \mathrm{sec}^{2}}{\text { in }}$

$\mathrm{m}_{\mathrm{i}}:=\mathrm{m}_{1}-\left(\mathrm{m}_{\mathrm{c} 0}+\mathrm{m}_{\mathrm{c} 1}+\mathrm{m}_{\mathrm{c} 2}\right)$

Impulsive mass - Eqn. 4.33 BNL (1995)

$\mathrm{m}_{\mathrm{i}}=2.75 \times 10^{4} \frac{\mathrm{lbf} \cdot \mathrm{sec}^{2}}{\text { in }}$

$F_{\max }:=m_{\mathrm{i}} \cdot \mathrm{PGA}+\mathrm{m}_{\mathrm{c} 0} \cdot \mathrm{SA}_{\mathrm{c} 0}+\mathrm{m}_{\mathrm{c} 1} \cdot \mathrm{SA} \mathrm{c1}+\mathrm{m}_{\mathrm{c} 2} \cdot \mathrm{SA}_{\mathrm{c} 2}$

$F_{\max }=3.5 \times 10^{6} \mathrm{lbf} \quad$ Conservative estimate of maximum hydrodynamic force

The above expression is a conservative estimate because it assumes that the peak impulsive and convective forces occur simultaneously. A less conservative estimate can be made via a square-root-sum-of-the-squares (SRSS) combination.

$$
\begin{aligned}
& F_{\text {srss }}:=\sqrt{\left(m_{i} \cdot P G A\right)^{2}+\left(m_{c 0} \cdot S A_{c 0}\right)^{2}+\left(m_{c 1} \cdot S A_{c 1}\right)^{2}+\left(m_{c 2} \cdot S A_{c 2}\right)^{2}} \\
& F_{\text {srss }}=2.98 \times 10^{6} \mathrm{lbf} \quad \text { SRSS estimate of peak hydrodynamic force } \\
& F_{\text {conmax }}:=\sqrt{\left(\mathrm{m}_{\mathrm{c} 0} \cdot \mathrm{SA}_{\mathrm{c} 0}\right)^{2}+\left(\mathrm{m}_{\mathrm{c} 1} \cdot \mathrm{SA} \mathrm{c1}\right)^{2}+\left(\mathrm{m}_{\mathrm{c} 2} \cdot \mathrm{SA}_{\mathrm{c} 2}\right)^{2}} \\
& F_{\text {conmax }}=5.34 \times 10^{5} \mathrm{lbf} \quad \begin{array}{l}
\text { Peak hydrodynamic force due to convective response }- \text { shows up in free } \\
\text { oscillations. }
\end{array}
\end{aligned}
$$


Prepared by: F. G. Abatt M\&D Professional Services $8 / 3 / 06$

Rev. 0
RPP-RPT-30807, Rev. 0

Theoretical Fluid Response

Calculations for Rigid Roofless Tank at 460 in. Waste Level
Checked by: K.R. Roberson

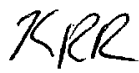

Recalculate Maximum Hydrodynamic Force Using Methodolodgy of Malhotra (2005):

The hydrodynamic force can be calculated by excluding the structural masses from Eqn. (3) of Malhotra (2005). First calculate the impulsive and convective masses.

$\mathrm{i}=0.1$

$\mathrm{HR}:=\left(\begin{array}{l}1.0 \\ 1.5\end{array}\right)$

ImpMassRatio $:=\left(\begin{array}{l}0.548 \\ 0.686\end{array}\right)$

Table 1 of Malhotra (2005)

$\operatorname{linterp}\left(\mathrm{HR}\right.$, ImpMassRatio, $\left.\frac{\mathrm{H}_{1}}{\mathrm{R}}\right)=5.54 \times 10^{-1}$

$\mathrm{m}_{\text {iMalhotra }}:=$ linterp $\left(\mathrm{HR}\right.$, ImpMassRatio, $\left.\frac{\mathrm{H}_{1}}{\mathrm{R}}\right) \mathrm{m}_{1}$

$\mathrm{m}_{\mathrm{iMalhotra}}=2.73 \times 10^{4} \frac{\mathrm{lbf} \cdot \mathrm{sec}^{2}}{\text { in }}$

$\mathrm{m}_{\mathrm{cMalhotra}}:=\mathrm{m}_{1}-\mathrm{m}_{\mathrm{i} \text { Malhotra }}$

$$
\mathrm{m}_{\mathrm{cMalhotra}}=2.19 \times 10^{4} \frac{\mathrm{lbf} \cdot \mathrm{sec}^{2}}{\text { in }}
$$

$\mathrm{R}_{\mathrm{i}}:=\mathrm{m}_{\mathrm{iMalhotra}} \cdot \mathrm{PGA}$

$R_{i}=2.91 \times 10^{6}{ }_{1 b f}$

Impulsive reaction - Eqn. (3) Malhotra (2005)

$\mathrm{R}_{\mathrm{c}}:=\mathrm{m}_{\mathrm{c} \text { Malhotra }} \cdot \mathrm{SA}_{\mathrm{c} 0} \quad \mathrm{R}_{\mathrm{c}}=5.59 \times 10^{5} \mathrm{lbf}$

Convective reaction - Eqn. (4) Malhotra (2005)

$\mathrm{R}_{\text {total }}:=\mathrm{R}_{\mathrm{i}}+\mathrm{R}_{\mathrm{c}}$

$\mathrm{R}_{\text {total }}=3.47 \times 10^{6} \mathrm{lbf}$

\section{References:}

BNL 1995, Seismic Design and Evaluation Guidelines for the Department of Energy High-Level Waste Storage Tanks and Appurtenances, BNL 52361, Rev. 10/95, Brookhaven National Laboratory, Upton, New York.

Malhotra, Praveen K, 2005, Sloshing Loads in Liquid Storage Tanks With Insufficient Freeboard, Earthquake Spectra, Volume 21, No. 4, pp. 1185-1192, November 2005. 
Prepared by: F. G. Abatt M\&D Professignal Services $7 / 11 / 06$

Rev. 0
RPP-RPT-30807, Rev. 0

Theoretical Fluid Response Calculations for Rigid Roofless Tank at 480 in. Waste Level
Checked by: K.R. Roberson

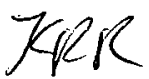

This worksheet contains calculations for a rigid open top tank with an initial liquid level of 480 in. The calculations are performed using the methodology in Chapter 4 on BNL (1995). The location of the fluid elements corresponds to the Dytran model of the flat top tank.

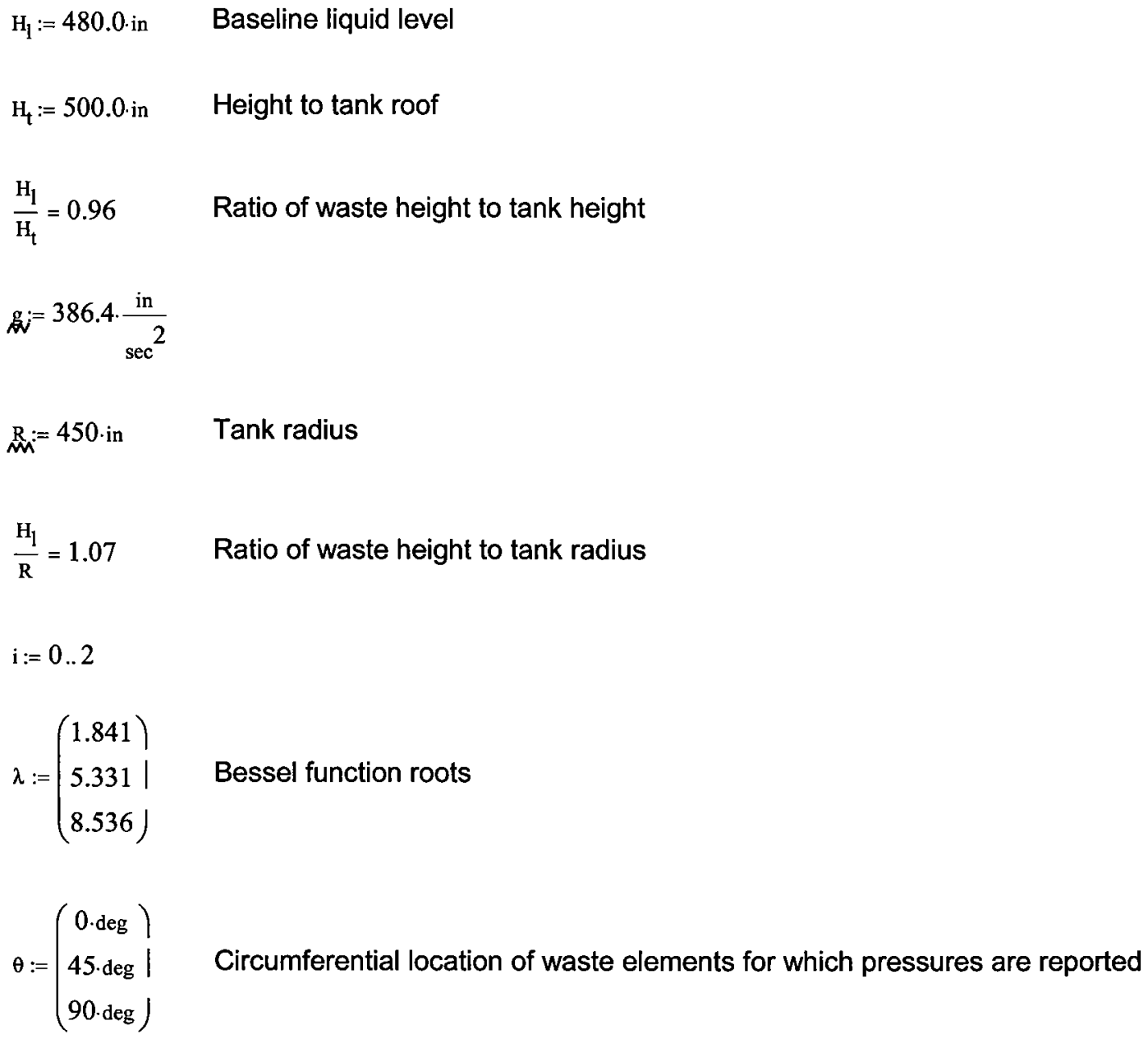

Convective Frequencies

$$
\begin{aligned}
& \text { fcon }_{i}:=\frac{1}{2 \cdot \pi} \cdot\left[\int\left[\lambda_{i}\left[\frac{g}{R} \cdot \tanh \left[\lambda_{i} \cdot\left(\frac{H_{1}}{R}\right)\right]\right]\right]\right] \quad \text { Eqn. } 4.14 \text { of BNL (1995) } \\
& f c o n=\left(\begin{array}{l}
0.196) \\
0.341 \mid \mathrm{Hz} \\
0.431)
\end{array}\right. \\
& \rho_{1}:=1.71 \cdot 10^{-4} \cdot \frac{\mathrm{lbf} \cdot \mathrm{sec}^{2}}{\text { in }^{4}} \quad \text { Waste density }- \text { specific gravity }=1.83
\end{aligned}
$$


Prepared by: F. G. Abatt M\&D Professional Services 7/11/06

Rev. 0
RPP-RPT-30807, Rev. 0

Theoretical Fluid Response Calculations for Rigid Roofless Tank at 480 in. Waste Level
Checked by: K.R. Roberson

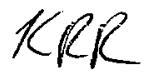

Determine Convective Pressures on the Tank Wall:

$\mathrm{z}=\left(\begin{array}{l}4.5 \cdot \text { in } \\ 25 \cdot \text { in } \\ 45 \cdot \text { in } \\ 65 \cdot \text { in } \\ 85 \cdot \text { in } \\ 105 \cdot \text { in } \\ 125 \cdot \text { in } \\ 145 \cdot \text { in } \\ 165 \cdot \text { in } \\ 185 \cdot \text { in } \\ 205 \cdot \text { in } \\ 225 \cdot \text { in } \\ 245 \cdot \text { in } \\ 265 \cdot \text { in } \\ 285 \cdot \text { in } \\ 305 \cdot \text { in } \\ 325 \cdot \text { in } \\ 345 \cdot \text { in } \\ 365 \cdot \text { in } \\ 385 \cdot \text { in } \\ 405 \cdot \text { in } \\ 425 \cdot \text { in } \\ 445 \cdot \text { in } \\ 465 \cdot \text { in }\end{array}\right)$

Vertical location of Euler element centroids at which pressures are reported. 
Prepared by: F. G. Abatt M\&D Professional Services 7/11/06

Rev. 0
RPP-RPT-30807, Rev. 0 Theoretical Fluid Résponse Calculations for Rigid Roofless Tank at 480 in. Waste Level
Checked by: K.R. Roberson

rkK

$\eta_{1}:=\frac{z}{H_{1}} \quad$ Dimensionless wall height

\begin{tabular}{|r|r|}
\hline & \multicolumn{1}{|c|}{0} \\
\hline 0 & $9.38 \cdot 10^{-3}$ \\
\hline 1 & 0.05 \\
\hline 2 & 0.09 \\
\hline 3 & 0.14 \\
\hline 4 & 0.18 \\
\hline 5 & 0.22 \\
\hline 6 & 0.26 \\
\hline 7 & 0.3 \\
\hline 8 & 0.34 \\
\hline 9 & 0.39 \\
\hline 10 & 0.43 \\
\hline 11 & 0.47 \\
\hline 12 & 0.51 \\
\hline 13 & 0.55 \\
\hline 14 & 0.59 \\
\hline 15 & 0.64 \\
\hline 16 & 0.68 \\
\hline 17 & 0.72 \\
\hline 18 & 0.76 \\
\hline 19 & 0.8 \\
\hline 20 & 0.84 \\
\hline 21 & 0.89 \\
\hline 22 & 0.93 \\
\hline
\end{tabular}

Ratio of tank wall vertical location to waste height for waste element centroids.

Determine convective coefficients as a function of dimensionless height per BNL 1995 Eqn. 4.4

$$
\begin{aligned}
& \operatorname{con}_{0}\left(\eta_{1}\right):=\left[\frac{2}{\left(\lambda_{0}\right)^{2}-1} \cdot \frac{\cosh \left[\lambda_{0} \cdot\left(\frac{H_{1}}{R}\right) \eta_{1}\right]}{\cosh \left[\lambda_{0} \cdot\left(\frac{H_{1}}{R}\right)\right]}\right] \\
& \operatorname{con}_{1}\left(\eta_{1}\right):=\left[\frac{2}{\left(\lambda_{1}\right)^{2}-1} \cdot \frac{\cosh \left[\lambda_{1}\left(\frac{\mathrm{H}_{1}}{\mathrm{R}}\right)^{-} \eta_{1}\right]}{\cosh \left[\lambda_{1} \cdot\left(\frac{\mathrm{H}_{1}}{\mathrm{R}}\right)\right]}\right] \\
& \operatorname{con}_{2}\left(\eta_{1}\right):=\left[\frac{2}{\left(\lambda_{2}\right)^{2}-1} \cdot \frac{\cosh \left[\lambda_{2}\left(\frac{H_{1}}{R}\right) \cdot \eta_{1}\right]}{\cosh \left[\lambda_{2}\left(\frac{H_{1}}{R}\right)\right]}\right]
\end{aligned}
$$


Prepared by: F. G. Abatt M\&D Professional Services 7/11/06

Rev. 0

$\operatorname{con}_{0}\left(n_{1}\right)=$\begin{tabular}{|r|r|}
\hline & 0 \\
\hline 0 & 0.23 \\
\hline 1 & 0.23 \\
\hline 2 & 0.23 \\
\hline 3 & 0.24 \\
\hline 4 & 0.24 \\
\hline 5 & 0.25 \\
\hline 6 & 0.26 \\
\hline 7 & 0.27 \\
\hline 8 & 0.28 \\
\hline 9 & 0.3 \\
\hline 11 & 0.32 \\
\hline 12 & 0.34 \\
\hline 13 & 0.36 \\
\hline 14 & 0.38 \\
\hline 15 & 0.41 \\
\hline 16 & 0.43 \\
\hline 17 & 0.47 \\
\hline 18 & 0.5 \\
\hline 19 & 0.54 \\
\hline 20 & 0.58 \\
\hline 21 & 0.63 \\
\hline 22 & 0.68 \\
\hline & 0.73 \\
\hline
\end{tabular}

RPP-RPT-30807, Rev. 0

Theoretical Fluid Response Calculations for Rigid Roofless Tank at 480 in. Waste Level

$\operatorname{con}_{2}\left(\eta_{1}\right)=$\begin{tabular}{|c|c|}
\hline & 0 \\
\hline 0 & $6.21 \cdot 10^{-6}$ \\
\hline 1 & $6.89 \cdot 10^{-6}$ \\
\hline 2 & $8.58 \cdot 10^{-6}$ \\
\hline 3 & $1.15 \cdot 10^{-5}$ \\
\hline 4 & $1.61 \cdot 10^{-5}$ \\
\hline 5 & $2.31 \cdot 10^{-5}$ \\
\hline 6 & $3.34 \cdot 10^{-5}$ \\
\hline 7 & $4.86 \cdot 10^{-5}$ \\
\hline 8 & $7.09 \cdot 10^{-5}$ \\
\hline 9 & $1.03 \cdot 10^{-4}$ \\
\hline 11 & $1.51 \cdot 10^{-4}$ \\
\hline 12 & $2.21 \cdot 10^{-4}$ \\
\hline 13 & $3.23 \cdot 10^{-4}$ \\
\hline 14 & $4.71 \cdot 10^{-4}$ \\
\hline 15 & $6.89 \cdot 10^{-4}$ \\
\hline 16 & $1.01 \cdot 10^{-3}$ \\
\hline 17 & $1.47 \cdot 10^{-3}$ \\
\hline 18 & $2.15 \cdot 10^{-3}$ \\
\hline 19 & $3.14 \cdot 10^{-3}$ \\
\hline 20 & $4.59 \cdot 10^{-3}$ \\
\hline 21 & $6.71 \cdot 10^{-3}$ \\
\hline 22 & $9.8 \cdot 10^{-3}$ \\
\hline & 0.01 \\
\hline
\end{tabular}


Prepared by: F. G. Abatt

M\&D Professional Services

7/11/06

Rev. 0
RPP-RPT-30807, Rev. 0

Theoretical Fluid Response Calculations for Rigid Roofless Tank at 480 in. Waste Level
Checked by: K.R. Roberson

KRER

Impulsive pressure coefficient as a function of dimensionless wall height

$c_{i}\left(n_{1}\right):=1-\operatorname{con}_{0}\left(\eta_{1}\right)-\operatorname{con}_{1}\left(\eta_{1}\right)-\operatorname{con}_{2}\left(\eta_{1}\right) \quad$ Eqn. 4.7 BNL (1995)

$c_{i}\left(\eta_{1}\right)=$\begin{tabular}{|r|r|}
\hline & 0 \\
\hline 0 & 0.77 \\
\hline 1 & 0.77 \\
\hline 2 & 0.77 \\
\hline 3 & 0.76 \\
\hline 4 & 0.75 \\
\hline 5 & 0.75 \\
\hline 6 & 0.74 \\
\hline 7 & 0.73 \\
\hline 8 & 0.71 \\
\hline 9 & 0.7 \\
\hline 10 & 0.68 \\
\hline 11 & 0.66 \\
\hline 12 & 0.64 \\
\hline 13 & 0.61 \\
\hline 14 & 0.59 \\
\hline 15 & 0.56 \\
\hline 16 & 0.52 \\
\hline 17 & 0.48 \\
\hline 18 & 0.44 \\
\hline 19 & 0.39 \\
\hline 20 & 0.34 \\
\hline 21 & 0.28 \\
\hline 22 & 0.21 \\
\hline
\end{tabular}

Calculate maximum values of dynamic wall pressures from spectral acceleration of dome input TH.

Consider the first three convective mode spectral accelerations for the $0.1 \%$ damped spectrum

$$
\begin{array}{ll}
\mathrm{SA}_{\mathrm{c} 0}:=0.066 \cdot \mathrm{g} & \mathrm{SA}_{\mathrm{c} 0}=25.5 \frac{\mathrm{in}}{\mathrm{sec}^{2}} \\
\mathrm{SA}_{\mathrm{c} 1}:=0.11 \cdot \mathrm{g} & \mathrm{SA}_{\mathrm{cl}}=42.5 \frac{\mathrm{in}}{\mathrm{sec}^{2}} \quad \text { ANSYS dome RS from Spectr } \\
\mathrm{SA}_{\mathrm{c} 2}:=0.17 \cdot \mathrm{g} & \mathrm{SA}_{\mathrm{c} 2}=65.69 \frac{\mathrm{in}}{\mathrm{sec}^{2}}
\end{array}
$$


Prepared by: F. G. Abatt M\&D Professjonal Services $7 / 11 / 06$

Rev. 0
RPP-RPT-30807, Rev. 0

Theoretical Fluid Response Calculations for Rigid Roofless Tank at 480 in. Waste Level
Checked by: K.R. Roberson

KRK

Associate the impulsive mode with the peak ground acceleration (PGA), since the tank is rigid.

$\mathrm{PGA}:=0.276 \cdot \mathrm{g} \quad \mathrm{PGA}=106.65 \frac{\mathrm{in}}{\mathrm{sec}^{2}} \quad$ ANSYS dome RS from Spectr

$\mathrm{p}_{\text {maxconv }}\left(\eta_{1}, \theta\right):=\left[\sqrt{\left(\operatorname{con}_{0}\left(\eta_{1}\right) \cdot \mathrm{SA}_{\mathrm{c} 0}\right)^{2}+\left(\operatorname{con}_{1}\left(\eta_{1}\right) \cdot \mathrm{SA}_{\mathrm{c} 1}\right)^{2}+\left(\operatorname{con}_{2}\left(\eta_{1}\right) \cdot \mathrm{SA}_{\mathrm{c} 2}\right)^{2}}\right] \cdot\left(\rho_{1} \cdot \mathrm{R} \cdot \cos (\theta \cdot \operatorname{deg})\right)$

$\mathbf{p}_{\text {maximpulsive }}\left(\eta_{1}, \theta\right):=\left[\sqrt{\left[\mathrm{c}_{i}\left(\eta_{1}\right) \cdot(\mathrm{PGA})\right]^{2}}\right] \cdot\left(\rho_{1} \cdot \mathrm{R} \cdot \cos (\theta \cdot \mathrm{deg})\right)$

$p_{\max }\left(\eta_{1}, \theta\right):=\left[\sqrt{\left[\left(c_{i}\left(\eta_{1}\right)\right) \cdot(\operatorname{PGA})\right]^{2}+\left(\operatorname{con}_{0}\left(\eta_{1}\right) \cdot S A_{c 0}\right)^{2}+\left(\operatorname{con}_{1}\left(\eta_{1}\right) \cdot S A_{c 1}\right)^{2}+\left(\operatorname{con}_{2}\left(\eta_{1}\right) \cdot S_{c_{c 2}}\right)^{2}}\right] \cdot\left(\rho_{1} \cdot R \cdot \cos (\theta \cdot \operatorname{deg})\right)$

$p_{\text {maximpulsive }}\left(n_{1}, 0\right)=$\begin{tabular}{|r|r|}
\hline & 0 \\
\hline 0 & 6.31 \\
\hline 1 & 6.3 \\
\hline 2 & 6.28 \\
\hline 3 & 6.24 \\
\hline 4 & 6.19 \\
\hline 5 & 6.13 \\
\hline 6 & 6.05 \\
\hline 7 & 5.96 \\
\hline 8 & 5.85 \\
\hline 10 & 5.73 \\
\hline 11 & 5.59 \\
\hline 12 & 5.43 \\
\hline 13 & 5.24 \\
\hline 14 & 4.04 \\
\hline 15 & 4.81 \\
\hline 16 & 4.56 \\
\hline 17 & 3.96 \\
\hline 18 & 3.61 \\
\hline 19 & 3.21 \\
\hline 20 & 2.77 \\
\hline 21 & 2.27 \\
\hline 22 & 1.7 \\
\hline & \\
\hline 2
\end{tabular}

Maximum impulsive dynamic pressures at theta $=0$. 
Prepared by: F. G. Abatt M\&D Professional Services 7/11/06

Rev. 0

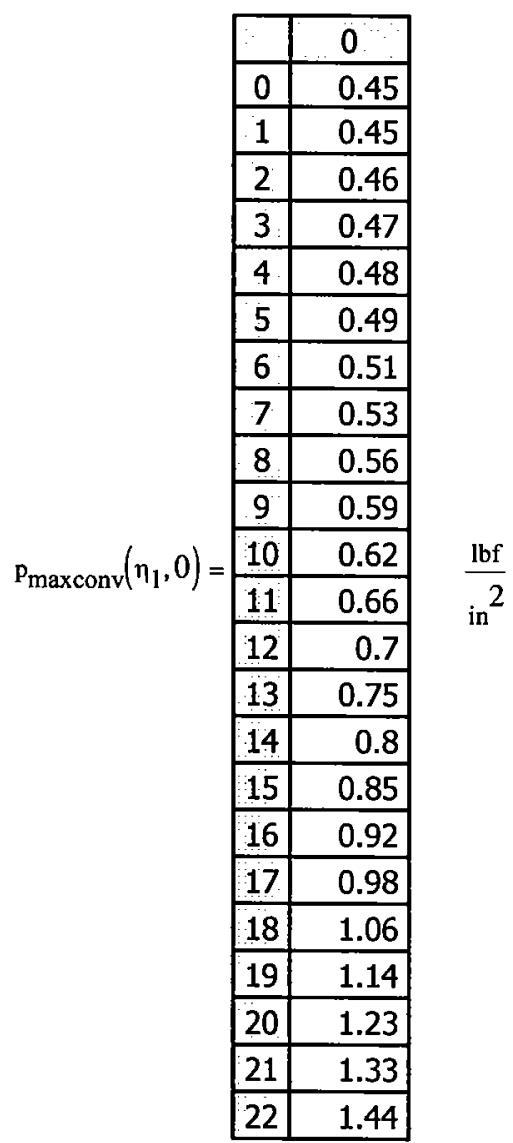

RPP-RPT-30807, Rev. 0 Theoretical Fluid Response Calculations for Rigid Roofless Tank at 480 in. Waste Level
Checked by: K.R. Roberson<smiles>CCC(C)CC(C)CC</smiles>

Maximum convective dynamic pressures at theta $=0$.

$p_{\max }\left(n_{1}, 0\right)=$\begin{tabular}{|r|r|}
\hline & 0 \\
\hline 0 & 6.33 \\
\hline 1 & 6.32 \\
\hline 2 & 6.3 \\
\hline 3 & 6.26 \\
\hline 4 & 6.21 \\
\hline 5 & 6.15 \\
\hline 6 & 6.07 \\
\hline 7 & 5.98 \\
\hline 8 & 5.88 \\
\hline 9 & 5.76 \\
\hline 11 & 5.62 \\
\hline 12 & 5.47 \\
\hline 13 & 5.29 \\
\hline 14 & 5.1 \\
\hline 15 & 4.88 \\
\hline 16 & 4.64 \\
\hline 17 & 4.37 \\
\hline 18 & 4.08 \\
\hline 19 & 3.76 \\
\hline 20 & 3.41 \\
\hline 21 & 3.03 \\
\hline 22 & 2.63 \\
\hline & 2.23 \\
\hline
\end{tabular}

$\frac{\mathrm{lbf}}{2} \quad$ Maximum total dynamic in $^{2}$ pressure at theta $=0$. 
Prepared by: F. G. Abatt M\&D Professional Services 7/11/06

Rev. 0
RPP-RPT-30807, Rev. 0

Theoretical Fluid Response Calculations for Rigid Roofless Tank at 480 in. Waste Level
Checked by: K.R. Roberson KRR

Calculate Maximum Slosh Height:

conmax $:=\left(\begin{array}{l}0.837) \\ 0.073 \\ 0.028\end{array}\right) \quad$ Maximum value of convective coefficients at $\eta_{1}=1$

$h_{\text {maxslosh }}=R \cdot \sqrt{\left(\operatorname{conmax} 0_{0} \frac{\mathrm{SA}_{\mathrm{c} 0}}{\mathrm{~g}}\right)^{2}+\left(\operatorname{conmax}_{1} \cdot \frac{\mathrm{SA}_{\mathrm{c} 1}}{\mathrm{~g}}\right)^{2}+\left(\operatorname{conmax}_{2} \cdot \frac{\mathrm{SA}_{\mathrm{c} 2}}{\mathrm{~g}}\right)^{2}} \quad$ Eqn. $4.60 \mathrm{BNL}$ (1995)
$\mathrm{h}_{\text {maxslosh }}=25.21 \mathrm{in} \quad$ Maximum theoretical slosh height 
Prepared by: F. G. Abatt M\&D Professional Services 7/11/06

Rev. 0
RPP-RPT-30807, Rev. 0

Theoretical Fluid Response Calculations for Rigid Roofless Tank at 480 in. Waste Level
Checked by: K.R. Roberson

TCRR

\section{Calculate Maximum Total Hydrodynamic Force:}

The maximum hydrodynamic force induced on the tank wall is given by Eqn. 4.31 of BNL 1995 with the instantaneous accelerations replaced by the maximum spectral accelerations. First determine the effective impulsive and convective masses.

$\mathrm{m}_{\text {lapprox }}:=\pi \cdot \mathrm{R}^{2} \cdot \mathrm{H}_{\mathrm{l}} \cdot \rho_{\mathrm{l}} \quad \mathrm{m}_{\text {lapprox }}=5.22 \times 10^{4} \frac{\mathrm{lbf} \cdot \mathrm{sec}^{2}}{\mathrm{in}} \quad \begin{aligned} & \text { Total waste mass based on circular cylinder } \\ & \text { approximation. }\end{aligned}$

$\mathrm{m}_{1}:=5.13 \cdot 10^{4} \cdot \frac{\mathrm{lbf} \cdot \mathrm{sec}^{2}}{\text { in }} \quad$ Actual waste mass reported by Dytran model.

$\mathrm{m}_{\mathrm{c} 0}:=\left[\frac{2}{\lambda_{0}\left[\left(\lambda_{0}\right)^{2}-1\right] \cdot\left(\frac{\mathrm{H}_{\mathrm{I}}}{\mathrm{R}}\right)}\right] \cdot \tanh \left[\lambda_{0} \cdot\left(\frac{\mathrm{H}_{1}}{\mathrm{R}}\right)\right] \cdot \mathrm{m}_{\mathrm{I}} \quad$ Eqn. $4.32 \mathrm{BNL}(1995)$

$\mathrm{m}_{\mathrm{c} 0}=2.1 \times 10^{4} \frac{\mathrm{lbf} \cdot \mathrm{sec}^{2}}{\mathrm{in}} \quad$ First mode convective mass

$\mathrm{m}_{\mathrm{cl}}:=\left[\frac{2}{\lambda_{1}\left[\left(\lambda_{1}\right)^{2}-1\right] \cdot\left(\frac{\left.\mathrm{H}_{1}\right)}{\mathrm{R}}\right)}\right] \cdot \tanh \left[\lambda_{1} \cdot\left(\frac{\mathrm{H}_{1}}{\mathrm{R}}\right)\right] \cdot \mathrm{m}_{1} \quad$ Second mode convective mass

$\mathrm{m}_{\mathrm{cl}}=658.02 \frac{\mathrm{lbf} \cdot \mathrm{sec}^{2}}{\text { in }}$

$\mathrm{m}_{\mathrm{c} 2}:=\left[\frac{2}{\lambda_{2}\left[\left(\lambda_{2}\right)^{2}-1\right] \cdot\left(\frac{\mathrm{H}_{1}}{\mathrm{R}}\right)}\right] \cdot \tanh \left[\lambda_{2} \cdot\left(\frac{\mathrm{H}_{1}}{\mathrm{R}}\right)\right] \cdot \mathrm{m}_{1} \quad$ Third mode convective mass

$\mathrm{m}_{\mathrm{c} 2}=156.8 \frac{\mathrm{lbf} \cdot \mathrm{sec}^{2}}{\text { in }}$

$m_{i}:=m_{1}-\left(m_{c 0}+m_{c 1}+m_{c 2}\right) \quad$ Impulsive mass - Eqn. 4.33. BNL (1995)

$\mathrm{m}_{\mathrm{i}}=2.95 \times 10^{4} \frac{\mathrm{lbf} \cdot \mathrm{sec}^{2}}{\text { in }}$ 
Prepared by: F. G. Abatt M\&D Professional Services $7 / 11 / 06$

Rev. 0
RPP-RPT-30807, Rev. 0

Theoretical Fluid Response Calculations for Rigid Roofless Tank at 480 in. Waste Level
Checked by: K.R. Roberson

KKR

$\mathrm{F}_{\max }:=\mathrm{m}_{\mathrm{i}} \cdot \mathrm{PGA}+\mathrm{m}_{\mathrm{c} 0} \cdot \mathrm{SA}_{\mathrm{c} 0}+\mathrm{m}_{\mathrm{cl}} \cdot \mathrm{SA}_{\mathrm{cl}}+\mathrm{m}_{\mathrm{c} 2} \cdot \mathrm{SA}_{\mathrm{c} 2}$

$F_{\max }=3.72 \times 10^{6} \mathrm{lbf} \quad$ Conservative estimate of maximum hydrodynamic force

The above expression is a conservative estimate because it assumes that the peak impulsive and convective forces occur simultaneously. A less conservative estimate can be made via a square-root-sum-of-the-squares (SRSS) combination.

$$
\begin{aligned}
& \mathrm{F}_{\mathrm{srss}}:=\sqrt{\left(\mathrm{m}_{\mathrm{i}} \cdot \mathrm{PGA}\right)^{2}+\left(\mathrm{m}_{\mathrm{c} 0} \cdot \mathrm{SA}_{\mathrm{c} 0}\right)^{2}+\left(\mathrm{m}_{\mathrm{cl}} \cdot \mathrm{SA}_{\mathrm{c} 1}\right)^{2}+\left(\mathrm{m}_{\mathrm{c} 2} \cdot \mathrm{SA}_{\mathrm{c} 2}\right)^{2}} \\
& \mathrm{~F}_{\mathrm{srss}}=3.19 \times 10^{6} \mathrm{lbf} \quad \text { SRSS estimate of peak hydrodynamic force }
\end{aligned}
$$

$F_{\text {conmax }}:=\sqrt{\left(m_{\mathrm{c} 0} \cdot \mathrm{SA}_{\mathrm{c} 0}\right)^{2}+\left(\mathrm{m}_{\mathrm{cl}} \cdot \mathrm{SA}_{\mathrm{cl}}\right)^{2}+\left(\mathrm{m}_{\mathrm{c} 2} \cdot \mathrm{SA}_{\mathrm{c} 2}\right)^{2}}$

$\mathrm{F}_{\text {conmax }}=5.37 \times 10^{5} \mathrm{lbf} \quad$ Peak hydrodynamic force due to convective response - shows up in free oscillations.

\section{Reference:}

BNL 1995, Seismic Design and Evaluation Guidelines for the Department of Energy High-Level Waste Storage Tanks and Appurtenances, BNL 52361, Rev. 10/95, Brookhaven National Laboratory, Upton, New York. 
Prepared by: F. G. Abatt M\&D Professional Services $8 / 3 / 06$

Rev. 0
RPP-RPT-30807, Rev. 0 Calculations for Rigid Flat Top Tank at 480 in. Waste Level
Checked by: K.R. Roberson

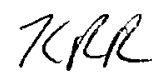

This worksheet contains calculations for a rigid flat top tank with an initial liquid level of 480 in. At this liquid level, the sloshing liquid interacts with the tank roof. The calculations are performed using the methodology in Chapter 4 and Appendix D of BNL (1995) and in Malthotra (2005). The location of the fluid elements corresponds to the Dytran model of the flat top tank.

$H_{1}:=480.0 \cdot$ in $\quad$ Baseline liquid level
$H_{t}:=500.0 \cdot$ in $\quad$ Height to tank roof
$h_{0}:=H_{t}-H_{1} \quad h_{0}=20$ in $\quad$ Freeboard distance
$\frac{H_{1}}{H_{t}}=0.96 \quad$ Ratio of waste height to tank height
$\frac{g}{2}:=386.4 \cdot \frac{\text { in }}{2} \quad$ Tank radius
$\frac{R_{M}:=450 \cdot \text { in }}{R} \quad$ Ratio of waste height to tank radius
$\frac{H_{1}}{R}=1.07 \quad$

$\mathrm{i}:=0 . .2$

$\lambda:=\left(\begin{array}{l}1.841 \\ 5.331 \\ 8.536\end{array}\right) \quad$ Bessel function roots

$\theta:=\left(\begin{array}{c}0 \cdot \mathrm{deg} \\ 45 \cdot \mathrm{deg} \\ 90 \cdot \mathrm{deg}\end{array}\right) \quad$ Circumferential location of waste elements for which pressures are reported

$\rho_{1}:=1.71 \cdot 10^{-4} \cdot \frac{\mathrm{lbf} \cdot \sec ^{2}}{\text { in }^{4}} \quad$ Liquid mass density - specific gravity of 1.83 
Prepared by: F. G. Abatt M\&D Professional Services $8 / 3 / 06$

Rev. 0

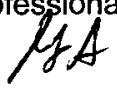

RPP-RPT-30807, Rev. 0

Calculations for Rigid Flat Top Tank at 480 in. Waste Level

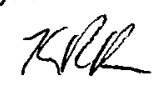

Convective Frequencies

$$
\begin{aligned}
& \operatorname{fcon}_{\mathrm{i}}:=\frac{1}{2 \cdot \pi} \cdot\left[\int\left[\lambda_{i}\left[\frac{\mathrm{g}}{\mathrm{R}} \cdot \tanh \left[\lambda_{\mathrm{i}}\left(\frac{\mathrm{H}_{\mathrm{l}}}{\mathrm{R}}\right)\right]\right]\right]\right] \quad \text { Eqn. 4.14 BNL (1995) } \\
& \mathrm{fcon}=\left(\begin{array}{l}
0.196) \\
0.341 \mathrm{~Hz} \\
0.431)
\end{array} \quad\right. \text { First three convective frequencies }
\end{aligned}
$$

Consider the first three convective mode spectral accelerations for the $0.1 \%$ damped spectrum

$$
\begin{array}{ll}
\mathrm{SA}_{\mathrm{c} 0}:=0.066 \cdot \mathrm{g} & \mathrm{SA}_{\mathrm{c} 0}=25.5 \frac{\mathrm{in}}{\mathrm{sec}^{2}} \\
\mathrm{SA}_{\mathrm{c} 1}:=0.11 \cdot \mathrm{g} & \mathrm{SA}_{\mathrm{cl}}=42.5 \frac{\mathrm{in}}{\mathrm{sec}^{2}} \\
\mathrm{SA}_{\mathrm{c} 2}:=0.17 \cdot \mathrm{g} & \mathrm{SA}_{\mathrm{c} 2}=65.69 \frac{\mathrm{in}}{\mathrm{sec}^{2}}
\end{array}
$$

Associate the impulsive mode with the peak ground acceleration (PGA), since the tank is rigid.

$$
\mathrm{PGA}:=0.276 \cdot \mathrm{g} \quad \mathrm{PGA}=106.65 \frac{\text { in }}{\mathrm{sec}^{2}} \quad \text { ANSYS dome RS from Spectr }
$$

\section{Calculate Maximum Slosh Height per BNL (1995):}

conmax $:=\left(\begin{array}{l}0.837 \\ 0.073 \\ 0.028\end{array}\right) \quad$ Maximum value of convective coefficients at $\eta_{1}=1$

$h_{s}:=R \cdot \sqrt{\left(\operatorname{conmax}_{0} \cdot \frac{\mathrm{SA}_{\mathrm{c} 0}}{\mathrm{~g}}\right)^{2}+\left(\operatorname{conmax}_{1} \cdot \frac{\mathrm{SA}_{\mathrm{c} 1}}{\mathrm{~g}}\right)^{2}+\left(\operatorname{conmax}_{2} \cdot \frac{\mathrm{SA}_{\mathrm{c} 2}}{\mathrm{~g}}\right)^{2}} \quad$ Eqn. $4.60 \mathrm{BNL}$ (1995)

$\mathrm{h}_{\mathrm{s}}=25.21$ in

Maximum theoretical slosh height for roofless tank per BNL (1995)

\section{B-24 of B-65}


Prepared by: F. G. Abatt M\&D Professjional Services $8 / 3 / 06$

Rev. 0
RPP-RPT-30807, Rev. 0 Calculations for Rigid Flat Top Tank at 480 in. Waste Level
Checked by: K.R. Roberson KRR

Recalculate the Maximum Slosh Height per Malhotra (2005):

$j:=0 . .1$

$\mathrm{H}_{\mathrm{T}}:=\left(\begin{array}{l}1.0 \\ 1.5\end{array}\right)$

$\mathrm{C}_{\text {cref }}:=\left(\begin{array}{l}1.52 \\ 1.48\end{array}\right)$

Table 1 of Malhotra (2005)

$\mathrm{C}_{\mathrm{c}}:=\operatorname{linterp}\left(\mathrm{H}_{\mathrm{T}}, \mathrm{C}_{\mathrm{cref}}, \frac{\mathrm{H}_{\mathrm{l}}}{\mathrm{R}}\right) \cdot \frac{\mathrm{sec}}{\sqrt{\mathrm{m}}} \quad \mathrm{C}_{\mathrm{c}}=1.51 \frac{\mathrm{sec}}{\mathrm{m}^{0.5}}$

$\mathrm{T}_{\text {con }}:=\mathrm{C}_{\mathrm{c}} \cdot \sqrt{\mathrm{R}}$

$\mathrm{T}_{\text {con }}=5.12 \mathrm{sec}$

$f_{\text {cMalhotra }}:=\frac{1}{T_{\text {con }}}$

$\mathrm{f}_{\mathrm{cMalhotra}}=0.195 \mathrm{~Hz}$

Fundamental convective frequency per Malhotra (2005)

Since this agrees with the frequency calculated via BNL (1995), the convective acceleration is the same in both cases.

$h_{\text {SMalhotra }}:=R \cdot \frac{\mathrm{SA}_{\mathrm{c} 0}}{\mathrm{~g}} \quad$ Eqn. (9) of Malhotra (2005)

$\mathrm{h}_{\text {sMalhotra }}=29.7 \mathrm{in} \quad$ Maximum slosh height for roofless tank per Malhotra (2005)

\section{Calculate the Central Half-Angle for Wetted Portion of Tank Roof:}

$\theta_{0}:=\operatorname{acos}\left(\frac{h_{0}}{h_{s}}\right) \quad$ Central half-angle of maximum impacted roof area per Eqn. D.2 BNL (1995)

$\theta_{0}=37.5 \mathrm{deg} \quad$ Central half-angle per Appendix D BNL (1995)

$\frac{h_{0}}{h_{\text {sMalhotra }}}=0.67 \quad$ Used to calculate $x_{f}$ from Figure 3 of Malhotra (2005)

$\mathrm{x}_{\mathrm{f}}:=0.35 \cdot \mathrm{R} \quad \mathrm{x}_{\mathrm{f}}=157.5 \mathrm{in} \quad$ Wetted width of tank roof per Figures 2 and 3 of Malhotra (2005)

$\psi_{0}:=\operatorname{acos}\left(\frac{x_{\mathrm{f}}}{\mathrm{R}}-1\right) \quad \psi_{0}=2.28$

$\theta_{\text {OMalhotra }}:=\pi-\psi_{0} \quad \theta_{0 \text { Malhotra }}=49.5 \mathrm{deg}$ Central half-angle per Malhotra (2005) 
Prepared by: F. G. Abatt

M\&D Professional Services

8/3/06

Rev. 0

\section{Maximum Roof Pressure:}

$r:=424.875$.in Typical centroidal radius of Dytran elements for which results are monitored

$p_{\mathrm{r}}(\mathrm{r}, \boldsymbol{\theta}):=\rho_{1} \cdot \mathrm{r} \cdot \mathrm{PGA} \cdot \cos (\boldsymbol{\theta})$

for $|\theta|<\left|\theta_{0}\right|$

maximum roof pressure

$p_{\text {maxroofMalhotra }}:=\rho_{l^{\prime}} x_{f} S A_{c 0}$
$\mathrm{p}_{\mathrm{T}}(\mathrm{R}, 0)=8.21 \frac{\mathrm{lbf}}{\text { in }^{2}}$

$\mathrm{p}_{\mathrm{r}}(\mathrm{r}, 0)=7.75 \frac{\mathrm{lbf}}{\text { in }^{2}}$

Peak roof pressure per Malhotra (2005)

$\mathrm{P}_{\operatorname{maxroofMalhotra}}=0.69 \frac{\mathrm{lbf}}{\mathrm{in}^{2}}$

Peak roof pressure per BNL (1995)

Predicted peak roof pressure for Dytran element per BNL (1995)

Calculate the Maximum Wall Pressure per Appendix D BNL (1995):

$\mathbf{P}_{\mathrm{ic}}(\theta):=\rho_{\mathbf{l}} \cdot \mathrm{R} \cdot \mathrm{PGA} \cdot \cos (\theta)$

Impulsive component of pressure due to constrained portion of the liquid.
Checked by: K.R. Roberson

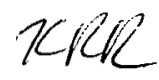


Prepared by: F. G. Abatt M\&D Professional Services 8/3/06

Rev. 0
RPP-RPT-30807, Rev. 0 Calculations for Rigid Flat Top Tank at 480 in. Waste Level
Checked by: K.R. Roberson

KRR
Vertical location of Euler element centroids at which pressures are reported.

\begin{tabular}{|r|r|}
\hline & 0 \\
\hline 0 & 0.01 \\
\hline 1 & 0.05 \\
\hline 2 & 0.09 \\
\hline 3 & 0.14 \\
\hline 4 & 0.18 \\
\hline 5 & 0.22 \\
\hline 6 & 0.26 \\
\hline 7 & 0.3 \\
\hline 8 & 0.34 \\
\hline 9 & 0.39 \\
\hline 10 & 0.43 \\
\hline 11 & 0.47 \\
\hline 12 & 0.51 \\
\hline 13 & 0.55 \\
\hline 14 & 0.59 \\
\hline 15 & 0.64 \\
\hline 16 & 0.68 \\
\hline 17 & 0.72 \\
\hline 18 & 0.76 \\
\hline 19 & 0.8 \\
\hline 20 & 0.84 \\
\hline 21 & 0.89 \\
\hline 22 & 0.93 \\
\hline 23 & 0.97 \\
\hline & \\
\hline
\end{tabular}

Ratio of tank wall vertical location to waste height for waste element centroids. 
Prepared by: F. G. Abatt M\&D Professipnal Services 8/3/06

Rev. 0
RPP-RPT-30807, Rev. 0 Calculations for Rigid Flat Top Tank at 480 in. Waste Level
Checked by: K.R. Roberson

Determine convective coefficients as a function of dimensionless height per Eqn. 4.4 of BNL (1995)

$$
\begin{aligned}
& \operatorname{con}_{0}\left(\eta_{1}\right):=\left[\frac{2}{\left(\lambda_{0}\right)^{2}-1} \cdot \frac{\cosh \left[\lambda_{0} \cdot\left(\frac{H_{1}}{R}\right) \cdot \eta_{1}\right]}{\cosh \left[\lambda_{0} \cdot\left(\frac{H_{1}}{R}\right)\right]}\right] \\
& \operatorname{con}_{1}\left(\eta_{1}\right):=\left[\frac{2}{\left(\lambda_{1}\right)^{2}-1} \cdot \frac{\cosh \left[\lambda_{1} \cdot\left(\frac{H_{1}}{R}\right)^{\prime} \eta_{1}\right]}{\cosh \left[\lambda_{1} \cdot\left(\frac{H_{1}}{R}\right)\right]}\right] \\
& \operatorname{con}_{2}\left(\eta_{1}\right):=\left[\frac{2}{\left(\lambda_{2}\right)^{2}-1} \cdot \frac{\cosh \left[\lambda_{2} \cdot\left(\frac{H_{1}}{R}\right) \cdot \eta_{1}\right]}{\cosh \left[\lambda_{2} \cdot\left(\frac{H_{1}}{R}\right)\right]}\right]
\end{aligned}
$$

Impulsive pressure coefficient as a function of normalized wall height

$$
\begin{aligned}
& c_{\mathrm{i}}\left(\eta_{1}\right):=1-\operatorname{con}_{0}\left(\eta_{1}\right) \\
& P_{\mathrm{iu}}\left(\eta_{1}, \theta\right):=c_{\mathrm{i}}\left(\eta_{1}\right) \cdot \rho_{\mathrm{I}} \cdot \mathrm{R} \cdot \mathrm{PGA} \cdot \cos (\theta) \\
& \mathrm{p}_{\mathrm{cu}}\left(\eta_{1}, \theta\right):=\operatorname{con}_{0}\left(\eta_{\mathrm{I}}\right) \cdot \rho_{1} \cdot \mathrm{R} \cdot \mathrm{SA}_{\mathrm{c} 0} \cdot \cos (\theta)
\end{aligned}
$$$$
\text { Eqn. 4.7 BNL (1995) - 1st term }
$$

Impulsive component of maximum wall pressure induced by unconstrained portion of liquid beneath the non-impacted portion of the roof - same as for roofless tank (Eqn. D.6 BNL 1995).

Convective component of maximum wall pressure induced by unconstrained portion of liquid beneath the non-impacted portion of the roof - same as for roofless tank (Eqn. D.7 BNL 1995).

$p_{\text {itotal }}\left(\eta_{1}, \theta\right):=p_{i c}(\theta)+P_{i u}\left(\eta_{1}, \theta\right)$

Total impulsive component of wall pressure

$p_{\text {total }}\left(\eta_{1}, \theta\right):=p_{\text {itotal }}\left(\eta_{1}, \theta\right)+p_{c u}\left(\eta_{1}, \theta\right)$

Total wall pressure - sum of impulsive and convective components. 
Prepared by: F. G. Abatt M\&D Professignal Services 8/3/06

Rev. 0

$\operatorname{con}_{0}\left(\eta_{1}\right)=$\begin{tabular}{|r|r|}
\hline & 0 \\
\hline 0 & 0.23 \\
\hline 1 & 0.23 \\
\hline 2 & 0.23 \\
\hline 3 & 0.24 \\
\hline 4 & 0.24 \\
\hline 5 & 0.25 \\
\hline 6 & 0.26 \\
\hline 7 & 0.27 \\
\hline 8 & 0.28 \\
\hline 9 & 0.3 \\
\hline 12 & 0.32 \\
\hline 13 & 0.34 \\
\hline 14 & 0.36 \\
\hline 15 & 0.41 \\
\hline 16 & 0.43 \\
\hline 17 & 0.47 \\
\hline 18 & 0.5 \\
\hline 19 & 0.54 \\
\hline 20 & 0.58 \\
\hline 21 & 0.63 \\
\hline 22 & 0.68 \\
\hline 23 & 0.73 \\
\hline & 0.79 \\
\hline 1
\end{tabular}

RPP-RPT-30807, Rev. 0 Calculations for Rigid Flat Top Tank at 480 in. Waste Level

\begin{tabular}{|r|r|}
\hline & \multicolumn{1}{c|}{0} \\
\hline 0 & 0.77 \\
\hline 1 & 0.77 \\
\hline 2 & 0.77 \\
\hline 3 & 0.76 \\
\hline 4 & 0.76 \\
\hline 5 & 0.75 \\
\hline 6 & 0.74 \\
\hline 7 & 0.73 \\
\hline 8 & 0.72 \\
\hline 9 & 0.7 \\
\hline 10 & 0.68 \\
\hline 11 & 0.66 \\
\hline 12 & 0.64 \\
\hline 13 & 0.62 \\
\hline 14 & 0.59 \\
\hline 15 & 0.57 \\
\hline 16 & 0.53 \\
\hline 17 & 0.5 \\
\hline 18 & 0.46 \\
\hline 19 & 0.42 \\
\hline 20 & 0.37 \\
\hline 21 & 0.32 \\
\hline 22 & 0.27 \\
\hline 23 & 0.21 \\
\hline & \\
\hline 19
\end{tabular}

Checked by: K.R. Roberson TURR

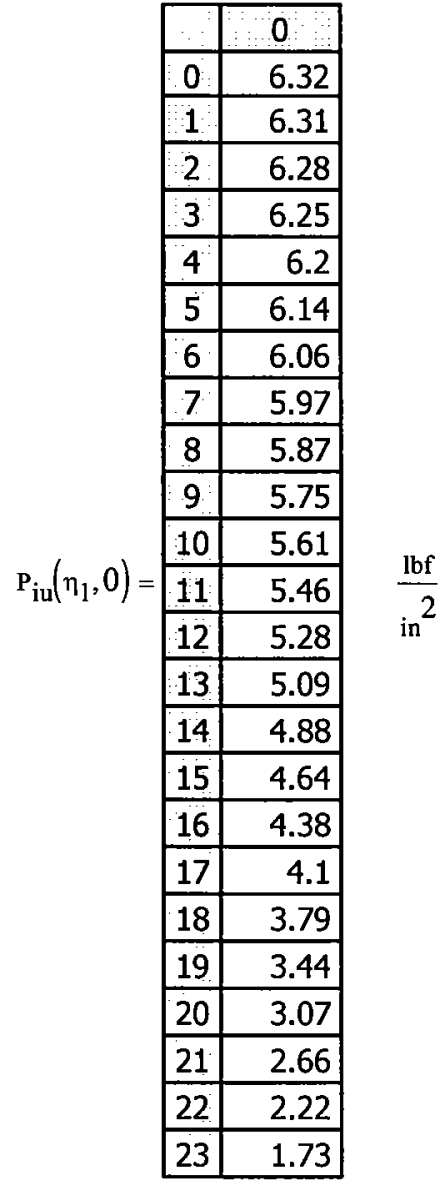


Prepared by: F. G. Abatt M\&D Professional Services 8/3/06

Rev. 0

$$
p_{\text {itotal0 }}:=P_{\text {iu }}\left(\eta_{1}, 0\right)+p_{\text {ic }}(0)
$$

RPP-RPT-30807, Rev. 0 Calculations for Rigid Flat Top Tank at 480 in. Waste Level

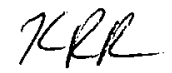

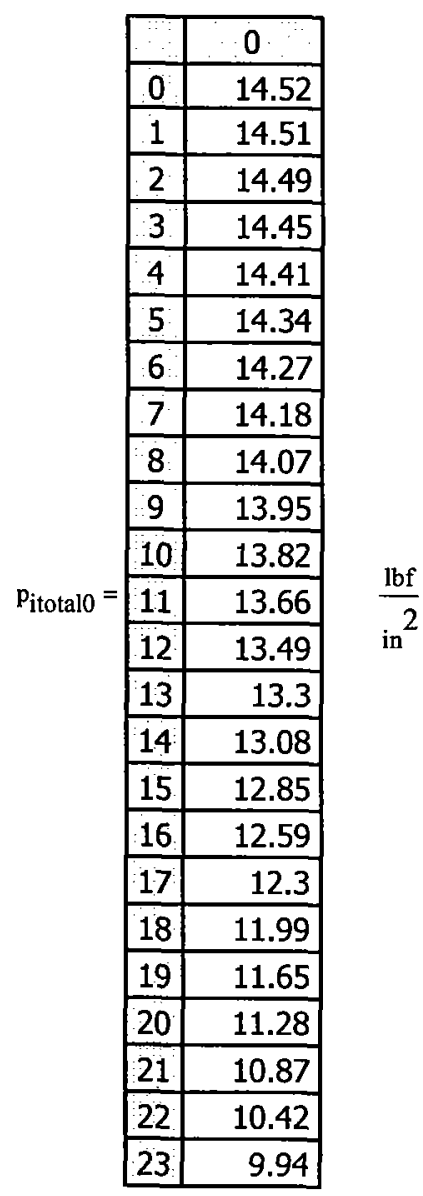

$p_{\mathrm{cu}}\left(\eta_{1}, 0\right)=$\begin{tabular}{|r|r|}
\hline & 0 \\
\hline 0 & 0.45 \\
\hline 1 & 0.45 \\
\hline 2 & 0.46 \\
\hline 3 & 0.47 \\
\hline 4 & 0.48 \\
\hline 5 & 0.49 \\
\hline 6 & 0.51 \\
\hline 7 & 0.53 \\
\hline 8 & 0.56 \\
\hline 9 & 0.59 \\
\hline 11 & 0.62 \\
\hline 12 & 0.66 \\
\hline 13 & 0.7 \\
\hline 14 & 0.74 \\
\hline 15 & 0.8 \\
\hline 16 & 0.85 \\
\hline 17 & 0.98 \\
\hline 18 & 1.06 \\
\hline 19 & 1.14 \\
\hline 20 & 1.23 \\
\hline 21 & 1.33 \\
\hline 22 & 1.43 \\
\hline 23 & 1.55 \\
\hline & \\
\hline 2 \\
lbf \\
\hline 1
\end{tabular}


Prepared by: F. G. Abatt M\&D Professignal Services $8 / 3 / 06$

Rev. 0

$$
\left(\eta_{1}\right):=p_{\text {itotal0 }}+p_{\text {cu }}\left(\eta_{1}, 0\right)
$$

RPP-RPT-30807, Rev. 0 Calculations for Rigid Flat Top Tank at 480 in. Waste Level
Checked by: K.R. Roberson Kilk

\section{Calculate the Maximum Total Hydrodynamic Force:}

The maximum hydrodynamic force induced on the tank wall is given by the sum of the terms in Equations D.12, D.13, and d.14 of BNL 1995.

$\mathrm{m}_{1}:=5.13 \cdot 10^{4} \cdot \frac{\mathrm{lbf} \cdot \mathrm{sec}^{2}}{\text { in }} \quad$ Actual waste mass reported by Dytran model.

$\mathrm{m}_{\mathrm{c} 0}:=\left[\frac{2}{\lambda_{0}\left[\left(\lambda_{0}\right)^{2}-1\right] \cdot\left(\frac{\mathrm{H}_{\mathrm{I}}}{\mathrm{R}}\right)}\right] \cdot \tanh \left[\lambda_{0} \cdot\left(\frac{\mathrm{H}_{1}}{\mathrm{R}}\right)\right] \cdot \mathrm{m}_{\mathrm{l}} \quad$ Eqn. $4.32 \mathrm{BNL}$ (1995)

$\mathrm{m}_{\mathrm{c} 0}=2.1 \times 10^{4} \frac{\mathrm{lbf} \cdot \mathrm{sec}^{2}}{\mathrm{in}} \quad$ First mode convective mass for roofless tank

$\mathrm{m}_{\mathrm{i}}:=\mathrm{m}_{1}-\mathrm{m}_{\mathrm{c} 0} \quad \mathrm{~m}_{\mathrm{i}}=3.03 \times 10^{4} \frac{\mathrm{lbf} \cdot \mathrm{sec}^{2}}{\text { in }} \quad$ Impulsive mass for roofless tank 
Prepared by: F. G. Abatt M\&D Professignal Services 8/3/06

Rev. 0

$$
\frac{\mathrm{m}_{\mathrm{c} 0}}{\mathrm{~m}_{1}}=0.41 \quad \frac{\mathrm{m}_{\mathrm{i}}}{\mathrm{m}_{\mathrm{l}}}=0.59
$$

epsilon $:=\frac{2 \cdot \theta_{0}+\sin \left(2 \cdot \theta_{0}\right)}{2 \cdot \pi}$

$F_{i c}:=$ epsilon $-\frac{H_{t}}{H_{l}} \cdot m_{1} \cdot P G A$

$F_{i c}=2.06 \times 10^{6} \mathrm{lbf}$

$F_{i u}:=(1-$ epsilon $) \cdot m_{i} \cdot P G A$

$F_{i u}=2.06 \times 10^{6} \mathrm{lbf}$

$\mathrm{F}_{\mathrm{cu}}:=(1-\mathrm{epsilon}) \cdot \mathrm{m}_{\mathrm{c} 0} \cdot \mathrm{SA} \mathrm{c} 0$

$F_{c u}=3.42 \times 10^{5} \mathrm{lbf}$

$F_{\text {total }}:=F_{i c}+F_{i u}+F_{c u}$

$F_{\text {total }}=4.47 \times 10^{6} \mathrm{lbf}$
RPP-RPT-30807, Rev. 0 Calculations for Rigid Flat Top Tank at 480 in. Waste Level
Checked by: K.R. Roberson

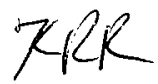

Dimensionless factor for wall force calculation Eqn. D.9 of BNL (1995).

Impulsive component of force due to constrained portion of liquid Eqn. D.12 of BNL (1995).

Impulsive component of force due to unconstrained portion of liquid Eqn. D.13 of BNL (1995).

Convective component of force due to unconstrained portion of liquid Eqn. D.14 of BNL (1995).

Total peak hydrodynamic force per BNL (1995)

Recalculate Maximum Hydrodynamic Force Using Methodolodgy of Malhotra (2005):

The hydrodynamic force can be calculated by excluding the structural masses from Eqn. (3) of Malhotra (2005). First calculate the impulsive and convective masses.

$\mathrm{j} i=0 . .1$

$\mathrm{HR}:=\left(\begin{array}{l}1.0 \\ 1.5\end{array}\right) \quad$ ImpMassRatio $:=\left(\begin{array}{l}0.548 \\ 0.686\end{array}\right) \quad$ Table 1 of Malhotra (2005)

linterp $\left(\mathrm{HR}\right.$, ImpMassRatio, $\left.\frac{\mathrm{H}_{1}}{\mathrm{R}}\right)=0.57$

$\mathrm{m}_{\mathrm{iMalhotra}}:=\operatorname{linterp}\left(\mathrm{HR}, \operatorname{ImpMassRatio}, \frac{\mathrm{H}_{\mathrm{I}}}{\mathrm{R}}\right) \mathrm{m}_{\mathrm{I}}$

$\mathrm{m}_{\mathrm{iMalhotra}}=2.91 \times 10^{4} \frac{\mathrm{lbf} \cdot \mathrm{sec}^{2}}{\text { in }}$

$\mathrm{m}_{\mathrm{cMalhotra}}:=\mathrm{m}_{1}-\mathrm{m}_{\mathrm{i} \text { Malhotra }}$

$\mathrm{m}_{\text {cMalhotra }}=2.22 \times 10^{4} \frac{\mathrm{lbf} \cdot \mathrm{sec}^{2}}{\text { in }}$ 
Prepared by: F. G. Abatt M\&D Professional Services 8/3/06

Rev. 0
RPP-RPT-30807, Rev. 0 Calculations for Rigid Flat Top Tank at 480 in. Waste Level
Checked by: K.R. Roberson

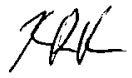

Modify the impulsive and convective masses to account for interaction with the tank roof per Eqns. (15) and (16) of Malhotra (2005).

$$
\begin{aligned}
& m_{\text {ibar }}:=m_{\text {iMalhotra }}+m_{\text {cMalhotra }}\left(1-\frac{\mathrm{h}_{0}}{h_{\text {sMalhotra }}}\right) \quad m_{\text {ibar }}=3.63 \times 10^{4} \frac{\mathrm{lbf} \cdot \mathrm{sec}^{2}}{\text { in }} \\
& \mathrm{m}_{\mathrm{cbar}}:=\mathrm{m}_{\mathrm{cMalhotra}}\left(\frac{\mathrm{h}_{0}}{\mathrm{~h}_{\text {sMalhotra }}}\right) \quad \mathrm{m}_{\mathrm{cbar}}=1.5 \times 10^{4} \frac{\mathrm{lbf} \cdot \mathrm{sec}^{2}}{\text { in }} \\
& \mathrm{R}_{\mathrm{ibar}}:=\mathrm{m}_{\mathrm{ibar}} \cdot \mathrm{PGA} \quad \mathrm{R}_{\mathrm{ibar}}=3.87 \times 10^{6} \mathrm{lbf} \quad \text { Impulsive component of peak reaction force } \\
& R_{c b a r}:=m_{c b a r} \cdot \mathrm{SA}_{c 0} \quad R_{c b a r}=3.82 \times 10^{5} \mathrm{lbf} \quad \text { Convective component of peak reaction force } \\
& \mathbf{R}_{\text {bar }}:=\mathbf{R}_{\text {ibar }}+\mathbf{R}_{\text {cbar }} \\
& \text { Total peak reaction force per Malhotra (2005) } \\
& R_{\mathrm{bar}}=4.26 \times 10^{6} \mathrm{lbf}
\end{aligned}
$$

\section{References:}

BNL 1995, Seismic Design and Evaluation Guidelines for the Department of Energy High-Level Waste Storage Tanks and Appurtenances, BNL 52361, Rev. 10/95, Brookhaven National Laboratory, Upton, New York.

Malhotra, Praveen K, 2005, Sloshing Loads in Liquid Storage Tanks With Insufficient Freeboard, Earthquake Spectra, Volume 21, No. 4, pp. 1185-1192, November 2005. 
This worksheet contains calculations for a rigid open top tank with an initial liquid level of 490 in. The calculations are performed using the methodology in Chapter 4 on BNL (1995). The location of the fluid elements corresponds to the Dytran model of the flat top tank.

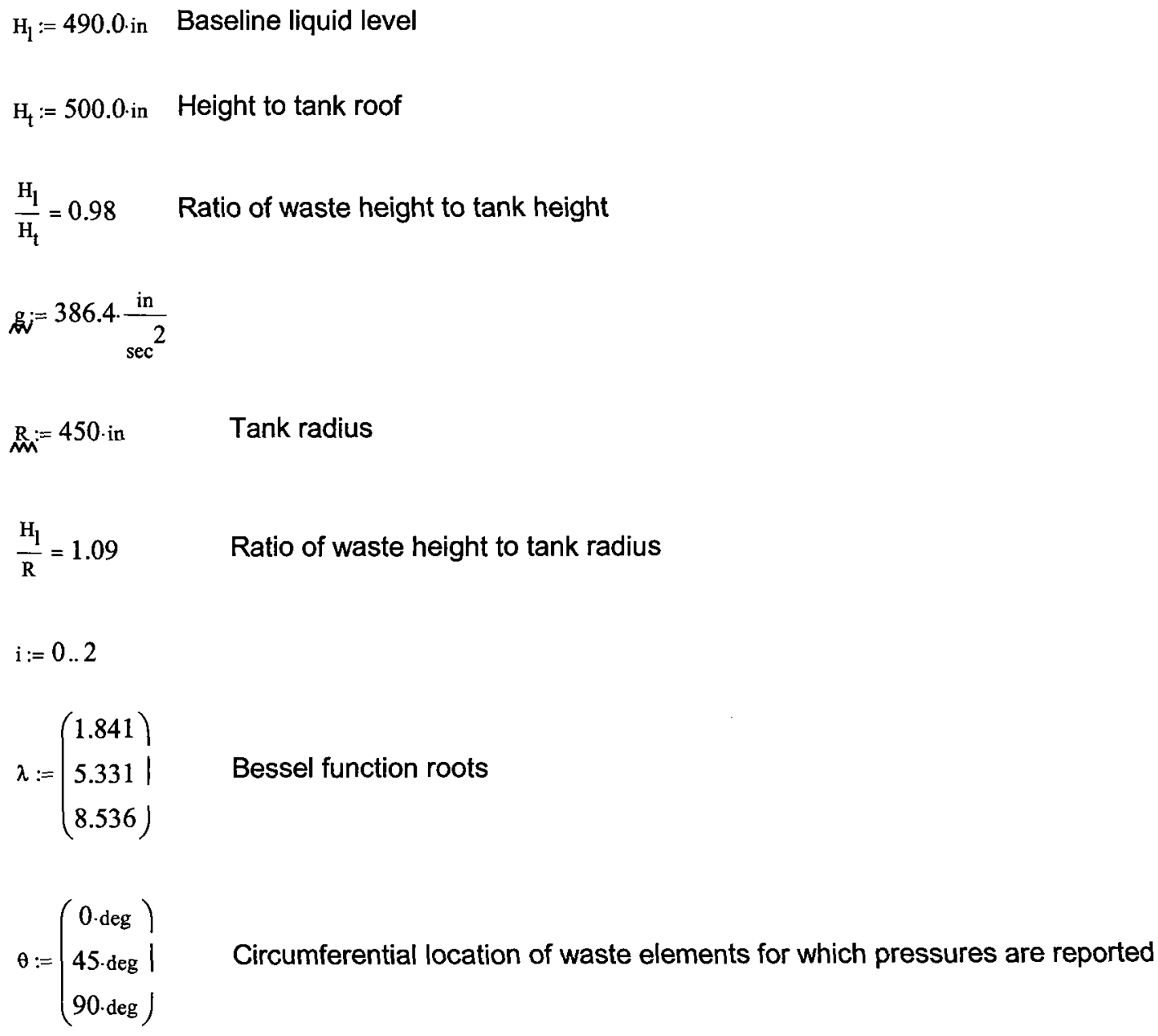


Prepared by: F. G. Abatt M\&D Professional Services 8/3/06

Rev. 0 RPP-RPT-30807, Rev. 0 Calculations for Rigid Roofless Tank at 490 in. Waste Level
Checked by: K.R. Roberson

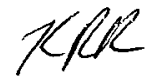

Determine Convective Pressures on the Tank Wall:

$z:=\left(\begin{array}{l}4.5 \cdot \text { in } \\ 25 \cdot \text { in } \\ 45 \cdot \text { in } \\ 65 \cdot \text { in } \\ 85 \cdot \text { in } \\ 105 \cdot \text { in } \\ 125 \cdot \text { in } \\ 145 \cdot \text { in } \\ 165 \cdot \text { in } \\ 185 \cdot \text { in } \\ 205 \cdot \text { in } \\ 225 \cdot \text { in } \\ 245 \cdot \text { in } \\ 265 \cdot \text { in } \\ 285 \cdot \text { in } \\ 305 \cdot \text { in } \\ 325 \cdot \text { in } \\ 345 \cdot \text { in } \\ 365 \cdot \text { in } \\ 385 \cdot \text { in } \\ 405 \cdot \text { in } \\ 425 \cdot \text { in } \\ 445 \cdot \text { in } \\ 465 \cdot \text { in } \\ 485 \cdot \text { in }\end{array}\right)$

Vertical location of Euler element centroids at which pressures are reported in Dytran model. 
Prepared by: F. G. Abatt M\&D Professional Services $8 / 3 / 06$

Rev. 0
RPP-RPT-30807, Rev. 0

Theoretical Fluid Response Calculations for Rigid Roofless Tank at 490 in. Waste Level
Checked by: K.R. Roberson

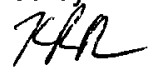

$\eta_{1}:=\frac{z}{H_{1}} \quad$ Dimensionless wall height

\begin{tabular}{|r|r|}
\hline & \multicolumn{1}{|c|}{0} \\
\hline 0 & $9.18 \cdot 10^{-3}$ \\
\hline 1 & 0.05 \\
\hline 2 & 0.09 \\
\hline 3 & 0.13 \\
\hline 4 & 0.17 \\
\hline 5 & 0.21 \\
\hline 6 & 0.26 \\
\hline 7 & 0.3 \\
\hline 8 & 0.34 \\
\hline 9 & 0.38 \\
\hline 10 & 0.42 \\
\hline 11 & 0.46 \\
\hline 12 & 0.5 \\
\hline 13 & 0.54 \\
\hline 14 & 0.58 \\
\hline 15 & 0.62 \\
\hline 16 & 0.66 \\
\hline 17 & 0.7 \\
\hline 18 & 0.74 \\
\hline 19 & 0.79 \\
\hline 20 & 0.83 \\
\hline 21 & 0.87 \\
\hline 22 & 0.91 \\
\hline 23 & 0.95 \\
\hline 24 & 0.99 \\
\hline
\end{tabular}

Ratio of tank wall vertical location to waste height for waste element centroids.

Determine convective coefficients as a function of dimensionless height per BNL 1995 Eqn. 4.4

$$
\begin{aligned}
& \operatorname{con}_{0}\left(\eta_{1}\right):=\left[\frac{2}{\left(\lambda_{0}\right)^{2}-1} \cdot \frac{\cosh \left[\lambda_{0} \cdot\left(\frac{H_{1}}{R}\right) \eta_{1}\right]}{\cosh \left[\lambda_{0} \cdot\left(\frac{H_{1}}{R}\right)\right]}\right] \\
& \operatorname{con}_{1}\left(\eta_{l}\right):=\left[\frac{2}{\left(\lambda_{1}\right)^{2}-1} \cdot \frac{\cosh \left[\lambda_{1}\left(\frac{\mathrm{H}_{l}}{\mathrm{R}}\right) \eta^{\prime} \eta_{1}\right]}{\cosh \left[\lambda_{1}\left(\frac{\mathrm{H}_{\mathrm{l}}}{\mathrm{R}}\right)\right]}\right] \\
& \operatorname{con}_{2}\left(\eta_{1}\right):=\left[\frac{2}{\left(\lambda_{2}\right)^{2}-1} \cdot \frac{\cosh \left[\lambda_{2} \cdot\left(\frac{H_{1}}{R}\right) \eta_{1}\right]}{\cosh \left[\lambda_{2}\left(\frac{H_{1}}{R}\right)\right]}\right]
\end{aligned}
$$


Prepared by: F. G. Abatt M\&D Professional Services 8/3/06

Rev. 0

\begin{tabular}{|r|r|}
\hline & \multicolumn{1}{|c|}{0} \\
\hline 0 & 0.22 \\
\hline 1 & 0.22 \\
\hline 2 & 0.23 \\
\hline 3 & 0.23 \\
\hline 4 & 0.24 \\
\hline 5 & 0.24 \\
\hline 6 & 0.25 \\
\hline 7 & 0.26 \\
\hline 8 & 0.27 \\
\hline 9 & 0.29 \\
\hline 10 & 0.3 \\
\hline 11 & 0.32 \\
\hline 12 & 0.34 \\
\hline 13 & 0.36 \\
\hline 14 & 0.39 \\
\hline 15 & 0.42 \\
\hline 16 & 0.45 \\
\hline 17 & 0.48 \\
\hline 18 & 0.52 \\
\hline 19 & 0.56 \\
\hline 20 & 0.6 \\
\hline 21 & 0.65 \\
\hline 22 & 0.7 \\
\hline 23 & 0.76 \\
\hline 24 & 0.82 \\
\hline & \\
\hline
\end{tabular}

RPP-RPT-30807, Rev. 0

Theoretical Fluid Résponse

Calculations for Rigid Roofless Tank at 490 in. Waste Level
Checked by: K.R. Roberson

Kfen

\begin{tabular}{|r|r|}
\hline & \multicolumn{1}{|c|}{0} \\
\hline 0 & $5.13 \cdot 10^{-6}$ \\
\hline 1 & $5.7 \cdot 10^{-6}$ \\
\hline 2 & $7.1 \cdot 10^{-6}$ \\
\hline 3 & $9.52 \cdot 10^{-6}$ \\
\hline 4 & $1.33 \cdot 10^{-5}$ \\
\hline 5 & $1.91 \cdot 10^{-5}$ \\
\hline 6 & $2.76 \cdot 10^{-5}$ \\
\hline 7 & $4.02 \cdot 10^{-5}$ \\
\hline 8 & $5.86 \cdot 10^{-5}$ \\
\hline 9 & $8.56 \cdot 10^{-5}$ \\
\hline 10 & $1.25 \cdot 10^{-4}$ \\
\hline 11 & $1.83 \cdot 10^{-4}$ \\
\hline 12 & $2.67 \cdot 10^{-4}$ \\
\hline 13 & $3.9 \cdot 10^{-4}$ \\
\hline 14 & $5.7 \cdot 10^{-4}$ \\
\hline 15 & $8.33 \cdot 10^{-4}$ \\
\hline 16 & $1.22 \cdot 10^{-3}$ \\
\hline 17 & $1.78 \cdot 10^{-3}$ \\
\hline 18 & $2.6 \cdot 10^{-3}$ \\
\hline 19 & $3.8 \cdot 10^{-3}$ \\
\hline 20 & $5.55 \cdot 10^{-3}$ \\
\hline 21 & $8.11 \cdot 10^{-3}$ \\
\hline 22 & 0.01 \\
\hline 23 & 0.02 \\
\hline 24 & 0.03 \\
\hline & \\
\hline &
\end{tabular}


Prepared by: F. G. Abatt M\&D Professignal Services $8 / 3 / 06$

Rev. 0
RPP-RPT-30807, Rev. 0

Theoretical Fluid Response Calculations for Rigid Roofless Tank at 490 in. Waste Level
Checked by: K.R. Roberson KICK

Impulsive pressure coefficient as a function of dimensionless wall height

$$
c_{i}\left(\eta_{1}\right):=1-\operatorname{con}_{0}\left(\eta_{1}\right)-\operatorname{con}_{1}\left(\eta_{1}\right)-\operatorname{con}_{2}\left(\eta_{1}\right) \quad \text { Eqn. 4.7 BNL (1995) }
$$

\begin{tabular}{|r|r|}
\hline & 0 \\
\hline 0 & 0.78 \\
\hline 1 & 0.78 \\
\hline 2 & 0.77 \\
\hline 3 & 0.77 \\
\hline 4 & 0.76 \\
\hline 5 & 0.76 \\
\hline 6 & 0.75 \\
\hline 7 & 0.74 \\
\hline 8 & 0.72 \\
\hline 9 & 0.71 \\
\hline 10 & 0.69 \\
\hline 11 & 0.67 \\
\hline 12 & 0.65 \\
\hline 13 & 0.63 \\
\hline 14 & 0.6 \\
\hline 15 & 0.57 \\
\hline 16 & 0.54 \\
\hline 17 & 0.5 \\
\hline 18 & 0.46 \\
\hline 19 & 0.42 \\
\hline 20 & 0.37 \\
\hline 21 & 0.31 \\
\hline 22 & 0.24 \\
\hline 23 & 0.17 \\
\hline 24 & 0.09 \\
\hline & \\
\hline
\end{tabular}

Calculate maximum values of dynamic wall pressures from spectral acceleration of dome input TH.

Consider the first three convective mode spectral accelerations for the $0.1 \%$ damped spectrum

$$
\begin{array}{ll}
\mathrm{SA}_{\mathrm{c} 0}:=0.066 \cdot \mathrm{g} & \mathrm{SA}_{\mathrm{c} 0}=25.5 \frac{\mathrm{in}}{\mathrm{sec}^{2}} \\
\mathrm{SA}_{\mathrm{c} 1}:=0.11 \cdot \mathrm{g} & \mathrm{SA}_{\mathrm{cl}}=42.5 \frac{\mathrm{in}}{\mathrm{sec}^{2}} \quad \text { ANSYS dome RS from Spectr } \\
\mathrm{SA}_{\mathrm{c} 2}:=0.17 \cdot \mathrm{g} & \mathrm{SA}_{\mathrm{c} 2}=65.69 \frac{\mathrm{in}}{\mathrm{sec}^{2}}
\end{array}
$$

\section{$B-38$ of $B-65$}


Prepared by: F. G. Abatt M\&D Professignal Services 8/3/06

Rev. 0
RPP-RPT-30807, Rev. 0 Theoretical Fluid Response Calculations for Rigid Roofless Tank at 490 in. Waste Level
Checked by: K.R. Roberson

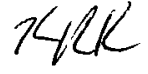

Associate the impulsive mode with the peak ground acceleration, since the tank is rigid.

$$
\begin{aligned}
& \mathrm{PGA}:=0.276 \mathrm{~g} \quad \mathrm{PGA}=106.65-\frac{\mathrm{in}}{\mathrm{sec}^{2}} \quad \text { ANSYS dome RS from Spectr } \\
& p_{\operatorname{maxconv}}\left(\eta_{1}, \theta\right):=\left[\sqrt{\left(\operatorname{con}_{0}\left(\eta_{1}\right) \cdot S A_{c 0}\right)^{2}+\left(\operatorname{con}_{1}\left(\eta_{1}\right) \cdot S A_{c 1}\right)^{2}+\left(\operatorname{con}_{2}\left(\eta_{1}\right) \cdot S A_{c 2}\right)^{2}}\right] \cdot\left(\rho_{1} \cdot R \cdot \cos (\theta \cdot \operatorname{deg})\right) \\
& p_{\text {maximpulsive }}\left(\eta_{1}, \theta\right):=\left[\sqrt{\left[c_{i}\left(\eta_{1}\right) \cdot(P G A)\right]^{2}}\right] \cdot\left(\rho_{1} \cdot R \cdot \cos (\theta \cdot \operatorname{deg})\right) \\
& p_{\max }\left(\eta_{1}, \theta\right):=\left[\sqrt{\left[\left(c_{i}\left(\eta_{1}\right)\right) \cdot(P G A)\right]^{2}+\left(\operatorname{con}_{0}\left(\eta_{1}\right) \cdot S A_{c 0}\right)^{2}+\left(\operatorname{con}_{1}\left(\eta_{1}\right) \cdot S A_{c 1}\right)^{2}+\left(\operatorname{con}_{2}\left(\eta_{1}\right) \cdot S A_{c 2}\right)^{2}}\right] \cdot\left(\rho_{1} \cdot R \cdot \cos (\theta \cdot \operatorname{deg})\right)
\end{aligned}
$$

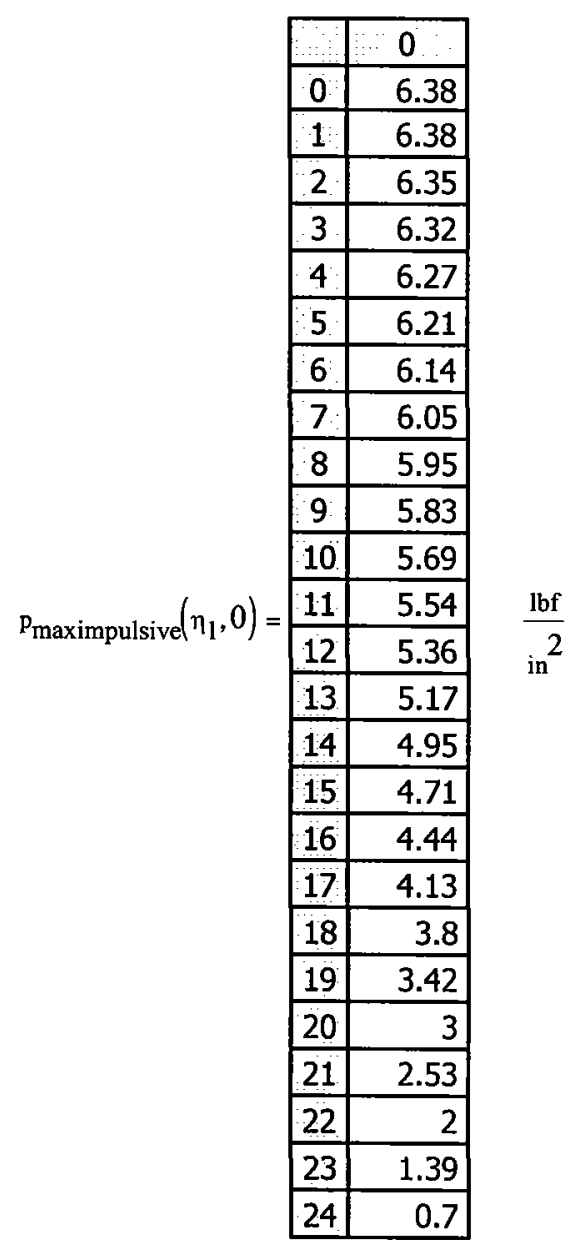

Maximum impulsive dynamic pressures at theta $=0$. 
Prepared by: F. G. Abatt M\&D Professignal Services 8/3/06

Rev. 0

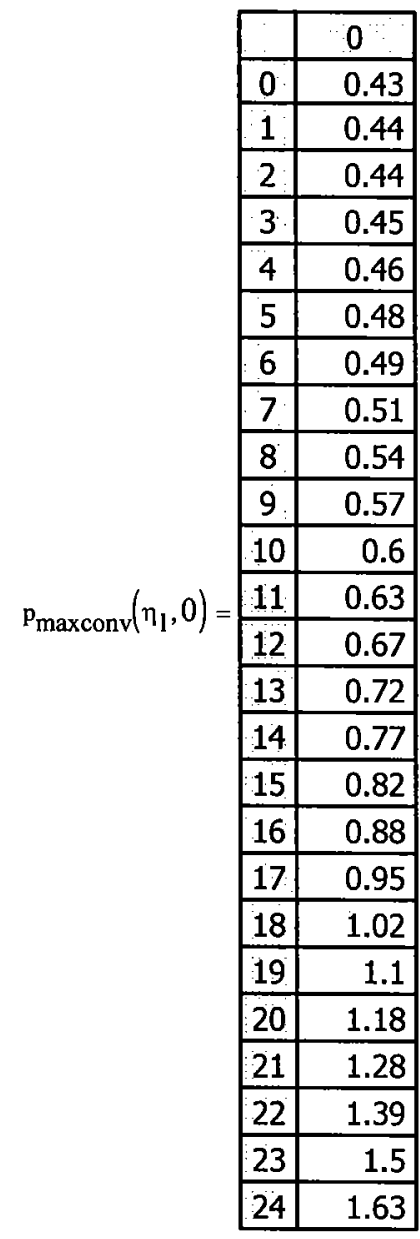

RPP-RPT-30807, Rev. 0

Theoretical Fluid Response

Calculations for Rigid Roofless Tank at 490 in. Waste Level

Checked by: K.R. Roberson

X⿻一𠃋 $\frac{\mathrm{lbf}}{2} \quad$ Maximum convective dynamic

in $^{2} \quad$ pressures at theta $=0$.
.

\begin{tabular}{|l|l|}
\hline & 0 \\
\hline 0 & 6.4 \\
\hline & 6.39 \\
\hline
\end{tabular}

\begin{tabular}{|r|r|}
\hline 0 & 6.4 \\
\hline 1 & 6.39 \\
\hline
\end{tabular}

\begin{tabular}{|l|r|}
\hline 2 & 6.37 \\
\hline 3 & 6.34 \\
\hline
\end{tabular}

\begin{tabular}{|l|l|}
\hline 3 & 6.34 \\
\hline 4 & 6.29 \\
\hline
\end{tabular}

\begin{tabular}{|l|l|}
\hline 4 & 6.29 \\
\hline 5 & 6.23 \\
\hline
\end{tabular}

\begin{tabular}{|l|l|}
\hline 5 & 6.23 \\
\hline 6 & 6.16 \\
\hline
\end{tabular}

\begin{tabular}{|l|l|}
\hline 6 & 6.16 \\
\hline 7 & 6.07 \\
\hline
\end{tabular}

\begin{tabular}{|l|r|}
\hline 7 & 6.07 \\
\hline 8 & 5.97 \\
\hline
\end{tabular}

\begin{tabular}{l|r|}
\hline 8 & 5.97 \\
\hline 9 & 5.85 \\
\hline
\end{tabular}

\begin{tabular}{|l|r|}
\hline 9 & 5.85 \\
\hline
\end{tabular}

\begin{tabular}{|l|r|}
\hline 10 & 5.72 \\
\hline
\end{tabular}

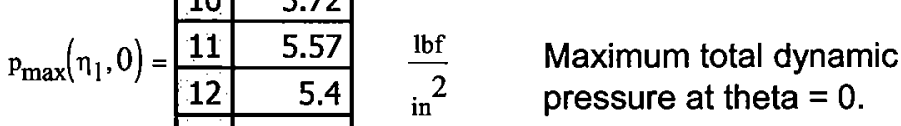

\begin{tabular}{|l|l|}
\hline 14 & 5.01 \\
\hline
\end{tabular}

\begin{tabular}{|l|l|}
\hline 15 & 4.78 \\
\hline
\end{tabular}

\begin{tabular}{|l|l|}
\hline 16 & 4.52 \\
\hline
\end{tabular}

\begin{tabular}{|l|l|}
\hline 17 & 4.24 \\
\hline
\end{tabular}

\begin{tabular}{|r|r|}
\hline 18 & 3.93 \\
\hline 19
\end{tabular}

\begin{tabular}{|l|r|}
\hline 19 & 3.6 \\
\hline 20 & 3.23 \\
\hline
\end{tabular}

\begin{tabular}{|r|r|}
\hline 20 & 3.23 \\
\hline
\end{tabular}

\begin{tabular}{|l|r|}
\hline 21 & 2.84 \\
\hline
\end{tabular}

\begin{tabular}{|l|l|}
\hline 22 & 2.43 \\
\hline
\end{tabular}

\begin{tabular}{|l|r|}
\hline 23 & 2.05 \\
\hline
\end{tabular}

\begin{tabular}{l|l|}
\hline 24 & 1.77 \\
\hline
\end{tabular} 
Prepared by: F. G. Abatt M\&D Professional Services 8/3/06

Rev. 0

\begin{tabular}{|r|r|}
\hline & 0 \\
\hline 0 & 4.53 \\
\hline 1 & 4.52 \\
\hline 2 & 4.5 \\
\hline 3 & 4.48 \\
\hline 4 & 4.45 \\
\hline 5 & 4.41 \\
\hline 6 & 4.35 \\
\hline 7 & 4.29 \\
\hline 8 & 4.22 \\
\hline 9 & 4.14 \\
\hline 10 & 4.05 \\
\hline 11 & 3.94 \\
\hline 12 & 3.82 \\
\hline 13 & 3.69 \\
\hline 14 & 3.54 \\
\hline 15 & 3.38 \\
\hline 16 & 3.2 \\
\hline 17 & 3 \\
\hline 18 & 2.78 \\
\hline 19 & 2.54 \\
\hline 20 & 2.28 \\
\hline 21 & 2.01 \\
\hline 22 & 1.72 \\
\hline
\end{tabular}

RPP-RPT-30807, Rev. 0

Theoretical Fluid Response Calculations for Rigid Roofless Tank at 490 in. Waste Level
Checked by: K.R. Roberson

KUK $\frac{\mathrm{lbf}}{2} \quad$ Maximum total dynamic pressure at theta $=45$ degrees.

Calculate the Maximum Slosh Height:

conmax $:=\left(\begin{array}{l}0.837) \\ 0.073 \\ 0.028\end{array}\right) \quad$ Maximum value of convective coefficients at $\eta_{1}=1$

$h_{\text {maxslosh }}:=R \cdot \sqrt{\left(\operatorname{conmax}_{0} \cdot \frac{\mathrm{SA}_{\mathrm{c} 0}}{\mathrm{~g}}\right)^{2}+\left(\operatorname{conmax}_{1} \cdot \frac{\mathrm{SA} \mathrm{cl}}{\mathrm{g}}\right)^{2}+\left(\operatorname{conmax} 2 \cdot \frac{\mathrm{SA}_{\mathrm{c} 2}}{\mathrm{~g}}\right)^{2}} \quad$ Eqn. $4.60 \mathrm{BNL}$ (1995)

$h_{\text {maxslosh }}=25.21$ in $\quad$ Maximum theoretical slosh height 
Prepared by: F. G. Abatt M\&D Professional Services 8/3/06

Rev. 0
RPP-RPT-30807, Rev. 0

Theoretical Fluid Response Calculations for Rigid Roofless Tank at 490 in. Waste Level
Checked by: K.R. Roberson

KRR

\section{Calculate Maximum Total Hydrodynamic Force:}

The maximum hydrodynamic force induced on the tank wall is given by Eqn. 4.31 of BNL 1995 with the instantaneous accelerations replaced by the maximum spectral accelerations. First determine the effective impulsive and convective masses.

$\mathrm{m}_{\text {lapprox }}:=\pi \cdot \mathrm{R}^{2} \cdot \mathrm{H}_{1} \cdot \rho_{1} \quad \mathrm{~m}_{\text {lapprox }}=5.33 \times 10^{4} \frac{\mathrm{lbf} \cdot \mathrm{sec}^{2}}{\text { in }} \quad \begin{aligned} & \text { Total waste mass based on circular cylinder } \\ & \text { approximation. }\end{aligned}$ $\mathrm{m}_{1}:=5.24 \cdot 10^{4} \cdot \frac{\mathrm{lbf} \cdot \mathrm{sec}^{2}}{\text { in }} \quad$ Actual waste mass reported by Dytran model.

$\mathrm{m}_{\mathrm{c} 0}:=\left[\frac{2}{\lambda_{0} \cdot\left[\left(\lambda_{0}\right)^{2}-1\right] \cdot\left(\frac{\mathrm{H}_{1}}{\mathrm{R}}\right)}\right] \cdot \tanh \left[\lambda_{0} \cdot\left(\frac{\mathrm{H}_{1}}{\mathrm{R}}\right)\right] \cdot \mathrm{m}_{\mathrm{l}} \quad$ Eqn. $4.32 \mathrm{BNL}(1995)$

$\mathrm{m}_{\mathrm{c} 0}=2.11 \times 10^{4} \frac{\mathrm{lbf} \cdot \mathrm{sec}^{2}}{\text { in }} \quad$ First mode convective mass

$\mathrm{m}_{\mathrm{c} 1}:=\left[\frac{2}{\lambda_{1} \cdot\left[\left(\lambda_{1}\right)^{2}-1\right] \cdot\left(\frac{\mathrm{H}_{1}}{\mathrm{R}}\right)}\right] \cdot \tanh \left[\lambda_{1} \cdot\left(\frac{\mathrm{H}_{1}}{\mathrm{R}}\right)\right] \cdot \mathrm{m}_{1} \quad$ Second mode convective mass

$\mathrm{m}_{\mathrm{cl}}=658.42 \frac{\mathrm{lbf} \cdot \mathrm{sec}^{2}}{\text { in }}$

$\mathrm{m}_{\mathrm{c} 2}:=\left[\frac{2}{\lambda_{2} \cdot\left[\left(\lambda_{2}\right)^{2}-1\right] \cdot\left(\frac{\mathrm{H}_{1}}{\mathrm{R}}\right)}\right] \cdot \tanh \left[\lambda_{2} \cdot\left(\frac{\mathrm{H}_{1}}{\mathrm{R}}\right)\right] \cdot \mathrm{m}_{1} \quad$ Third mode convective mass

$\mathrm{m}_{\mathrm{c} 2}=156.9 \frac{\mathrm{lbf} \cdot \mathrm{sec}^{2}}{\text { in }}$

$\mathrm{m}_{\mathrm{i}}:=\mathrm{m}_{1}-\left(\mathrm{m}_{\mathrm{c} 0}+\mathrm{m}_{\mathrm{c} 1}+\mathrm{m}_{\mathrm{c} 2}\right) \quad$ Impulsive mass - Eqn. 4.33 BNL (1995)

$\mathrm{m}_{\mathrm{i}}=3.05 \times 10^{4} \frac{\mathrm{lbf} \cdot \mathrm{sec}^{2}}{\text { in }}$ 
Prepared by: F. G. Abatt M\&D Professional Services 8/3/06

Rev. 0
RPP-RPT-30807, Rev. 0

Theoretical Fluid Response Calculations for Rigid Roofless Tank at 490 in. Waste Level
Checked by: K.R. Roberson

Kuk

$$
\begin{aligned}
& F_{\max }:=m_{1} \cdot P G A+m_{c 0} \cdot S A_{c 0}+m_{c 1} \cdot S A_{c 1}+m_{c 2} \cdot S A_{c 2} \\
& F_{\max }=3.83 \times 10^{6} \mathrm{lbf} \quad \text { Conservative estimate of maximum hydrodynamic force }
\end{aligned}
$$

The above expression is a conservative estimate because it assumes that the peak impulsive and convective forces occur simultaneously. A less conservative estimate can be made via a square-root-sum-of-the-squares (SRSS) combination.

$$
\begin{aligned}
& \mathrm{F}_{\mathrm{srss}}:=\sqrt{\left(\mathrm{m}_{\mathrm{i}} \cdot \mathrm{PGA}\right)^{2}+\left(\mathrm{m}_{\mathrm{c} 0} \cdot \mathrm{SA}_{\mathrm{c} 0}\right)^{2}+\left(\mathrm{m}_{\mathrm{cl}} \cdot \mathrm{SA}_{\mathrm{c} 1}\right)^{2}+\left(\mathrm{m}_{\mathrm{c} 2} \cdot \mathrm{SA}_{\mathrm{c} 2}\right)^{2}} \\
& \mathrm{~F}_{\mathrm{srss}}=3.3 \times 10^{6} \mathrm{lbf} \quad \text { SRSS estimate of peak hydrodynamic force }
\end{aligned}
$$

$\mathrm{F}_{\text {conmax }}:=\sqrt{\left(\mathrm{m}_{\mathrm{c} 0} \cdot \mathrm{SA}_{\mathrm{c} 0}\right)^{2}+\left(\mathrm{m}_{\mathrm{c} 1} \cdot \mathrm{SA}_{\mathrm{cl}}\right)^{2}+\left(\mathrm{m}_{\mathrm{c} 2} \cdot \mathrm{SA}_{\mathrm{c} 2}\right)^{2}}$

$\mathrm{F}_{\text {conmax }}=5.39 \times 10^{5} \mathrm{lbf} \quad \begin{aligned} & \text { Peak hydrodynamic force due to convective response - shows up in free } \\ & \text { oscillations. }\end{aligned}$

Reference:

BNL 1995, Seismic Design and Evaluation Guidelines for the Department of Energy High-Level Waste Storage Tanks and Appurtenances, BNL 52361, Rev. 10/95, Brookhaven National Laboratory, Upton, New York. 
Prepared by: F. G. Abatt M\&D Professional Services 8/3/06

Rev. 0

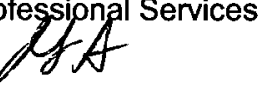

RPP-RPT-30807, Rev. 0 Calculations for Rigid Flat Top Tank at 490 in. Waste Level
Checked by: K.R. Roberson

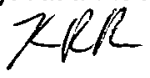

This worksheet contains calculations for a rigid flat top tank with an initial liquid level of 490 in. At this liquid level, the sloshing liquid interacts with the tank roof. The calculations are performed using the methodology in Chapter 4 and Appendix D of BNL (1995) and in Malthotra (2005). The location of the fluid elements corresponds to the Dytran model of the flat top tank.

$\mathrm{H}_{1}:=490.0$ in $\quad$ Baseline liquid level
$\mathrm{H}_{\mathrm{t}}:=500.0$ in $\quad$ Height to tank roof
$\mathrm{h}_{0}:=\mathrm{H}_{\mathrm{t}}-\mathrm{H}_{1} \quad \mathrm{~h}_{0}=10 \mathrm{in} \quad$ freeboard distance
$\frac{\mathrm{H}_{1}}{\mathrm{H}_{\mathrm{t}}}=0.98 \quad$ Ratio of waste height to tank height
$\frac{\mathrm{sec}}{2}:=386.4 \cdot \frac{\text { in }}{\mathrm{R}}:=450$ in $\quad$ Tank radius
$\frac{\mathrm{H}_{1}}{\mathrm{R}}=1.089 \quad$ Ratio of waste height to tank radius

$\mathrm{i}:=0 . .2$

$\lambda:=\left(\begin{array}{l}1.841 \\ 5.331 \\ 8.536)\end{array} \quad\right.$ Bessel function roots

$\theta:=\left(\begin{array}{c}0 \cdot \mathrm{deg} \\ 45 \cdot \mathrm{deg} \\ 90 \cdot \mathrm{deg}\end{array}\right) \quad$ Circumferential location of waste elements for which pressures are reported

$\rho_{1}:=1.71 \cdot 10^{-4} \cdot \frac{\mathrm{lbf} \cdot \mathrm{sec}^{2}}{\text { in }^{4}} \quad$ Liquid mass density - specific gravity of 1.83 
Prepared by: F. G. Abatt

M\&D Professignal Services

$8 / 3 / 06$

Rev. 0

\section{Convective Frequencies}

fcon $_{\mathrm{i}}:=\frac{1}{2 \cdot \pi} \cdot\left[\sqrt{\left.\left[\lambda_{\mathrm{i}}\left[\frac{\mathrm{g}}{\mathrm{R}} \cdot \tanh \left[\lambda_{\mathrm{i}} \cdot\left(\frac{\mathrm{H}_{\mathrm{l}}}{\mathrm{R}}\right)\right]\right]\right]\right]}\right.$

fcon $=\left(\begin{array}{l}0.197) \\ 0.341 \mid \mathrm{Hz} \\ 0.431)\end{array} \quad\right.$ First three convective frequencies

Eqn. 4.14 BNL (1995)

Consider the first three convective mode spectral accelerations for the $0.1 \%$ damped spectrum

$\mathrm{SA}_{\mathrm{c} 0}:=0.066 \cdot \mathrm{g}$

$$
\mathrm{SA}_{\mathrm{c} 0}=25.502 \frac{\text { in }}{\sec ^{2}}
$$

$\mathrm{SA}_{\mathrm{cl}}:=0.11 \cdot \mathrm{g}$

$$
\mathrm{SA}_{\mathrm{cl}}=42.504 \frac{\text { in }}{\mathrm{sec}^{2}}
$$

ANSYS dome RS from Spectr

$\mathrm{SA}_{\mathrm{c} 2}:=0.17 \cdot \mathrm{g}$

$$
\mathrm{SA}_{\mathrm{c} 2}=65.688 \frac{\mathrm{in}}{\mathrm{sec}^{2}}
$$

Associate the impulsive mode with the peak ground acceleration, since the tank is rigid.

$\mathrm{PGA}:=0.276 . \mathrm{g} \quad \mathrm{PGA}=106.646 \frac{\mathrm{in}}{\mathrm{sec}^{2}} \quad$ ANSYS dome RS from Spectr

\section{Calculate Maximum Slosh Height per BNL (1995):}

conmax $:=\left(\begin{array}{l}0.837 \\ 0.073 \\ 0.028\end{array}\right) \quad$ Maximum value of convective coefficients at $\eta_{1}=1$

$\mathbf{h}_{\mathrm{s}}:=\mathbf{R} \cdot \sqrt{\left(\operatorname{conmax}_{0} \cdot \frac{\mathrm{SA}_{\mathrm{c} 0}}{\mathrm{~g}}\right)^{2}+\left(\operatorname{conmax}_{1} \cdot \frac{\mathrm{SA}_{\mathrm{cl}}}{\mathrm{g}}\right)^{2}+\left(\operatorname{conmax}_{2} \cdot \frac{\mathrm{SA}_{\mathrm{c} 2}}{\mathrm{~g}}\right)^{2}} \quad$ Eqn. $4.60 \mathrm{BNL}(1995)$

$h_{s}=25.211$ in Maximum theoretical slosh height for roofless tank per BNL (1995) 
Prepared by: F. G. Abatt M\&D Professjonal Services 8/3/06

Rev. 0
RPP-RPT-30807, Rev. 0 Calculations for Rigid Flat Top Tank at 490 in. Waste Level
Checked by: K.R. Roberson kin

\section{Recalculate the Maximum Slosh Height per Malhotra (2005):}

$\mathrm{j}:=0 . .1$

$\mathrm{H}_{\mathrm{r}}:=\left(\begin{array}{l}1.0) \\ 1.5)\end{array} \mathrm{C}_{\text {cref }}:=\left(\begin{array}{l}1.52 \\ 1.48\end{array}\right) \quad\right.$ Table 1 of Malhotra (2005)

$\mathrm{C}_{\mathrm{c}}:=\operatorname{linterp}\left(\mathrm{H}_{\mathrm{T}}, \mathrm{C}_{\mathrm{cref}}, \frac{\mathrm{H}_{\mathrm{l}}}{\mathrm{R}}\right) \frac{\mathrm{sec}}{\sqrt{\mathrm{m}}} \quad \mathrm{C}_{\mathrm{c}}=1.513 \frac{\mathrm{sec}}{\mathrm{m}^{0.5}}$

$\mathrm{T}_{\text {con }}:=\mathrm{C}_{\mathrm{c}} \cdot \sqrt{\mathrm{R}} \quad \mathrm{T}_{\text {con }}=5.115 \mathrm{sec}$

$f_{\text {cMalhotra }}=\frac{1}{T_{\text {con }}} \quad f_{c \text { Malhotra }}=0.196 \mathrm{~Hz} \quad \begin{aligned} & \text { Fundamental convective frequency per } \\ & \text { Malhotra }(2005)\end{aligned}$

Since this agrees with the frequency calculated via BNL (1995), the convective acceleration is the same in both cases.

$\mathrm{h}_{\mathrm{sMalhotra}}:=\mathrm{R} \cdot \frac{\mathrm{SA}_{\mathrm{c} 0}}{\mathrm{~g}} \quad$ Eqn. (9) of Malhotra (2005)

$\mathrm{h}_{\text {sMalhotra }}=29.7 \mathrm{in} \quad$ Maximum slosh height for roofless tank per Malhotra (2005)

\section{Calculate the Central Half-Angle for Wetted Portion of Tank Roof:}

$\theta_{0}:=\operatorname{acos}\left(\frac{\mathrm{h}_{0}}{\mathrm{~h}_{\mathrm{s}}}\right)$

$\theta_{0}=66.6 \mathrm{deg}$

Central half-angle of maximum impacted roof area per Eqn. D.2 BNL (1995)

$\frac{\mathrm{h}_{0}}{\mathrm{~h}_{\text {sMalhotra }}}=0.34$

Used to calculate $x_{f}$ from Figure 3 of Malhotra (2005)

$x_{f}:=0.77 \cdot R \quad x_{f}=346.5$ in $\quad$ Wetted width of tank roof per Figure 3 of Malhotra (2005)

$\psi_{0}:=\operatorname{acos}\left(\frac{\mathrm{x}_{\mathrm{f}}}{\mathrm{R}}-1\right) \quad \Psi_{0}=1.803$

$\theta_{\text {OMalhotra }}:=\pi-\psi_{0} \quad \theta_{0 \text { Malhotra }}=76.7 \mathrm{deg}$ Central half-angle per Malhotra (2005)

B-46 of B-65 
Prepared by: F. G. Abatt

M\&D Professional Services

8/3/06

Rev. 0

Maximum Roof Pressure:

$r:=424.875 \cdot$ in Typical centroidal radius of Dytran elements for which results are monitored

$\mathrm{p}_{\mathrm{r}}(\mathrm{r}, \theta):=\rho_{\mathrm{I}} \cdot \mathbf{r} \cdot \mathrm{PGA} \cdot \cos (\theta)$

$$
\text { for }|\theta|<\left|\theta_{0}\right| \quad \text { maximum roof pressure }
$$

$\mathrm{p}_{\mathrm{r}}(\mathrm{R}, 0)=8.21 \frac{\mathrm{lbf}}{\text { in }^{2}}$

Peak roof pressure per BNL (1995)

$\mathrm{p}_{\mathrm{r}}(\mathrm{r}, 0)=7.75 \frac{\mathrm{lbf}}{\text { in }^{2}}$

$p_{\text {maxroofMalhotra }}:=\rho_{1} \cdot x_{f} S A_{c 0}$

$\mathrm{P}_{\text {maxroofMalhotra }}=1.51 \frac{\mathrm{lbf}}{\mathrm{in}^{2}}$

Maximum Wall Pressure:

$\mathrm{p}_{\mathrm{ic}}(\theta):=\rho_{\mathrm{l}} \cdot \mathrm{R} \cdot \mathrm{PGA} \cdot \cos (\theta) \quad$ Impulsive component of pressure due to constrained portion of the liquid.
Checked by: K.R. Roberson

$z / C$
Peak roof pressure per Malhotra (2005)

Predicted peak roof pressure for Dytran element per BNL (1995)
RPP-RPT-30807, Rev. 0

Calculations for Rigid Flat Top Tank at $490 \mathrm{in.}$ Waste Level

$\mathrm{p}_{\mathrm{ic}}(\theta)=\left(\begin{array}{cc}8.206 \\ 5.803 \\ 0 & \left.\right|^{\mathrm{lbf}} \\ \mathrm{in}^{2}\end{array}\right.$ 
Prepared by: F. G. Abatt M\&D Professional Services 8/3/06

Rev. 0

$$
\eta_{1}:=\left(\begin{array}{l}
4.5 \cdot \text { in } \\
25 \cdot \text { in } \\
45 \cdot \text { in } \\
65 \cdot \text { in } \\
85 \cdot \text { in } \\
105 \cdot \text { in } \\
125 \cdot \text { in } \\
145 \cdot \text { in } \\
165 \cdot \text { in } \\
185 \cdot \text { in } \\
205 \cdot \text { in } \\
225 \cdot \text { in } \\
245 \cdot \text { in } \\
265 \cdot \text { in } \\
285 \cdot \text { in } \\
305 \cdot \text { in } \\
325 \cdot \text { in } \\
345 \cdot \text { in } \\
365 \cdot \text { in } \\
385 \cdot \text { in } \\
405 \cdot \text { in } \\
425 \cdot \text { in } \\
445 \cdot \text { in } \\
465 \cdot \text { in } \\
485 \cdot \text { in }
\end{array}\right)
$$

RPP-RPT-30807, Rev. 0 Calculations for Rigid Flat Top Tank at 490 in. Waste Level
Checked by: K.R. Roberson

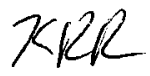

Vertical location of Euler element centroids at which pressures are reported.

\begin{tabular}{|r|r|}
\hline & \multicolumn{1}{|c|}{0} \\
\hline 0 & $9.184 \cdot 10^{-3}$ \\
\hline 1 & 0.051 \\
\hline 2 & 0.092 \\
\hline 3 & 0.133 \\
\hline 4 & 0.173 \\
\hline 5 & 0.214 \\
\hline 6 & 0.255 \\
\hline 7 & 0.296 \\
\hline 8 & 0.337 \\
\hline 9 & 0.378 \\
\hline 10 & 0.418 \\
\hline 11 & 0.459 \\
\hline
\end{tabular}

$\eta_{1}=$\begin{tabular}{|r|r|}
\hline 11 & 0.459 \\
\hline 12 & 0.5 \\
\hline 13 & 0.541 \\
\hline 14 & 0.582 \\
\hline 15 & 0.622 \\
\hline 16 & 0.663 \\
\hline 17 & 0.704 \\
\hline 18 & 0.745 \\
\hline 19 & 0.786 \\
\hline 20 & 0.827 \\
\hline 21 & 0.867 \\
\hline 22 & 0.908 \\
\hline 23 & 0.949 \\
\hline 24 & 0.99 \\
\hline
\end{tabular}

Ratio of tank wall vertical location to waste height for waste element centroids. 
Prepared by: F. G. Abatt M\&D Professional Services 8/3/06

Rev. 0
RPP-RPT-30807, Rev. 0 Calculations for Rigid Flat Top Tank at 490 in. Waste Level
Checked by: K.R. Roberson

$$
\text { KAM }
$$

Determine convective coefficients as a function of dimensionless height per BNL (1995) Eqn. 4.4

$$
\begin{aligned}
& \operatorname{con}_{0}\left(\eta_{1}\right):=\left[\frac{2}{\left(\lambda_{0}{ }^{2}-1\right.} \cdot \frac{\cosh \left[\lambda_{0} \cdot\left(\frac{H_{1}}{R}\right) \cdot \eta_{1}\right]}{\cosh \left[\lambda_{0} \cdot\left(\frac{H_{1}}{R}\right)\right]}\right] \\
& \operatorname{con}_{1}\left(\eta_{1}\right):=\left[\frac{2}{\left(\lambda_{1}\right)^{2}-1} \cdot \frac{\cosh \left[\lambda_{1} \cdot\left(\frac{H_{1}}{R}\right) \cdot \eta_{1}\right]}{\cosh \left[\lambda_{1}\left(\frac{H_{1}}{R}\right)\right]}\right] \\
& \operatorname{con}_{2}\left(\eta_{1}\right):=\left[\frac{2}{\left(\lambda_{2}\right)^{2}-1} \cdot \frac{\cosh \left[\lambda_{2} \cdot\left(\frac{H_{1}}{R}\right) \eta_{1}\right]}{\cosh \left[\lambda_{2}\left(\frac{H_{1}}{R}\right)\right]}\right]
\end{aligned}
$$

Impulsive pressure coefficient as a function of dimensionless wall height

$$
\begin{aligned}
& c_{i}\left(\eta_{1}\right):=1-\operatorname{con} 0\left(\eta_{1}\right) \\
& \text { Eqn. 4.7 BNL (1995) - 1st term } \\
& P_{i u}\left(\eta_{1}, \theta\right):=c_{i}\left(\eta_{1}\right) \cdot \rho_{\Gamma} \cdot R \cdot P G A \cdot \cos (\theta) \quad \text { Impulsive component of maximum wall pressure induced by } \\
& \text { unconstrained portion of liquid beneath the non-impacted portion of } \\
& \text { the roof - same as for roofless tank (BNL } 1995 \text { Eqn. D.6). } \\
& \mathrm{p}_{\mathrm{cu}}\left(\eta_{1}, \theta\right):=\operatorname{con}_{0}\left(\eta_{1}\right) \cdot \rho_{1} \cdot \mathrm{R} \cdot \mathrm{SA} \mathrm{c}_{0} \cdot \cos (\theta) \\
& \text { Convective component of maximum wall pressure induced by }
\end{aligned}
$$

$$
p_{\text {total }}\left(\eta_{1}, \theta\right):=p_{\text {itotal }}\left(\eta_{1}, \theta\right)+p_{\text {cu }}\left(\eta_{1}, \theta\right) \quad \begin{aligned}
& \text { Total wall pressure - sum of impulsive and convective } \\
& \text { components. }
\end{aligned}
$$


Prepared by: F. G. Abatt M\&D Professjonal Services 8/3/06

Rev. 0

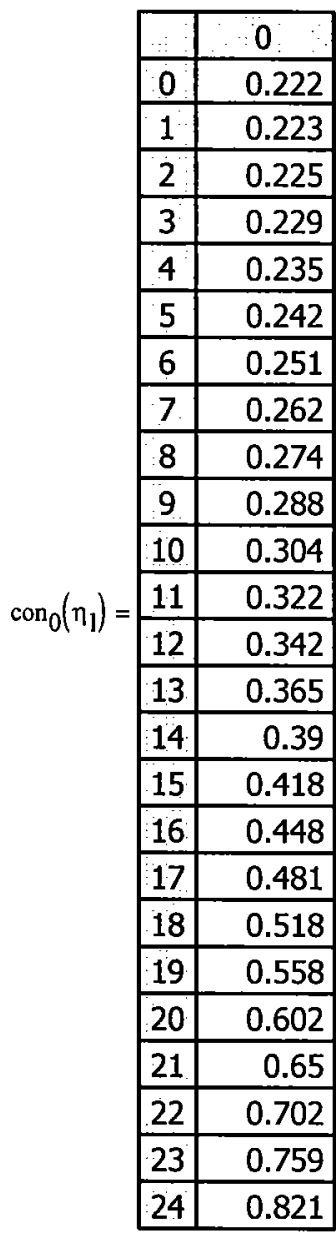

RPP-RPT-30807, Rev. 0

Calculations for Rigid Flat Top Tank at 490 in. Waste Level

Checked by: K.R. Roberson

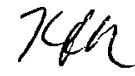

\begin{tabular}{|r|r|}
\hline & 0 \\
\hline 0 & 0.778 \\
\hline 1 & 0.777 \\
\hline 2 & 0.775 \\
\hline 3 & 0.771 \\
\hline 4 & 0.765 \\
\hline 5 & 0.758 \\
\hline 6 & 0.749 \\
\hline 7 & 0.738 \\
\hline 8 & 0.726 \\
\hline 9 & 0.712 \\
\hline 10 & 0.696 \\
\hline 11 & 0.678 \\
\hline 12 & 0.658 \\
\hline 13 & 0.635 \\
\hline 14 & 0.61 \\
\hline 15 & 0.582 \\
\hline 16 & 0.552 \\
\hline 17 & 0.519 \\
\hline 18 & 0.482 \\
\hline 19 & 0.442 \\
\hline 20 & 0.398 \\
\hline 21 & 0.35 \\
\hline 22 & 0.298 \\
\hline 23 & 0.241 \\
\hline 24 & 0.179 \\
\hline & \\
\hline
\end{tabular}


Prepared by: F. G. Abatt M\&D Professjonal Services 8/3/06

Rev. 0

$\mathrm{p}_{\text {itotal0 } 0}:=\mathrm{P}_{\mathrm{iu}}\left(\eta_{1}, 0\right)+\mathrm{p}_{\mathrm{ic}}(0)$
RPP-RPT-30807, Rev. 0 Calculations for Rigid Flat Top Tank at $490 \mathrm{in}$. Waste Level
Checked by: K.R. Roberson

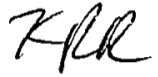

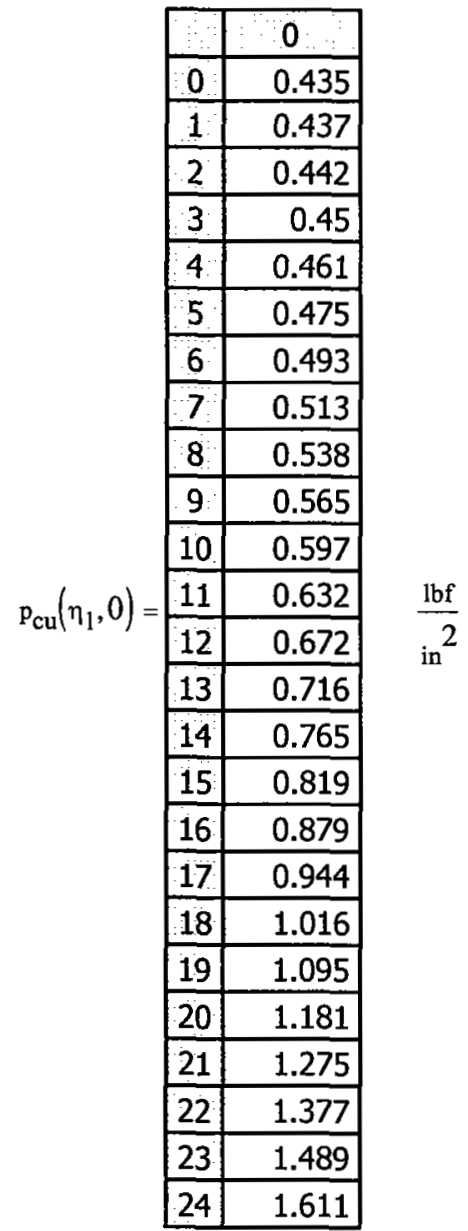


Prepared by: F. G. Abatt M\&D Professional Services $8 / 3 / 06$

Rev. 0
RPP-RPT-30807, Rev. 0 Calculations for Rigid Flat Top Tank at $490 \mathrm{in.}$ Waste Level
Checked by: K.R. Roberson

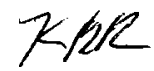

$\operatorname{datat}\left(n_{1}\right):=p_{\text {itotal0 }}+p_{\text {cu }}\left(n_{1}, 0\right)$

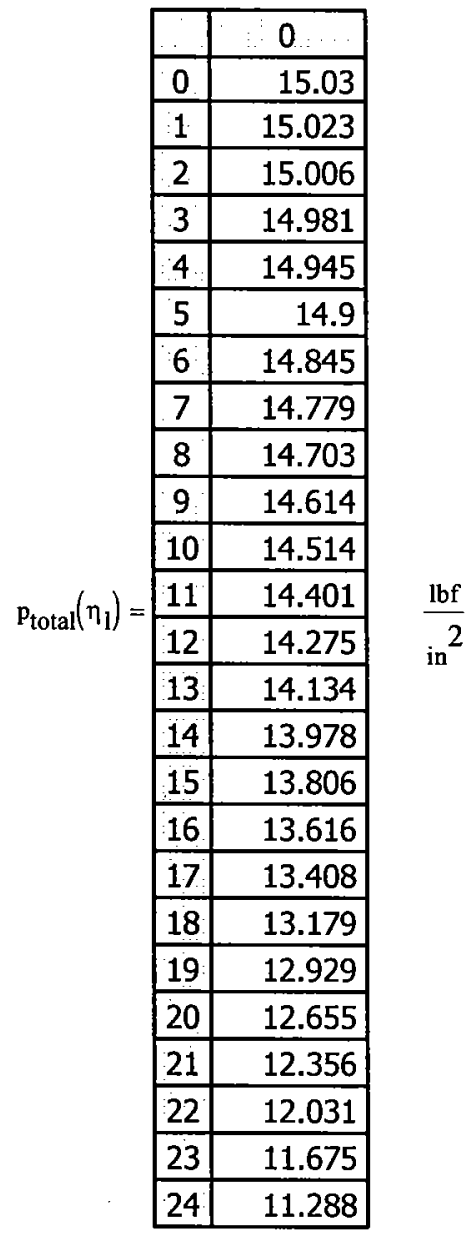

Calculate Maximum Total Hydrodynamic Force:

The maximum hydrodynamic force induced on the tank wall is given by the sum of the terms in Equations D.12, D.13, and d.14 of BNL (1995).

$\mathrm{m}_{1}:=5.24 \cdot 10^{4} \cdot \frac{\mathrm{bf} \cdot \mathrm{sec}^{2}}{\text { in }} \quad$ Actual waste mass reported by Dytran model.

$\mathrm{m}_{\mathrm{c} 0}:=\left[\frac{2}{\lambda_{0} \cdot\left[\left(\lambda_{0}{ }^{2}-1\right] \cdot\left(\frac{\mathrm{H}_{1}}{\mathrm{R}}\right)\right.}\right] \cdot \tanh \left[\lambda_{0} \cdot\left(\frac{\mathrm{H}_{\mathrm{I}}}{\mathrm{R}}\right)\right] \cdot \mathrm{m}_{\mathrm{I}} \quad$ Eqn. $4.32 \mathrm{BNL}(1995)$

$\mathrm{m}_{\mathrm{c} 0}=2.11 \times 10^{4} \frac{\mathrm{lbf} \cdot \mathrm{sec}^{2}}{\mathrm{in}} \quad$ First mode convective mass for roofless tank

$\mathrm{m}_{\mathrm{i}}:=\mathrm{m}_{1}-\mathrm{m}_{\mathrm{c} 0} \quad \mathrm{~m}_{\mathrm{i}}=3.13 \times 10^{4} \frac{\mathrm{lbf} \cdot \mathrm{sec}^{2}}{\mathrm{in}} \quad$ Impulsive mass for roofless tank 
Prepared by: F. G. Abatt M\&D Professional Services $8 / 3 / 06$

Rev. 0

$\frac{\mathrm{m}_{\mathrm{c} 0}}{\mathrm{~m}_{1}}=0.403 \quad \frac{\mathrm{m}_{\mathrm{i}}}{\mathrm{m}_{1}}=0.597$

epsilon $:=\frac{2 \cdot \theta_{0}+\sin \left(2 \cdot \theta_{0}\right)}{2 \cdot \pi}$

$\mathrm{F}_{\mathrm{ic}}:=\operatorname{epsilon} \cdot \frac{\mathrm{H}_{\mathrm{t}}}{\mathrm{H}_{\mathrm{I}}} \cdot \mathrm{m}_{1} \cdot \mathrm{PGA}$

$\mathrm{F}_{\mathrm{ic}}=2.772 \times 10^{6} \mathrm{lbf}$

$F_{i u}:=(1-$ epsilon $) \cdot m_{i} \cdot P G A$

$\mathrm{F}_{\mathrm{iu}}=1.715 \times 10^{6} \mathrm{lbf}$

$\mathrm{F}_{\mathrm{cu}}:=(1-$ epsilon $) \cdot \mathrm{m}_{\mathrm{c} 0} \cdot \mathrm{SA} \mathrm{c} 0$

$\mathrm{F}_{\mathrm{cu}}=2.766 \times 10^{5} \mathrm{lbf}$

$F_{\text {total }}:=F_{i c}+F_{i u}+F_{\text {cu }}$

$F_{\text {total }}=4.764 \times 10^{6} \mathrm{lbf}$
RPP-RPT-30807, Rev. 0 Calculations for Rigid Flat Top Tank at 490 in. Waste Level
Checked by: K.R. Roberson

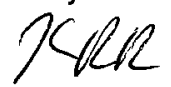

Dimensionless factor for wall force calculation Eqn. D.9 of BNL (1995).

Impulsive component of force due to constrained portion of liquid Eqn. D.12 of BNL (1995).

Impulsive component of force due to unconstrained portion of liquid Eqn. D.13 of BNL (1995).

Convective component of force due to unconstrained portion of liquid Eqn. D.14 of BNL (1995).

Total peak hydrodynamic force per Appendix D BNL (1995)

Recalculate Maximum Hydrodynamic Force Using Methodolodgy of Malhotra (2005):

The hydrodynamic force can be calculated by excluding the structural masses from Eqn. (3) of Malhotra (2005). First calculate the impulsive and convective masses.

$\dot{w}=0 . .1$

$$
\begin{aligned}
& \mathrm{HR}:=\left(\begin{array}{l}
1.0 \\
1.5
\end{array}\right)
\end{aligned}
$$

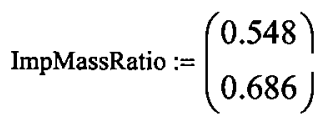

$$
\begin{aligned}
& \operatorname{linterp}\left(H R, I m p M a s s R a t i o, \frac{H_{1}}{R}\right)=0.573 \\
& \mathrm{~m}_{\text {iMalhotra }}:=\operatorname{linter}\left(\mathrm{HR}, \text { ImpMassRatio, } \frac{\mathrm{H}_{1}}{\mathrm{R}}\right) \mathrm{m}_{1} \\
& \mathrm{~m}_{\mathrm{iMalhotra}}=3 \times 10^{4} \frac{\mathrm{lbf} \cdot \mathrm{sec}^{2}}{\text { in }} \\
& \mathrm{m}_{\mathrm{cMalhotra}}:=\mathrm{m}_{1}-\mathrm{m}_{\mathrm{i} \text { Malhotra }} \\
& \mathrm{m}_{\mathrm{cMalhotra}}=2.24 \times 10^{4} \frac{\mathrm{lbf} \cdot \mathrm{sec}^{2}}{\text { in }}
\end{aligned}
$$


Prepared by: F. G. Abatt

M\&D Professiongl Services

$8 / 3 / 06$

Rev. 0
RPP-RPT-30807, Rev. 0 Calculations for Rigid Flat Top Tank at 490 in. Waste Level
Checked by: K.R. Roberson

$$
\begin{array}{ll}
\mathrm{R}_{\mathrm{i}}:=\mathrm{m}_{\mathrm{iMalhotra}} \cdot \mathrm{PGA} & \text { Eqn. (3) Malhotra (2005) } \\
\mathrm{R}_{\mathrm{c}}:=\mathrm{m}_{\mathrm{cMalhotra}} \cdot \mathrm{SA}_{\mathrm{c} 0} & \text { Eqn. (4) Malhotra (2005) }
\end{array}
$$

Modify the impulsive and convective masses to account for interaction with the tank roof per Eqns. (15) and (16) of Malhotra (2005).

$$
\begin{array}{ll}
\mathrm{m}_{\mathrm{ibar}}:=\mathrm{m}_{\mathrm{i} \text { Malhotra }}+\mathrm{m}_{\mathrm{cMalhotra}}\left(1-\frac{\mathrm{h}_{0}}{\mathrm{~h}_{\mathrm{sMalhotra}}}\right) & \mathrm{m}_{\mathrm{ibar}}=4.49 \times 10^{4} \frac{\mathrm{lbf} \cdot \mathrm{sec}^{2}}{\mathrm{in}} \\
\mathrm{m}_{\mathrm{cbar}}:=\mathrm{m}_{\mathrm{cMalhotra}} \cdot\left(\frac{\mathrm{h}_{0}}{\mathrm{~h}_{\mathrm{sMalhotra}}}\right) & \mathrm{m}_{\mathrm{cbar}}=7.54 \times 10^{3} \frac{\mathrm{lbf} \cdot \mathrm{sec}^{2}}{\mathrm{in}} \\
\mathrm{R}_{\mathrm{ibar}}:=\mathrm{m}_{\mathrm{ibar}} \cdot \mathrm{PGA} \quad \mathrm{R}_{\mathrm{ibar}}=4.78 \times 10^{6} \mathrm{lbf} & \text { Impulsive component of peak reaction force } \\
\mathrm{R}_{\mathrm{cbar}}:=\mathrm{m}_{\mathrm{cbar}} \cdot \mathrm{SA}_{\mathrm{c} 0} \quad \mathrm{R}_{\mathrm{cbar}}=1.92 \times 10^{5} \mathrm{lbf} & \text { Convective component of peak reaction force } \\
\mathrm{R}_{\mathrm{bar}}:=\mathrm{R}_{\mathrm{ibar}}+\mathrm{R}_{\mathrm{cbar}} & \text { Total peak reaction force per Malhotra (2005) } \\
\mathrm{R}_{\mathrm{bar}}=4.98 \times 10^{6} \mathrm{lbf} &
\end{array}
$$

\section{References:}

BNL 1995, Seismic Design and Evaluation Guidelines for the Department of Energy High-Level Waste Storage Tanks and Appurtenances, BNL 52361, Rev. 10/95, Brookhaven National Laboratory, Upton, New York.

Malhotra, Praveen K, 2005, Sloshing Loads in Liquid Storage Tanks With Insufficient Freeboard, Earthquake Spectra, Volume 21, No. 4, pp. 1185-1192, November 2005. 
Prepared by: F. G. Abatt M\&D Professignal Services

$6 / 1 / 06$

Rev. 0
RPP-RPT-30807, Rev. 0

Theoretical Fluid Response Calculations for Rigid Roofless Tank at 500 in. Waste Level - Dytran Configuration
Checked by: K.R. Roberson

Karl

$$
\begin{aligned}
& H_{1}:=500.0 \text { in Baseline liquid level } \\
& H_{t}:=500.0 \text {.in Height to tank roof } \\
& \frac{\mathrm{H}_{1}}{\mathrm{H}_{\mathrm{t}}}=1 \quad \text { Ratio of waste height to tank height } \\
& \mathrm{g}:=386.4 \cdot \frac{\text { in }}{\sec ^{2}} \\
& \mathrm{R}:=450 \cdot \text { in } \quad \text { Tank radius } \\
& \frac{H_{1}}{R}=1.11 \quad \text { Ratio of waste height to tank radius } \\
& \mathrm{i}:=0 . .2 \\
& \lambda:=\left(\begin{array}{l}
1.841 \\
5.331 \mid \\
8.536)
\end{array} \quad\right. \text { Bessel function roots } \\
& \theta:=\left(\begin{array}{c}
0 \cdot \mathrm{deg} \\
45 \cdot \mathrm{deg} \\
90 \cdot \mathrm{deg}
\end{array}\right) \quad \text { Circumferential location of waste elements for which pressures are reported }
\end{aligned}
$$

Convective Frequencies

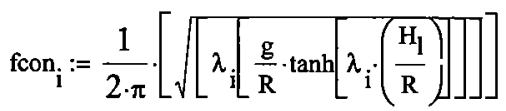

$$
\begin{aligned}
& \text { fcon }=\left(\begin{array}{l}
0.2 \\
0.34 \mid \mathrm{Hz} \\
0.43
\end{array}\right) \\
& \text { First three convective frequencies } \\
& \rho_{1}:=1.71 \cdot 10^{-4} \cdot \frac{\mathrm{lbf} \cdot \mathrm{sec}^{2}}{\text { in }^{4}} \quad \text { waste density }- \text { specific gravity }=1.83
\end{aligned}
$$

\section{B-55 of B-65}


Prepared by: F. G. Abatt M\&D Professional Services

$6 / 1 / 06$

Rev. 0
RPP-RPT-30807, Rev. 0

Theoretical Fluid Response Calculations for Rigid Roofless Tank at 500 in. Waste Level - Dytran

Configuration
Checked by: K.R. Roberson

Kip

Determine Convective Pressures on the Tank Wall:

$$
\eta_{1}:=\left(\begin{array}{l}
4.5 \cdot \text { in } \\
25 \cdot \text { in } \\
45 \cdot \text { in } \\
65 \cdot \text { in } \\
85 \cdot \text { in } \\
105 \cdot \text { in } \\
125 \cdot \text { in } \\
145 \cdot \text { in } \\
165 \cdot \text { in } \\
185 \cdot \text { in } \\
205 \cdot \text { in } \\
225 \cdot \text { in } \\
245 \cdot \text { in } \\
265 \cdot \text { in } \\
285 \cdot \text { in } \\
305 \cdot \text { in } \\
325 \cdot \text { in } \\
345 \cdot \text { in } \\
365 \cdot \text { in } \\
385 \cdot \text { in } \\
405 \cdot \text { in } \\
425 \cdot \text { in } \\
445 \cdot \text { in } \\
465 \cdot \text { in } \\
485 \cdot \text { in }
\end{array}\right)
$$$$
\text { Vertical location of Euler element centroids at which pressures }
$$$$
\text { are reported. }
$$

Ratio of tank wall vertical location to waste height for waste element centroids. 
Prepared by: F. G. Abatt M\&D Professional Services 6/1/06

Rev. 0

\begin{tabular}{|r|r|}
\hline & 0 \\
\hline 0 & $9 \cdot 10^{-3}$ \\
\hline 1 & 0.05 \\
\hline 2 & 0.09 \\
\hline 3 & 0.13 \\
\hline 4 & 0.17 \\
\hline 5 & 0.21 \\
\hline 6 & 0.25 \\
\hline 7 & 0.29 \\
\hline 8 & 0.33 \\
\hline 9 & 0.37 \\
\hline 10 & 0.41 \\
\hline 11 & 0.45 \\
\hline 12 & 0.49 \\
\hline 13 & 0.53 \\
\hline 14 & 0.57 \\
\hline 15 & 0.61 \\
\hline 16 & 0.65 \\
\hline 17 & 0.69 \\
\hline 18 & 0.73 \\
\hline 19 & 0.77 \\
\hline 20 & 0.81 \\
\hline 21 & 0.85 \\
\hline 22 & 0.89 \\
\hline 23 & 0.93 \\
\hline 24 & 0.97 \\
\hline & \\
\hline 13 &
\end{tabular}

RPP-RPT-30807, Rev. 0

Theoretical Fluid Response Calculations for Rigid Roofless Tank at 500 in. Waste Level - Dytran Configuration
Checked by: K.R. Roberson

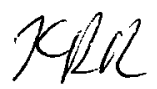

Determine convective coefficients as a function of dimensionless height per BNL 1995 Eqn. 4.4

$\operatorname{con}_{0}\left(\eta_{1}\right):=\left[\frac{2}{\left(\lambda_{0}\right)^{2}-1} \cdot \frac{\cosh \left[\lambda_{0} \cdot\left(\frac{H_{1}}{R}\right) \cdot \eta_{1}\right]}{\cosh \left[\lambda_{0} \cdot\left(\frac{H_{1}}{R}\right)\right]}\right]$

$\operatorname{con}_{1}\left(\eta_{1}\right):=\left[\frac{2}{\left(\lambda_{1}\right)^{2}-1} \cdot \frac{\cosh \left[\lambda_{1} \cdot\left(\frac{H_{1}}{R}\right) \cdot \eta_{l}\right]}{\cosh \left[\lambda_{1}\left(\frac{H_{1}}{R}\right)\right]}\right]$ 
Prepared by: F. G. Abatt M\&D Professipnal Services 6/1/06

Rev. 0
RPP-RPT-30807, Rev. 0 Theoretical Fluid Response

Calculations for Rigid Roofless Tank at 500 in. Waste Level - Dytran Configuration
Checked by: K.R. Roberson<smiles>[Mg]</smiles>

$$
\operatorname{con}_{2}\left(\eta_{1}\right):=\left[\frac{2}{\left(\lambda_{2}\right)^{2}-1} \cdot \frac{\cosh \left[\lambda_{2} \cdot\left(\frac{H_{1}}{R}\right) \cdot \eta_{1}\right]}{\cosh \left[\lambda_{2} \cdot\left(\frac{H_{1}}{R}\right)\right]}\right]
$$

$\operatorname{con}_{0}\left(\eta_{1}\right)=$\begin{tabular}{|r|r|}
\hline & 0 \\
\hline 0 & 0.21 \\
\hline 1 & 0.21 \\
\hline 2 & 0.22 \\
\hline 3 & 0.22 \\
\hline 4 & 0.23 \\
\hline 5 & 0.23 \\
\hline 6 & 0.24 \\
\hline 7 & 0.25 \\
\hline 8 & 0.26 \\
\hline 9 & 0.28 \\
\hline 10 & 0.29 \\
\hline 12 & 0.31 \\
\hline 13 & 0.33 \\
\hline 14 & 0.35 \\
\hline 15 & 0.37 \\
\hline 16 & 0.4 \\
\hline 17 & 0.43 \\
\hline 18 & 0.46 \\
\hline 19 & 0.5 \\
\hline 20 & 0.54 \\
\hline 21 & 0.58 \\
\hline 22 & 0.62 \\
\hline 23 & 0.67 \\
\hline 24 & 0.73 \\
\hline & 0.79 \\
\hline
\end{tabular}

\begin{tabular}{|c|r|}
\hline & \multicolumn{1}{|c|}{0} \\
\hline 0 & $3.91 \cdot 10^{-4}$ \\
\hline 1 & $4.08 \cdot 10^{-4}$ \\
\hline 2 & $4.47 \cdot 10^{-4}$ \\
\hline 3 & $5.12 \cdot 10^{-4}$ \\
\hline 4 & $6.06 \cdot 10^{-4}$ \\
\hline 5 & $7.33 \cdot 10^{-4}$ \\
\hline 6 & $9.03 \cdot 10^{-4}$ \\
\hline 7 & $1.12 \cdot 10^{-3}$ \\
\hline 8 & $1.41 \cdot 10^{-3}$ \\
\hline 9 & $1.77 \cdot 10^{-3}$ \\
\hline 10 & $2.23 \cdot 10^{-3}$ \\
\hline 11 & $2.82 \cdot 10^{-3}$ \\
\hline 12 & $3.57 \cdot 10^{-3}$ \\
\hline 13 & $4.52 \cdot 10^{-3}$ \\
\hline 14 & $5.72 \cdot 10^{-3}$ \\
\hline 15 & $7.24 \cdot 10^{-3}$ \\
\hline 16 & $9.18 \cdot 10^{-3}$ \\
\hline 17 & 0.01 \\
\hline 18 & 0.01 \\
\hline 19 & 0.02 \\
\hline 20 & 0.02 \\
\hline 21 & 0.03 \\
\hline 22 & 0.04 \\
\hline 23 & 0.05 \\
\hline 24 & 0.06 \\
\hline & \\
\hline 19 &
\end{tabular}

$\operatorname{con}_{2}\left(\eta_{1}\right)=$\begin{tabular}{|c|c|}
\hline & \multicolumn{1}{c|}{0} \\
\hline 0 & $4.25 \cdot 10^{-6}$ \\
\hline 1 & $4.72 \cdot 10^{-6}$ \\
\hline 2 & $5.87 \cdot 10^{-6}$ \\
\hline 3 & $7.88 \cdot 10^{-6}$ \\
\hline 4 & $1.1 \cdot 10^{-5}$ \\
\hline 5 & $1.58 \cdot 10^{-5}$ \\
\hline 6 & $2.29 \cdot 10^{-5}$ \\
\hline 7 & $3.32 \cdot 10^{-5}$ \\
\hline 11 & $1.51 \cdot 10^{-4}$ \\
\hline 12 & $2.21 \cdot 10^{-4}$ \\
\hline 13 & $3.23 \cdot 10^{-4}$ \\
\hline 14 & $4.71 \cdot 10^{-4}$ \\
\hline 15 & $6.89 \cdot 10^{-4}$ \\
\hline 16 & $1.01 \cdot 10^{-3}$ \\
\hline 17 & $1.47 \cdot 10^{-3}$ \\
\hline 18 & $2.15 \cdot 10^{-3}$ \\
\hline 19 & $3.14 \cdot 10^{-3}$ \\
\hline 20 & $4.59 \cdot 10^{-3}$ \\
\hline 21 & $6.71 \cdot 10^{-3}$ \\
\hline 22 & $9.8 \cdot 10^{-3}$ \\
\hline 23 & 0.01 \\
\hline 24 & 0.02 \\
\hline & \\
\hline 10 & $1.03 \cdot 10^{-4}$ \\
\hline 1 &
\end{tabular}


Prepared by: F. G. Abatt M\&D Profesgignal,Services

$6 / 1 / 06$

Rev. 0

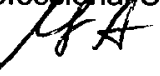

RPP-RPT-30807, Rev. 0

Theoretical Fluid Response

Calculations for Rigid Roofless Tank at 500 in. Waste Level - Dytran

Configuration
Checked by: K.R. Roberson

KRR

Impulsive pressure coefficient as a function of dimensionless wall height

$c_{i}\left(\eta_{1}\right):=1-\operatorname{con}_{0}\left(\eta_{1}\right)-\operatorname{con}_{1}\left(\eta_{1}\right)-\operatorname{con}_{2}\left(\eta_{1}\right) \quad$ BNL 1995 Eqn. 4.7

$c_{i}\left(n_{I}\right)=$\begin{tabular}{|c|c|}
\hline & 0 \\
\hline 0 & 0.79 \\
\hline 1 & 0.79 \\
\hline 2 & 0.78 \\
\hline 3 & 0.78 \\
\hline 4 & 0.77 \\
\hline 5 & 0.77 \\
\hline 6 & 0.76 \\
\hline 7 & 0.75 \\
\hline 8 & 0.74 \\
\hline 9 & 0.72 \\
\hline 10 & 0.71 \\
\hline 12 & 0.69 \\
\hline 13 & 0.67 \\
\hline 14 & 0.64 \\
\hline 15 & 0.62 \\
\hline 16 & 0.59 \\
\hline 17 & 0.56 \\
\hline 18 & 0.52 \\
\hline 19 & 0.49 \\
\hline 20 & 0.44 \\
\hline 21 & 0.39 \\
\hline 22 & 0.34 \\
\hline 23 & 0.28 \\
\hline 24 & 0.21 \\
\hline & 0.13 \\
\hline
\end{tabular}

Calculate maximum values of dynamic wall pressures from spectral acceleration of dome input $\mathrm{TH}$. 
Prepared by: F. G. Abatt M\&D Professignal/Services

$6 / 1 / 06$

Rev. 0
RPP-RPT-30807, Rev. 0

Theoretical Fluid Response Calculations for Rigid Roofless Tank at 500 in. Waste Level - Dytran Configuration
Checked by: K.R. Roberson

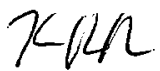

Consider the first three convective mode spectral accelerations for the $0.1 \%$ damped spectrum
$\mathrm{SA}_{\mathrm{c} 0}:=0.066 \cdot \mathrm{g}$
$\mathrm{SA}_{\mathrm{c} 0}=25.5 \frac{\mathrm{in}}{\mathrm{sec}^{2}}$
$\mathrm{SA}_{\mathrm{cl}}:=0.11 \cdot \mathrm{g}$
$\mathrm{SA}_{\mathrm{c} 1}=42.5 \frac{\text { in }}{\sec ^{2}}$
$\mathrm{SA}_{\mathrm{c} 2}:=0.17 \cdot \mathrm{g}$
$\mathrm{SA}_{\mathrm{c} 2}=65.69 \frac{\mathrm{in}}{\mathrm{sec}^{2}}$

Associate the impulsive mode with the ZPA, since the tank is rigid.

$$
P G A:=0.276 \cdot g \quad P G A=106.65 \frac{\text { in }}{\sec ^{2}} \quad \text { ANSYS dome RS from Spectr }
$$

$p_{\operatorname{maxconv}}\left(\eta_{1}, \theta\right):=\left[\sqrt{\left(\operatorname{con}_{0}\left(\eta_{1}\right) \cdot \mathrm{SA}_{\mathrm{c} 0}\right)^{2}+\left(\operatorname{con}_{1}\left(\eta_{1}\right) \cdot \mathrm{SA}_{\mathrm{cl}}\right)^{2}+\left(\operatorname{con}_{2}\left(\eta_{1}\right) \cdot \mathrm{SA}_{\mathrm{c} 2}\right)^{2}}\right] \cdot\left(\rho_{1} \cdot \mathrm{R} \cdot \cos (\theta \cdot \operatorname{deg})\right)$

$\mathbf{p}_{\text {maximpulsive }}\left(\eta_{1}, \theta\right):=\left[\sqrt{\left[\mathrm{c}_{\mathrm{i}}\left(\eta_{\mathrm{l}}\right) \cdot(\mathrm{PGA})\right]^{2}}\right] \cdot\left(\rho_{1} \cdot \mathbf{R} \cdot \cos (\theta \cdot \operatorname{deg})\right)$

$p_{\max }\left(\eta_{1}, \theta\right):=\left[\sqrt{\left[\left(c_{i}\left(\eta_{1}\right)\right) \cdot(\mathrm{PGA})\right]^{2}+\left(\operatorname{con}_{0}\left(\eta_{1}\right) \cdot \mathrm{SA}_{\mathrm{c} 0}\right)^{2}+\left(\operatorname{con}_{1}\left(\eta_{1}\right) \cdot \mathrm{SA}_{\mathrm{cl}}\right)^{2}+\left(\operatorname{con}_{2}\left(\eta_{1}\right) \cdot \mathrm{SA}_{\mathrm{c} 2}\right)^{2}}\right] \cdot\left(\rho_{1} \cdot \mathrm{R} \cdot \cos (\theta \cdot \operatorname{deg})\right)$ 
Prepared by: F. G. Abatt M\&D Professional Services $6 / 1 / 06$

Rev. 0

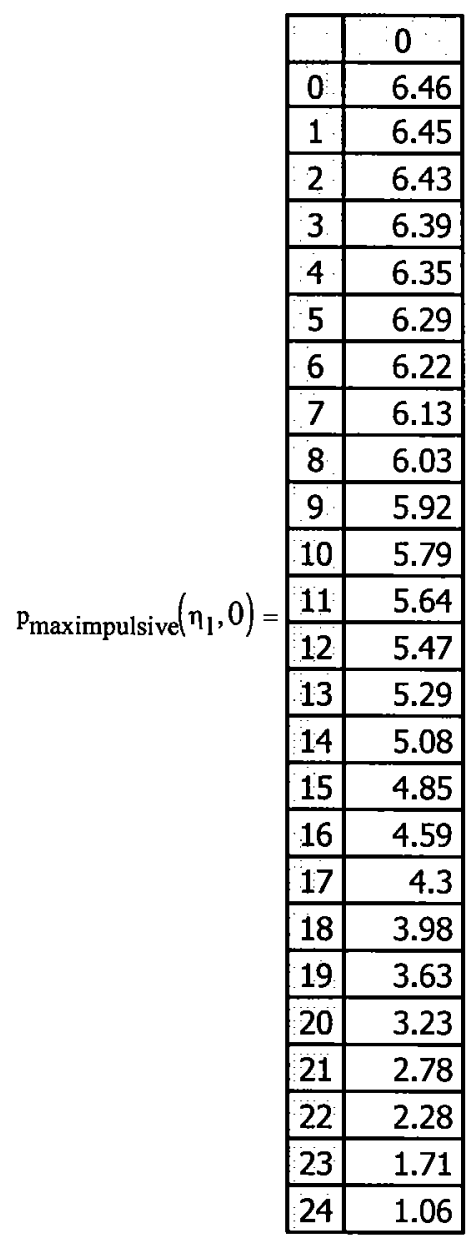

RPP-RPT-30807, Rev. 0 Theoretical Fluid Response Calculations for Rigid Roofless Tank at 500 in. Waste Level - Dytran Configuration
Checked by: K.R. Roberson

YQR $\frac{\mathrm{lbf}}{2}$

Maximum impulsive dynamic pressures at theta $=0$.

\begin{tabular}{|l|l|}
\hline & 0 \\
\hline 0 & 0.42 \\
\hline 1 & 0.42 \\
\hline 2 & 0.42 \\
\hline 3 & 0.43 \\
\hline 4 & 0.44 \\
\hline 5 & 0.46 \\
\hline 6 & 0.47 \\
\hline 7 & 0.49 \\
\hline 8 & 0.52 \\
\hline 9 & 0.54 \\
\hline 10 & 0.57 \\
\hline 11 & 0.61 \\
\hline 12 & 0.65 \\
\hline 13 & 0.69 \\
\hline 14 & 0.74 \\
\hline 15 & 0.79 \\
\hline 16 & 0.85 \\
\hline 17 & 0.91 \\
\hline 18 & 0.98 \\
\hline 19 & 1.05 \\
\hline 20 & 1.14 \\
\hline 21 & 1.23 \\
\hline 22 & 1.33 \\
\hline 23 & 1.44 \\
\hline 24 & 1.56 \\
\hline
\end{tabular}

$\frac{\text { lbf }}{\text { in }^{2}}$

Maximum convective dynamic pressures at theta $=0$. 
Prepared by: F. G. Abatt M\&D Professjonal Services $6 / 1 / 06$

Rev. 0

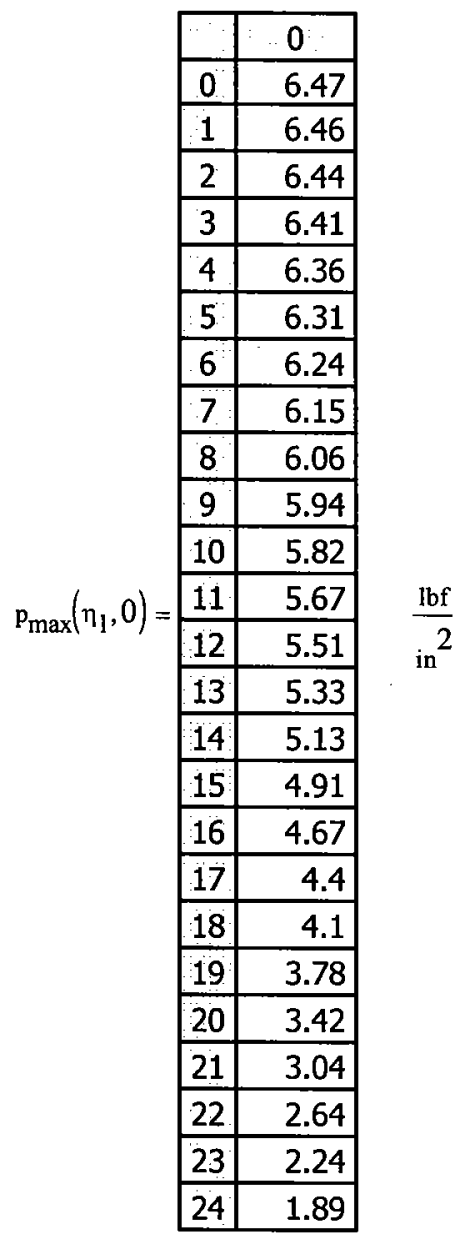

RPP-RPT-30807, Rev. 0 Theoretical Fluid Response Calculations for Rigid Roofless Tank at 500 in. Waste Level - Dytran Configuration
Maximum total dynamic pressure at theta $=0$.

\begin{tabular}{|r|r|}
\hline & \multicolumn{1}{|c|}{0} \\
\hline 0 & 4.57 \\
\hline 1 & 4.57 \\
\hline 2 & 4.55 \\
\hline 3 & 4.53 \\
\hline 4 & 4.5 \\
\hline 5 & 4.46 \\
\hline 6 & 4.41 \\
\hline 7 & 4.35 \\
\hline 8 & 4.28 \\
\hline 9 & 4.2 \\
\hline 10 & 4.11 \\
\hline
\end{tabular}

$\mathrm{p}_{\max }\left(\eta_{1}, 45\right)=$

\begin{tabular}{|r|r|}
\hline 10 & 4.11 \\
\hline 11 & 4.01 \\
\hline
\end{tabular}

\begin{tabular}{|r|r|}
\hline 12 & 3.9 \\
\hline 13 & 3.77 \\
\hline
\end{tabular}

\begin{tabular}{|r|r|}
\hline 13 & 3.77 \\
\hline
\end{tabular}

\begin{tabular}{|l|r|}
\hline 14 & 3.63 \\
\hline
\end{tabular}

\begin{tabular}{|r|r|}
\hline 15 & 3.47 \\
\hline
\end{tabular}

\begin{tabular}{|r|r|}
\hline 16 & 3.3 \\
\hline
\end{tabular}

\begin{tabular}{|r|r|}
\hline 17 & 3.11 \\
\hline
\end{tabular}

\begin{tabular}{|r|r|}
\hline 18 & 2.9 \\
\hline
\end{tabular}

\begin{tabular}{|r|r|}
\hline 19 & 2.67 \\
\hline
\end{tabular}

\begin{tabular}{|l|r|}
\hline 20 & 2.42 \\
\hline
\end{tabular}

\begin{tabular}{|l|l|}
\hline 21 & 2.15 \\
\hline
\end{tabular}

\begin{tabular}{|l|r|}
\hline 22 & 1.87 \\
\hline
\end{tabular} $\frac{\mathrm{lbf}}{2} \quad$ Maximum total dynamic pressure at theta $=\mathbf{4 5}$ degrees. 
Prepared by: F. G. Abatt M\&D Professional Services

$6 / 1 / 06$

Rev. 0
RPP-RPT-30807, Rev. 0

Theoretical Fluid Response

Calculations for Rigid Roofless Tank at 500 in. Waste Level - Dytran Configuration
Checked by: K.R. Roberson

RKM
Maximum total dynamic

pressure at theta $=90$ degrees.

\section{Calculate Maximum Slosh Height:}

conmax $:=\left(\begin{array}{l}0.837 \\ 0.073 \mid \\ 0.028)\end{array} \quad\right.$ Maximum value of convective coefficients at $\eta_{1}=1$

$\mathrm{h}_{\text {maxslosh }}:=\mathrm{R} \cdot \sqrt{\left(\operatorname{conmax}_{0} \cdot \frac{\mathrm{SA} \mathrm{c} 0}{\mathrm{~g}}\right)^{2}+\left(\operatorname{conmax}_{1} \cdot \frac{\mathrm{SA} \mathrm{c} 1}{\mathrm{~g}}\right)^{2}+\left(\operatorname{conmax}_{2} \cdot \frac{\mathrm{SA} \mathrm{c} 2}{\mathrm{~g}}\right)^{2}}$

$\mathrm{h}_{\operatorname{maxslosh}}=25.21$ in $\quad$ Maximum theoretical slosh height 
Prepared by: F. G. Abatt M\&D Professional Services 6/1/06

Rev. 0
RPP-RPT-30807, Rev. 0 Theoretical Fluid Response Calculations for Rigid Roofless Tank at 500 in. Waste Level - Dytran Configuration
Checked by: K.R. Roberson

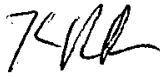

\section{Calculate Maximum Total Hydrodynamic Force:}

The maximum hydrodynamic force induced on the tank wall is given by Eqn. 4.31 of BNL 1995 with the instantaneous accelerations replaced by the maximum spectral accelerations. First determine the effective impulsive and convective masses.

$\mathrm{m}_{\text {lapprox }}:=\pi \cdot \mathrm{R}^{2} \cdot \mathrm{H}_{\mathrm{I}} \mathrm{\rho}_{\mathrm{I}} \quad \mathrm{m}_{\text {lapprox }}=5.44 \times 10^{4} \frac{\mathrm{lbf} \cdot \mathrm{sec}^{2}}{\mathrm{in}} \quad \begin{aligned} & \text { Total waste mass based on circular cylinder } \\ & \text { approximation. }\end{aligned}$

$\mathrm{m}_{1}:=5.35 \cdot 10^{4} \cdot \frac{\mathrm{bf} \cdot \mathrm{sec}^{2}}{\text { in }} \quad$ Actual waste mass reported by Dytran model.

$\mathrm{m}_{\mathrm{c} 0}:=\left[\frac{2}{\lambda_{0}\left[\left(\lambda_{0}\right)^{2}-1\right] \cdot\left(\frac{\mathrm{H}_{1}}{\mathrm{R}}\right)}\right] \cdot \tanh \left[\lambda_{0} \cdot\left(\frac{\mathrm{H}_{1}}{\mathrm{R}}\right)\right] \cdot \mathrm{m}_{\mathrm{I}}$

$\mathrm{m}_{\mathrm{c} 0}=2.12 \times 10^{4} \frac{\mathrm{lbf} \cdot \mathrm{sec}^{2}}{\text { in }} \quad$ First mode convective mass

$\mathrm{m}_{\mathrm{c} 1}:=\left[\frac{2}{\lambda_{1}\left[\left(\lambda_{1},{ }^{2}-1\right] \cdot\left(\frac{\left.\mathrm{H}_{1}\right)}{\mathrm{R}}\right)\right.}\right] \cdot \tanh \left[\lambda_{1} \cdot\left(\frac{\mathrm{H}_{\mathrm{I}}}{\mathrm{R}}\right)\right] \cdot \mathrm{m}_{1}$

Second mode convective mass

$\mathrm{m}_{\mathrm{cl}}=658.8 \frac{\mathrm{lbf} \cdot \mathrm{sec}^{2}}{\text { in }}$

$\mathrm{m}_{\mathrm{c} 2}:=\left[\frac{2}{\lambda_{2} \cdot\left[\left(\lambda_{2}\right)^{2}-1\right] \cdot\left(\frac{\left.\mathrm{H}_{1}\right)}{\mathrm{R}}\right)}\right] \cdot \tanh \left[\lambda_{2} \cdot\left(\frac{\mathrm{H}_{1}}{\mathrm{R}}\right)\right] \cdot \mathrm{m}_{1}$

Third mode convective mass

$\mathrm{m}_{\mathrm{c} 2}=156.99 \frac{\mathrm{lbf} \cdot \mathrm{sec}^{2}}{\text { in }}$

$m_{i}:=m_{1}-\left(m_{c 0}+m_{c 1}+m_{c 2}\right) \quad$ Impulsive mass

$\mathrm{m}_{\mathrm{i}}=3.15 \times 10^{4} \frac{\mathrm{lbf} \cdot \mathrm{sec}^{2}}{\text { in }}$ 
Prepared by: F. G. Abatt

M\&D Professignal Services

$6 / 1 / 06$

Rev. 0

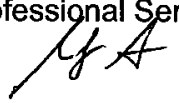

RPP-RPT-30807, Rev. 0

Theoretical Fluid Response Calculations for Rigid Roofless Tank at 500 in. Waste Level - Dytran Configuration
Checked by: K.R. Roberson

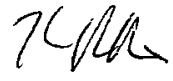

$\mathrm{F}_{\max }:=\mathrm{m}_{\mathrm{i}} \cdot \mathrm{PGA}+\mathrm{m}_{\mathrm{c} 0} \cdot \mathrm{SA}_{\mathrm{c} 0}+\mathrm{m}_{\mathrm{cl}} \cdot \mathrm{SA}_{\mathrm{cl}}+\mathrm{m}_{\mathrm{c} 2} \cdot \mathrm{SA}_{\mathrm{c} 2}$

$F_{\max }=3.94 \times 10^{6} \mathrm{lbf} \quad$ Conservative estimate of maximum hydrodynamic force

The above expression is a conservative estimate because it assumes that the peak impulsive and convective forces occur simultaneously. A less conservative estimate can be made via a square-root-sum-of-the-squares (SRSS) combination.

$$
\begin{aligned}
& \mathrm{F}_{\mathrm{srss}}:=\sqrt{\left(\mathrm{m}_{\mathrm{i}} \cdot \mathrm{PGA}\right)^{2}+\left(\mathrm{m}_{\mathrm{c} 0} \cdot \mathrm{SA}_{\mathrm{c} 0}\right)^{2}+\left(\mathrm{m}_{\mathrm{cl}} \cdot \mathrm{SA}_{\mathrm{c} 1}\right)^{2}+\left(\mathrm{m}_{\mathrm{c} 2} \cdot \mathrm{SA}_{\mathrm{c} 2}\right)^{2}} \\
& \mathrm{~F}_{\mathrm{srss}}=3.4 \times 10^{6} \mathrm{lbf} \quad \text { SRSS estimate of peak hydrodynamic force } \\
& \mathrm{F}_{\mathrm{conmax}}:=\sqrt{\left(\mathrm{m}_{\mathrm{c} 0} \cdot \mathrm{SA}_{\mathrm{c} 0}\right)^{2}+\left(\mathrm{m}_{\mathrm{cl}} \cdot \mathrm{SA}_{\mathrm{c} 1}\right)^{2}+\left(\mathrm{m}_{\mathrm{c} 2} \cdot \mathrm{SA}_{\mathrm{c} 2}\right)^{2}} \\
& \mathrm{~F}_{\text {conmax }}=5.41 \times 10^{5} \mathrm{lbf} \quad \begin{array}{l}
\text { Peak hydrodynamic force due to convective response - shows up in free } \\
\text { Oscillations. }
\end{array}
\end{aligned}
$$

Reference:

BNL 1995, Seismic Design and Evaluation Guidelines for the Department of Energy High-Level Waste Storage Tanks and Appurtenances, BNL 52361, Rev. 10/95, Brookhaven National Laboratory, Upton, New York. 